\title{
Pacific Northwest Laboratory Annual Report for 1989 to the DOE Office of Energy Research
}

Part 2: Environmental Sciences

March 1990

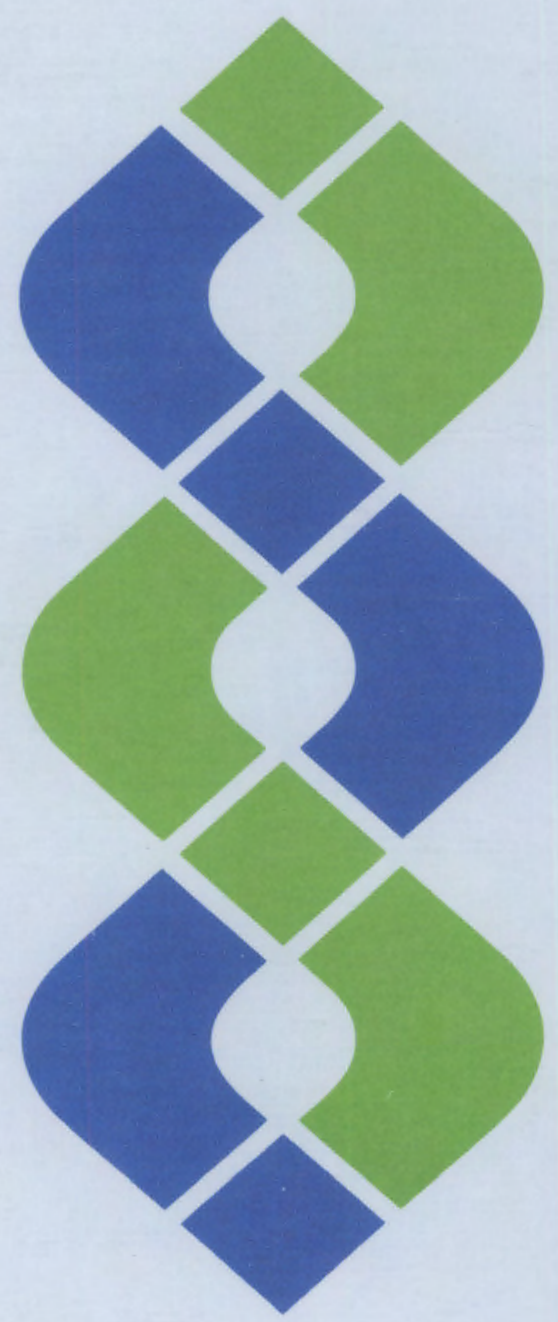

Prepared for the U.S. Department of Energy under Contract DE-AC06-76RLO 1830

Pacific Northwest Laboratory Operated for the U.S. Department of Energy by Battelle Memorial Institute 


\section{DISCLAIMER}

This report was prepared as an account of work sponsored by an agency of the United States Government. Neither the United States Government nor any agency thereof, nor Battelle Memorial Institute, nor any of their employees, makes any warranty, expressed or implied, or assumes any legal liability or responsibility for the accuracy, completeness, or usefulness of any information, apparatus, product, or process disclosed, or represents that its use would not infringe privately owned rights. Reference herein to any specific commercial product, process, or service by trade name, trademark, manufacturer, or otherwise, does not necessarily constitute or imply its endorsement, recommendation, or favoring by the United States Government of any agency thereof, or Battelle Memorial Institute. The views and opinions of authors expressed herein do not necessarily state or reflect those of the United States Government or any agency thereof.

\section{PACIFIC NORTHWEST LABORATORY operated by \\ BATTELLE MEMORIAL INSTITUTE for the \\ UNITED STATES DEPARTMENT OF ENERGY \\ under Contract DE-ACO6-76RLO 1830}

Printed in the United States of America

Available to DOE and DOE contractors from the

Office of Scientific and Technical Information, P.O. Box 62, Oak Ridge, TN 37831; prices available from (615) 576-8401. FTS 626-8401.

Available to the public from the National Technical Information Service, U.S. Department of Commerce, 5285 Port Royal Rd., Springfield, VA 22161.

NTIS Price Codes, Microfiche A01

Printed Copy

\begin{tabular}{cr}
\hline Price Code & Page Range \\
\hline A02 & $1-10$ \\
A03 & $11-50$ \\
A04 & $51-75$ \\
A05 & $76-100$ \\
A06 & $101-125$ \\
A07 & $126-150$ \\
A08 & $151-175$ \\
A09 & $176-200$ \\
A10 & $201-225$ \\
A11 & $226-250$ \\
A12 & $251-275$ \\
A13 & $276-300$ \\
A14 & $301-325$
\end{tabular}

\begin{tabular}{cc}
\hline Price Code & Page Range \\
\hline A15 & $326-350$ \\
A16 & $351-375$ \\
A17 & $376-400$ \\
A18 & $401-425$ \\
A19 & $426-450$ \\
A20 & $451-475$ \\
A21 & $476-500$ \\
A22 & $501-525$ \\
A23 & $526-550$ \\
A24 & $551-575$ \\
A25 & $576-600$ \\
A99 & $601-U p$
\end{tabular}


Pacific Northwest Laboratory Annual Report for 1989 to the DOE Office of Energy Research

\section{Part 2: Environmental Sciences}

Staff Members of Pacific Northwest Laboratory

March 1990

Prepared for the U.S. Department of Energy under Contract DE-AC06-76RLO 1830

Pacific Northwest Laboratory

Richland, Washington 99352 
-

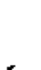




\section{Preface}

This 1989 Annual Report from Pacific Northwest Laboratory (PNL) to the U.S. Department of Energy (DOE) describes research in environment, safety, and health conducted during fiscal year 1989 . The report again consists of five parts, each in a separate volume.

The five parts of the report are oriented to particular segments of the PNL program. Parts 1 to 4 report on research performed for the DOE Office of Health and Environmental Research in the Office of Energy Research. Part 5 reports progress on ali research performed for the Assistant Secretary for Environment, Safely, and Health. In some instances, the volumes report on research funded by other DOE components or by other governmental entities under interagency agreements. Each part consists of project reports authored by scientists from several PNL research departments, reflecting the multidisciplinary nature of the research effort.

The parts of the 1989 Annual Report are:

Part 1: Biomedical Sciences

Program Manager: J. F. Park J. F. Park, Report Coordinator

S. A. Kremi, Editor

Part 2: Environmental Sciences

Program Manager: R. E. Wildung M. G. Hefty, Report Coordinator and Editor

Part 3: Atmospheric Sciences

Program Manager: C. E. Elderkin $\quad$ C. E. Elderkin, Report Coordinator

E. L. Owczarski, Editor

Part 4: Physical Sciences

Program Manager: $\quad$ L. H. Toburen $\quad$ L. H. Toburen, Report Coordinator

K. A. Parneli, Editor

Part 5: Environment, Safety, Health,

and Quality Assurance

Program Managers:

L. G. Faust

S. K. Ennor, Report Coordinator and Editor

J. M. Selby

Activities of the scientists whose work is described in this annual report are broader in scope than the articles indicate. PNL staff have responded to numerous requests from DOE during the year for planning, for service on various task groups, and for special assistance.

Credit for this annual report goes to the many scientists who performed the research and wrote the individual project reports, to the program managers who directed the research and coordinated the technical progress reports, to the editors who edited the individual project reports and assembled the five parts, and to Ray Baalman, editor in chief, who directed the total effort.

W. J. Bair and T. S. Tenforde

Environment, Health, and Safety

Research Program 
Previous reports in this series:

\section{Annual Report for:}

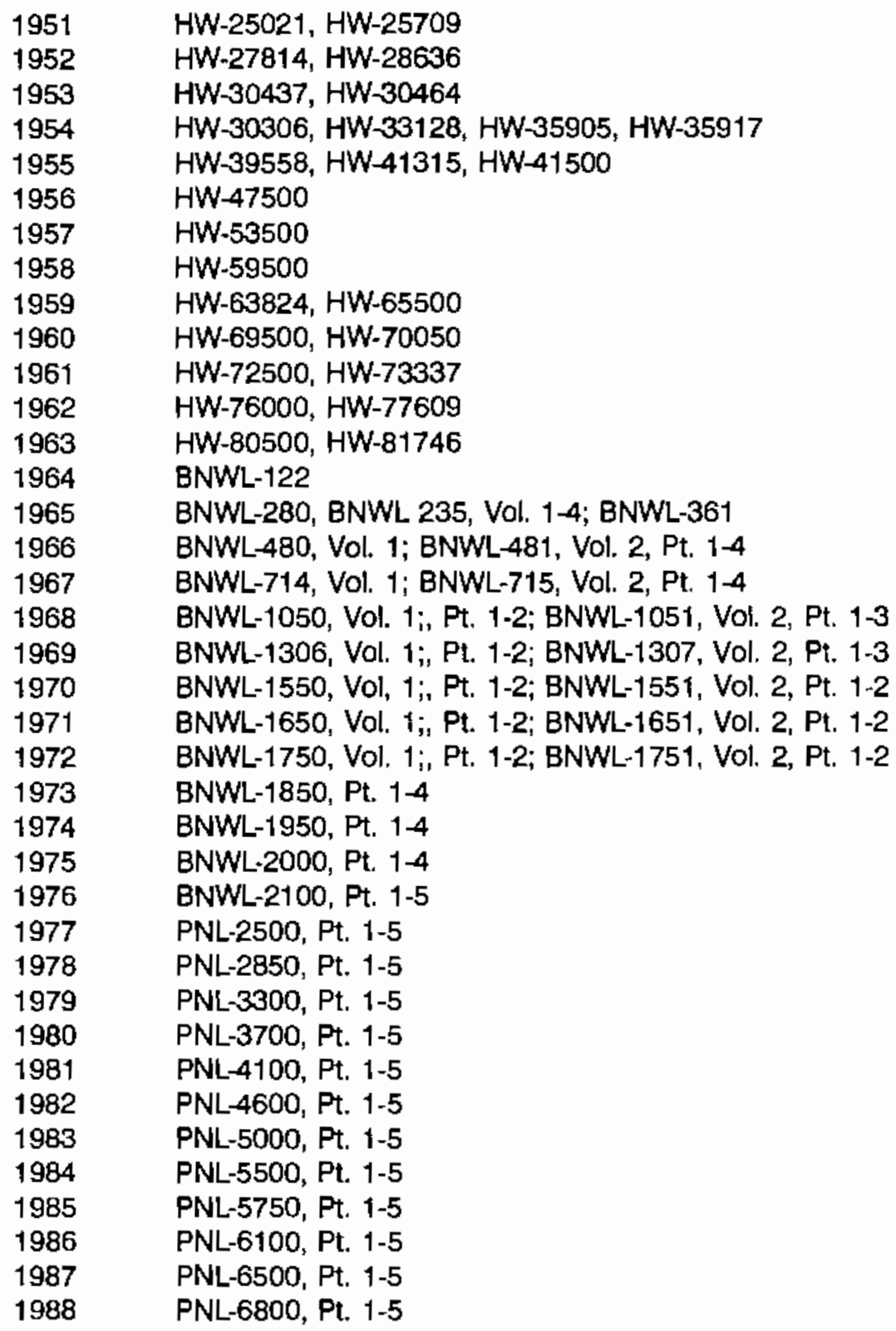




\section{Foreword}

This report summarizes progress in environmental sciences research conducted by Pacific Northwest Laboratory (PNL) for the Office of Health and Environmental Pesearch in FY 1989. Pesearch is directed toward developing a fundamental understanding of processes controlling the long-term fate and biological effects of fugitive chemicals and other stressors resulting from energy development. The report is organized by major research areas. Within this division, individual reports summarize the progress of projects in these areas. Additional sections summarize exploratory research, educational institutional interactions, technology transfer, and publications.

The PNL research program continues to make important contributions to the resolution of important national environmental problems. The research, focused principally on subsurface contaminant transport and detection and management of human-induced changes in biological systems, forms the basis for defining and quantifying processes that affect humans and the environment at the local, regional, and global levels. Each research project forms a component in an integrated laboratory, intermediate-scale, and field approach designed to examine multiple phenomena at increasing levels of complexity. This approach is providing system-level insights into critical environmental processes. University liaisons continue to be expanded to strengthen this research and to use PNL resources to train the scientists needed to address long-term environmental problems.

Building on technical strengths in geochemistry, environmental microbiology, hydrodynamics, terrestrial sciences, and theoretical ecology, research in the PNL environmental sciences is in an exciting phase, as reflected in the formation (October 1, 1989) of the Environmental Sciences Research Center. This Center has enabled PNL's Subsurface Science Program to extend into basic research addressing key problems in environmental restoration of DOE sites. New internal and external investments have been made in molecular sciences, chemistry, bioremediation, remote imagery, subsurface fluid dynamics, geostatistics, and theoretical ecology. This report (note particularly the publications section) reflects the results of many of these investments and illustrates the value of these results in environmental research.

Paymond E. Wildung

Program Manager

Environmental Sciences 


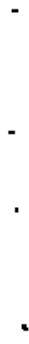




\section{Contents}

Preface $\ldots \ldots \ldots \ldots \ldots \ldots \ldots \ldots \ldots \ldots \ldots \ldots \ldots \ldots \ldots \ldots \ldots \ldots \ldots \ldots$ iii

Foreword $\ldots \ldots \ldots \ldots \ldots \ldots \ldots \ldots \ldots \ldots \ldots \ldots \ldots \ldots \ldots \ldots \ldots$

Detecting and Managing Change in Terrestrial Ecosystems $\ldots \ldots \ldots \ldots$

Understanding Terrestrial Ecosystems $\ldots \ldots \ldots \ldots \ldots \ldots \ldots \ldots \ldots \ldots \ldots \ldots$

Landscape Ecological Studies: Quantitative Remote Sensing of

Ecological Processes--Evaportranspiration, D. E. Gibbons, S. O. Link,

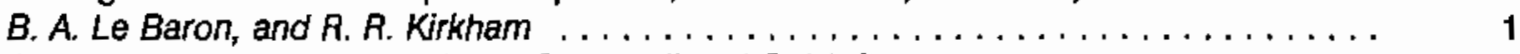

Arid Lands Water Balance, $M$. D. Campbell and G. W. Gee $\ldots \ldots \ldots \ldots \ldots \ldots \ldots$

A Microcosm-Level Gas Exchange Study on the Effects of
Nitrogen and Water on Bromus tectorum, S. O. Link and H. Bolton, Jr. . . . . . . .

Subsurface Science $\ldots \ldots \ldots \ldots \ldots \ldots \ldots \ldots \ldots \ldots \ldots \ldots \ldots \ldots$

Subsurface Microbial Phenomena, J. K. Fredrickson and F. J. Brockman ........ 13

Groundwater Dating at the Savannah River Site, E. M. Murphy,

J. K. Fredrickson, J. A. Franz, and J. C. Linehan ... . . . . . . . . . . . . . . 20

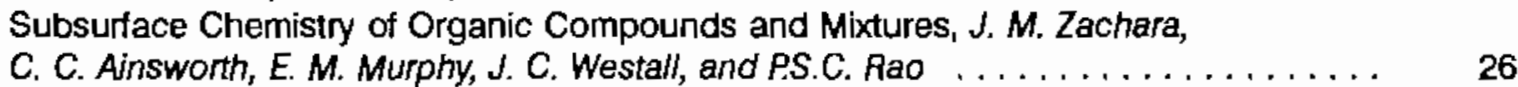

Chemistry/Microbiology Controlling Chelated Radionuclide
Transport, $D$. C. Givin and $H$. Bolton, $J r . \ldots \ldots \ldots \ldots \ldots \ldots \ldots \ldots \ldots \ldots \ldots$

Intermediate-Scale Subsurface Transport of Co-Contaminants,

Subsurface Flow Physics of Immiscible Organic Liquids,

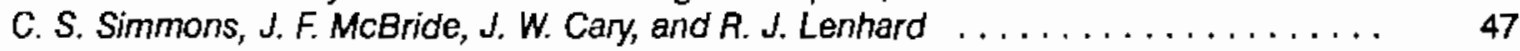

Subsurface Science Program Liaison, J.Wright . . . . . . . . . . . . . 52

Estimating Steady-State Diffusive and Advective Fluxes

from Different Soil Types, P. C. Owczarski, D. J. Holford, H. D. Freeman,

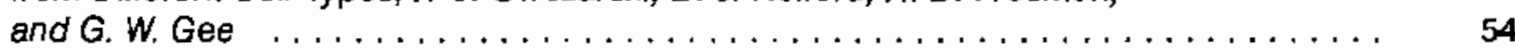

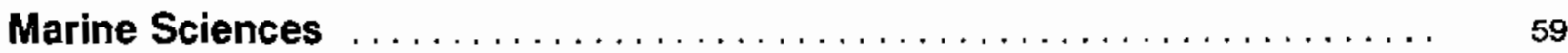

Cause and Progression of Leukemia in a Marine Invertebrate,

R. A. Elston, L. Berntsen-Stephens, D. Bonar, K. Brooks,

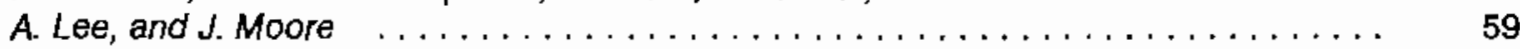

Theoretical (Quantitative) Ecology $\ldots \ldots \ldots \ldots \ldots \ldots \ldots \ldots \ldots \ldots \ldots$

Dynamics of Wild Populations, L. L. Eberhardt $\ldots \ldots \ldots \ldots \ldots \ldots \ldots \ldots \ldots \ldots \ldots \ldots \ldots$

Designs for Environmental Field Studies, J. M. Thomas

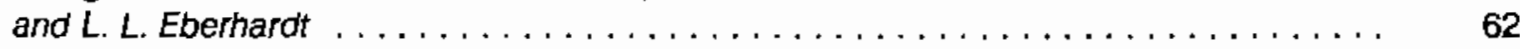


Biogenic Cycling of Volatile Nitrogen-Containing Species,

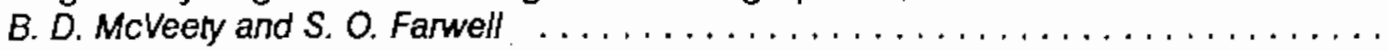

Optimal Measurement Scales and Experimental Design for Detecting and

Predicting Global Ecosystems Change, J. M. Thomas, V. I. Cullinan,

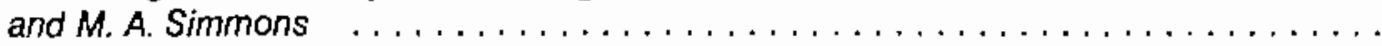

A Knowledge-Based System for Evaluating Human Disturbance and Global

Climate Change in Arid Regions, M. G. Foley, K. A. Hoover,

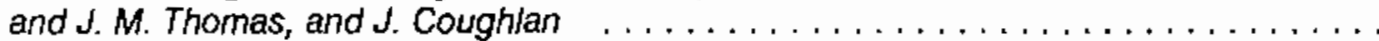

Remote Sensing of Plant Stress: Correlations with Plant Biochemical

Processes, R. J. Fellows, B. A. Le Baron, and D. E. Gibbons . . . . . . . . . . . .

Fluxes of Biogenic Gases from the Ocean Surface, E. A. Crecelius

Development of a Passive Ditflusion Sensor for the Measurement of

Ambient Mercury Vapor Concentrations, $N$. S. Bloom $\ldots \ldots \ldots \ldots \ldots \ldots \ldots \ldots$

Educational Institution interactions $\ldots \ldots \ldots \ldots \ldots \ldots \ldots \ldots \ldots$

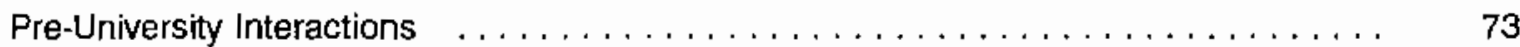

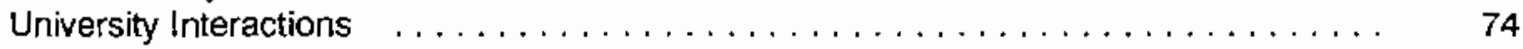

Hanford Environmental Research Park $\ldots \ldots \ldots \ldots \ldots \ldots \ldots \ldots \ldots \ldots \ldots \ldots$

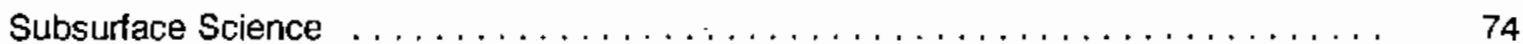

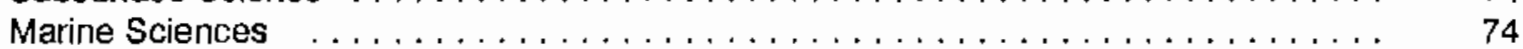

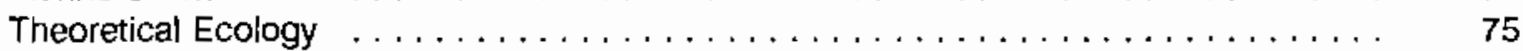

Technology Transfer $\ldots \ldots \ldots \ldots \ldots \ldots \ldots \ldots \ldots \ldots \ldots \ldots \ldots \ldots$

Detecting and Managing Change in Terrestrial Ecosystems $\ldots \ldots \ldots \ldots \ldots \ldots \ldots$

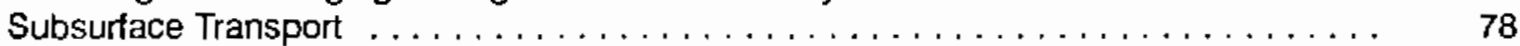

Marine Sciences $\ldots \ldots \ldots \ldots \ldots \ldots \ldots \ldots \ldots \ldots \ldots \ldots \ldots \ldots \ldots \ldots$

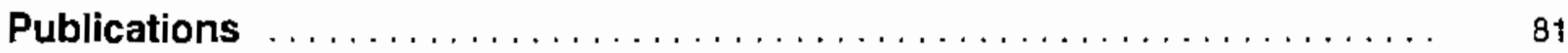

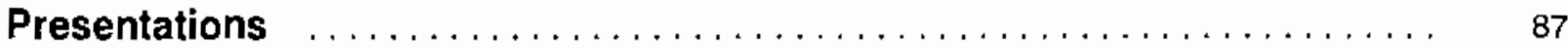

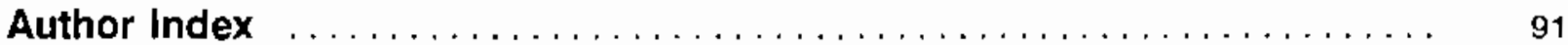

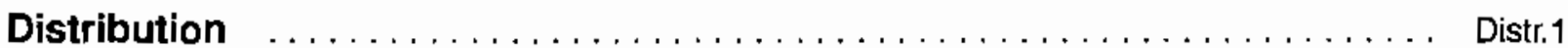




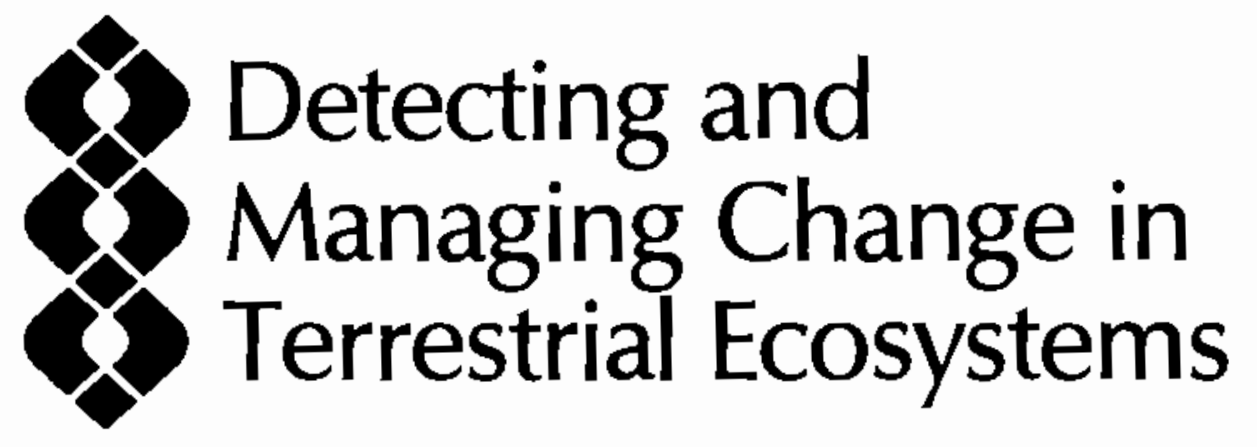




\section{Detecting and Managing Change in Terrestrial Ecosystems}

Extrapolations of predictions conceming how large-scale ecological systems respond to natural and energy-related disturbances require a thorough understanding of critical controlling mechanisms that influence ecological, hydrologic, biogeochemical, and atmospheric processes. The interaction of these processes over local and regional scales largely determines the extent of long-term change. Only recently has technology become available to make simultaneous measurements of ecological processes over large areas. Expert systems, user friendly interfaces, and visualization methods are being developed to effectively apply system-level models and provide new perspectives in data display. Development and application of new technology to solve environmental problems provide the focus of this research.

\section{Understanding Terrestrial Ecosystems}

Long-term ecological research has been conducted at Hanford as part of the Environmental Research Park Program beginning with the establishment of the Arid Lands Ecology (ALE) Reserve in 1966. Since the Research Park's inception at Hanford, its ecological programs have made major contributions to understanding the functioning and management of terrestrial and aquatic ecosystems. The long-term research goal has been to provide the U.S. Department of Energy (DOE) with a scientific basis for management and policy decisions regarding the future of arid and semi-arid lands and interconnected surface waters worldwide.

The physical and biotic features of the Haniord Site are representative of a large portion of the world; over $25 \%$ of the Earth's land area is arid or semi-arid. The Site encompasses over $1450 \mathrm{~km}^{2}$ in the western United States, a region that is likely to be affected both by energy development activities and changes in climatic regime during the coming decades. Therefore, the Hanford Site is well positioned to function as an intensive study site to address questions concerning both regional and global climatic change.

Field studies at Hanford include experiments relevant to major policy issues facing DOE and the nation. Three ongoing project areas are briefly described that form the core of our ecological research program: 1) landscape ecological studies, 2) arid lands water balance studies, and 3) microcosm-level gas exchange studies. Hanford's Environmental Research Park, another core research area, is further discussed in the Educational Institution Interactions section. The Park provides the long-term protection, continuity, and organizational structure necessary for the successful completion of terrestrial ecosystem studies; it aiso provides the necessary institutional structure for faculty and student participation from the academic community.

\section{Landscape Ecological Studies: Quantitative Remote Sensing of Ecological Processes- Evapotranspiration}
D. E. Gibbons, S. O. Link, B. A. Le Baron, and R. R. Kirkham

Determination of evapotranspiration (ET), using the energy balance approach, involves the quantitative measurement of several parameters (e.g., net radiation, canopy temperatures, air temperatures). It would be extremely valuable to determine the distribution of the spatially variable parameters of canopy temperature and net radiation by satellite in order to scale estimates of ET from localized (point) measurements to landscape size. During FY 1989, a multidisciplinary Pacific Northwest Laboratory (PNL) staff was engaged in ET/quantitative remote sensing research. Field measurements of vegetation/soil radiative properties, atmospheric quantities, and ET were conducted for the Hanford National Environmental Fesearch Park, concurrent with two LANDSAT Thematic Mapper (TM) overpasses. A suite of field radiometers and thermographs from the PNL remote sensing laboratory were used. Specifically, the field activities included 
- developing 100 - by $100-\mathrm{m}$ sampling plots (located near ET measuring stations) with 50 gridded sampling points for the plots

- developing a vegetation/soil community sampling technique (systematic sampling with random starting points)

- conducting ground truth (GT) measurements (concurrent with TM overpass) of

- canopy/soil temperatures and reflectances

- radiosonde atmospheric quantities

- aerosol optical depths [visible/near infrared (NIR)]

- soil moisture

- plant/soil thermal emissivities

- ET measurements of vegetation/soil communities using lysimeter/Bowen ratio stations.

FY 1989 tasks for the ET remote sensing study were divided into three classes of measurement: 1) thermal, 2) reflective, and 3) lysimeter/Bowen ratio.

\section{Landscape Thermal Measurements}

A distribution of the temperatures across large areas must be determined in order to scale the estimate of ET to landscape size from point measurements. The LANDSAT TM has a $120-\mathrm{m}$ ground resolution thermal channel (band 6, 10.5-12.5 microns) that is highly calibrated, and with proper atmospheric and ground corrections can consistently yield surface temperature determinations within $0.6^{\circ} \mathrm{C}$ of ground measurements (Wukelic et al. 1989).

A thermal data collection was carried out on the Hanford Site during FY 1989 to support the landscape measurements of ET using temperature data determined by satellite. The objectives were to 1) acquire TM data for Hanford and 2) produce and verify a digital, quantitative temperature map using the acquired TM data. Two LANDSAT data acquisitions were obtained and analyzed. Concurrent with the overpasses, field data were collected that included 1) radiosonde measurements [launched from the Hanford Meteorological Station (HMS)], 2) temperature measurements of the vegetation communities, 3) Columbia River temperatures, and 4) thermal emissivities of vegetation and soil landcover. Since the TM integrates temperatures within one pixel from several vegetation types in a community, a special sampling technique for estimating temperatures was devised. Sampling plots were laid out (as noted above) before overpass. These plots were chosen near weighing lysimeters/Bowen ratio stations located in the various vegetation communities on the Hanford Site.

The GT sampling of plant community surface temperature, for comparison to TM band 6 data, is constrained by the narrow field-of-view of handheld thermal radiometers and large spatial variation in surface temperature. Estimates are made of the mean surface temperature of a plant stand equivalent in size to $120 \mathrm{~m}$. The field-of-view of hand-held thermal radiometers used for GT sampling may range from only 5 to $20 \mathrm{~cm}$, depending on the model and the height it is held above a surface target. Within an Artemisia-Agropyron community at Hanford, midday surface temperatures in the spring can vary more than $30^{\circ} \mathrm{C}$ between a patch of bare soil and the canopy of an adjacent shrub. Therefore, sample size and sampling bias are considered key issues in designing a GT sampling plan.

Two sampling designs were compared and field tested before overflight for the purpose of obtaining an unbiased estimate of the mean surface temperature of a 1-hectare ArtemisiaAgropyron stand: a weighted-average of selected targets and a random transect sampling design. The field results indicated that random transect sampling would provide a less biased, more precise estimate of mean stand temperature than the commonly used weighted average of selected targets. Some of the findings follow:

- Weighted averages based on cover can give low estimates of stand temperature.

- Post-stratification of the random transect data showed that surface temperature was influenced more by shade patches and cloud cover than by species. Therefore, selective sampling of species as stand targets does not necessarily give a representative measure of the temperature mean and variance.

- Use of LANDSAT TM thermal data requires conversion of ground data, measured in ${ }^{\circ} \mathrm{C}$, to uncorrected spectral radiance $\left(\mathrm{R}_{u}\right)$. The 
relationship between ${ }^{\circ} \mathrm{C}$ and $\mathrm{R}_{u}$ is nonlinear, thus introducing another source of error in the weighted-average temperature estimate.

- In contrast, the sampling error associated with target cover as a weighing factor, target selection bias, compounded variances, and the nonlinearity of $\mathrm{R}_{\mathrm{u}} /{ }^{\circ} \mathrm{C}$ is absent when random transect sampling is used to estimate mean stand temperature.

Based on these field test results, the random transect sampling technique was used for collecting thermal GT data during TM overflights. As indicated below, the resulting plot mean temperatures compared well with the TM-determined temperatures.

For analysis, the TM scenes were registered to ground control points, and TM digital numbers (DN) of the sampling plots were extracted. Atmospheric corrections (using the local radiosonde data) were determined by the computer code LOWTAAN 6. Look-up tables of DN- and TM-determined temperatures were calculated. The temperatures obtained using the average DN values of the sample plots for different plant communities were compared with the GT temperature values. As shown in Figure 1, both the uncorrected and atmospherically corrected temperature values were compared to corresponding GT values. The excellent agreement of the corrected water temperature values (Columbia River) of less than $0.5^{\circ} \mathrm{C}$ with respect to GT values indicates that the influence of the atmosphere has been accounted for using LOWTRAN 6. The GT technique for nonwater temperatures indicated very good agreement for homogeneous communities (less than $1.3^{\circ} \mathrm{C}$ variance) and good agreement for heterogeneous communities (less than $3^{\circ} \mathrm{C}$ but within two standard deviations of mean plot temperature).

An atmospherically corrected brightness temperature map of the Hanford Site was produced using the look-up tables and color coded by computer. This digital temperature map when combined with ancillary data will be used to estimate ET for Hanford.

In conclusion, FY 1989 analysis of LANDSAT TM data for Hanford indicates the following:

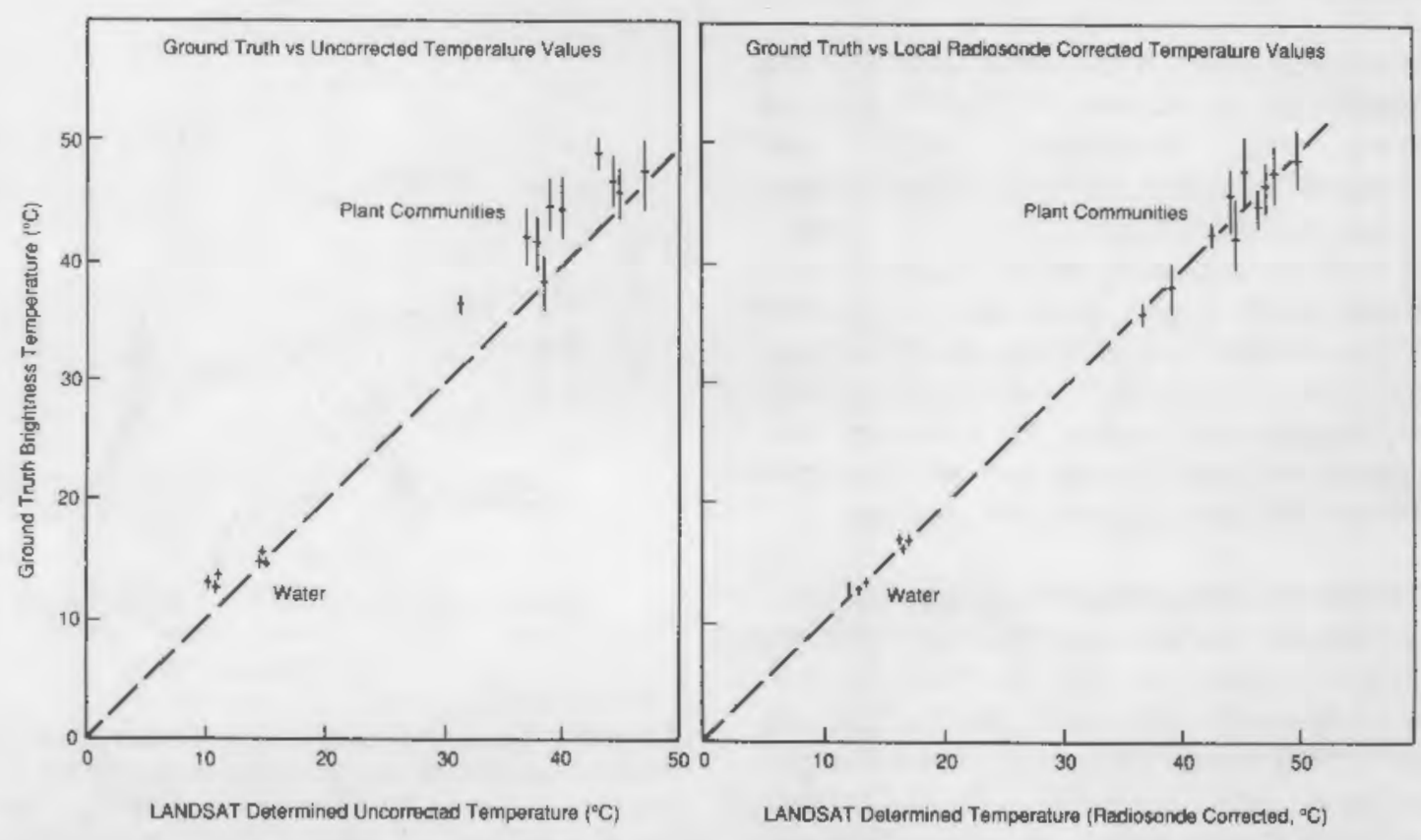

FIGURE 1. Comparison of Ground Truth (GT) Temperatures with LANDSAT-Determined Values (May 8 and June 1, 1969). The dotted line indicates a 1-to-1 comparison between GT- and TM-determined temperature values. 
- Atmospheric corrections are necessary when using satellite data since errors as high as $6^{\circ} \mathrm{C}$ could result from using uncorrected data.

- Absolute radiometric brightness temperature distributions of surface features can be produced.

- The devised sampling plot method of integrating temperature data for plant communities can be compared with satellite data, giving good results when compared to the sampling plot mean temperature values.

\section{Landscape Reflectance Measurements}

Reflectance measurements in the visible and NIR spectral regions can provide an important link to biophysical parameters useful for surface change detection. This is particularly valuable since satellites can provide spatially resolved maps of reflectance data for large areas of the earth's surface.

To this end, we have collected numerous GT spectral signatures of surface targets typical of the Hanford Site to facilitate validation of measurement ecological quantities using remotely sensed data. The goal is to identify key spectral regions that can be used for change detection analysis.

To facilitate this effort, a relational database has been developed to archive and retrieve spectral signatures. This database contains over 400 reflectance spectra collected on the Hanford Site. These reflectance measurements provide a unique spectral "signature" of the targets at various phenological stages, times of the year, sun angles, view angles, and moisture levels. Subsets of spectra can be extracted by querying the database by target type, location, or date and time. The spectra are then loaded into an interactive environment for data analysis and graphics.

Pacific Northwest Laboratory's remote sensing laboratory uses two portable spectroradiometers for collecting GT reflectance data. Both are commercially available instruments designed for field use. During FY 1989, spectral scans of Hanford targets were collected using the portable spectroradiometers on May 8 and June 1 in conjunction with LANDSAT TM overpasses. The measurements were made at four defined locations representative of different vegetative communities. At each location, in a fashion similar to the thermal measurements, spectra were taken at 25 points on a 100 by $100-\mathrm{m}$ grid. In theory, the average of the point scans should be representative of the community's integrated spectral signature and linked to the satellite's digital number for the vegetation community.

The goal was to derive characteristic spectral signature curves for the surface targets on the Hanford Site. Preliminary examination of these curves in aggregate suggests (Figure 2) 1) bare ground exhibits a smooth function with reflectance, increasing with wavelength through the visible; 2) growing vegetation has a low reflectance at about $660 \mathrm{~nm}$ (due to photosynthetic absorption), which rapidly increases in the NIR; 3) the ratio of the photosynthetic and NIR regions seems to be a function of canopy thickness; 4) reflectance curves tend to flatten and increase uniformly with wavelength for senescent vegetation; 5) in general, curves shift up and down with

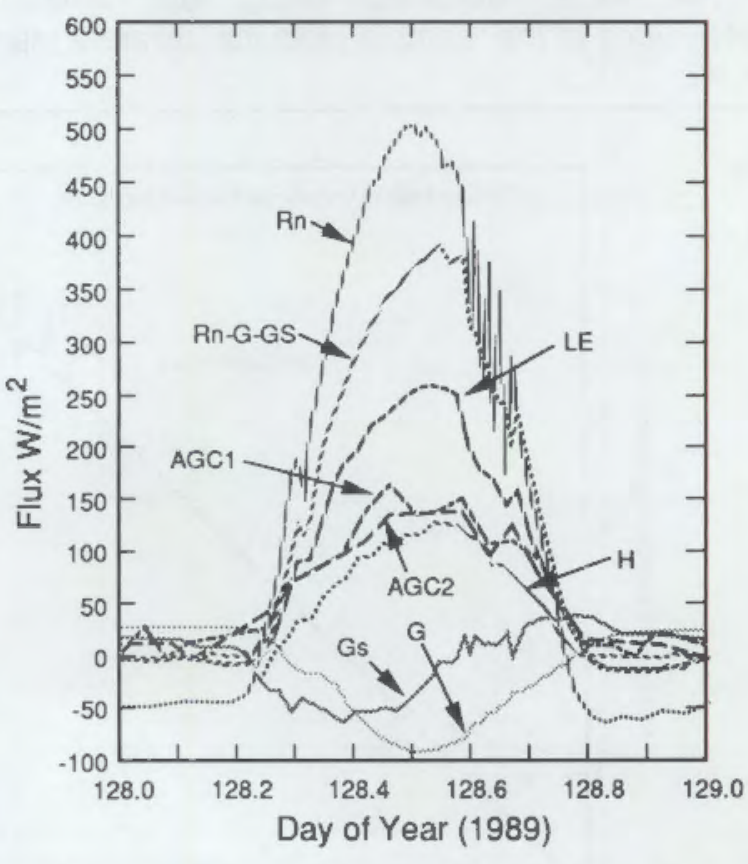

FIGURE 2. Energy Flux Balance at ALE Grass Site on May 8 , 1989. All values were recorded at the location of the two weighing lysimeters. The indicated fluxes are: $R_{n}=$ net radiation, $\mathrm{G}=$ soil heat, $\mathrm{H}=$ sensible heet, $\mathrm{LE}=$ evapotranspirstion, GS = soil heat storage $(0-5 \mathrm{~cm})$, and AGC1 and AGC2 refer to two different weighing lysimeters at the site. 
sun exposure, but the characteristic shape is maintained; and 6) spectral signatures are strongly affected by the percent of target area to background area.

Remote sensing of the Earth's surface from space or even an airborne platform will require an evaluation of the effect of the intervening atmosphere. The atmosphere contains many species that mask the received signal, but relatively few are both abundant and temporally variable. For noncloudy atmospheres, aerosol particles govern the extinction (scattering and absorption) of radiation in the visible and NIR regions. Consequently, quantifying the amount of aerosol, and to a lesser extent, water vapor and ozone, for radiative transfer models enables the most significant sources of signal contamination to be determined.

A computer-controlled sun photometer located at the HMS is used to measure the direct normal radiation at 12 wavelengths in the 300 - to $1000-\mathrm{nm}$ spectral region using a $1.5^{\circ}$ field of view. This set of measurements is automatically collected every 5 minutes from sunrise to sunset. These data are routinely reduced to derive estimates of the total column aerosol extinction commonly referred to as the aerosol optical depth.

During the FY 1989 field season, optical depths were obtained from the HMS photometer data for both the May 8 and June 1 overflight. These measurements of the atmospheric extinction will facilitate calibration of the satellite digital image using coincident GT reflectance data.

Aerosol optical depth exhibits day to day variation as a result of meteorological conditions, forest fires, agricultural field burning, and anthropogenic pollution. However, this variation is typically superimposed on a dominating annual cycle in the aerosol optical depth.

Aerosol optical depth measurements for the Hanford Site spanning 5 years (1985-1989) were folded into one "typical" year and smoothed using a nonparametric fit. The results showed a sinusoidal variation throughout the year with a maximum in May and a minimum in October. The brief but strong increase in the aerosol optical depth in the fall appears to coincide with agricultural field burning. Data collected during
TM overpasses will be used to make a small but significant correction for atmospheric effects due to aerosols.

\section{Lysimeter/Bowen Ratlo Measurements}

A unique facility has been developed over the past 3 years that allows detailed measurement of ET in plant communities located on the Hanford Site. Telemetry-linked dataloggers recordenvironmental conditions and lysimeter weights throughout the year, and also perform the Bowen ratio/energybalance measurements during the growing season. The albedo and surface temperatures were measured with infrared thermometers. This comprehensive data set for a semi-arid environment will be used to develop landscape models of ET that can be driven by remotely sensed data obtainable from aircraft or satellites.

Three methods for estimating ET were used during FY 1989 to determine the effects of the plant community on ET. At the same elevation, a bunchgrass (burned) and a sagebrushbunchgrass (unburned) community were monitored using neutron-probes, weighing lysimeters, and Bowen ratio/energy-balance micrometeorological stations. The three methods show good agreement, with ET rates (approximately 30 -day averages) ranging from a springtime high of $0.19 \mathrm{~cm}$ to $0.02 \mathrm{~cm}$ in the fall. Data indicate that ET rates are very similar between the two communities but that weighing lysimeters may lose water earlier in the spring than the surrounding plant communities.

The Bowen ratio and weighing lysimeter data for the satellite overflights on May 8 and June 1, 1989, at the ALE grass site are shown in Figures 2 and 3. Bowen ratio estimates of ET are similar and higher than the weighing lysimeter measurement for the 2 days. The June 1 weighing lysimeter estimate of ET is significantly less than the May $B$ weighing lysimeter estimate. About $1 \mathrm{~cm}$ more water is lost from the sagebrush sites than the grass sites during 1989. (Weight change data for the weighing lysimeters are given in Figures 1 and 2 in the Arid Lands Water Balance section.)

In Table 1, ET estimates are tabulated on approximately monthly intervals for the neutron probe and weighing lysimeters. The rates are 


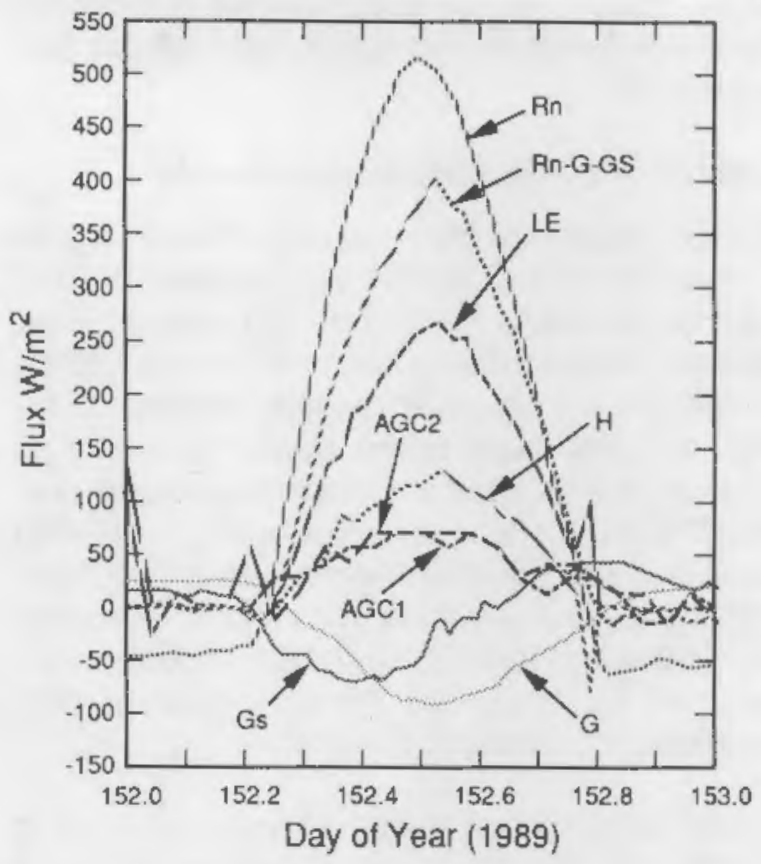

FIGURE 3. Energy Flux Balance at ALE Grass Site on June 1, 1989. All values were recorded at the location of the two weighing lysimeters. The indicated fluxes are: $R_{n}=n e t$ rediation, $\mathrm{G}=$ soil heat, $\mathrm{H}=$ sensible heat, $L E=$ evapotranspiration, GS = soil heat storage $(0-5 \mathrm{~cm})$, and AGC1 and AGC2 refer to two different weighing lysimeters at the site, similar; however, the lysimeters lost water earlier in the spring, and the neutron probe data indicate a greater water loss.

Planned FY 1990 ET remote sensing activities include:

- development/evaluation of appropriate ET/remote sensing models for arid shrubsteppe environments using the Hanford temperature and net radiation map

- production of a preliminary supervised and verified landcover classification map of the ALE Reserve

- data analysis of reflectance signatures to be used for determination of net radiation by LANDSAT TM for Hanford

- spring 1990 LANDSAT GT data collection similar to FY 1989 to broaden the Hanford database, improve on GT-data collection procedures, and test ET/remote sensing models

- begin using a Geographical Information System (GIS) to coordinate the ET/remote sensing database for the Hanford Site.

TABLE 1. Calculated ET Using Changes in Soil Water Storage

\begin{tabular}{|c|c|c|c|c|c|c|c|}
\hline 0 Depth $(\mathrm{cm})$ & $\begin{array}{c}\text { Total } \\
\text { Storage }(\mathrm{cm})\end{array}$ & $\begin{array}{l}\text { Storage } \\
\text { Change } \\
\end{array}$ & $\begin{array}{l}\text { Days in } \\
\text { Interval }\end{array}$ & $\begin{array}{l}\text { Rain } \\
(\mathrm{cm}) \\
\end{array}$ & $\begin{array}{l}\text { Rain } \\
\text { Storage }\end{array}$ & $\begin{array}{c}E T(\mathrm{~cm}) \\
N P\end{array}$ & $\begin{array}{l}\text { ET (cm) } \\
\text { Lysimeter }\end{array}$ \\
\hline $\begin{array}{l}\text { ALE GPASS } \\
23-M A R-89\end{array}$ & 34.13 & & & & & ALE GRASS & AGC \\
\hline 25-APR-89 & 31.57 & 2.56 & 33 & 1.10 & 3.67 & 0.11 & 0.14 \\
\hline 25-MAY-89 & 30.15 & 1.41 & 30 & 3.87 & 5.29 & 0.18 & 0.16 \\
\hline 29-JUN-89 & 28.21 & 1.94 & 35 & 0.42 & 2.36 & 0.07 & 0.06 \\
\hline 28-JUL-89 & 27.64 & 0.57 & 29 & 0.05 & 0.62 & 0.02 & 0.02 \\
\hline 28-AUG-89 & 27.29 & 0.35 & 31 & 0.48 & 0.84 & 0.03 & 0.02 \\
\hline 26-SEP-89 & 27.09 & 0.20 & 29 & 0.33 & 0.53 & 0.02 & 0.02 \\
\hline ALE SAGE & & & & & & ALE SAGE & ASB \\
\hline 23-MAR-89 & 34.19 & & & & & & \\
\hline 25-APR-89 & 31.15 & 3.04 & 33 & 1.10 & 4.14 & 0.13 & 0.15 \\
\hline 25-MAY-89 & 29.38 & 1.77 & 30 & 3.87 & 5.64 & 0.19 & 0.15 \\
\hline 29-JUN-89 & 27.48 & 1.89 & 35 & 0.42 & 2.31 & 0.07 & 0.05 \\
\hline 28-JUL-89 & 26.71 & 0.77 & 29 & 0.05 & 0.82 & 0.03 & 0.02 \\
\hline 28-AUG-89 & 26.25 & 0.46 & 31 & 0.48 & 0.95 & 0.03 & 0.02 \\
\hline 26-SEP-89 & 26.13 & 0.12 & 29 & 0.33 & 0.45 & 0.02 & 0.02 \\
\hline
\end{tabular}




\section{Reference}

Wukelic, G. E., D. E. Gibbons, L. M. Martucci, H. P. Foote. 1989. "Radiometric Calibration of LANDSAT Thematic Mapper Thermal Band." Remote Sensing of Environment 28:339-347.

\section{Arid Lands Water Balance}

\section{D. Campbell and G. W. Gee}

Global change related effects as well as hazardous waste disposal activities in arid areas have drawn increased attention to the water status and movement of contaminants in the vadose zone. Reviews by Gee and Hillel (1988) and Gee et al. (1988) indicate the need for better documentation of the interrelations of the five elements of water budget (i.e., precipitation, ET, water storage, drainage, and run-off) at arid sites. Four weighing lysimeters were installed during 1986 (Gee 1987) at the ALE Reserve on the Hanford Site in southeastern Washington State to measure four of the five elements of water budget on grass and grassshrub sites. The fifth element, run-off was prevented by an upward-protruding lip on the weighing lysimeters.

Natural precipitation, ET, drainage, and storage were measured on silt loam soils at the ALE Reserve. Hourly weight changes were recorded during the past year. All four lysimeters were installed by enclosing undisturbed soil monoliths and thus had the natural vegetation growing on them. Two of the lysimeters were located at a bunchgrass site, and two more were located at a sagebrush-bunchgrass site (Gee 1987).

Water budgets of all four lysimeters are shown in Figures 1 and 2. There was no drainage from any of the lysimeters. Thus, the precipitation was partitioned into ET and storage. Total precipitation was measured by a tipping bucket rain gauge and by weight increase on the weighing lysimeters. Both devices recorded almost $20 \mathrm{~cm}$ of precipitation during the period shown. There appears to have been little difference between the water budgets from the four lysimeters. Only the degree of depletion of soil moisture appears to have been different, with the grass removing water slightly faster and to a slightly greater degree than the grass-shrub combination, perhaps because of shading on the grass-shrub lysimeters. The

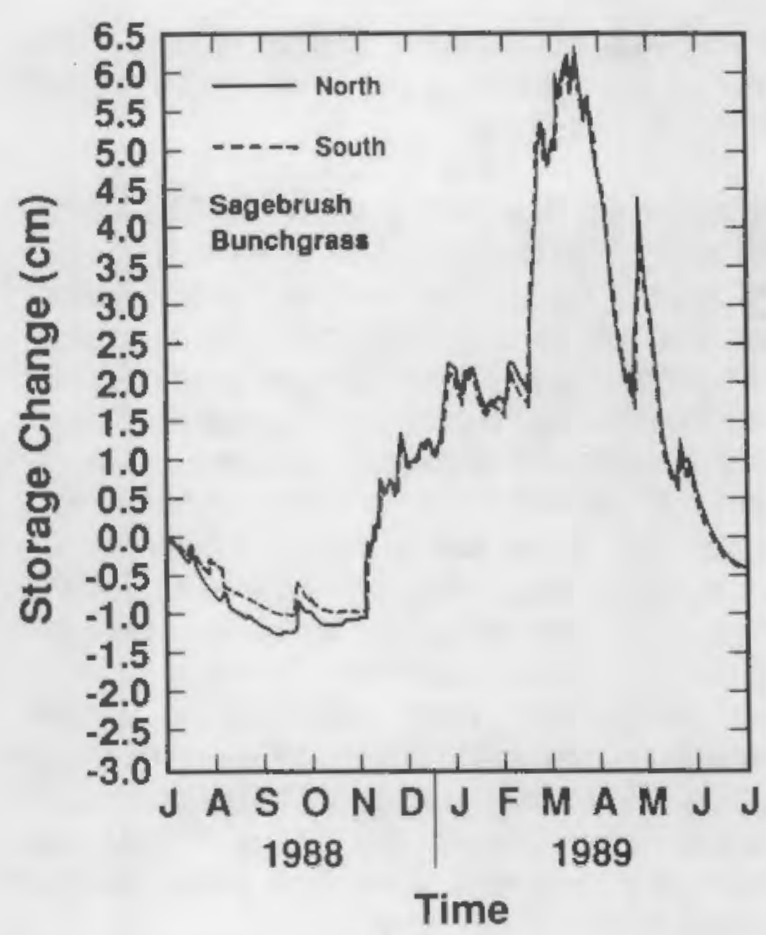

FIGURE 1. Water Budgets for the ALE SagebrushBunchgrass Lysimeters

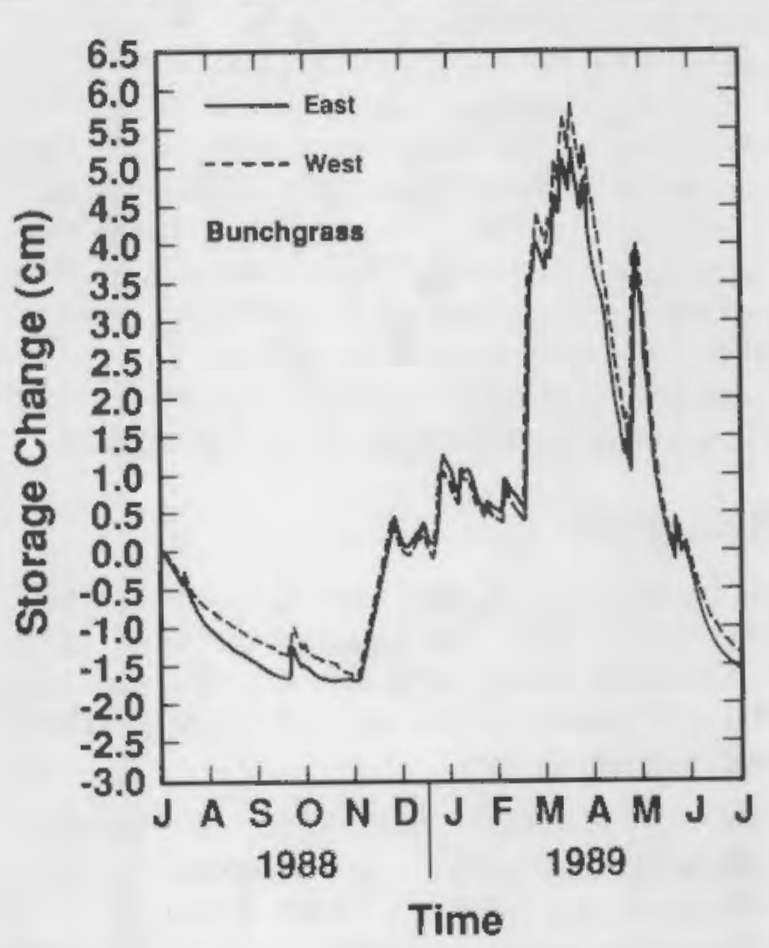

FIGURE 2. Weter Budgets for the ALE Bunchgrass Lysimeters 
grass-shrub combination slightly favored water storage, again, possibly due to shading of the soil surface by the shrub.

A comparison was made between the four lysimeters at ALE and four other lysimeters with silt loam soil located about $8 \mathrm{~km}$ north of the ALE lysimeters. Two had no vegetation; two were vegetated. One vegetated and one nonvegetated lysimeter were irrigated with twice the average precipitation. All lysimeters with vegetation growing on the silt loam soil reached a similar water depletion level near 6 vol\% by the end of the dry season, showing a similar soil water extraction limit for the plants. The nonvegetated lysimeters, likewise, reached a common extraction limit near 15 vol\% from evaporation alone, showing a uniform response of bare soil to climate. While no drainage occurred from the lysimeters, downward movement of water through the silt loam soils was clearly demonstrated when soil water storage exceeded the 25 -vol\% level.

These data are currently being used to validate unsaturated water flow models for arid sites. Preliminary use of these models (Fayer et al. 1986) indicates a potential for drainage through the vadose zone with the prospect of mineral transport whenever soil moisture exceeds 25 vol\% for these silt loam soils. The likelihood of such a water level appears to be significantly higher when vegetation is eliminated, when precipitation is more than doubled, when potential ET decreases (e.g., solar radiation, temperature, etc.) significantly, or when a combination of these three prevails. The quantitative effects of these variables on recharge need to be further documented for the Hanford Site.

\section{References}

Fayer, M. J., G. W. Gee, and T. L. Jones. 1986. UNSAT-H Version 1.0: Unsaturated Flow Code Documentation and Applications for Hanford Site. PNL-5899, Pacific Northwest Laboratory, Richland, Washington.

Gee, G. W. 1987. "Installation of PrecisionWeighing Lysimeters for Evapotranspiration Measures at Hanford's Arid Land Ecology Reserve.' In Pacific Northwest Laboratory Annual Report for 1986 to the DOE Office of Energy
Research: Part 2, Environmental Sciences. PNL-6100 PT2, Pacific Northwest Laboratory, Richland, Washington.

Gee, G. W., P. A. Beedlow, and R. L. Skaggs. 1988. "Water Balance." In Shrub-Steppe: Balance and Change in a Semi-Arid Terrestrial Ecosystems. eds. W. H. Rickard, L. E. Rogers, B. E. Vaughan, and S. F. Liebetrau. Elsevier Science Publishing Company, New York.

Gee, G. W., and D. Hillel. 1988. "Groundwater Recharge in Arid Regions: Review and Critique of Estimation Methods." Hydrologic. Processes Intern. J. 2:255-266.

\section{A Microcosm-Level Gas Exchange Study on the Effects of Nitrogen and Water on Bromus tectorum}

\section{S. O. Link and H. Bolton, Jr.}

Ecosystems have dynamic efficiencies for processing and utilizing limiting essential resources such as water, nutrients, and energy. Water is the most limiting resource for vascular plants and soil microorganisms in the arid shrub-steppe, while nitrogen is the most limiting nutrient. When a resource is no longer limiting, or stress is applied, the efficiency with which an ecosystem processes these resources may change. Ecosystem efficiencies for limiting resources have direct implications for ecosystem productivity, the ability to sustain impacts, and the ability to act as a source/sink for global climate effects. Recently, we investigated the response of two arid ecosystems to additional water and nitrogen. This investigation allowed us to determine the efficiencies of these ecosystems for water use, nitrogen cycling, and energy capture (or carbon gain). The first ecosystem was an undisturbed perennial shrub-steppe (dominated by sagebrush, Artemisia tridentata and bunchgrass, Agropyron spicatum), while the second was a disturbed annual grassland (dominated by cheatgrass, Bromus tectorum). In the field, significant increases in carbon gain and water use for both ecosystems were found when additional water and nitrogen were added (Link et al. 1989). In addition, the application of both water and nitrogen had a synergistic response with a greater yield than when either was applied separately. 
The field research utilized single leaf or branchtip gas exchange measurements. A microcosmlevel whole-plant gas exchange chamber, which is environmentally controlled, was constructed during $F Y$ 1989. The objectives of our research this year were twofold. First, to apply the whole-plant gas exchange technology developed this year to intact soil-core microcosms of the cheatgrass ecosystem. These cheatgrass microcosms were incubated in the growth chamber with treatments similar to the field experiments the previous year (i.e., additional water and nitrogen). Thus, our second objective was to determine if data obtained for carbon gain and water use in growth chamber incubated microcosms were comparable to the field.

Twenty intact soil-core microcosms were obtained from the cheatgrass field on November 4, 1988. Four treatments with five replicates were created. Treatments included: control ( $1 \mathrm{~L}$ of distilled weter added at the beginning of the experiment), nitrogen (soil enriched with $100 \mathrm{~kg} \mathrm{ha}{ }^{-1}$ of $\mathrm{NH}_{4} \mathrm{NO}_{3}$ fertilizer and $1 \mathrm{~L}$ of distilled water added at the beginning of the experiment), water $(1 \mathrm{~L}$ distilled water added biweekly), and nitrogen plus water (enriched with $100 \mathrm{~kg} \mathrm{ha}^{-1}$ of $\mathrm{NH}_{4} \mathrm{NO}_{3}$ fertilizer and $1 \mathrm{~L}$ of distilled water added biweekly). Microcosms were incubated in the growth chamber with temperature fluctuations of $20^{\circ} \mathrm{C} / 15^{\circ} \mathrm{C}$ for light/dark periods of 12 hours each. Photosynthetically active radiation (PAR) averaged $265 \mu \mathrm{mol}$ photons $m^{-2} s^{-1}$.

The microcosm-level whole-plant gas exchange system is a dynamic open flow system. Carbon dioxide concentrations were measured with an infrared gas analyzer (IRGA). Water vapor concentrations entering and leaving the gas exchange chamber were measured with two dewpoint hydrometers. The gas exchange chamber was constructed of clear acrylic plastic and lined with clear Teflon tape to minimize gas absorption by the plastic. Temperature in the chamber was controlled with peltier chips, heat exchange fins, and a circulating fan encased in a stainless steel airtight chamber. A mass flow controller controlled air flow to maintain a constant chamber dewpoint temperature. Gas exchange measurements were

\footnotetext{
(10) Tetlon is a registered tredemark of E. I. du Pont de Nemours and Compeny, Wilmington, Delaware.
}

initiated 2 days after cheatgrass germination with observations repeated after 3 and 5 weeks. Chamber experimental conditions of air temperature $\left(20^{\circ} \mathrm{C}\right)$, dewpoint temperature $\left(8.2^{\circ} \mathrm{C}\right)$, PAR at the top of the canopy (925 $\mu$ mol photons $\left.\mathrm{m}^{-2} \mathrm{~s}^{-1}\right)$, and $\mathrm{CO}_{2}$ in the incoming air stream (355 $\pm 5 \mathrm{ppm}$ ) were held constant for all observations. The technical capabilities of the gas exchange system allowed us to control chamber air temperature and dewpoint temperature for humidity control to within $0.5^{\circ} \mathrm{C}$ of the setpoint temperature. This level of control was sufficient to maintain instrument noise levels to less than $5 \%$ of full scale.

Transpiration decreased with plant age for the four treatments (Figure 1). Plant age was a stronger determinant of transpiration rates than were the treatment effects, with treatment differences not consistent over time. In the last observation period, transpiration rates were significantly greater in the water treatment than in the three other treatments. These results were not consistent with field data, where only plants in the nitrogen plus water treatment had transpiration rates significantly higher than the three other treatments (Link et al. 1989). Net photosynthesis was affected by plant age only at the third sampling, dropping close to zero for plants in the nitrogen and nitrogen plus water treatments (Figure 2). These two treatments were significantly

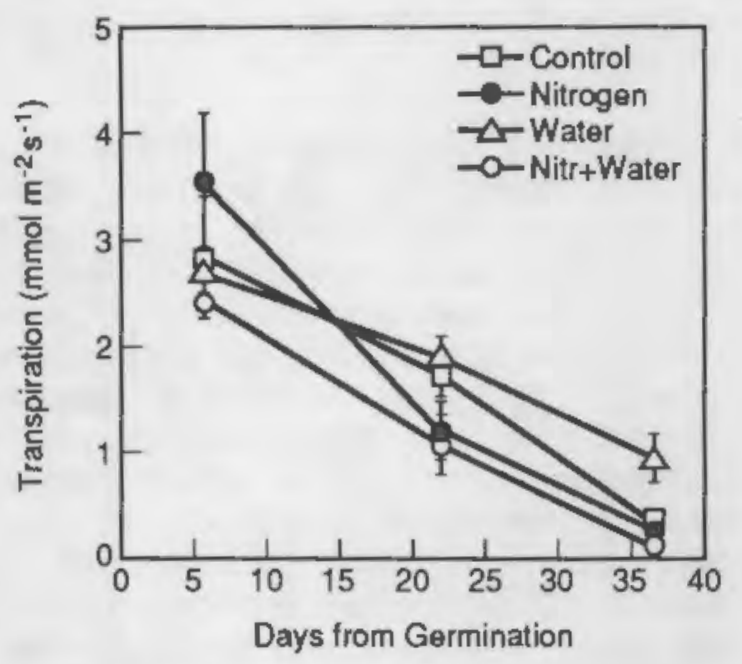

FIGUAE 1. Transpiration of Bromus tectorum as a Function of Time from Soil Treatments including a Control, Additional Nitrogen, Additional Water, and Additional Nitrogen and Water. Bars are one standard error of the mean. 


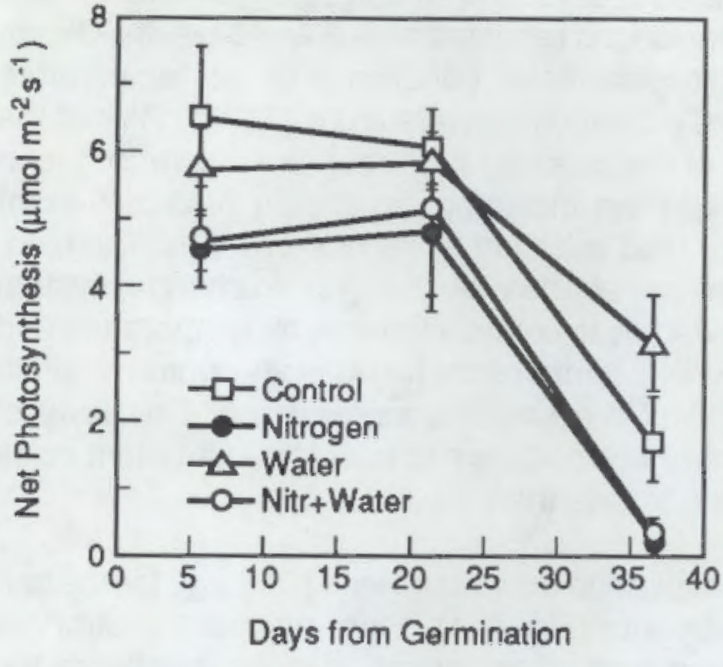

FIGURE 2. Net Photosynthesis of Bromus tectorum as a Function of Time from Soil Treatments including a Control, Addilional Nitrogen, Additional Water, and Additional Nitrogen and Water. Bars are one standard error of the mean.

lower than the control and water treatments. In the field, net photosynthesis was lower in the water treatment than in the three other treatments, which were not significantly different from one another (Link et al. 1989). Shoot oven-dried biomass was significantly higher for the nitrogen plus water treatment compared with the three other treatments (Figure 3). This is in contrast to results in the field where biomass was significantly greater for the water and nitrogen plus water treatments compared with the control and nitrogen treatments (Link et al. 1989).

In conclusion, a microcosm-level whole-plant gas exchange chamber performed well under laboratory conditions. Data collected in our growth chamber study were not identical to field data obtained the previous year. However, plant growth in the growth chamber was not phenologically similar to field-grown cheatgrass (personal observation). A more rigorous simulation of the field growing season in the growth chamber, including temperature fluctuations of weekly maximum/minimum values, saturating light conditions for the average number of clear days, and soil moisture conditions, may be needed for a better growth chamber-field comparison. Current growth chamber capabilities were unable to adequately simulate these field conditions. Laboratory growth chambers, which can adequately simulate

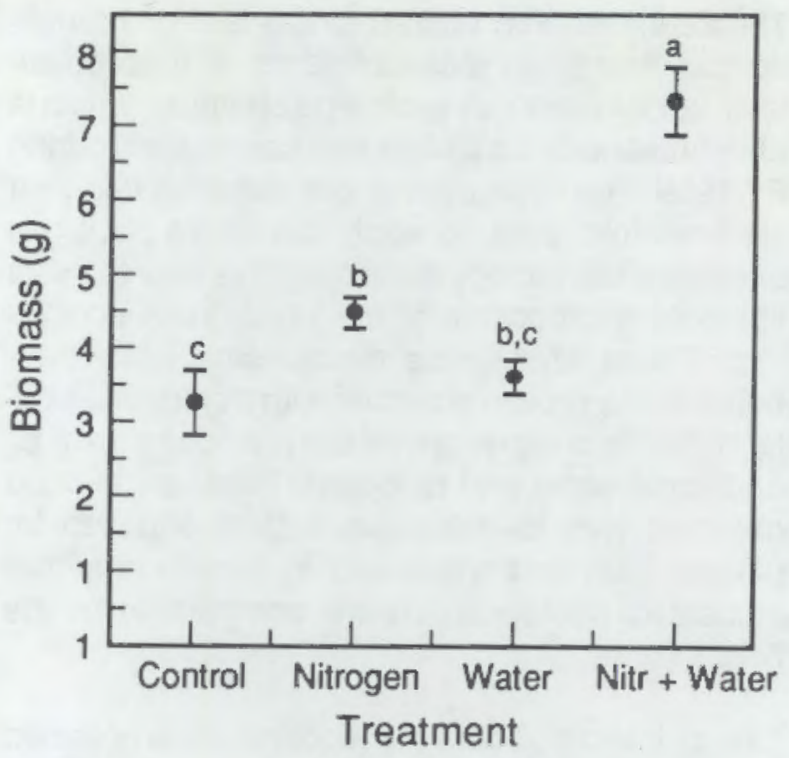

FIGURE 3. Final Shoot Biomass of Bromus tectorum from Soil Treatments including a Control, Additional Nitrogen, Additional Water, and Additional Nitrogen and Water. Different letters above the bars indicate significant differences at the $95 \%$ confidence level by Duncan's Multiple Range Test.

the field, may be needed to understand the efficiencies of arid ecosystems and address future global climate change hypotheses.

In the future, efficiencies of arid ecosystems for water, energy, and nitrogen will be determined using a holistic approach in determining both above- and below ground pools and processes. Capabilities developed in the annual grassland will be applied to the perennial shrub-steppe where questions of landscape-level distribution of pools and processes in this more diverse ecosystem will have to be rigorously addressed. Studies will continue on the linkage between microcosms and field measurements to determine how useful microcosms are at simulating field responses.

\section{Reference}

Link, S. O., P. A. Beedlow, M. E. Thiede, and J. L. Downs. 1989. "The Effect of Water and Nitrogen Perturbations on Gas Exchange in Arid Lands Ecosystems." In Pacific Northwest Laboratory Annual Report for 1988 to the DOE Office of Energy Research: Part 2: Environmental Sciences. PNL-6800 Pt. 2, Pacific Northwest Laboratory, Richland, Washington. 


\section{Future Research}

Pacific Northwest Laboratory research in the next few years will focus on developing more accurate predictions of how ecological, hydrologic, biogeochemical, and atmospheric processes interact to influence long-term changes and how spatial scales influence environmental responses in arid and semi-arid environments.

Over the last two decades, there has been growing scientific concern over the potential for anthropogenic activities to significantly modify the Earth's climate. Recently, because of this concern, a major global climate change research program is being supported by every major division of the federal government.

Our future research goals in this area are directed toward 1) understanding the functional response of the shrub-steppe ecosystem to the predicted decrease in precipitation and increase in radiatively important gases (RIG) and air temperatures, 2) predicting changes in climate-induced biotic boundaries, 3) defining the processes through which such changes will occur, and 4) developing mitigative strategies based on our current understanding of environmental processes and past biotic/climatic relationships as revealed through our paleoecologic studies.

Current scientific discussions of the deleterious effects of anthropological influence by advancing technology on the natural environment are well documented. Some of these effects appear to be real and extensive (e.g., El Nino and ozone depletion). These influences in climatic conditions are occurring at the local, regional, and global spatial levels. Global Circulation Models (GCM), which attempt to evaluate and predict climatic change, partition the Earth's surface into spatial grids approximately $1000 \mathrm{~km}$ (or larger) on a side. However, gradients of land cover and ecological processes occur within the GCM-sized areas. These must be carefully identified and monitored for global models used in climatic scenarios to make proper political, economic, and social decisions to modify the human influence on the environment.
Arid and semi-arid areas of the Western United States do not exist in isolation from other climatic regimes, and the problem of scaling up from station (point) measurements of ecological processes to landscape, regional, and global areas must be addressed in the future. One planned approach at PNL is to use multispectral remote sensing technology to qualitatively and quantitatively measure ecological quantities over large areas. Results would be validated using statistically determined locations for GT field data. Such studies anticipate using remote sensing of environmental change as part of the new series of NASA-launched satellite instruments of the Earth Observing System (EOS 1995).

The successful development and use of spatial models that depict environmental responses over landscape and region-sized areas rely on the ability to integrate and synthesize large amounts of information from a wide variety of sources. To support this effort, we plan to develop knowledgebased approaches to analyze and model biosphere processes. Initially, this research will concentrate on distinguishing and quantifying landscape-sized units associated with the ALE Reserve at Hanford. Further research would focus on developing knowledge-based systems to evaluate environmental health and predict responses to stress factors over regional areas.

The resolution of issues surrounding the effects of large-scale environmental changes will require new paradigms in ecology. Our current view of ecosystems and how they respond to stress has grown from structure-function research conducted at laboratory- and plot-sized scales. Future ecological research must build on physical theories to develop a thermodynamic perspective of the biosphere that can be measured over a range of scales from global to individual study plots $\left(\mathrm{m}^{2}\right)$. This perspective will need to recognize physical models of the atmosphere, oceans, and land area surlaces, and use data gathered from both local and spaceborne instruments. 


\section{Subsurface}

Science 


\section{Subsurface Science}

The contamination of subsurface environments by mixed waste chemicals is a major concern on DOE lands and many waste sites nationally. The scientific community is now being asked to 1) predict the rates at which these contaminants migrate through subsurface environments to estimate health risks and to assist in clean-up activities and 2) develop more effective in situ remediation techniques to degrade, immobilize, or mobilize contaminants. Transport predictions and contaminant remediation are especially difficult on DOE lands where the co-disposal of radionuclides, metal ions, salts, organic solutes, and organic liquids to the ground has created unique environmental questions.

PNL is performing basic scientific studies of the chemical, microbiologic, and hydrologic behavior of these contaminants and mixtures because understanding of the processes that control their fate is limited. This basic research targets DOE site contaminants, but broader scientific benefits are anticipated that will assist in predicting the subsurface behavior of organic-inorganic mixtures and organic liquids generally under different geochemical and hydrologic conditions. Microbiological research is investigating the nature of microorganisms in different deep hydrogeological environments, their ability to degrade aromatic organic chemicals and complexing ligands, and the relationship of these processes to sorption phenomena. Subsurface chemistry studies are investigating multisolute sorption phenomena, co-solvent effects and complexation, and abiotic surface-enhanced degradation on subsoil and aquifer materials. Hydrological investigations are defining the flow physics of organic liquid/water multiphase mixtures in saturated and unsaturated porous media, and systematically examining the effects of subsurface heterogeneities on transport. Multidisciplinary transport studies are being performed in columns and in a unique intermediate-scale experimental facility where the combined effects of microbiology, chemistry, and hydrology on chemical transport can be assessed. The research is driving the development of improved contaminant migration models and effective new strategies to reduce migration rates and remove contaminants from groundwater.

\section{Subsurface Microbial Phenomena}

\section{J. K. Fredrickson and F. J. Brockman}

\section{Contributors}

D. L. Balkwill (Florida State University), S. Harvey, S. W. Li, B. M. McVeety, D. L. Stewart, A. J. Valocchi (University of Illinois), and D. J. Workman

The contamination of subsurface environments with organic and inorganic chemicais has become a national concern and is an acute problem at DOE sites nationwide (e.g., Hanford, Idaho National Engineering Laboratory, Lawrence Livermore National Laboratory, and Savannah Piver). Degradation of organic compounds by microorganisms offers a potential means for the economic destruction of organic compounds in situ. Bioremediation, or the use of microorganisms to destroy or stabilize hazardous wastes, is being used by industry and others in attempts to clean up contaminated subsoils and groundwater.
While some of these technologies are successful, many attempts fail completely or result in only partial degradation of the target contaminant. Key reasons for the mixed success of in situ remediation are a lack of understanding of the distributions and metabolic functions of subsurface microorganisms and the interactions between microbial activities, such as biodegradation, and chemical and physical properties.

The goals of this project continue to be: 1) to gain a better understanding of the fundamental microbiological properties of deep aquifers including the capacity of indigenous microorganisms to degrade organic contaminants and the relationship between microbial populations and physical and chemical properties and 2) to probe the interactions between microbial degradation, contaminant sorption, and flow. The technical approach to achieving these goals has included iteration between field, laboratory, and column transport experiments. This approach allows for the 
development of fundamental information on the physiology and ecology of subsurface microorganisms and for the testing of hypotheses relevant to the field in well-defined experimental systems.

This section summarizes the results of select investigations into the microbiology of deep subsurface environments and experiments to elucidate the microbial biochemistry of aromatic compound degradation, and its genetic control. In addition, studies to gain a mechanistic understanding of the interactions between sorptiondesorption and biodegradation have continued, and have resulted in a greater understanding of the interactions between mineral sorbent (clay), subsurface bacteria, and organic compounds. These studies were conducted during FY 1989 jointly with the Subsurface Chemistry of Organic Mixtures Project and will be reported in that section. Joint experiments were conducted with the Intermediate-Scale Investigations Project to extend the static sorption-biodegradation experiments to hydrodynamic systems. These experiments were conducted in one-dimensional columns using a synthetic alumina-montmorrilinite porous media, a quinoline-degrading subsurface bacterium, and quinoline. These experiments also served as a precursor to intermediate-scale experiments planned for FY 1990 to obtain preliminary information on the effects of flow and sorption on biodegradation. In conjunction with the column and intermediate-scale experiments, scientists at the University of Illinois, in collaboration with PNL, are developing a model for describing the transport of biologically and chemically reactive solutes in two-dimensional heterogeneous intermediatescale systems. This effort began late FY 1989 and, therefore, will not be reported here.

\section{Deep Subsurface Microbiology Investigations}

The inability to predict the rate or extent of biodegradation of organic compounds in the subsurface based on static incubations and the variability in the rate and extent of in situ biodegradation of organic compounds in aquifers have been suggested to be due, in part, to spatial variability in the distribution of microbial populations. Thus, before contaminant degradation can be predicted from either static or dynamic laboratory experiments, there is a need to evaluate the spatial distributions of indigenous heterotrophic bacteria and identify the physical and/or chemical properties of the sediments controlling their presence and abundance. This past year, an integrated geochemical/microbiological/ hydrological experiment (GEMHEX) was conducted using a series of intact cores obtained from two distinct deep subsurface strata in the southeastern coastal plain near the Savannah River Site (SRS). This research was conducted jointly between PNL's Subsurface Chemistry of Organic Chemical Mixtures project and Florida State University as part of the OHER Deep Subsurface Microbiology program. The results presented in this section focus on the issue of microbial contamination of core samples by drill mud bacteria and the diversity of heterotrophic bacteria based on physiological and genetic analysis of over 210 isolates.

A series of intact subsurface sediment cores were obtained from the Middendorf ( 364 to $411 \mathrm{~m}$ ) and Cape Fear $(460$ to $466 \mathrm{~m})$ formations, which underlay the coastal plain in South Carolina, to determine the diversity and distribution of bacterial populations within single subsurface geological formations. Populations of total heterotrophic bacteria, as enumerated. on 1\% PTYG agar, ranged from $10^{3}$ colony forming units (CFU)/g to greater than $10^{6} \mathrm{CFU} / \mathrm{g}$ within the Middendorf and from below detection to greater than $10^{5} \mathrm{CFU} / \mathrm{g}$ within the Cape Fear formation (Figure 1). Denitrifiers ranged from 100 most probable number (MPN)/g to greater than $10^{4} \mathrm{MPN} / \mathrm{g}$ in the Middendorf. In the Cape Fear they were consistently lower, ranging from below detection to greater than $10^{4} \mathrm{MPN} / \mathrm{g}$. Populations of denitritying bacteria followed trends similar to those for chemoheterotrophs, although the populations were consistently lower (Figure 1). The denitrifying bacteria are likely to be a subset of the heterotrophic bacteria since they are facultative and use nitrate as an electron acceptor only in the absence of oxygen. Their consistent presence in the Middendorf and Cape Fear formations suggests that these bacteria may maintain the $\mathrm{NO}_{3}^{-}$concentrations in these sediments at low levels.

Sulfate-reducing bacteria were absent in the Cape Fear formation but were detected in 2 out of 12 Middendorf core samples (Figure 1). In those Middendorf samples where they were detected, the populations were near the lower limit of detection, indicating the sulfate-reducing bacteria 


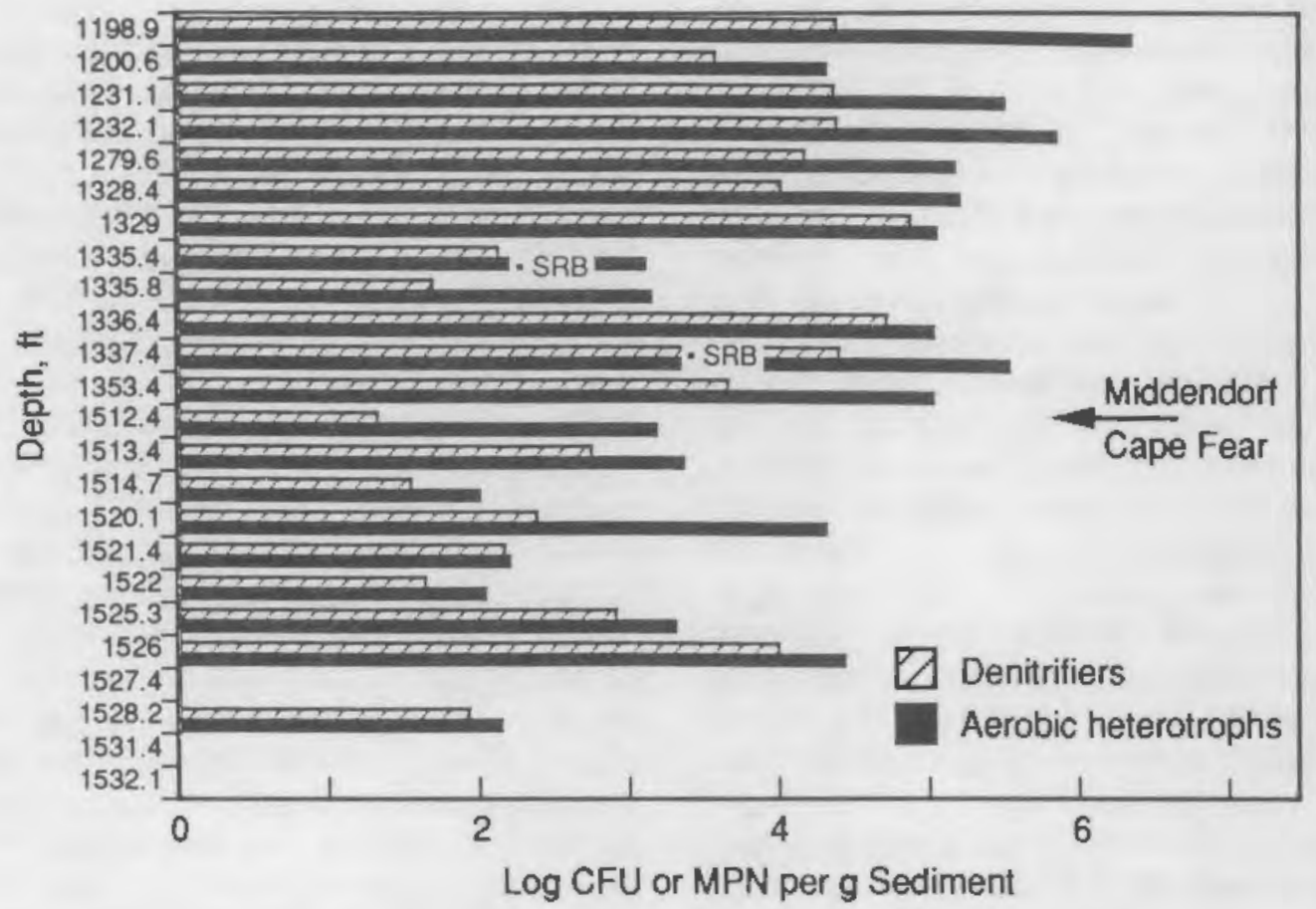

FIGURE 1. Populations of Aerobic Chemoheterotrophic Bacteria and Denitrifying Bacteria as a Function of Depth in the Middendorf and Cape Fear Formations. SRB indicates the preaence of suliate-reducing becteria.

are probably present throughout the aquifer at low population densities. These organisms may be responsible for the fixation of high levels of sulfur in these samples and its subsequent release to pore waters. We also enriched for lithotrophic sulfur-oxidizing bacteria but detected activity only in one sample from the Middendorf, which was comprised of almost pure lignite. The enrichment medium was selective for autotrophic bacteria; however, there may have been enough organic carbon carried over in the dilutions from this sample to support heterotrophic bacterial growth. Heterotrophic sulfur-oxidizing bacteria are known to be important microorganisms in the geochemical cycling of sulfur and are typically found at interfaces (or zones with anoxic microsites) between zones of sulfate reduction and zones that can support aerobic metabolism.

The analysis of displaced pore water from the cored sediments indicates that the sediments were contaminated with drilling fluids during the coring process. However, the presence of solutes (i.e., bromide) from drill muds in the core samples is not necessarily indicative of the presence of drilling fluid colloids. The relative movement of colloids through porous media can be quite different from nonreactive solutes. A number of factors including colloid size, pore size, and the physicalchemical interactions between colloids and the immobile phase influence the transport of colloidal materials in porous media. The complexity of these factors makes it difficult to predict whether a colloid such as a bacterial cell will move in advance of a conservative tracer or be removed from solution by filtration. Therefore, as part of this study, direct comparisons of the physiological and genetic characteristics between drill mud bacteria and bacteria from the core samples were made to assist in evaluating the extent of bacterial movement into sediments during rotary mud coring.

The G-21 drill muds, which contain bacterial isolates used in these studies for comparison with core sample isolates, were derived from recirculating enclosed tank muds sampled just prior to coring of the Cape Fear formation. These muds likely contained a mixture of microorganisms from Allendale municipal water (used for mixing drill muds), from dry muds, and from various strata overlying the Cape Fear through which the muds circulated. Earlier physiological studies of bacteria 
from core samples from the Middendorf and overlying formations from three boreholes that were drilled $25 \mathrm{~km}$ to the northwest on the SRS indicated that the majority of chemoheterotrophic bacteria $(89 \%)$ were unique to the individual strata from which core samples were obtained. This suggests that bacteria from the Cape Fear formation would also be different in comparison to bacteria associated with sediments from overlying formations. The Cape Fear core isolates were chosen for comparison with drill mud bacteria because the chemoheterotroph populations were, in general, 1 to $2 \log$ units lower than those associated with the Middendorf cores (Figure 1) and the number of distinct colony types were fewer. The lower populations and diversity of colony types, therefore, would make it easier to identify those bacteria that may be potential contaminants from the drilling muds. Because the majority of the bacteria in the Cape Fear formation are distinct from the indigenous bacteria present in the recirculating drilling muds, comparisons of the physiological and genetic properties of core sample and drill mud bacteria are used as an indicator of contamination.

Thirteen heterotrophic bacterial isolates from the G-21 drill muds and a total of 96 from the Cape Fear core samples (between 13 and 22 isolates from each), where colony growth on heterotrophic medium was observed, were used for physiological comparisons. A commercially available microtitre plate test system (GN plates, BIOLOG, Inc., Hayward, California) was used to obtain substrate utilization patterns for the various isolates. A specific isolate was used for comparison to determine if it metabolized at least one of the $95 \mathrm{GN}$ plate substrates. Approximately $5 \%$ of the cultures were negative for all 95 of the substrates. All of the recognizably distinct colony types, based on morphology and color, present at the countable dilutions (between 30 and 200 colonies per plate) from each of the Cape Fear samples were isolated and purified. Substrate utilization patterns for each drill mud isolate were then compared with the patterns obtained for each core sample isolate, and the total number of mismatches between their substrate utilization patterns was determined.

The number of comparisons between G-21 drill mud bacteria and core sediment bacteria, where the number of mismatches out of a total of 95 was less than 10 , ranged from $0.8 \%$ to $2.6 \%$ and from $6 \%$ to $22 \%$ for $11-20$ mismatches of the total number of comparisons made (Table 1). Studies with individual isolates to evaluate the repeatability of the microtitre plate substrate utilization assay indicated that the differences between assays conducted at different times were five substrates or less. These results indicate that the heterotrophic bacteria from the G-21 drill muds were physiologically different from those isolated from the core samples and that extensive contamination of Cape Fear core samples with bacteria from the drill muds was unlikely. However, the $1 \%$ to $2 \%$ of the comparisons that fell into the less than 10 mismatches category are potentially the same or similar organisms and, hence, could be contaminants. Therefore, DNA hybridization analysis was used to assess the genetic relatedness between those drill mud isolates and core sample bacteria whose substrate utilization patterns matched most closely. DNA hybridization is a standard method in bacterial systematics used to assess the genetic relatedness between two microorganisms and is expressed as percent homology with $100 \%$ indicating that the organisms are almost identical in their DNA base sequence.

Four drill mud isolates accounted for a majority $(83 \%)$ of the $\leq 20$ mismatches in substrate utilization pattern comparisons with Cape Fear core bacteria. Chromosomal DNA was extracted from those four isolates, labeled with ${ }^{32} \mathrm{P}$-dCTP, and

TABLE 1. Comparison of Substrate Utilization Patterns Between G-21 Drill Mud Bacterial Isolates and Cape Fear Core Sample Isolates

\begin{tabular}{|c|c|c|c|}
\hline \multirow{3}{*}{$\begin{array}{l}\text { Cape Fear } \\
\text { Sample ID }\end{array}$} & \multirow{3}{*}{$\begin{array}{c}\text { Number of } \\
\text { Dietinct } \\
\text { Isolates } \\
\end{array}$} & \multicolumn{2}{|c|}{$\begin{array}{l}\text { Number of } \\
\text { Mismatches/95 Substrates }\end{array}$} \\
\hline & & $0-10$ & 11.20 \\
\hline & & \multicolumn{2}{|c|}{$\begin{array}{c}\% \text { of total comparisons } \\
\text { in catagory }(\varepsilon)\end{array}$} \\
\hline 28D & 13 & 2.4 & 21.9 \\
\hline $28 E$ & 16 & 1.4 & 15.9 \\
\hline $28 \mathrm{H}$ & 22 & 1.7 & 7.0 \\
\hline $28 \mathrm{~F}$ & 20 & 0.8 & 12.7 \\
\hline $28 !$ & 13 & 1.2 & 18.9 \\
\hline$G-21{ }^{(b)}$ & 12 & 2.6 & 5.8 \\
\hline Total & 96 & 1.6 & 12.7 \\
\hline
\end{tabular}

(a) A totel of 13 isoletes from G-21 drill muds were used for comparison.

(b) Core sample from the Cape Fear $(560-463 \mathrm{~m})$ that was pared and homogenized onsite. The total heterotroph population on 1\% PTYG was $3.3 \mathrm{log}$ CFU/g sediment. 
hybridized with the Cape Fear isolates that were physiologically most similar. Of these four isolates, two accounted for all nine of the drill-mud Cape Fear pairwise comparisons with $\leq 10$ mismatches in substrate utilization pattern comparisons. Of these nine pairs, three had DNA homologies greater than $60 \%$. A value of $60 \%$ homology is typically used as a cutoff point for delineating organisms in the same species. These results indicate, to an even greater extent than the substrate utilization pattern comparisons, that the predominant drill mud bacteria were distinct from those in the core samples. Therefore, based on physiological and genetic analyses, the majority (93/96) of the heterotrophic bacteria isolated from the Cape Fear core samples are unlikely to be contaminants introduced during the drilling process.

Although these results indicate that contamination of core samples with drill mud bacteria was nonexistent or minimal, it should be cautioned that even relatively low levels of contamination could have a substantial impact on the results of some experiments (i.e., metabolism of organic contaminants). For example, if there were a contamination of core sample with only $1.0 \%$ of the drill mud bacteria, as many as $10^{5}$ bacteria per gram could be introduced into the core samples since the drill muds contained $107 \mathrm{CFU} / \mathrm{ml}$. This could have a substantial impact on the rate and/or extent of biodegradation of a specific compound. Future subsurface microbiological investigations involving the use of rotary mud coring must continue the standard practice of paring outer core materials and should consider the use of microbial tracers in the drill muds to better assess the level of contamination in individual samples.

The diversity of viable heterotrophic bacteria was determined based on colony morphology and color and on physiologic properties using commercially available multiple-test systems to determine the overall diversity of chemoheterotrophic bacteria within a defined subsurface geological formation. The multiple-test systems that were used include the Biolog GN plate, as described earlier, and the API Rapid NFT kits (Analytab Products, Plainview, New York). There was considerably greater diversity of chemoheterotrophic bacteria in the Middendorf sediments than the Cape Fear formation (Table 2) based on both colony and physiological diversity. Within the Middendorf formation, viable counts of chemoheterotrophs varied by several orders of magnitude between the various core samples, but diversity was relatively independent of the total population. Heterotrophic diversity was lower in the Cape Fear formation than in the Middendort, coinciding with lower population densities, but still harbored a relatively diverse array of bacteria in those core samples with detectable levels of culturable bacteria. In addition to considerable diversity of heterotrophic bacteria within a given core segment, there was considerable diversity among core samples within a given formation. Throughout all of the GEMHEX cores, very few unique physiological types occurred in more than one core segment (Table 3 ). Only $12 \%$ of the distinct API types occurred in greater than one core segment, and only $5 \%$ occurred in more than two. The greatest number of distinct physiological types occurred in the Middendorf formation and only 6/157 types occurred in both the Cape Fear and Middendorf formations.

In summary, microbial populations were larger and more diverse in the Middendorf than in the Cape Fear formation. We believe that this difference is principally due to variations in the hydrophysical properties of the two formations. Based on physiological and genetic comparisons between drill mud isolates and isolates obtained from the Cape Fear formation, there was little contamination of core segments with drill mud bacteria, despite direct evidence of contamination with drill mud solutes. Substantial diversity of aerobic chemoheterotrophic bacteria was found in both formations, although more so in the Middendort. This diversity may, in part, explain the inability of static sediment incubation experiments to predict the rate and/or extent of biodegradation in the subsurface. This diversity has both positive and negative ramifications with regards to the prospects of in situ remediation of deep subsurface formations. The positive aspects are that with such a diverse microbial population the chances are increased that indigenous microorganisms will have the desired capacity to degrade a specific contaminant or perform a specific function within a given formation. Alternatively, microorganisms with the desired traits may be heterogeneously distributed within a given formation and present at sparse populations such that atternpts to stimulate their growth and activity for remediation purposes may be ineffective. 
TABLE 2. Microbial Diversity of Chemoheterotrophic Bacteria lsolated from Unconsolidated Sediment Cores from the Middendor' and Cape Fear Formations

\begin{tabular}{|c|c|c|c|c|c|}
\hline \multirow[b]{2}{*}{ Sample } & \multirow[b]{2}{*}{$\begin{array}{l}\text { Geological } \\
\text { Formation } \\
\end{array}$} & \multirow[b]{2}{*}{$\begin{array}{l}\text { Viable Count } \\
\text { Log (CFU/gdw) }\end{array}$} & \multicolumn{3}{|c|}{ Microbial Diversity } \\
\hline & & & $\begin{array}{c}\text { Number of } \\
\text { Distinct } \\
\text { Colony Types } \\
\end{array}$ & $\begin{array}{l}\text { Number of } \\
\text { API Types }\end{array}$ & $\begin{array}{c}\text { Number of } \\
\text { Biolog } \\
\text { Types } \\
\end{array}$ \\
\hline 24A & Middendort & 6.4 & 13 & 12 & 10 \\
\hline 24-B & Middendorf & 4.3 & 13 & 12 & 13 \\
\hline 24-E & Middendorf & 5.0 & 12 & 11 & 10 \\
\hline 24-H & Middendorf & 5.9 & 12 & 10 & 10 \\
\hline $24-C$ & Middendorf & 5.2 & 11 & 10 & 9 \\
\hline $24 \mathrm{~J}$ & Middendorf & 5.2 & 16 & 12 & 14 \\
\hline 24-D & Middendorf & 5.5 & 9 & 7 & $2^{(a)}$ \\
\hline lignite & Middendort & 3.1 & 10 & 9 & 7 \\
\hline lignite-sand & Middendort & 3.4 & 17 & 16 & 16 \\
\hline $24-F$ & Middendorf & 5.0 & 14 & n.d. & n.d. (b) \\
\hline $24-G$ & Middendorf & 5.5 & 15 & 15 & $11^{(a)}$ \\
\hline $24-1$ & Middendorf & 5.0 & 16 & 14 & 13 \\
\hline $28-A$ & Cape Fear & 3.1 & 7 & 7 & n.d. \\
\hline 28-B & Cape Fear & 3.3 & 5 & 5 & n.d. \\
\hline $28-C$ & Cape Fear & 2.0 & - & - & - \\
\hline & Cape Fear & $\mathrm{NG}^{(c)}$ & - & - & - \\
\hline 28-G & Cape Fear & 4.3 & 9 & 7 & n.d. \\
\hline 28-D & Cape Fear & 4.3 & 3 & 3 & 13 \\
\hline $28-E$ & Cape Fear & 2.0 & 2 & 2 & 16 \\
\hline $28-\mathrm{H}$ & Cape Fear & 3.3 & 10 & 8 & 22 \\
\hline 28-F & Cape Fear & 4.4 & 8 & 7 & 20 \\
\hline $28-J$ & Cape Fear & NG & - & - & n.d. \\
\hline $28-1$ & Cape Fear & 2.1 & 6 & 4 & 13 \\
\hline $28-K$ & Cape Fear & NG & - & - & n.d. \\
\hline $28-L$ & Cape Fear & NG & - & - & n.d. \\
\hline
\end{tabular}

(a) Not all colony types were evaluated using the Biolog GN plates, some isolates lost viability before they could be analyzed.

(b) n.d. indicates analyses were not done.

(c) NG represents no growth at the lowest dilution.

TABLE 3. Degree to Which Distinct Physiological Types, Based on Unique API Patterns, Occur in Different GEMHEX Core Segments

$\begin{array}{ccc}\text { Number of Cores } & & \begin{array}{c}\text { Number of Distinct } \\ \text { Distinct API }\end{array} \\ & 1 & 138 \\ 2 & 10 \\ 3 & 2 \\ 4 & 5 \\ 5 & 0 \\ 6 & 2 \\ 7 & 0 \\ 8 & 0 \\ \text { Total } & 157 \\ \text { Middendort only } & 112 \\ \text { Cape Fear only } & 36 \\ \text { Cape Fear \& Middendorf } & 6\end{array}$

\section{Biodegradation of Aromatic Compounds by Subsurface Bacteria}

Previous microbiological investigations of subsurface sediments from DOE's SRS, near Aiken, South Carolina, indicated an abundant population of aerobic heterotrophs at depths to $260 \mathrm{~m}$. This research also demonstrated that bacteria able to degrade homo-and heterocyclic compounds were present in some deep aquifers and unsaturated sediments; therefore, the potential exists for the application of in situ strategies for the bioremediation of deep aquiters. These preliminary findings also underscored the need to further investigate the metabolism of organic compounds by subsurface microorganisms in vitro and under conditions 
simulating subsurface environments. Experimental studies in FY 1989 have focused on the physiology and genetics of a deep subsurface bacterium that is able to utilize quinoline, a heterocyclic nitrogen-containing polyaromatic hydrocarbon, as the sole source of carbon, nitrogen, and energy. A variety of other aromatic compounds, including naphthaiene, aminonaphthalene, benzene, biphenyl, benzoate, and mono- and di-hydroxylated benzoates, were also utilized as the sole source of carbon and energy.

Organic carbon that can be used by a particular bacterium is usually present at very low concentrations in the deep subsurface, necessitating very efficient uptake and utilization systems. The quinoline-degrading bacterium rapidly mineralized quinoline under aerobic conditions and at extremely low concentrations (Figure 2). At two parts per billion quinoline, $42 \%$ of the labeled carbon evolved as ${ }^{14} \mathrm{CO}_{2}$ within 10 minutes by quinoline-induced cells. Quinoline utilization required the synthesis of catabolic enzymes, as induction required 20 hours and was inhibited in the presence of chloramphenicol. The data indicate that the bacterium possesses an inducible, high-affinity uptake and utilization system that probably reflects the oligotrophic nature of uncontaminated deep subsurface environments. The catabolic pathway of aerobic quinoline degradation has been partially elucidated as follows: 1) quinoline is hydroxylated on the

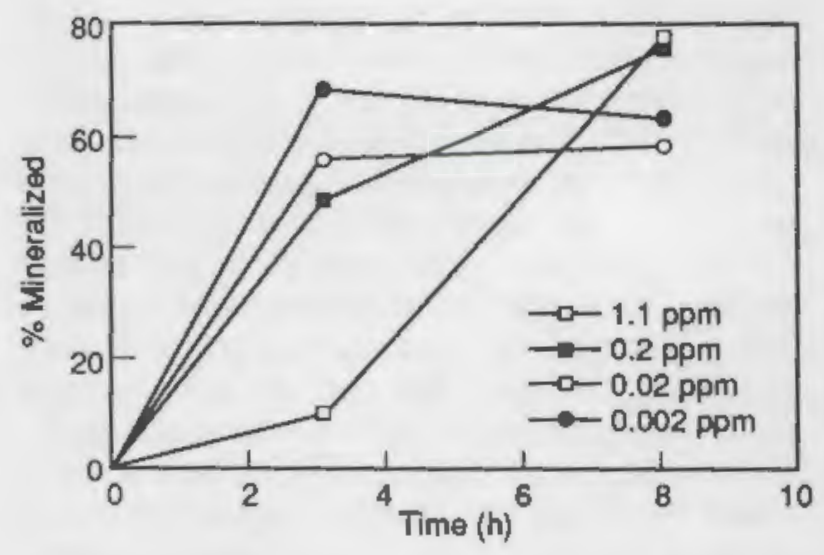

FIGUAE 2. Mineralization of ${ }^{14} \mathrm{C}$-labeled Quinoline by Strain $866 \mathrm{~A}$, Isolated from Sediments Obtained from the Middendorf Aquifer Formation $(203 \mathrm{~m})$ from Borehole P28 Drilled at DOE's Savannah Aiver Site (SRS) pyridine moiety to yield 2-hydroxyquinoline, 2) the benzene moiety of quinoline is attacked and opened, and 3) the pyridine moiety of quinoline is opened. The same metabolites are produced independent of whether quinoline or 2-hydroxyquinoline is the substrate, indicating that 2-hydroxyquinoline, or a subsequent metabolite, is the inducer of quinoline catabolism. At concentrations in the part per million range, reaction kinetics are $1>2>>3$ (an unusual situation in microbial catabolic pathways). Quinoline (but not 2-hydroxyquinoline) induces the ability to use pyridine derivatives containing a carboxy group at one of the two-ring juncture carbons of quinoline. The required location of the carboxy group suggests that the bacterium possesses an extra-diol (meta) cleavage enzyme. Three different assays for dioxygenase activity (i.e., ring cleavage enzymes) have not yielded any detectable dioxygenase activity in this bacterium during quinoline catabolism. However, a dioxygenase(s) is present as molecular oxygen consumption increases tenfold on addition of quinoline to quinoline-induced cells. These data suggest that the ring cleavage enzymes used for quinoline catabolism by the subsurface bacterium are under different regulatory control and/or are structurally different from characterized ring cleavage enzymes of surface bacteria.

The bacterium was shown to contain four plasmids, two of which were involved in the aerobic degradation of quinoline. Plasmid-curing experiments showed that a 320-kilobase plasmid was necessary for quinoline and 2-hydroxyquinoline catabolism. A 50-kilobase plasmid was necessary for the ability to open and use the pyridine moiety ring. Plasmid profiles, determined by gel electrophoresis, of the different plasmid-cured mutants and the parent bacterium are shown in Figure 3. Sixteen quinoline-minus transposon mutants have been isolated, and mapping of the insertions will further delineate the role of plasmids and chromosomal genes in quinoline catabolism. Degradation of other aromatic compounds was not affected by curing of the different plasmids; however, one plasmid could not be cured and may encode catabolic pathways for some of these compounds. The residence of catabolic genes on plasmids suggests that the genes are required only occasionally and that the catabolic trait may be held by only a very few subsurface bacteria. In the 


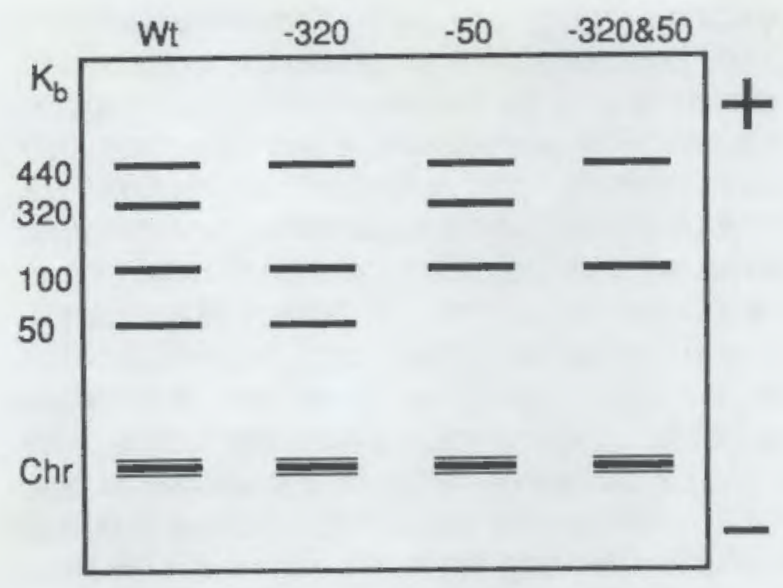

FIGURE 3. Plasmid Profile of the Quinoline Degrading Wild Type $(W t)$ and Mutants Cured of the $320 \mathrm{~K}_{\mathrm{b}}(-320), 50 \mathrm{~K}_{\mathrm{b}}$ $(-50)$, and the 320 and $50 K_{b}(-320$ and 50$)$ Plasmids as Determined by Gel Electrophoresis. Chromosomal DNA bands are identified as $\mathrm{Chr}$

presence of a compound that can be used by a plasmid encoded pathway, plasmids containing catabolic genes may be capable of genetic transfer to other bacteria. Additional experiments have been conducted to determine if a quinolinedegrading bacterium carrying a plasmidassociated transposon marker could transfer the antibiotic-resistance marker to other bacteria. Marker transfer, presumably by conjugation, was observed at frequencies of 10-4 to $10-8$ in plate matings. Efforts are under way to characterize the plasmids and potential degradative genes that were transferred. Thus, the degradation of xenobiotic compounds in the subsurface may be assisted by the genetic transfer of degradative capabilities between subsurface bacteria. In situ bioremediation strategies (i.e., the stimulation of growth and activity of the indigenous bacteria) could greatly enhance the transfer frequency of degradative capabilities among subsurface bacteria.

The transformation of quinoline under anaerobic (denitrifying) conditions to 2-hydroxyquinoline and other polar intermediates by the same subsurface bacterium that degrades quinoline aerobically was observed, but mineralization was not. The bacterium was capable of fermentative growth under denitrifying conditions. Nitrate was hypothesized to be the electron acceptor in the anaerobic degradation of quinoline; however, preliminary experiments indicated that the bacterium did not respire nitrate. A terminal electron acceptor such as $\mathrm{Fe}^{2+}$ may be present in uncontaminated deep aquifers at concentrations higher than $\mathrm{NO}_{3}^{-}$, suggesting that subsurface bacteria may have evolved biochemical pathways, which use more readily available electron acceptors. The terminal electron acceptor used by this bacterium in the anaerobic degradation of quinoline is being investigated in FY 1990.

Characteristics of, and insights gained from, the quinoline-degrading bacterium highlight the need for a greater understanding of the physiology, metabolic potential, and genetics of deep subsurface microorganisms. This information is essential for predicting the subsurface transport and attenuation rates of organic contaminants, and for devising biological in situ remediation strategies.

\section{Groundwater Dating at the Savannah River Site (SRS)}

\section{E. M. Murphy, J. K. Fredrickson, J. A. Franz, and J. C. Linehan}

An understanding of the hydrochemical factors important to microbial ecology is critical to the future use of microorganisms for in situ bioremediation of contaminated groundwater. Abundant and diverse populations of microorganisms were found at depths down to $260 \mathrm{~m}$ in Atlantic coastal plain sediments near the SRS. These microorganisms are capable of affecting both the chemical and isotopic composition and the geochemical evolution of groundwater (Chappelle et al. 1988); however, the factors controlling their origin, distribution, and diversity are poorly understood. Recent PNL studies performed within the DOE/OHER Deep Microbiology Program found that the most significant factor affecting the distribution of microorganisms in the Middendorf aquifer was hydraulic conductivity, which directly and indirectly influences nutrient flux and pore space accessibility. In addition, the association of the microorganisms with high-flux intervals may be an indication of their origin in subsurface environments. There are two possible origins of microorganisms in groundwater 1) the microorganisms may have been transporfed through the aquifer from the recharge zone or 2) they may have evolved in situ from organisms entrained in the 
original coastal plain sediments. The association of microorganisms with high-flux intervals suggests that the microorganisms were transported through the porous media to their current location. In this case, the age of groundwater would indicate the minimum amount of time that the microbial population has evolved. The occurrence of unique metabolic properties may be directly related to the amount of time that the microbial population has been isolated. In addition, such unique metabolic properties may affect whether or not a microbial population is capable of degrading contaminants at DOE sites. Groundwater age, coupled with information on the geochemical evolution of groundwater, may aid in our understanding of the distribution and ecology of microbes along flow paths from recharge to groundwater discharge.

The influence of nutrient flux is important in the Middendorf aquifer, because these groundwaters contain very small amounts of dissolved organic carbon [(DOC) generally $<0.5 \mathrm{mg} / \mathrm{L}]$. In spite of these low DOC values, previous DOE investigators have found that over $90 \%$ of the microorganisms in this formation are heterotrophic (Fredrickson et al. 1989). Lignite was present in several of the cores taken from the Middendorf aquifer, with the highest concentrations of organic carbon in "black sands" adjacent to the lignite. However, the lowest populations of heterotrophic bacteria were found in these high organic zones, suggesting that the lignite was too recalcitrant or that the chemical conditions associated with the lignite were too harsh to favor microbial growth. Therefore, organic products leaching from the lignite may be the primary carbon substrate for the microorganisms. Knowledge of the microbial carbon substrate may indicate whether these microorganisms are capable of degrading contaminants at DOE sites, and factors affecting the distribution and activity of microbial populations will necessarily have a direct impact on in situ bioremediation of contaminated aquifers. The objectives of this study were to 1) derive an age of the groundwater in the Middendorf, which would indicate a minimum age of the microbial population, and 2) identify potential carbon substrates used by the microorganisms.

\section{Chemistry and Groundwater Age of the Middendorf Aquifer}

Groundwater samples were collected from the Middendorf aquifer in $10-L$, heavy wall, polypropylene bottles for $\delta^{13} \mathrm{C}$ and ${ }^{14} \mathrm{C}$ analyses. In addition, samples were collected for ion chemistry and DOC. An in-line, Hydrolab sonde was used to monitor field $\mathrm{pH}$, temperature, conductivity, Eh, and dissolved oxygen. The potentiometric surface of the Middendorf aquifer and location of the boreholes are shown in Figure 1. Inorganic carbon was extracted from the groundwater samples on a vacuum line by acidification to $\mathrm{CO}_{2}$ with phosphoric acid. A VG-602D mass spectrometer was used to measure the $\delta^{13} \mathrm{C}$ of the $\mathrm{CO}_{2}$ sample. The $\mathrm{CO}_{2}$ was then reduced to graphite for the ${ }^{14} \mathrm{C}$ measurement at the University of Arizona National Science Foundation Accelerator Facility. Cations were measured by inductively coupled argon plasma (ICAP) chromatography, and anions were measured by ion chromatography. All organic and inorganic carbon measurements were done on a Dohrman Carbon Analyzer.

Groundwater in the Middendorf aquifer generally flows from the outcrop (along the fall line) toward the ocean; however, the portion of the aquifer near SRS flows toward the Savannah River (Figure 1). The chemistry of the Middendorf groundwaters is characterized by low $\mathrm{pH}$, low conductivity, and dominant ions of $\mathrm{Na}-\mathrm{Ca}-\mathrm{SO}_{4}-\mathrm{HCO}_{3}$ (Table 1). Except for the wells farthest downgradient (i.e., P-24-TA, C-6, and C-10), the conductivities are generally below $50 \mu \mathrm{moh}$. Several ions, including $\mathrm{HCO}_{3}{ }^{-}, \mathrm{SO}_{4}{ }^{2-}, \mathrm{K}^{+}$, and $\mathrm{Na}^{+}$, increase by over an order of magnitude from recharge to the distall end of the flowpath. The $\mathrm{Cl}^{-}$concentration remains relatively constant. Calcium increases by over an order of magnitude between recharge and $\mathrm{C}-6$, but then drops significantly between $\mathrm{C}-6$ and $\mathrm{C}-10$. Unlike many of the other groundwater samples, $\mathrm{Na}^{+}$is by far the dominant cation in C-10. Most of the Middendorf aquiter underlying SRS was deposited as upper delta plain sediments, characterized by coarser sediments, quartzitic sands, and conglomerates. The sediments at $\mathrm{C}-10$ are unique, in that they were deposited under a lower 


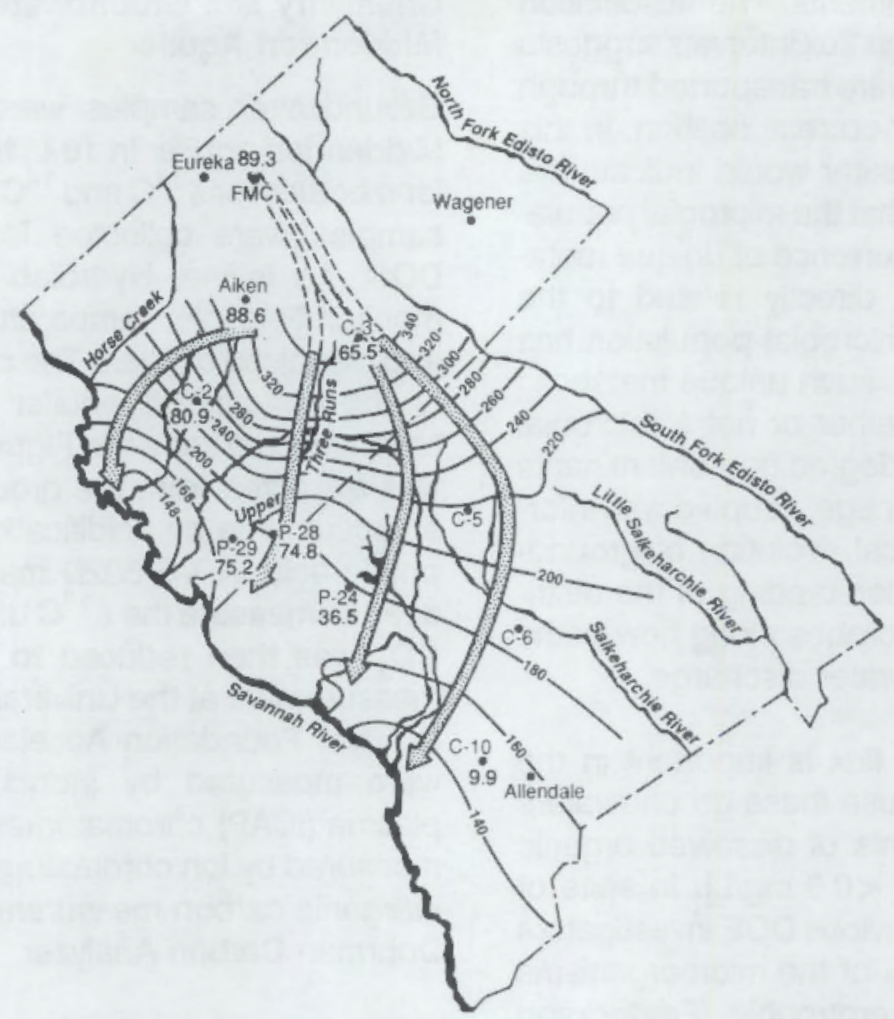

FIGURE 1. Potentiometric Surface of the Middendorf Aquifer. Arrows represent probable flow paths. Well locations and ${ }^{14} \mathrm{C}$ activities are shown.

delta plain environment. These sediments are fine to medium quartzitic sands with thick silt and clay beds. Lignite and iron sulfide minerals are common in these sediments. Sodium concentrations in C-10 may be a direct result of ion exchange with the clays found in the lower delta plain environment.

The evolution of groundwater in coastal plain sediments is typically characterized by increasing $\mathrm{pH}$, conductivity, $\mathrm{HCO}_{3}^{-}, \mathrm{SO}_{4}{ }^{2-}, \mathrm{Na}^{+}$, and $\mathrm{Cl}^{-}$. Caicium concentrations generally decrease due to ion exchange (Lee and Strickland 1988). In flow paths extending toward the coast, the groundwater eventually evolves to $\mathrm{NaCl}$ dominance, resulting from mixing with subsurface brines. The short flow path between the fall line and the Savannah River in this study shows a segment of this evolutionary path characterized by increasing $\mathrm{pH}$, conductivity, $\mathrm{HCO}_{3}^{-}, \mathrm{SO}_{4}{ }^{2-}$, and $\mathrm{Na}^{+}$. Cation exchange is probably a dominant reaction in the distal portion of the flow path. The ${ }^{14} \mathrm{C}$ activities (Figure 1) are also consistent with the relative position of the boreholes in the flow path. The recharge well has the highest ${ }^{14} \mathrm{C}$ activity, 89.3 pmc (percent modern carbon), while C-10, the farthest downgradient sampling position, has a ${ }^{14} \mathrm{C}$ activity of 9.9 pmc. CSOTOP, a carbon isotope subroutine of the geochemical model PHREEQE, will be used to determine groundwater ages.

The $\delta^{13} \mathrm{C}$ values of the inorganic carbon are light (negative) and show little variation from recharge to distal end of the flow path (Table 1). These light $\delta^{13} \mathrm{C}$ values cannot be explained by inorganic carbonate reactions and suggest that the dissolved inorganic carbon (DIC) may be heavily influenced by microbial oxidation of organic carbon. The DOC of the Middendorf groundwaters is generally less than $0.5 \mathrm{mg} / \mathrm{L}$, a value that may be too low to support an active microbial population. The Middendorf sediments, however, contain pockets of lignite and fossiliferous organic matter that may serve as the carbon substrate for the microorganisms. The oxidation of organic carbon complicates 
TABLE 1. Water Chemistry Analysee in $\mathrm{mg} / \mathrm{L}$ for the Middendort Aquifer

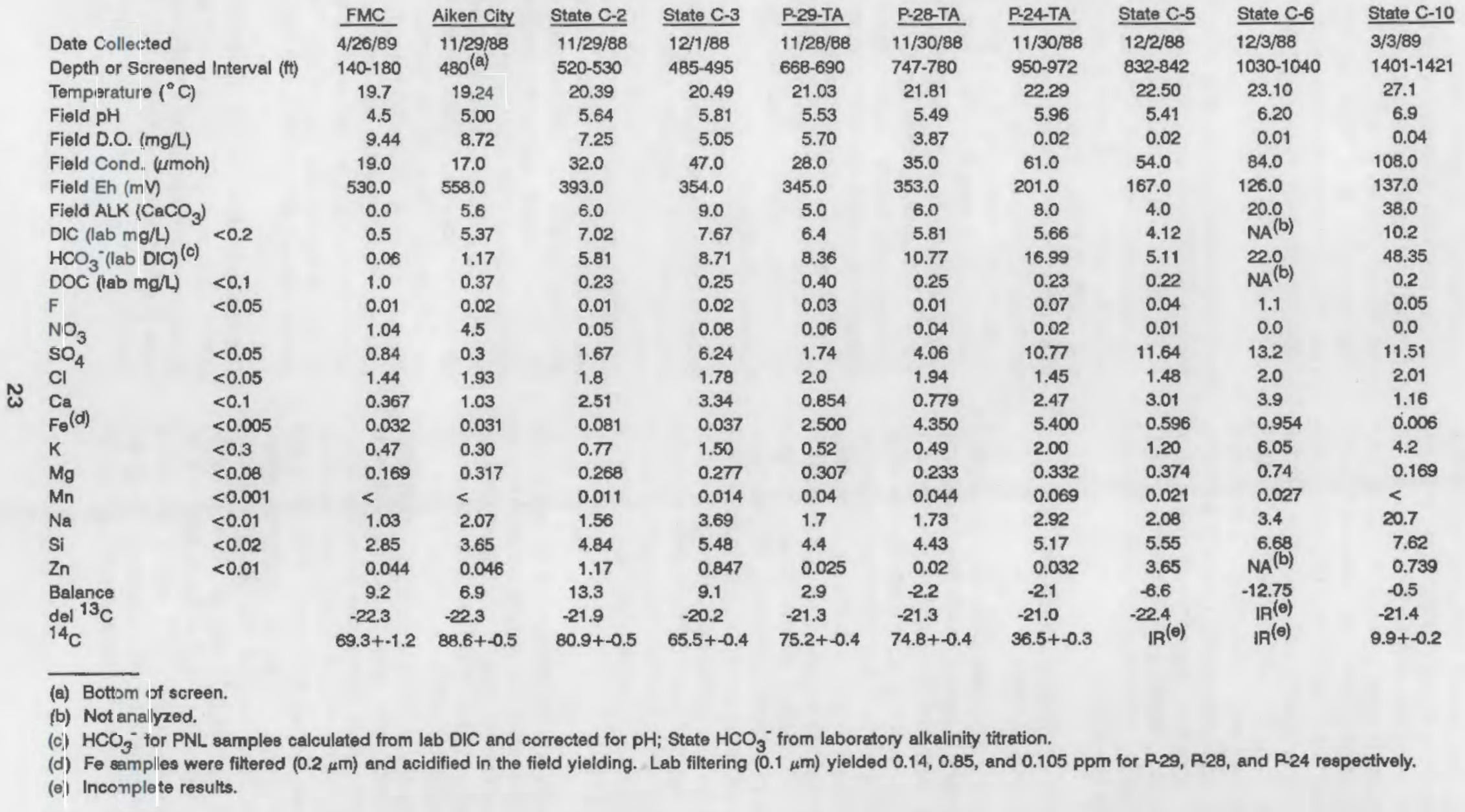


the assignment of groundwater ages to the Middendorf aquifer. Geochemical techniques for determining groundwater ages rely on carbon mass balance; the extent of dissolution and precipitation of inorganic carbon species can be verified by fractionization of the $\delta^{13} \mathrm{C}$ values. The $\delta^{13} \mathrm{C}$ fractionation factors for these inorganic carbon reactions are well known. Microbial oxidation of organic carbon to DIC also results in the fractionation of $\delta^{13} \mathrm{C}$, and constants for these reactions are not well understood. To resolve a groundwater age and identify potential microbial substrates, laboratory experiments have been initiated on the metabolism of organic matter extracted from the Middendorf cores by microbial isolates from this aquifer.

\section{Determination of Organic Substrates and In Situ Microbial Activity}

Organic matter extracted from the Middendorf cores and bacteria isolated from this aquifer can be used in controlled laboratory experiments to 1) identify potential microbial carbon substrates and 2) determine the $\delta^{13} \mathrm{C}$ fractionation factors as organic carbon is oxidized to $\mathrm{CO}_{2}$. It is hypothesized that the distribution of microorganisms in the subsurface will depend on the distribution and composition of organic substrates. Furthermore, the general composition of the subsurface microflora should be directly related to the fractionation of stable isotopes of carbon. Fractionation factors for microbial reactions will be incorporated into the PHREEQE/CSOTOP program for interpretation of groundwater ages.

Mineral-bound organic matter was isolated from the SRS cores using the methyl isobutyl ketone (MIBK) extraction technique developed by Rice and MacCarthy (1988). The MIBK extraction procedure separates the sediment organic matter into the following three primary fractions: 1) organic acids including fulvic acid, 2) humic acid, and 3) humin. The humin fraction can be further separated into lipids, bound humic acid, and insoluble humin residue. Organics were extracted from two core sediments: 1) ID \#24-I, primarily sands coated with black organic material (\% organic carbon $=0.72$ ) and 2) ID \#74, a chunk of lignite found at a depth of $1353 \mathrm{ft} 4$ in. to $1353 \mathrm{ft} 9$ in. Elemental analyses and $\delta^{13} \mathrm{C}$ values are being determined for these organic fractions. The lignite and humic acids were characterized using ultra high-speed magic angle spinning/cross polarization solid nuclear magnetic resonance spectroscopy (CPMAS NMR). Spectra were determined with a Varian VXR-300 instrument (75 MHz) equipped with Doty Scientific, Inc. ultra high-speed CPMAS probes for SRS bulk lignite, SRS 24 I humic acid (MIBK extract), and three International Humic Substances Society (IHSS) reference samples (i.e., Peat, Suwannee, and Leonardite humic acids).

In previous work performed at PNL, Tween-40, an aliphatic surfactant, was metabolized by over $90 \%$ of the Middendorf microbial isolates (Fredrickson, personal communication). This observation is interesting because CPMAS NMR spectra indicate that the SRS organic matter is highly aliphatic (0-60 ppm, Table 2), especially when compared to the IHSS soil and aquatic humic acids. In addition to the higher aliphaticity of the SRS samples, an increase in aliphaticity occurs between SRS 241 humic acid and its probable parent material, SRS lignite. This small increase could be an artifact of the MIBK extraction procedure. The extraction procedure may introduce MIBK condensation products that would arbitrarily increase the percent aliphatic carbon, resulting in an underestimate of the aromatic carbon contribution in the SRS 24I humic acid sample.

Subsurface sediments typically have extremely low concentrations of organic carbon. Because of these low concentrations, the chemical and physical features of mineral-bound organic matter in the subsurface are largely unknown. As a resuit, extremely simple surrogate organic compounds are often used in laboratory studies, and it is difficult to determine whether or not these simple compounds provide realistic information on subsurface microbial processes. Similarities between the SRS lignite and IHSS Leonardite humic acid, in respect to their relative distribution of both aromatic and aliphatic carbon, suggest that Leonardite humic acid may serve as a more realistic model compound for organic matter in the Middendorf aquifer (Table 2 and Figure 2).

The degradation of acetate, Tween-40, Leonardite humic acid, and SRS organic extracts is being studied in a closed-system respirometer with bacteria isolated from the Middendorf aquifer. The change in the $\delta^{13} \mathrm{C}$ values from organic substrate 
TABLE 2. CPMAS Nuclear Magnetic Reeonance Resulte for Internetional Humic Substances Society (IHSS) Humic Acids and Organic Matter from Savannah Fiver Site Cores. The ppm chemical shifts are shown in parentheses; table values rapresent percent carbon distribution in sample.

\begin{tabular}{|c|c|c|c|c|c|c|c|c|}
\hline Material & $\begin{array}{c}\text { Ketone } \\
\text { Carbonyl } \\
(240-190)\end{array}$ & $\begin{array}{l}\text { Carboxyl } \\
(190-165)\end{array}$ & $\begin{array}{c}\text { Aromatic } \\
\text { Phenol } \\
(165-148)\end{array}$ & $\begin{array}{l}\text { Aromatic } \\
(148-98)\end{array}$ & $\begin{array}{c}\text { Total } \\
\text { Aromatic } \\
\text { (165-98) }\end{array}$ & $\begin{array}{c}\text { Aliphatic } \\
\text { C-O } \\
(98-60) \\
\end{array}$ & $\begin{array}{l}\text { Aliphatic } \\
(60-0)\end{array}$ & $\begin{array}{c}\text { Total } \\
\text { Aliphatic } \\
\text { (98-0) } \\
\end{array}$ \\
\hline Peat humic acid & 3.3 & 8.9 & 8.3 & 31.2 & 39.5 & 12.9 & 35.4 & 48.3 \\
\hline Suwannee humic acid & 3.2 & 7.6 & 7.1 & 29.1 & 36.2 & 20.8 & 32.3 & 53.1 \\
\hline Leonardite humic acid & 2.8 & 6.2 & 8.8 & 43.2 & 52.0 & 5.2 & 33.7 & 38.9 \\
\hline SRS 24I humic acid & 2.5 & 2.0 & 5.7 & 29.6 & 35.3 & 7.6 & 55.5 & 63.1 \\
\hline SAS Lignite & 2.0 & 2.6 & 9.9 & 41.9 & 51.8 & 2.3 & 42.4 & 44.7 \\
\hline
\end{tabular}
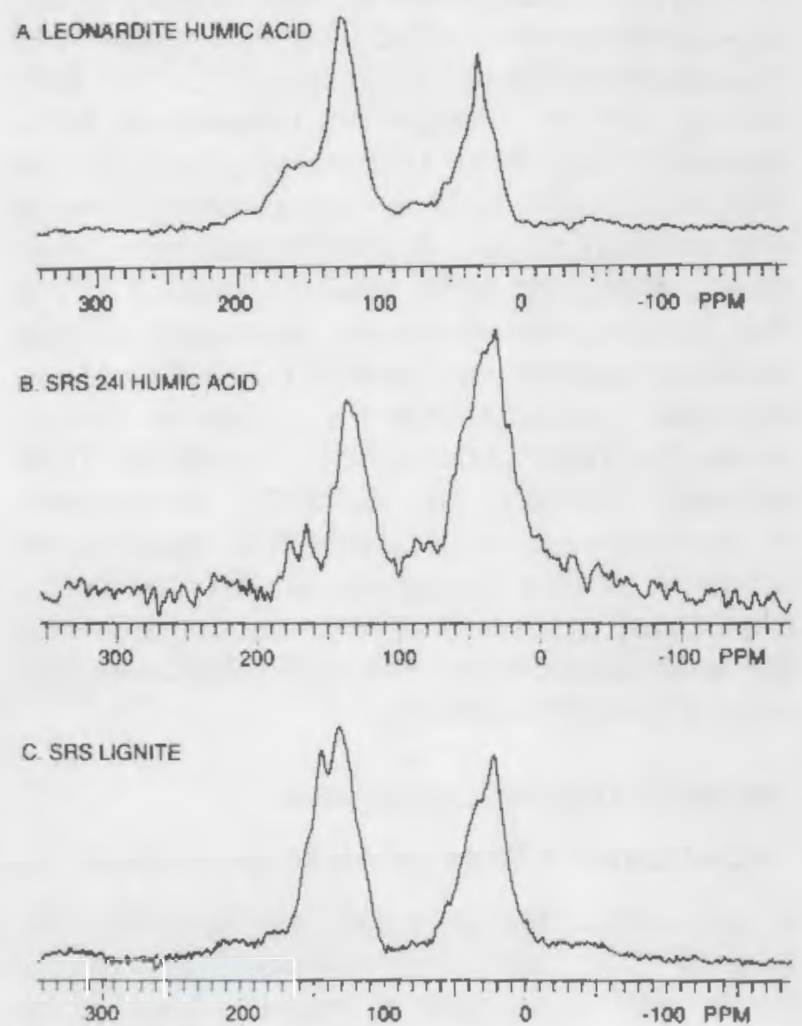

FIGURE 2. CPMAS Nuclear Magnetic Resonance Spectra of a) International Humic Substances Society Leonardite Humic Acid, b) Savannah River Site 241 Humic Acid, and c) Savannah River Site Lignite. Chemical shitts designated in parts per million (ppm).

to $\mathrm{CO}_{2}$ and the mass transfer of carbon are measured to determine the $\delta^{13} \mathrm{C}$ fractionation factors and assess potential carbon substrates.
These fractionation factors will then be used to model the groundwater ages in the Middendorf. The work described here was jointly supported by PNL's Subsurface Microbiology and Subsurface Chemistry Projects, and will be completed in FY 1990.

\section{References}

Chapelle, F. H., J. T. Morris, P. B. McMahon, and J. L. Zelibor, Jr. 1988. "Bacterial Metabolism and the $\delta^{13} \mathrm{C}$ Composition of Ground Water, Floridan Aquifer System, South Carolina." Geology 16:117-121.

Fredrickson, J. K, T. R. Garland, R. J. Hicks, J. M. Thomas, S. W. Li, and K. M. McFadden. (in press). "Lithotrophic and Heterotrophic Bacteria in Deep Subsurface Sediments and Their Relation to Sediment Properties." Geomicrobiology J.

Lee, R. W., and D. J. Strickland. 1988. "Geochemistry of Groundwater in Tertiary and Cretaceous Sediments of the Southeastern Coastal Plain in Eastern Georgia, South Carolina, and Southeastern North Carolina." Water Resour. Pies. 24:291-303.

Rice, J. A., and P. MacCarthy. 1988. "Characterization of a Stream Sediment Humin." in: Aquatic Humic Substances: Influence on Fate and Treatment of Pollutants, Advances in Chemistry Series, No. 219, (eds.) I. H. Suffet and P. MacCarthy, American Chemical Society. 


\section{Subsurface Chemistry of Organic Compounds and Mixtures}

\author{
J. M. Zachara, C. C. Ainsworth, E. M. Murphy \\ (PNL), J. C. Westall (Oregon State University), \\ and P.S.C. Rao (University of Florida)
}

This ongoing research project has been investigating interfacial reactions of organic compounds and organic compound mixtures on subsurface materials such as subsoils and aquifer sediments. Contaminant mixtures (including solute and solvent mixtures) have been emphasized in the research because these are common on DOE lands, and current information and models are inadequate to predict their environmental behavior. The research goal has been to understand sorption and surface transformation reactions of select nitrogen-, oxygen-, and sulfur-containing aromatic organic carcinogens on subsurface materials at the microscopic scale as a basis for 1) developing improved models to predict environmental concentrations and transport, and 2) identitying innovative scientific strategies for remediating subsoil and groundwater contamination. The research has taken a mechanistic or chemical reaction-based approach so that results would be applicable to a range of geochemical environments.

Past research has focused on the geochemical and sorption behavior of ionogenic organic compounds such as the $\mathrm{N}$-heterocycles and aromatic amines. The mechanisms, kinetics, and thermodynamics of sorption of these compounds were determined on a variety of mineral surfaces and subsurface materials. Sorption was found to be profoundly influenced by multisolute and multisolvent mixtures, and new models were proposed to describe the chemical interactions and their effects. Two university subcontracts with Oregon State University and University of Florida were established to assist PNL in developing a generalized theory for sorption reactions of both anionic and cationic organic compounds on subsurface materials. More recently the project has investigated the sorption behavior of hydrophobic organic compounds ( $\mathrm{HOC}$ ) on low-carbon subsurface materials, with the objectives of developing a two-phase model (mineral and organic) for predicting $\mathrm{HOC}$ sorption coefficients on a wide variety of low-carbon subsoils and aquifer materials. Additionally, collaborative research has been established with PNL's Subsurface Microbiology Project to investigate the combined influence of both sorption and microbiological degradation on subsurface chemical dynamics.

In FY 1989, PNL research was performed on four topics related to the contaminant dynamics of ionogenic and hydrophobic organic substances in subsurface environments. These include the 1) co-solvent effects on acridine sorption by subsurface clay minerals and particulate organic matter, 2) effects of competitive sorption/microbiological degradation reactions on contaminant dynamics, 3) influence of mineralbound humic substances on HOC sorption under low-carbon conditions, and 4) sorptivity differences in subsurface organic carbon for HOC. The work strategy was to complete the research on ionogens and HOCs in FY 1989 so that investigations of organic chemical-radionuclide sorption phenomena (of high priority to DOE production sites) could be initiated in FY 1990. In addition to the four activities noted above, significant project resources were devoted toward completion of collaborative research with the Office of Energy Research Deep Microbiology Program. This research, termed the GEMHEX experiment, focused on evaluating cause-effect relationships between vertical variations in microbiological populations within distinct water-bearing units and fine-scale variation ingeohydrochemical characteristics of the porous media.

\section{Ionogenic Organic Compounds}

\section{Co-Solvent Effects on Acridine Sorption}

In low-carbon soil or subsurface material, the sorption of ionizable nitrogen-heterocycle compounds or aromatic amines is controlled by ion exchange of the protonated species with inorganic ions associated with the surface layer of silicate clays. Ionization (1) and exchange (2) reactions are needed to describe the sorption process.

$$
\begin{aligned}
& \mathrm{BH}^{+}=\mathrm{B}+\mathrm{H}^{+} \mathrm{K}_{\mathrm{a}} \\
& \mathrm{NaX}+\mathrm{BH}^{+}=\mathrm{BHX}+\mathrm{Na}^{+} \mathrm{K}_{\text {ex }}
\end{aligned}
$$

where $\mathrm{B}$ is the neutral compound, $\mathrm{BH}^{+}$is the cationic species, and $X$ is a unit of negative charge on the layer lattice silicate or subsurface 
sorbent. Our past research has evaluated the thermodynamics of reactions (1) and (2) on reference clay minerals and subsurface materials for a number of organic ionogens including pyridine, quinoline, and acridine. The exchange process of these compounds has been shown to be approximately ideal, with the organic cation being strongly sorbed by negatively charged surfaces (log $\left.K_{e x}=1-3\right)$.

This past year the sorption of acridine, a hydrophobic three-ring nitrogen heterocycle, in the presence of the co-solvent methanol was studied on a natural smectite clay mineral isolated from a subsurface material. The research was performed to address an important environmental quality issue on DOE sites and to resolve hypotheses associated with the sorption mechanism. The objectives of this research were to 1) determine the effects of co-solvent on a strongly sorbing organic cation and 2) ascertain the relative contributions of electrostatic versus solvation forces in the sorption of large HOCs.

Sorption of acridine was measured over a large initial concentration range on the subsurface clay in constant ionic strength solutions (0.01 $\mathrm{M} \mathrm{NaClO}_{4}$ ) with 0-30 mole percent methanol $(\mathrm{MeOH})$. Surface exchange constants, $\mathrm{K}_{e x}$ for reaction (2) were calculated as a function of mole percent $\mathrm{MeOH}$ from the sorption isotherms. The solubility of solid acridine was also measured in the electrolyte and the co-solvent mixtures. The $\mathrm{pH}$, a critical variable in these experiments, was measured with the standardization procedures of Deligny et al. (1960) and Bates et al. (1963).

Sorption of acridine decreased with increasing mole percent $\mathrm{MeOH}$, and the exchange constant for reaction (2) in co-solvent was observed to decrease in an approximate log-linear trend (as shown in Figure 1a for the relative exchange constant, ${ }^{c} \mathrm{~K}_{\mathrm{ex}}{ }^{\mu} \mathrm{K}_{\mathrm{ex}}$, where $\mathrm{c}$ denotes co-solvent and $w$ denotes water). The log-linear decrease in the relative exchange constant with increasing mole percent $\mathrm{MeOH}$ was found to be qualitatively similar in magnitude to the log-linear increase in the relative solubility of acridine ( ${ }^{\circ} \mathrm{S} / \mathrm{N} S \mathrm{~S}$, where $\mathrm{c}$ denotes co-solvent and $w$ denotes water), Figure $1 \mathrm{~b}$, that occurs as methanol is added to water.
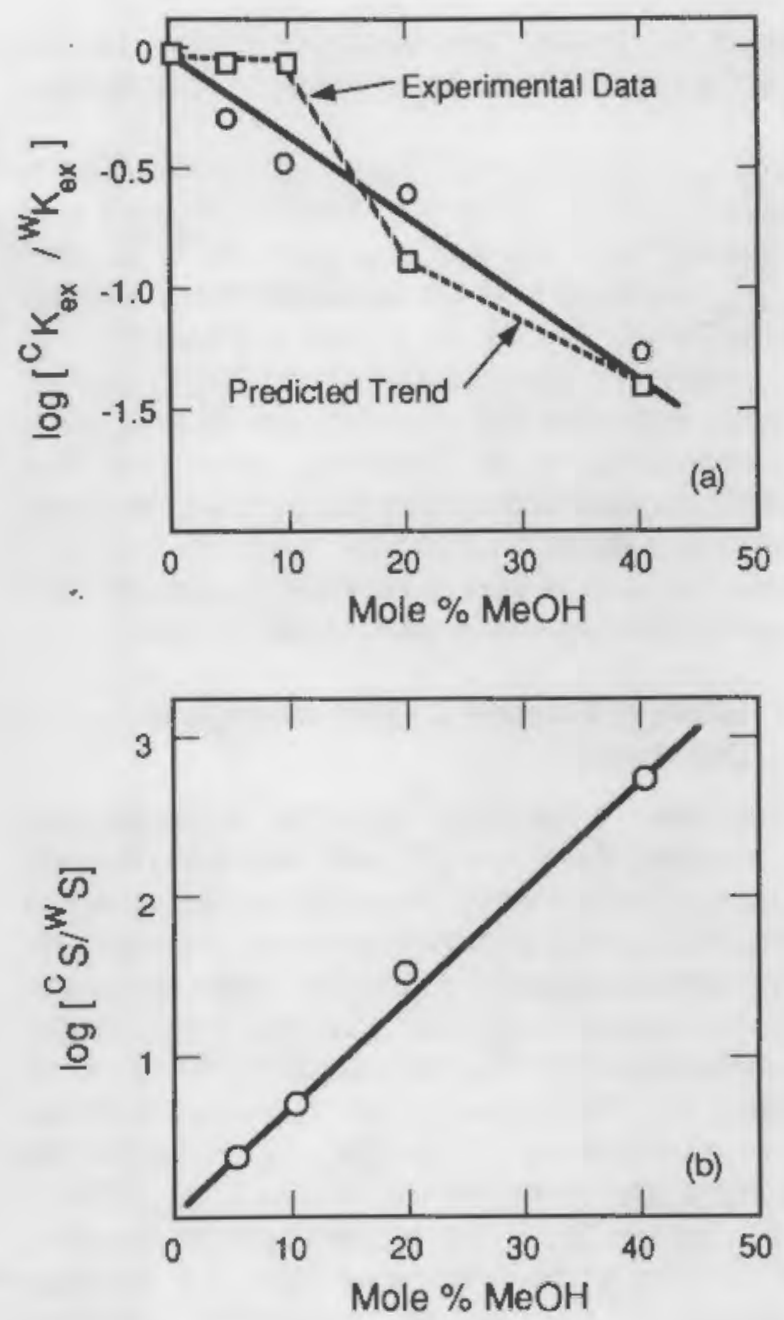

FIGURE 1. a) Change in the Relative Exchenge Constant of Acridine on Smectite $\left[{ }^{c} K_{e x} /{ }^{W} K_{e x}\right]$ and b) the Relative Aqueous Solubility of Acridine [ $\left[\mathrm{S} /{ }^{W} \mathrm{~S}\right.$ ] as a Function of Mole Percent Methanol

Because $\mathrm{Na}^{+} \rightarrow \mathrm{BH}^{+}$exchange on the natural clay was nearly ideal in water, the influence of $\mathrm{MeOH}$ on ${ }^{\circ} \mathrm{K}_{\mathrm{ex}}$ was evaluated from a thermodynamic perspective in terms of the medium effect on the exchanging ions. That is, ${ }^{c} \mathrm{~K}_{\mathrm{ex}} /{ }^{\mathrm{N}} \mathrm{K}_{\mathrm{ex}}$ was hypothesized to equal $\left[\mathrm{m}_{\mathrm{m}} \gamma_{\mathrm{BH}} / \gamma_{\mathrm{Na}}\right]$, where $\mathrm{m} \gamma$ are single ion transfer activity coefficients related to the difference in standard state chemical potential between that in water $\left(4^{\circ}\right)$ and in the co-solvent mixture of a given composition $\left(u^{\circ *}\right)$ and $\ln \mathrm{m}_{\mathrm{m}} \gamma=$ $\left(u^{0^{*}}-u^{9}\right) / R T$. To test this hypothesis, the ratio of $\left[\mathrm{m} \gamma_{\mathrm{BH}} / \gamma_{\mathrm{ma}}\right]$ was estimated independently and 
used to predict the variation in the relative exchange constant with co-solvent concentration.

The $\gamma_{\mathrm{mBH}}$ was approximated from the ratio of compound solubility in water to that in co-solvent (i.e., data in Figure 1b), with $\ln { }_{\mathrm{m}} \gamma_{\mathrm{BH}}=\ln \left[{ }^{\mathrm{w}} \mathrm{S} /{ }^{\mathrm{c}} \mathrm{S}\right]$, and $\mathrm{m}^{\gamma} \mathrm{Na}$ was taken from the literature data of Alfenaar and Deligny (1967). As shown in Figure 1b, the independent thermodynamic prediction agrees quite well with the trend in the experimental observations. It is, therefore, concluded that solvation plays a dominant role in stabilizing large organic cations on clay-type surfaces, and acridine sorption is less in co-solvent because of a reduction in interfacial solvophobic forces.

\section{Effect of Sorption on Microbiological Degradation}

Quinoline, a two-ring ionizable N-heterocyclic compound ( $\mathrm{pKa}=4.92$ ), was found in previous studies to be rapidly degraded by a bacterium isolated from the Middendorf formation at the SRS. Quinoline is strongly sorbed by cation exchange to subsurface materials and clay minerals like montmorillonite. The conditional exchange constant $\left(K_{\mathcal{C}}\right)$ for quinoline on Na-montmorillonite varies from about 200 to 1200 depending on the surface concentration $\left[\mathrm{K}_{\mathrm{c}}=\left(\mathrm{Na}^{+}\right) \mathrm{N}_{\mathrm{QH}} /\left(\mathrm{QH}^{+}\right)\right.$ $\mathrm{N}_{\mathrm{Na}}$, where $\mathrm{QH}=$ the ionized quinoline cation, $\mathrm{N}=$ surface mole fractions and () denotes activities]. This strong interaction between quinoline and the clay surface would suggest that if an organism can mineralize only the quinoline in solution then the actual degradation rate of the compound (as measured by $\mathrm{CO}_{2}$ evolution) in subsurface material could be strongly influenced, if not controlled by the presence and concentration of layer silicate-type minerals in the mineral matrix. It is implied, therefore, that degradation measurements made in the absence of realistic concentrations of subsurface materials could grossly overestimate the degradation rates that would actually occur in the vadose and saturated zones.

Previously, research into the effects of sorption on microbial degradation clearly demonstrated that the presence of Na-montmorillonite caused a reduction in the rate of microbial mineralization of quinoline. It was not clear, however, whether the decreased degradation rate was a result of sorption or a physical interaction between the clay and the microorganism. Therefore, work continued in FY 1989 in an attempt to elucidate the mechanism causing the reduction in microbial utilization in the presence of clay. A series of experiments were conducted in which the clay concentration was held constant and 1) the total amount of quinoline at the the beginning of the experiment at time equal $0(t=0)$ was held constant causing the solution concentration at $t=0$ to decrease with increasing clay, 2) the quinoline solution concentration at $\mathrm{t}=0$ remained constant causing the total quinoline concentration to increase with increasing clay, and 3) the concentration of acetate (an easily metabolized substrate that does not readily interact with clay) was held constant. The degradation rate of quinoline was measured for up to 16 hours; each study was inoculated with approximately the same number of organisms ( $10^{8}$ cells $\left./ \mathrm{mL}\right)$, and ${ }^{14} \mathrm{C}-\mathrm{CO}_{2}$ was monitored.

When the total quinoline concentration is held constant (at $t=0$ ), the degradation rate of quinoline was observed to decrease as the concentration of clay increased (Figure 2a). In cultures without clay, the evolution of ${ }^{14} \mathrm{C}-\mathrm{CO}_{2}$ reached a maximum after 8 hours with approximately $46 \%$ of the added ${ }^{14} \mathrm{C}$ accounted for; the same results were obtained at the lowest clay concentration. However, with $0.69 \mathrm{meq} / \mathrm{L}$ of clay only about $31 \%$ of the added ${ }^{14} \mathrm{C}$ was recovered after 8 hours, and further evolution was very slow. The addition of higher levels of clay depressed the rate of evolution further, and even after 16 hours only $23 \%$ and $12 \%$ of the total ${ }^{14} \mathrm{C}$ added had evolved. At the two highest clay concentrations (7.49 and $14.2 \mathrm{meq} / \mathrm{L})$, the rate was basically linear. At $t=0$ the aqueous quinoline concentrations were very low $\left(\sim 10^{-7} \mathrm{M}\right)$, and may be too low to act as an effective carbon source; therefore, the degradation rate observed with the two highest clay concentrations (Figure $2 \mathrm{a}$ ) is probably a reflection of the rate of quinoline desorption.

When the $t=0$ aqueous quinoline concentration was held constant while the clay concentration increased, the degradation rate of quinoline decreased implying that the clay affected the rate of degradation. Additionally, acetate utilization also decreased as clay concentration increased (Figure $2 b$ ). There is a significant decrease in acetate 

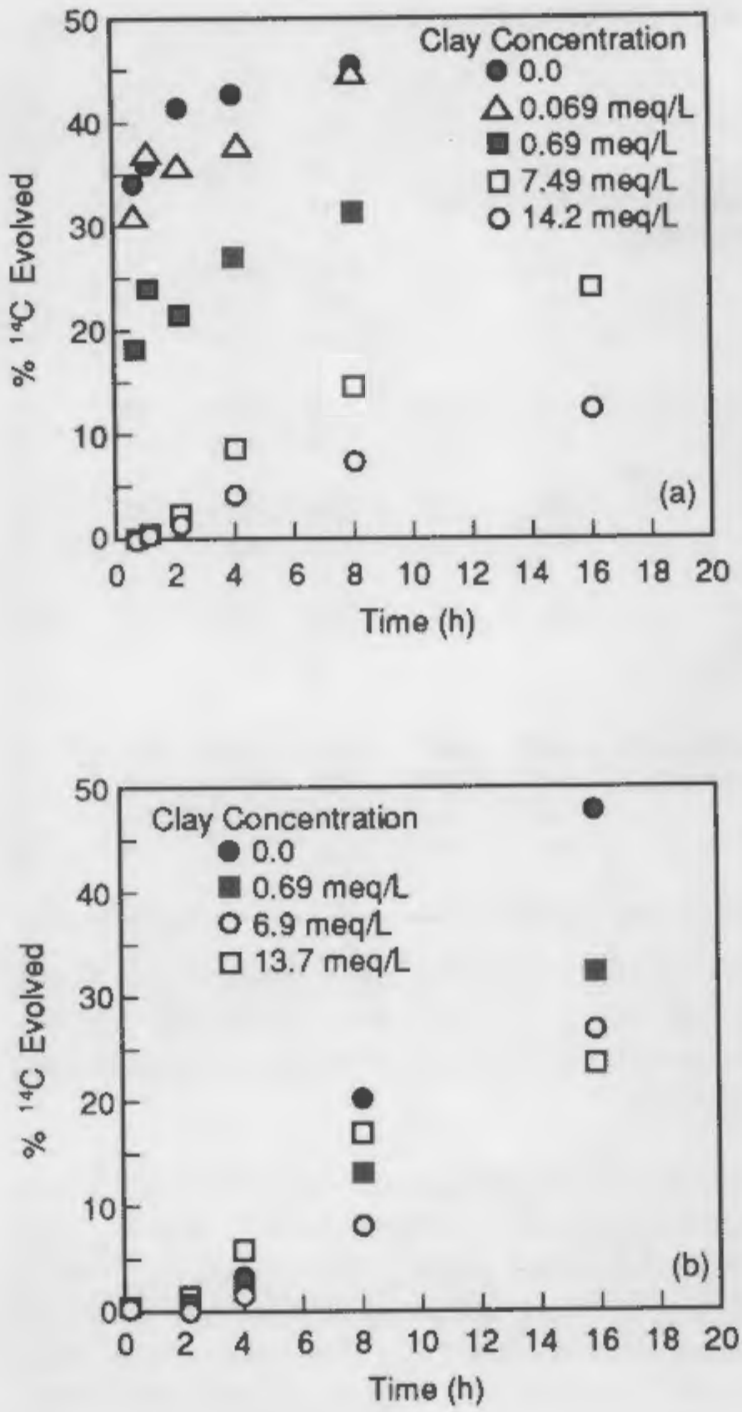

FIGURE 2. Microbial Utilization of a) Quinoline $(\mathbf{T}=0$ Total Concentration $=1.0=\mu \mathrm{M})$, and b) Acetate $(T=0$ Concentration $=\sim 2.5 \mu \mathrm{M}$ ) as a Function of Time and

Na-Montmorillonite

utilization with the initial clay addition, but the effect of increasing clay concentration diminishes at the higher clay levels; similar results were observed for quinoline when the $\mathrm{t}=0$ aqueous quinoline concentration was held constant while the clay concentration increased. These results suggest that the clay was binding to the organism (the clay particles are approximately 10 times smaller than the microorganism) and affecting its ability to take up acetate and quinoline.
Results from the above studies suggest that both mechanisms (desorption and physical interactions) affected the rate of quinoline utilization in clay suspensions. At present, the partitioning of the observed decrease in quinoline degradation rate between the two mechanisms is not possible. It would appear, however, that the effect of the physical interaction between the clay and microorganism is most apparent when the aqueous quinoline (or acetate) concentration is great enough to act as an effective carbon source. Additionally, over the range of clay concentrations used in this study, the magnitude of the decrease in acetate (or quinoline) degradation is greatest after the initial clay addition (Figure 2b), and additions of more clay do not have as great an affect on the degradation rate. Since physical interactions showed little additional effect on the acetate or quinoline degradation rate at the two highest clay concentrations, it is suggested that at extremely low-aqueous quinoline concentrations (as seen in the highest two clay concentrations in Figure 2a) desorption is the dominant mechanism. While it is believed that desorption is the dominant retardation mechanism in low-aqueous concentration systems, it is unknown if the microorganism can perturb the microenvironment in a manner that would facilitate desorption, or if the microorganism can use quinoline (or other organic compounds) by directly absorbing material from the surface. These questions are being investigated during FY 1990.

\section{Hydrophobic Organic Compounds (HOC)}

The sorption of organic compounds on soil and subsurface materials influences the transport velocity of the organic contarninants, and the ease in which they may be removed from contaminated zones. The carbon-referenced predictive approach is most commonly used to estimate the sorption of nonpolar HOC on subsurface materials. This approach is based on the observation that the sorption of a wide variety of low-solubility neutral organic compounds (e.g., pesticides, heterocyclic organics, and other compounds) is controlled by the particulate organic carbon fraction of soils and subsurface materials. The intensity of HOC sorption to organic carbon has been correlated to a compound's water solubility and its octanol/water 
partition coefficient $\left(\mathrm{K}_{\text {ow }}\right)$. Predictive relationships based on the above correlations and the sorbent's organic carbon content have been used to provide estimates of $\mathrm{HOC}$ sorption across a range of geomedia. Implicit in these predictive relationships based on water solubility and $\mathrm{K}_{\text {ow }}$ is the assumption that HOC-organic carbon interactions are not affected by differences in the chemical composition or physical arrangement of the sorbent's organic carbon fraction. Accordingly, the sorption coefficient $\left(K_{p}\right)$ normalized to the organic carbon content $\left(K_{o c}=K_{p} / t_{o c}\right.$, where $f_{o c}$ is the mass fraction of organic carbon) should yield a single sorption coefficient $\left(K_{o c}\right)$ unique to a given compound regardless of the sorbent properties. However, it has been found that $K_{p}$ normalized to the organic carbon content is not constant on different subsurface materials, nor is it quantitatively predictable from $\mathrm{K}_{\text {ow }}$.

\section{Sorptlvity Differences in Subsurface Organic Carbon}

Research published by this project has shown that, while sorption of a slightly polar compound (i.e., carbazole) is controlled by the organic carbon fraction of the soil, the $\mathrm{K}_{\mathrm{oc}}$ is not constant for different natural subsurface sorbents, nor is it quantitatively predictable from the $\mathrm{K}_{\text {ow }}$. Additionally, subsurface sorbents with low organic carbon exhibited markedly different affinities for carbazole. Research on the comparative sorptivity of subsurface organic carbon from different climatic, vegetative, and geochemical zones continued this year using the hydrophobic compounds dibenzothiophene and anthracene. The objective was to carefully compare the relative sorptivity of organic carbon on low-carbon subsoils and low-carbon aquifer materials to define the relative importance of organic carbon composition and physical structure (i.e., coatings versus particulate) on HOC sorption.

Sorption of dibenzothiophene $\left(\log \mathrm{K}_{\mathrm{ow}}=4.38\right.$; water solubility $=1.47 \mathrm{mg} / \mathrm{L})$ and anthracene $(\log$ $\mathrm{K}_{\text {ow }}=4.45$; water solubility $=0.075 \mathrm{mg} / \mathrm{L}$ ) on a variety of subsurface materials, showing a range of organic carbon content, exhibited linear partitioning (Table 1). Sorption was well correlated with the $f_{o c}$ of the sorbents $\left(r^{2}=0.91\right)$; correlation between sorption and other sorbent properties was poor. For instance, correlation to clay content
TABLE 1. Selected Soil and Subsurface Material Properties

\begin{tabular}{|c|c|c|c|c|c|c|}
\hline Soil & & $\begin{array}{l}\text { Depth } \\
\text { (m) }\end{array}$ & $\begin{array}{l}O C \\
\% \\
\end{array}$ & $\mathrm{pH}$ & $\begin{array}{c}\text { Sand } \\
\% \\
\end{array}$ & $\begin{array}{c}\text { Clay } \\
\%\end{array}$ \\
\hline Kenoma & Ap & 0.2 & 2.06 & 6.16 & 8 & 22 \\
\hline \multirow{4}{*}{$\begin{array}{l}\text { Nertic } \\
\text { Argiudoll) }\end{array}$} & B1t & 0.6 & 1.43 & 5.55 & 5 & 45 \\
\hline & Bat & 0.8 & 0.92 & 6.03 & 5 & 53 \\
\hline & $\mathrm{BC}$ & 1.2 & 0.50 & 6.74 & 5 & 42 \\
\hline & C & 1.6 & 0.20 & 7.19 & 8 & 37 \\
\hline Cloudland & AP & 0.15 & 1.19 & 5.32 & 36 & 10 \\
\hline \multirow{3}{*}{$\begin{array}{l}\text { (Typic } \\
\text { Fragiudult) }\end{array}$} & E & 0.3 & 0.19 & 4.65 & 41 & 19 \\
\hline & $B t x$ & 1.2 & 0.09 & 4.38 & 35 & 43 \\
\hline & C & 1.8 & 0.05 & 4.23 & 60 & 30 \\
\hline $\begin{array}{l}\text { Cecil } \\
\text { (Typic } \\
\text { Hapludult) }\end{array}$ & C & 1.7 & 0.08 & 5.33 & 26 & 28 \\
\hline Middendorf & $24 B$ & 366 & 0.07 & 8.66 & 85 & 8 \\
\hline \multirow[t]{3}{*}{ Sediments } & $24 C$ & 375 & 0.03 & 8.53 & 88 & 5 \\
\hline & $24 \mathrm{E}$ & 405 & 0.06 & 7.64 & 92 & 4 \\
\hline & 241 & 412 & 0.72 & 5.56 & 89 & 4 \\
\hline
\end{tabular}

was $r^{2}=0.25$. However, the $K_{p}$ values varied as a function of $f_{o c}$ in a manner inconsistent with the prevailing notion of carbon-referenced partitioning (Figure 3).

The diagonal line in Figure 3 depicts the $K_{p}$ versus $f_{o c}$ relationship as calculated from the $K_{o w}$ for dibenzothiophene $\left(\log \mathrm{K}_{\mathrm{oc}}=1.00 \log \mathrm{K}_{\mathrm{ow}}-0.21\right.$; and $\left.K_{o c}=K_{p} / f_{o c}\right)$. Good agreement is found between the predicted $\mathrm{K}_{\mathrm{oc}}$ (the slope of the diagonal line) and sorption data for near-surface materials with substantial organic carbon. At lower $f_{o c}$, however, the agreement between calculated and experimental data deteriorates with decreasing $f_{o c}$. At low $f_{o c}$, the difference between predicted and experimental sorption data for dibenzothiophene approaches an order of magnitude. Interestingly, sorption of dibenzothiophene to the deep subsurface Middendorf sediments is approximately a factor of five greater than predicted regardless of the $f_{o c}$. While the data are not shown here, similar results were observed for anthracene.

At present, the factors that influence the intensity of HOC sorption to low organic carbon subsurface materials are not definitively known. However, the anomalous behavior of the Middendorf sediments relative to shallower subsoils and aquifer 


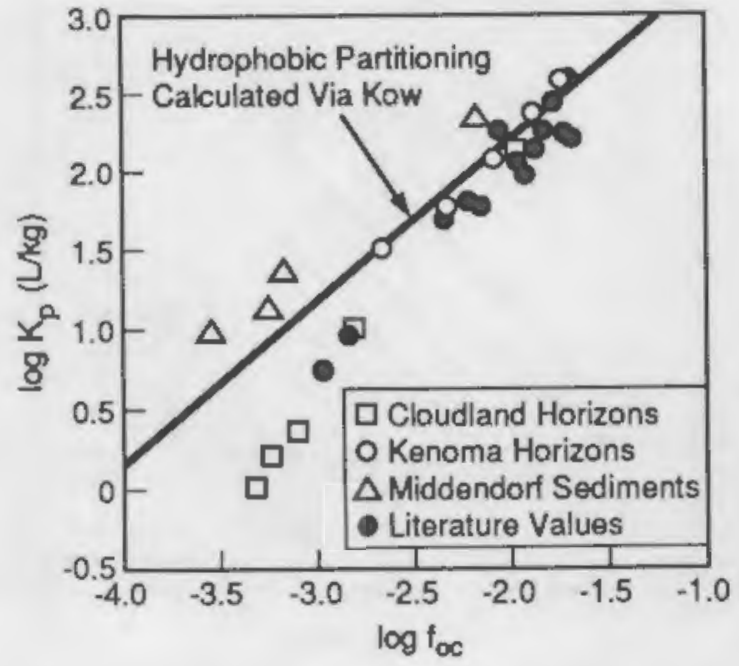

FIGURE 3, Relationship Between the Dibenzothiophene Linear Partition Coefficients $\left(\mathrm{K}_{\mathrm{p}}\right)$ and the Fractional Organic Carbon Content ( ${ }^{\circ} \mathrm{O}$ ) for 14 Near-Surface, and Deep Subsurface Materials. The diagonal line represents the calculated reletionship between $\log K_{p}$ and $\log f_{o c}$ as determined from the dibenzothiophene $\mathrm{K}_{\text {ow' }}$

sediments is ascribed to the highly aromatic nature of the carbon fraction in these sediments that has been documented by ${ }^{13} \mathrm{C}$ NMR analyses on this project. Additionally, recent publications on the interaction of HOCs and DOC demonstrated that the chemical properties (i.e., molecular weight, polarity, functional groups) and composition (i.e., aliphatic, aromatic, polysaccharide content) are directly related to the intensity of sorption. Alternatively, the physical structure and conformation of the organic carbon, in the soils that exhibit similar sorption behavior as the Cloudland horizons, may become less particulate-like (threedimensional) and more two dimensional (more diffuse over the mineral surface), and hence, influence its ability to partition HOCs. These hypotheses are currently being investigated under this program, and initial fundings are summarized in the following section.

\section{Influence of Humic Coatings}

Sorption of HOC to organic matter in soil, sediment, and aquiler material as well as binding of $\mathrm{HOC}$ to dissolved and colloidal humic substances are dominant processes controlling $\mathrm{HOC}$ aqueous concentrations and transport in the environment. A significant $f_{o c}$ in low-carbon subsurface materials is believed to exist in the adsorbed state on the surface of mineral particles. The inherent complexity of natural organic/mineral systems suggests that an investigation using wellcharacterized mineral substrates and reference organic substances might better define the role of humic coatings and mineral surfaces in the sorption of HOC by low-carbon aquifer materials. Therefore, the objectives of the current study were to 1) investigate the dependence of $\mathrm{HOC}$ sorptivity on the fractional surface coverage of mineral surfaces with humic substances, 2) establish whether HOC sorptivity was influenced by the aromaticity/ aliphilicity of the humic coating, and 3 ) identify whether different mineral surfaces imparted a different structure to the adsorbed organic substances that affected HOC sorption.

The formation of natural organic coatings on kaolinite and on hematite was consistent with a ligand-exchange mechanism between carboxylic acid groups on the humic substance and hydroxylated surface sites on the solids. The amount of sorption depended primarily on the concentration of hydroxylated surface sites on the mineral and the properties of the humic substance. The sorption of humic substances to both hematite and kaolinite was proportional to their aromatic carbon content and inversely proportional to the oxygen/ carbon ratio (Figure 4). Humic acids were invariably more strongly adsorbed than fulvic acids. These observations suggest that in a shallow aquifer, humic acids from either terrestrial or aquatic sources are more likely to form organic coatings on mineral surfaces than fulvic acids. Furthermore, these findings suggest that the organic carbon associated with mineral surfaces in aquifers will have a large aromatic carbon content, which contrasts with the DOC in groundwater that typically has a larger percentage of aliphatic carbon.

Kaolinite and hematite sorb $\mathrm{HOC}$ very weakly, and large mineral surface areas ( 400 to $1600 \mathrm{~m}^{2} / \mathrm{L}$ ) that greatly exceed those found in groundwater were needed to measure a statistically signilicant change in solution concentration. Past studies of HOC sorption on mineral solids may have been influenced by trace organic impurities that were carefully removed in this study. Sorbed humic substances, however, greatly enhance HOC sorption at low surface coverage and $f_{o c}$. The type of humic coating influenced the amount of $\mathrm{HOC}$ adsorbed, and the most aromatic substance, Peat humic 


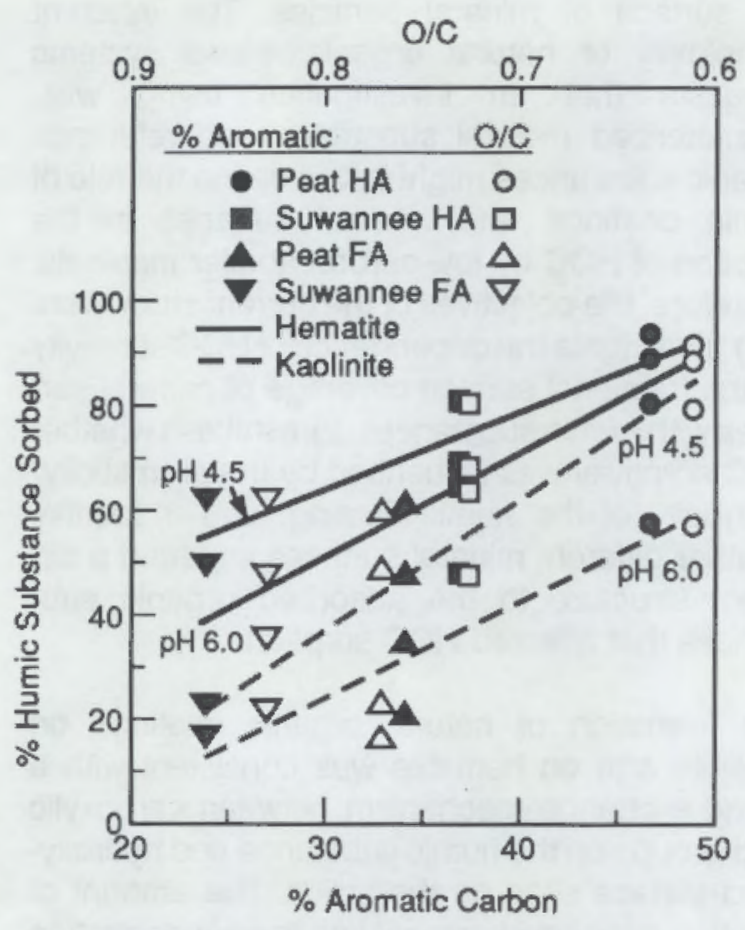

FIGURE 4. The Sorption of Humic and Fulvic Acids (HA and FA) was Directly Proportional to Their Aromatic Carbon Content and Inversely Proportional to Their Oxygen to Carbon Ratio (O/C)

acid, was the strongest sorbent. The lower polarity and higher molar volume of the Peat humic acid, as compared to the Suwannee humic acid, apparently promoted the higher sorptivity of Peat humic acid for HOC when associated with the mineral surface.

The sorption of HOC was nonlinear on hematite and on kaolinite coated with Peat humic acid (Figure 5). The isotherms conformed to the linear form of the Freundlich equation:

$\log S=\log K_{F}+N \log C_{e}$

where $\mathrm{K}_{\mathrm{F}}$ and $\mathrm{N}$ are constants specific to the coated hematite and kaolinite, $S=$ micromoles of $\mathrm{HOC}$ adsorbed per gram of solid, and $\mathrm{C}_{e}=$ micromoles of HOC per milliliter of solution. The Freundlich constants and linear correlation coefficients are shown in the inset of Figure 5. Chiou et al. $(1983,1985)$ argue that HOC isotherm linearity (i.e., $N=1$ ) is evidence for partitioning of $\mathrm{HOC}$ into an organic phase. The nonlinearity of

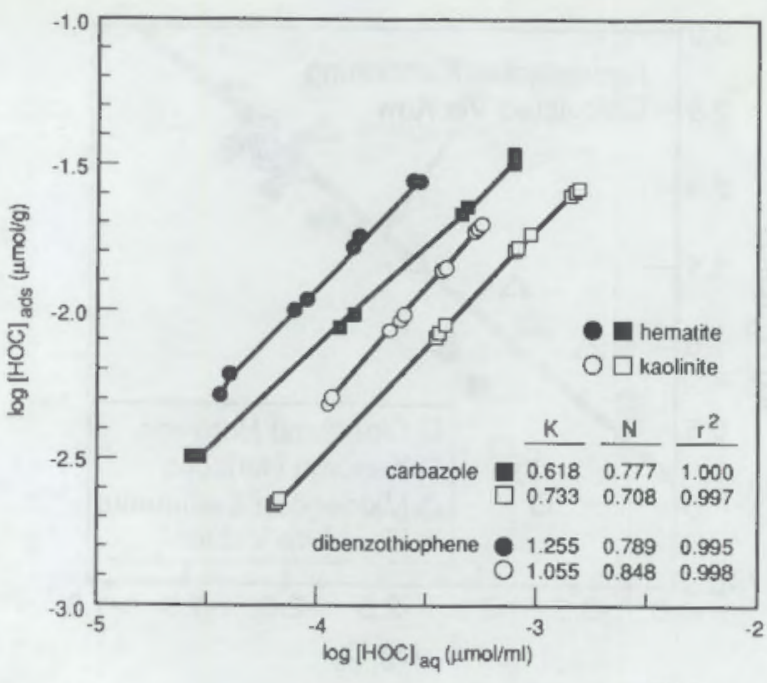

FIGURE 5. Influence of Humic Substance Coatings on Hematite and Kaolinite on the Sorption of Carbezole and Dibenzothiophene at Two Different Mass Fractions of Organic Carbon. The Freundlich constants for these nonlinear isotherms are shown in the inset.

the isotherms (i.e., $N \neq 1$ ) on the hematite-humate sorbent suggest that the sorbed humic substance is behaving as a hydrophobic surface rather than a hydrophobic phase.

The mineral surface, particularly the concentration and spatial distribution of hydroxyl sites, influences the amount of HOC adsorbed on the organic coating. The difference in selectivity for the same humic substance on hematite and on kaolinite suggested that the mineral surface influences the structure of the sorbed humic substance in ways that are important to HOC sorption. The distribution of surface hydroxyl sites, which represents points of attachment for carboxyl groups on the humic substance, affects the interfacial configuration of the humic coatings, possibly altering the size or accessibility of the hydrophobic domain.

Humic surface coatings may be an important sorbing phase for HOC in low-carbon substrates, as are typically found in aquifers. The $\mathrm{K}_{\mathrm{oc}}$ values were strongly dependent on the chemical and physical properties of the organic coating. Furthermore, the experimental $\mathrm{K}_{o c}$ values were both higher and lower than those predicted from the $\mathrm{K}_{\mathrm{ow}}$, suggesting a wide range of error can be associated with contaminant transport models that estimate 
carbon sorption binding constants from $\mathrm{K}_{\text {ow }}$. Importantly, the accurate prediction of contaminant transport may require chemical information on both the dissolved and mineral-bound organic matter.

\section{Collaboration With Deep Microbiology Research}

\section{The GEMHEX Experiment}

Approximately twenty-three $0.5-\mathrm{m}$ core sections were obtained from the fourth Deep Microbiology borehole near the SRS in September 1989. The samples were distributed uniformly between the Middendorf and Cape Fear formations because our objective was to investigate the extent of variation in microbiologic populations within waterbearing units and to identify the geohydrochemical factors governing such distributions. Information on microbial population variations within formations is scarce, and understanding the extent of these variations and their controlling factors is essential for the design of future, more effective in situ bioremediation techniques. Displacement and chemical analyses of the pore waters in the cores and chemical/mineralogic/physical analyses of the core solids were performed by this project while the microbiological determinations were made by the PNL Subsurface Microbiology Project in collaboration with Florida State University.

The analyses of the core pore waters for bromine (an anionic tracer added to the drill mud slurry) demonstrated that the drilling mud filtrate had displaced a significant fraction of the formation waters. Because the drill mud contained significant microbiological populations (around $10^{-7} \mathrm{cfu} / \mathrm{g}$ ), the finding of drill mud filtrate in the pore waters led to concern that the core samples had been microbiologically contaminated by the drill mud. Our efforts during the year focused on demonstrating that the core samples were not microbiologically contaminated. Four column transport experiments using intact core samples were first performed to determine if drill mud particles and microorganisms present together in the drill mud slurry could be transported under pressure through the intact core material. Both mud particles and microorganisms exhibited nearly identical transport velocities through the intact cores (see Figure 6), and both were retarded by factors of approximately two relative to bromine. It was, therefore, concluded that the cores would be
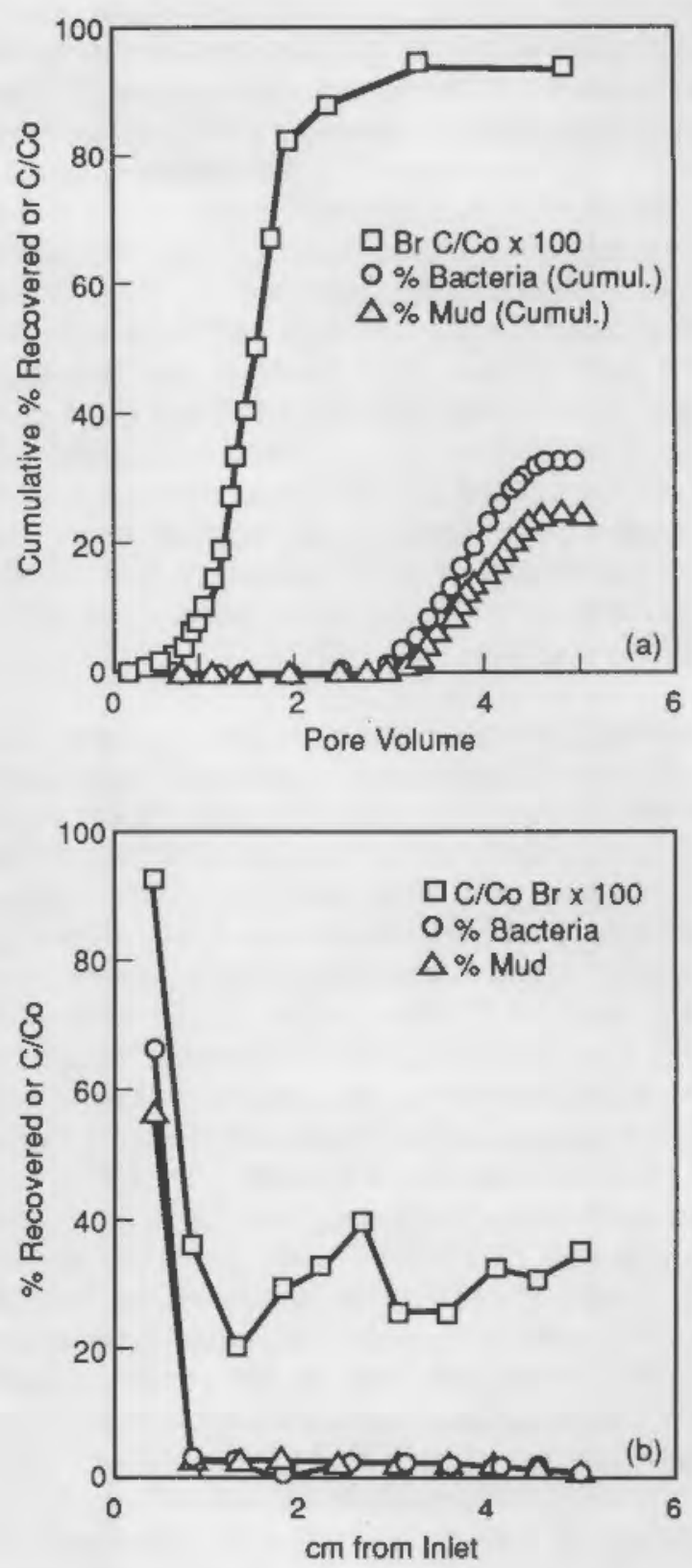

FIGURE 6. Transport of Organisms and Drill Mud Particles Through Intact Middendort Core Sediments. a) Column effluent samples show the retarded breakthrough of mud particles and organisms relative to bromine and b) Distribution of mud particles and organisms at the end of the experiment show that significant particle filtration occurs at the mud slurry/ porous media interface $(0-1 \mathrm{~cm}$ from inlet).

considered uncontaminated only if both the formation microorganisms and the formation clay minerals could be shown to be distinct from the drill slurry. 
Detailed mineralogic $(X$-ray diffraction) and chemical composition (PIXE) studies were performed on the clay-sized fraction removed from several different core samples of varying mud filtrate contamination. The clay minerals in the core samples had a different chemical signature and exhibited subtle crystallographic differences from the drill slurry clays. Additionally, physiologic and genetic analyses showed that the formation microflora were distinct and different from those in the drill mud slurry. These analyses collectively led us to conclude that the core samples, while tainted with drill mud filtrate, were free from microbiological contamination. This finding provided confidence that the microbiological characterization data on the core samples were valid and representative of formation conditions.

The microbiological data generated by the PNL Subsurface Microbiology Project and Florida State University were then integrated with the chemical and physical information developed by this project to interpret the microbiological distributions. Microbiological populations were found to be significantly higher in the Middendorf formation (log cfu/g $=3.0-6.7$ ) than in the Cape Fear (log $\mathrm{cfu} / \mathrm{g}=<2.0$ to 5.2). The Middendorf formation was a more transmissive unit, contained more organic carbon and total sulfur, and was of lower $\mathrm{pH}$ than the Cape Fear formation. Microbial populations within the Middendorf, like the porosity and particle size distribution, were generally similar with depth, in spite of large differences in total chemical composition and pore-water composition over this same depth interval. In contrast, populations within the Cape Fear formation showed large differences with depth that correlated well with bulk density and porosity but poorly with chemical variables. It was concluded that hydrophysical factors related to pore size, pore space, and hydraulic conductivity are more important than chemical composition in controlling microbiological populations within a given formation and between adjacent formations.

\section{Future Research}

In FY 1990 the project will complete research on the subsurface chemistry of ionogenic nitrogencontaining organic compounds and polyaromatic compounds containing nitrogen, sulfur, and oxygen. The project will initiate research (in FY 1990) on the subsurface chemistry of priority organic compounds and mixtures that have been frequently discharged to the ground at DOE production sites. Organic chemicals that are of concern from both an environmental quality/health perspective (e.g., solvents) and those that modify and facilitate the transport behavior of radionuclides (e.g., organic acids, complexing agents, extractants) will be investigated. Our research will transition rapidly into investigations of the sorption behavior of organic-radionuclide mixtures in FY 1990 and FY 1991. Thermodynamic and surface chemical models developed by this project for large organic cations and anions will now be extended to new research (FY 1990-1993) on the sorption behavior cationic/anionic radionuclideorganic complexes on subsurface materials and natural oxides and layer silicates removed from DOE site materials. Collaborative research on sorption-microbiological degradation interrelationships (with the PNL Subsurface Microbiology project) will continue with initial emphasis on polyaromatic hydrocarbons in FY 1990 and organicradionuclide complexes in FY 1991-1993.

\section{References}

Alfenaar, M., and C. L. Deligny. 1967. "Activity Coefficients of Individual Ions." Recueil. 86:929-951.

Bates, R. G., M. Paabo, and R. A. Robinson. 1963. "Interpretation of $\mathrm{pH}$ Measurements in Alcoholwater Solvents." J. Phys. Chem. 67:1833-1838.

Chiou, C. T., P. E. Porter, and D. W. Schmedding. 1983. "Partition Equilibria of Nonionic Organic Compounds Between Soil Organic Matter and Water." Environ. Sci. Technol. 17:227-231.

Chiou, C. T., and T. D. Stroup. 1985. "Soil Sorption of Organic Vapors and Effects of Humidity on Sorptive Mechanism and Capacity." Environ. Sci. Technol. 19:1196-1200.

Deligny, C. W., P.F.M. Luykx, M. Rehbach, and A. A. Wiemeke. 1960. "The pH of Some Standard Solutions in Methanol and Methanol-water Mixtures at $25^{\circ} \mathrm{C} . '$ Recueil. 79:699-712. 


\section{Chemistry/Microbiology Controlling Chelated Radionuclide Transport}

\section{C. Girvin and H. Bolton, Jr.}

Synthetic chelating agents such as ethylenediaminetetraacetic acid (EDTA), diethylenetriaminepentaacetic acid (DTPA), and nitrilotriacetic acid (NTA) have been used to decontaminate nuclear reactors and for various nuclear waste processing procedures because they form strong water-soluble complexes with a wide range of radionuclide and metal ions. The disposal of synthetic chelating agents and radionuclides at several mixed waste sites has increased radionuclide transport in the subsurface environment. At specific DOE sites, enhanced ${ }^{60} \mathrm{Co}$ migration has been reported in soil and subsoil pore waters. The dissolved ${ }^{60} \mathrm{Co}$ in these pore waters exists as an anionic species, with up to $90 \%$ of the cobalt associated with EDTA. This enhanced transport at these mixed waste disposal sites is presumably due to the reduced adsorption of the chelated radionuclide by subsurface materials relative to the adsorption of the unchelated radionuclide. Under these conditions, a decrease in chelate concentration via biodegradation would decrease radionuclide migration. However, subsurface conditions can exist where chelation of radionuclides would increase radionuclide adsorption and lead to a decrease in radionuclide mobility. Under these conditions, biodegradation of the chelate would be undesirable.

The current limited scientific understanding of both chelated radionuclide adsorption and biodegradation and the physicochemical and microbiological parameters that influence these processes prevent an assessment of their role in controlling chelated radionuclide transport at DOE mixed waste sites. This lack of knowledge precludes manipulating the geochemical and microbiological conditions in the subsurface environment to limit radionuclide migration when synthetic chelating agents are present. To provide such information, this project focuses on the adsorption of synthetic chelates and chelated radionuclides, the subsurface physicochemical conditions influencing microbial biodegradation and transformations of synthetic chelates, and the synergistic influence adsorption and microbial processes have on each other. Because of the complex nature of the individual adsorption and biodegradation processes, this research begins with the investigation of each process separately and then proceeds to investigations of the combined processes and their interactions. This report describes progress during the first year of the project for individual studies of chelated radionuclide adsorption and biodegradation.

\section{Chelated Radionuclide Adsorption}

The goal of this research is to mechanistically describe chelated radionuclide adsorption over a range of subsurface materials and conditions present at DOE waste sites. Initially, research focused on cobalt-EDTA adsorption by aluminum oxide in the absence of microbiological activity. Cobalt and EDTA were selected for initial study because of their co-migration in pore waters at specific DOE waste sites. Aluminum oxide was chosen because it is an important sorbent occurring in many subsoils and subsurface materials. This cobalt-EDTA-aluminum oxide system will be used in future joint studies of chelated radionuclide adsorption and biodegradation from which combined adsorption-biodegradation models will be developed.

The adsorption of $\mathrm{Co}^{2+}$, EDTA, and the Co-EDTA complex on $\gamma-\mathrm{Al}_{2} \mathrm{O}_{3}$ has been studied as a function of solution $\mathrm{pH}$, and total cobalt and EDTA concentrations to mechanistically describe adsorption using the surface coordination reaction approach. This approach couples specific surface coordination reactions of Co-EDTA and surtace hydroxyls of the oxide $(\mathrm{XOH})$ with aqueous speciation reactions and thus provides a generalized description of the adsorption process. In the absence of EDTA and atmospheric $\mathrm{CO}_{2}$, the aqueous speciation of cobalt is dominated by $\mathrm{Co}^{2+}$ for $\mathrm{pH}<9.5$. As a result, cobalt adsorption exhibits a cation-like adsorption edge with increasing $\mathrm{pH}$ (Figure 1). All experiments reported here were performed in a $\mathrm{CO}_{2}$-free $\mathrm{N}_{2}$ atmosphere glove box to prevent precipitation of $\mathrm{CoCO}_{3}$ above pH 9. For equalmolar concentrations of cobalt and EDTA, aqueous cobalt exists predominantly as the anionic chelate, Co-EDTA ${ }^{2 .}$ or Co-HEDTA; , over the $\mathrm{pH}$ range studied, even in the presence of dissolved aluminum, which was measured by ICP-MS. The $\mathrm{pH}$ dependence of cobalt adsorption is thus reversed, with a ligand-like adsorption edge observed (Figure 1). The cation-like and ligand-like adsorption edges (Figure 1) are virtually identical 


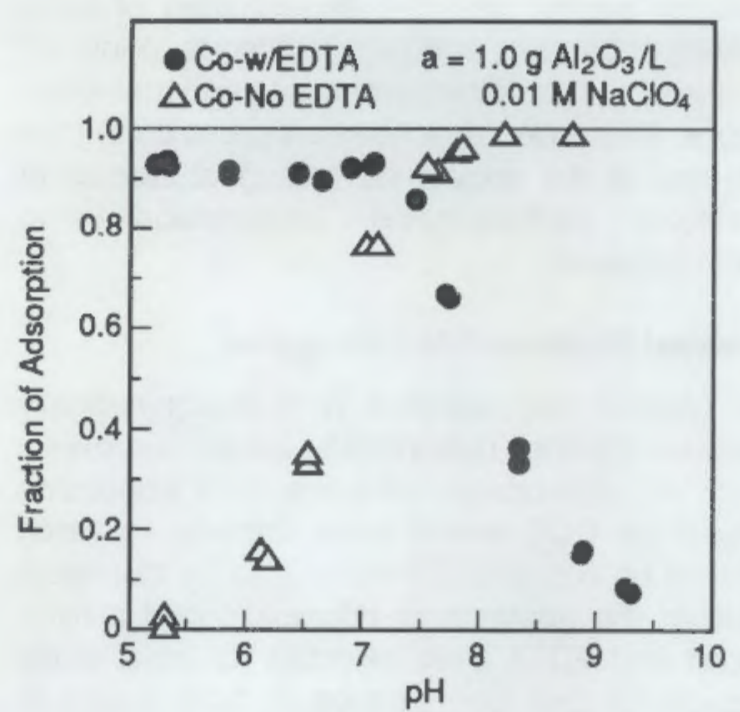

FIGURE 1. Cobalt and Cobalt-EDTA Adsorption on $\gamma-\mathrm{Al}_{2} \mathrm{O}_{3}$ as a Function of $\mathrm{pH}$ for Total Cobalt and EDTA Concentrations of $0.2 \mu \mathrm{M}$

to those observed for separate experiments with cobalt or EDTA at $10^{-5} \underline{\mathrm{M}}$, respectively (data not shown).

This observed adsorption behavior (e.g., Figure 1) can qualitatively describe cobalt migration in subsurface waters at DOE sites for varying equalmolar concentrations of cobalt and EDTA under specific geochemical conditions. The quantity of aluminum oxide adsorption sites used in these studies was representative of oxidic subsoils. Under these conditions and in the presence of dissolved aluminum from the oxide surface, which competes with cobalt for the EDTA, the adsorption of cobalt as a EDTA chelate approached $100 \%$ below $\mathrm{pH}=7$ (Figure 1). For an oxidic subsoil, this result, observed for all equalmolar concentrations of cobalt and EDTA studied, implies that EDTA significantly enhances cobalt adsorption relative to cobalt adsorption in the absence of EDTA (Figure 1). Conversely, for a pH greater than 7 the presence of EDTA will reduce cobalt adsorption (Figure 1). The implication for cobalt migration in the field is depicted for an idealized mixed waste leachate migration scenario (Figure 2). With no chelate present, a hypothetical retardation curve due to cation-like adsorption is shown by curve 'B.'
For oxide-dominated sediments and equalmolar cobalt and EDTA concentrations, EDTA will reduce cobalt mobility in acid subsoils as shown by the increased attenuation of cobalt in retardation curve "A." Conversely, under basic conditions EDTA will decrease the adsorptive retardation of cobalt, and the retardation curve will shift toward that of a conservative constituent (i.e., curve " $\mathrm{C}$ ").

Adsorption studies have also investigated how decreasing EDTA concentrations relative to cobalt and the introduction of native groundwater cations [e.g., Fe (III)], which compete with cobalt for EDTA, effect ligand-like adsorption. In both cases, the ligand-like adsorption edge of cobalt-EDTA is transformed into a cation-like edge (Figure 1) due to a change in the aqueous speciation of both cobalt and EDTA. For acid subsoil conditions, the effect of these changes upon the cobalt migration scenario (Figure 2) would be an increase in mobility with the retardation of cobalt shifting from curve "A" to "B." Conversely, cobalt migration would decrease for basic conditions, with a shift in cobalt retardation from curve " $\mathrm{C}$ ' to "B."

The mechanistic hypothesis currently being tested for the ligand-like cobalt-EDTA adsorption data is that surface coordination reactions of the type

$$
\begin{aligned}
& \mathrm{XOH}_{2}^{+}+\mathrm{COEDTA}^{2-}=\left(\mathrm{XOH}_{2}^{+}-\mathrm{COEDTA}^{2-}\right)^{-} \\
& \mathrm{XOH}_{2}^{+}+\mathrm{COHEDTA}^{-}=\left(\mathrm{XOH}_{2}^{+}-\mathrm{COHEDTA}\right)^{\circ}
\end{aligned}
$$

will describe the observed adsorption of chelated cobalt when these reactions are coupled with aqueous speciation reactions. The applicability of the surface coordination reaction approach to describe adsorption requires that adsorption reach equilibrium and is reversible within a set time frame and that Langmuirian adsorption isotherms describe the data. These three conditions are met for the ligand-like adsorption of cobalt-EDTA, with adsorption and desorption reaching at least $95 \%$ of its final value within 6 hours. If this type of mechanistic interpretation of the ligand-like adsorption behavior of cobalt-EDTA is successful with oxides, clays, and subsoils, the mathematical representation of this adsorption model can subsequently be coupled with biodegradation models and incorporated into contaminant transport 


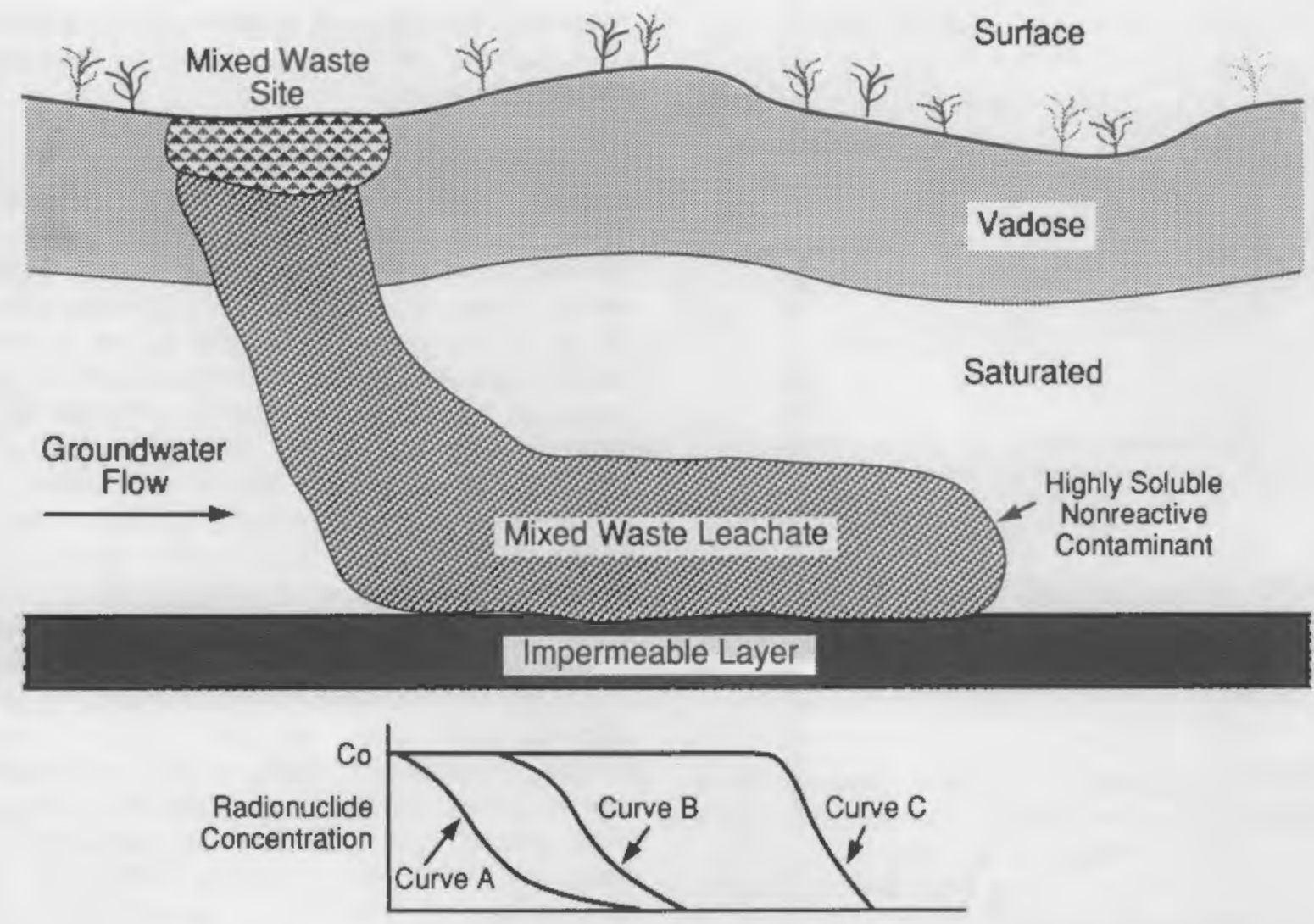

FIGURE 2. Mixed Waste Leachate Migration in an Idealized Uniform Porous Medium. Curves A, B, and C refer to three hypothetical radionuclide retardation scenarios as a function of distance.

models. This approach may also be applicable to the other chelates and radionuclides present at DOE mixed waste sites.

\section{Chelate Blodegradation in Subsurface Sediments}

The goal of this research is to quantify chelate persistence in subsurface sediments and determine how geochemical conditions influence chelate biodegradation. Initial research has focused on subsurface sediments to provide initial estimates of chelate persistence and also provide an enrichment for chelate degrading subsurface isolates or consortia. These isolates or consortia will be used in future joint studies of chelated radionuclide adsorption and biodegradation from which combined adsorption-biodegradation models will be developed.

Subsurface sediment samples were obtained near DOE's SRS in South Carolina as part of the
Subsurface Science Program. Six sediment samples were selected to provide a range of chemical and physical properties as a function of depth. The formation names and depths from which the sediment samples were obtained are listed in Figure 3. Biodegradation of the chelates EDTA, DTPA, and NTA at 10-5 M was studied in subsurface sediment slurries with $\mathrm{O}_{2}$ (aerobic) and $\mathrm{NO}_{3}{ }^{-}$(denitrification) as the terminal electron acceptors. Aerobic biodegradation of the ${ }^{14} \mathrm{C}$-labeled chelates occurred in select sediment samples over the 115-day incubation indicating that subsurface microorganisms have the potential to change chelate concentrations in subsurface sediments (Figure 3). Biodegradation was greater in some subsurface sediments than the surface soil. Maximum mineralization of all three chelates was not in the same sediment samples indicating that unique microbial populations may be responsible for the biodegradation of each chelate. The Ellenton sediment had the highest amount of NTA 


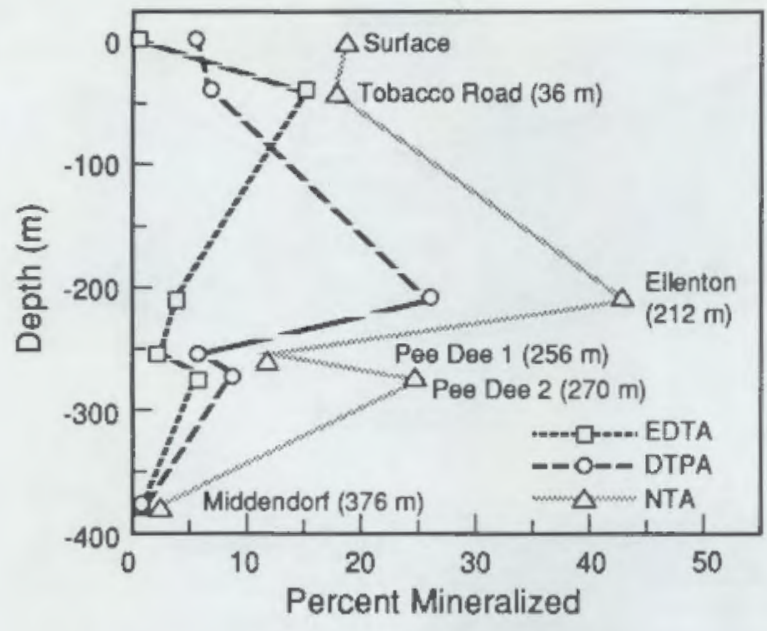

FIGURE 3. Chelate Biodegradation in Subsurface Sediment Samples. Formation names from which the sediments were obtained and depth from the surface are listed on the right of the curves.

and DTPA degraded, while the Tobacco Road sediment had the highest amount of EDTA degraded. The relative order of chelate persistence was EDTA > DTPA > NTA. Biodegradation was stratified as a function of depth, with zones of enhanced biodegradation present at $>200 \mathrm{~m}$. The spatial heterogeneity of chelate biodegradation and ultimately chelate persistence with depth have implications for modeling chelate persistence and radionuclide mobility in the subsurface environment. The observed chelate degradation could alter the hypothetical migration scenarios shown in Figure 2. For example, for mildly basic, oxidic subsurface materials, the retardation curve " $\mathrm{C}$ " for equalmolar chelate and radionuclide concentrations would be shifted to curve "B," thus decreasing radionuclide mobility. The converse would hold for acidic conditions in oxidic subsurface materials.

Anaerobic biodegradation of all three chelates under denitrifying conditions was very low over 100 days. The relative order of chelate persistence was similar to the aerobic incubations with EDTA > DTPA > NTA, but the maximum mineralization was only $5 \%$. These results suggest that chelates will persist when low redox conditions are present in the subsurface environment. This has implications for several mixed waste sites where chelates, radionuclides, metals, and other organics have been co-disposed. Soluble carbon at these sites usually results in a microbial induced decrease in redox.

Additional soluble carbon as an equal mixture of acetate, citrate, glutamate, and succinate was added at $10 \mu \mathrm{g} / \mathrm{ml}$ to the Tobacco Road and Ellenton sediment samples with the ${ }^{14} \mathrm{C}$ chelates added. These two sediment samples were selected to provide both a "high" and a "low" chelate biodegradation potential for all three chelates (see Figure 3). Previous work reported in the literature demonstrated that EDTA biodegradation was enhanced when soluble carbon was added to surface soils, implicating a co-metabolic biodegradation of EDTA. In our study, soluble carbon significantly reduced chelate biodegradation in all sediment samples and for all three chelates (data not shown). Co-metabolism of the chelates did not occur with the addition of soluble carbon, and degradation of these chelates may be under catabolite repression. These results are relevant to mixed waste sites containing chelates, radionuclide, metals, and other organic contaminants. First, the presence of soluble carbon in the groundwater at these mixed waste sites may decrease the chelate degradative potential of the subsurface microbial community even though a chelate biodegrading population is present. Second, bioremediation strategies for several organic contaminants would involve injection of soluble carbon to enhance organic contaminant bioremediation. Results indicate that this bioremediation strategy, while viable for some organic contaminants, would decrease chelate biodegradation and enhance chelate persistence in the subsurface environment. Thus, the injection of soluble carbon into an aquifer characterized by oxidic subsurface materials and $\mathrm{pH}$ greater than 7 would inhibit chelate biodegradation and thus minimize any beneficial microbially induced transition from curve " $\mathrm{C}$ " to " $\mathrm{B}$ " in Figure 2.

\section{Future Research}

The continued investigation of chelated radionuclide adsorption on oxides, smectitic clays, and subsoils dominated by oxides and/or clays, along with biodegradation studies of synthetic chelates and microbial-driven geochemical modifications of 
the subsurface environment, will extend the applicability of this research to several DOE sites. In addition, combined adsorption-biodegradation studies will be initiated based on results from the separate studies. The objective of the combined studies on progressively more complex systems is to quantify the effect of each process on the other and to incorporate these effects into a coupled mathematical model of adsorption-biodegradation. This mathematical description can be incorporated into transport codes for simulation and prediction of radionuclide and chelate mobility. Research results and model development will also aid in the evaluation of effective remediation strategies at DOE sites where chelates and radionuclides have been co-disposed.

\section{Intermediate-Scale Subsurface Transport of Co-Contaminants}

\section{G. P. Streile, J. E. Szecsody, J. F. McBride, and F. J. Brockman}

\section{Contributors}

\section{A. J. Valocchi and B. E. Rittmann (University of IIlinois)}

Subsurface environmental contamination commonly consists of complex mixtures of compounds that are subjected to simultaneous chemical, microbiological, and hydrological phenomena. Furthermore, the natural subsurface environment is often highly spatially heterogeneous in its physical, chemical, and biological properties. Design of effective disposal practices, prediction of the spatial extent and temporal development of subsurface contaminant plumes, and design and testing of contamination remediation methodologies are necessary to protect the public health. The ability to accurately predict the subsurface transport, transformation, and fate of contaminant mixtures in complex environments is critical to the success of these endeavors. Previous field experimentation has shown that predictive capability is hampered by a lack of understanding of microbiological, chemical, and hydrological processes (and their interaction) on a mechanistic level. This mechanistic understanding can best be gained through controlled laboratory experimentation that focuses on specific processes or interactions. The goal of this project is to conduct such experiments to identity, elucidate the mechanisms of, and quantify 1) synergistic interactions between sorption, biodegradation, and transport processes, 2) processes occurring only in spatially heterogeneous porous media systems, and 3) competitive effects occurring in contaminant mixtures.

The research approach is to conduct laboratory experiments in one-dimensional flow columns as well as in multidimensional flow cells containing controlled porous media heterogeneities (i.e., intermediate-scale systems). The experiments begin with simpler systems and progress to more complex systems as phenomena occurring in the simpler systems are better understood. Reactive transport modeling is used interactively with experimentation to resolve scientific issues regarding process mechanisms and their quantification.

The research of this project has been designed to build from the results of other DOE/OHER Subsurface Science projects, namely "Subsurface Chemistry of Organic Compounds and Mixtures" and "Subsurface Microbial Phenomena" (summarized elsewhere in this report). These companion projects include experimental investigations (and mathematical simulations) of the single processes of chemical sorption or microbiological degradation in static (batch) systems. Jointly, these companion projects are also investigating sorption/degradation interaction in batch systems. Research of this project will extend the understanding of these phenomena to dynamic transport systems and to systems with macroscopicscale spatial heterogeneity in physical, chemical, and microbiological properties.

The compounds studied include quinoline, naphthalene, and aminonaphthalene. These compounds were selected because they exhibit a range of chemical sorption and microbial degradation characteristics suitable for relevant transport experiments, and because significant information already exists on small-scale processes that affect these compounds in batch systems. Quinoline undergoes hydrophobic sorption and $\mathrm{pH}$-dependent sorption by ion exchange of the positively charged species, and is associated with a relatively rapid rate of metabolic pathway induction and microbial transformation. Aminonaphthalene undergoes hydrophobic sorption, 
$\mathrm{pH}$-dependent sorption by ion exchange of the positively charged species, and a surfacecatalyzed abiotic transformation, and is associated with a relatively slow rate of metabolic pathway induction and microbial transformation. Naphthalene undergoes only hydrophobic sorption and is associated with a relatively slow rate of metabolic pathway induction and microbial transformation. As research progresses on the DOE/OHER "Chemistry/Microbiology Controlling Chelated Radionuclide Transport" and "Subsurface Flow Physics of Immiscible Organic Liquids' projects, future work on this project will include studies using organic-chelated radionuclides and soluble components of immiscible organic liquids.

This project began in FY 1989. Research efforts to date are divided into four areas: 1) onedimensional transport with sorption, 2) onedimensional transport with biodegradation, 3) onedimensional transport with sorption and biodegradation, and 4) multidimensional tracer transport in layered porous media systems. In addition to this research into process mechanisms, preliminary work developed experimental methodology to produce experimental systems that contain the wellcharacterized chemical and microbial properties needed for quantitative investigation of coupled processes.

\section{Experimental Methodology Development}

\section{Preparation of Model Sorbing Porous Media}

The OHER "Subsurface Chemistry of Organic Compounds and Mixtures" project has generated much detailed mechanistic data for batch sorption of the chosen organic compounds onto purephase solid mineral sorbents. To maximize the potential for transport experiments to yield quantitative information regarding additional coupled processes, a procedure for producing a porous media containing only one of these previously studied solid-phase sorbents was developed.

A clay-coating procedure was adapted from the literature and used to develop a procedure to deposit a montmorillonitic clay (SWy-1, Wyoming bentonite) onto the surface of alumina particles that negligibly sorb the organic compounds of interest. Three deposition mechanisms (doublelayer repression, bridging by polyvalent ions, and surface charge attraction) were tested using a variety of electrolytes and mixing steps. The durability of the clay/alumina bond was tested by subjecting the coated particles to mechanical mixing and then packing the particles into a flow column through which aqueous solutions were passed at flow velocities greater than any expected in actual experiments. Bonding was considered durable if no clay particles were found in the effluent of the column. Sodium-saturated particles failed because the porous system dispersed too readily when in contact with the aqueous solution, thereby reducing the hydraulic conductivity sufficiently to prevent flow at reasonable waterpressure gradients. The most durable bonding was achieved by washing the bentonite with $1 \underline{\mathrm{M} \mathrm{NaClO}}{ }_{4}$ and $0.001 \underline{\mathrm{M} \mathrm{HClO}}{ }_{4}$, flocculating the clay on the alumina particles with $2 \mathrm{M} \mathrm{CaCl}_{2}$, drying, and then rewashing with a dilute calcium chloride solution. As the amount of calcium on the clay was augmented by the choice of electrolytes and mixing steps, the durability and suitability of the clay-alumina bond increased.

After the development of the clay-coating procedure, model subsurface porous media were prepared. Stocks and mixtures of high-purity alumina particles of various average particle sizes (uncoated as well as coated) were tested for their saturated hydraulic conductivities when packed into columns. Based on their conductivities, two coated and two uncoated model porous media were selected for use in column and layered flow cell experiments.

\section{Initialization of Uniform Column Microbial Conditions}

In accordance with the strategy of investigating first the simplest systems that contain poorly understood processes, initial transport experiments in columns with biodegradation require spatially uniform and temporally stable microbial distributions. Procedures were developed for achieving the desired initial conditions.

First, a method was perfected for inoculating the model subsurface material with quinolinedegrading bacteria isolated from Savannah River Plant subsurface cores. Flow inoculation of the clay-coated alumina particles packed into 8-cm-long columns was unsuccessful. Log-phase bacteria and starved (therefore smaller) bacteria failed to migrate farther than $2 \mathrm{~cm}$ from the inflow 
plate at a multitude of flow rates. Spraying the inoculum onto the clay before packing the column yielded a column with an acceptable uniformity in population density (a maximum threefold difference per 1-cm increment). In the spray inoculation method, a known mass of oven-dried clay-coated alumina particles is spread out on a sterile plastic sheet. Next, a known mass of sterile saline solution is misted on the particles until the volume applied yields $25 \%$ water saturation in a packed column. Pre-wetting increases the osmotic and matric potential to a range that will not stress and kill the inoculum. Then, before packing, the inoculum solution is misted on the particles until an equivalent $50 \%$ water saturation is achieved. The column is then packed in $1-\mathrm{cm}$ increments and pressure saturated to obtain $100 \%$ water saturation of the pore space.

Even though a column may be uniformly packed with induced microbes (i.e., microbes for which the metabolic pathway for degrading the organic compound of interest has been induced), this does not mean that the microbes will be able to degrade the compound to their optimum potential once the compound is introduced to the column. For this reason, a procedure was developed to acclimate the microbes in the column to degradation of the organic solute at the expected levels of the experiments to follow. Figure 1 illustrates column response to the acclimation procedure for quinoline transformation. Inflow of the aqueous

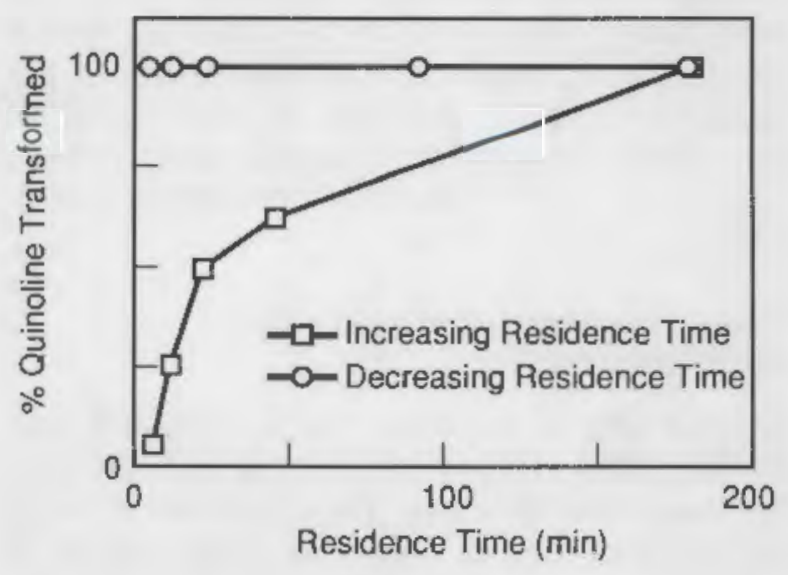

FIGURE 1. Sequential Procedure for Acclimating Microbes in Column to Flowing Quinoline Solution quinoline solution is initially adjusted so the flowing solution has a 5-min residence time in the column. This rate is maintained until the percent quinoline transformed while flowing through the column (as measured by effluent concentration of quinoline and its first transformation product, 2-hydroxyquinoline) is constant with time. Residence time is then incrementally increased (i.e., quinoline flux was decreased) and the equilibrium transformation response noted until quinoline and 2-hydroxyquinoline are absent in the effluent. Next, residence time is incrementally decreased. The uniform response of the column during the decreasing residence time measurements, as shown in Figure 1, indicates that the microbes in the column are acclimated to the flowing quinoline. This procedure facilitates repeatable responses through time in a particular column and minimizes variability in bacterial activity between columns.

\section{One-Dimensional Transport with Sorption}

Sorption of quinoline during transport was investigated in one-dimensional columns with different operating parameters. The objectives of these experiments are to 1) compare the equilibrium sorption partition coefficient determined by column experiments run at different values of $\mathrm{pH}$ and ionic strength, with partition coefficients predicted from batch isotherm experiments under similar conditions, 2) determine the existence of physical or chemical kinetic controls on sorption as a function of flow velocity, and identily the mechanisms, and 3) develop appropriate quantitative mathematical submodels for sorption during transport. Stainless steel columns of $0.5-\mathrm{cm}$ diameter and 5 to $30 \mathrm{~cm}$ in length were packed with a model porous media (clay-coated alumina particles) prepared as described above. Quinoline was added to $\mathrm{CaCl}_{2}$ solutions of various ionic strengths and $\mathrm{pH}$ values, and the resulting solution was pulse injected into the columns. Influent solutions for some experiments included tritium (as a conservative tracer) and ${ }^{45} \mathrm{Ca}$ (for determining accessibility of sorption sites during isotopic displacement with cold $\mathrm{Ca}$ ). In-line detectors were used to measure electrical conductivity $\left(\mathrm{CaCl}_{2}\right), \mathrm{pH}$, and UV absorbance (quinoline), and effluent sampies were measured for tritium and ${ }^{45} \mathrm{Ca}$ using a scintillation counter. Figure $2 a$ and $b$ show data for breakthrough of tritium, electrical conductivity $\left(\mathrm{CaCl}_{2}\right)$, and ${ }^{85} \mathrm{Ca}$. 


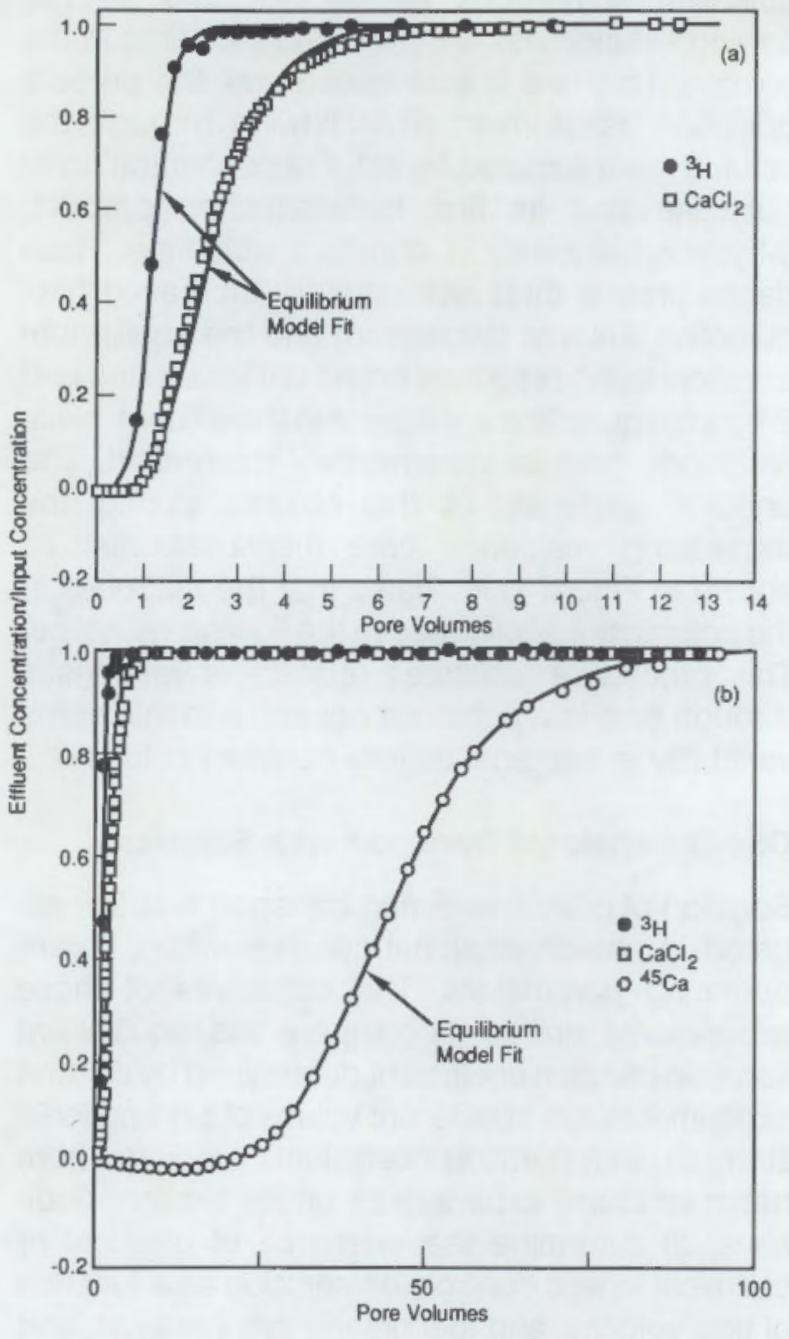

FIGURE 2. Effluent Breakthrough Curves for a Column With Clay Sorbent and Without Microbes. Shown are data and equilibrium model fits for a) tritium and calcium chloride, and b) tritium, calcium chloride and ${ }^{45} \mathrm{Ca}$.

Along with the data are plots of fitted transport models that account for advection, pore-scale dispersion, and equilibrium sorption. The goodness of fit of these model curves indicates that physical nonequilibrium processes (e.g., diffusion into immobile water regions) are not likely to be important in the porous media systems used in these columns.

In contrast, data of quinoline breakthrough (shown in Figure 3) could not be adequately described by an equilibrium sorption/transport model. Because physical kinetic limitations are deemed unlikely based on the previous data, the quinoline

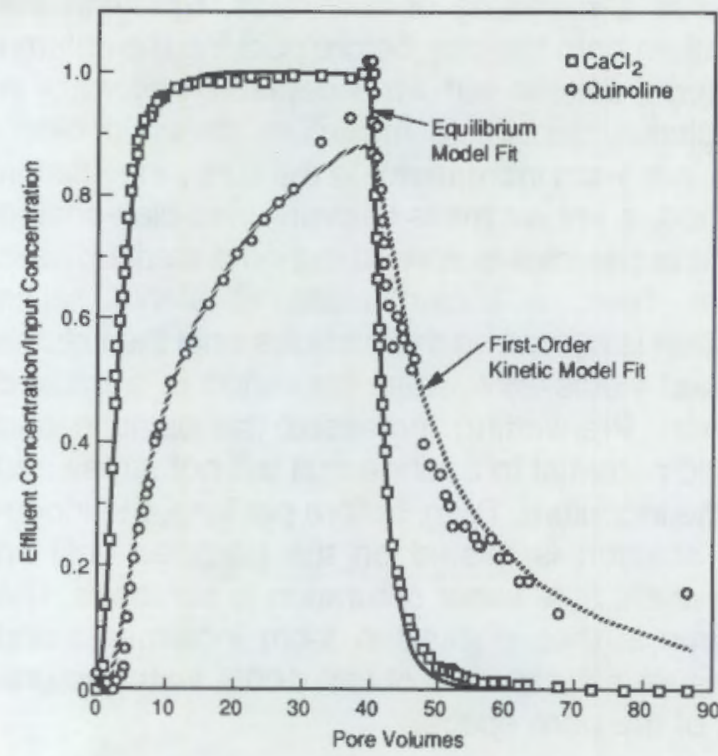

FIGURE 3. Effluent Breakthrough Curves for Calcium Chloride and Quinoline Transport in Columns With Clay Sorbent and Without Quinoline-Degrading Microbes. Shown are data and model fits.

breakthrough was modeled with a first-order chemical kinetic sorption model. The resulting fitted kinetic model curve is also shown on Figure 3. Quinoline sorption parameters needed by this model are the equilibrium partition coefficient and the reverse (desorption) rate parameter. The equilibrium partition coefficient can be determined from the area between the leading edges of the quinoline and the tracer breakthrough curves. Using this value, the reverse rate parameter is obtained from the model fit. Table 1 gives column experiment determinations of the equilibrium partition coefficient as a function of $\mathrm{pH}$ and ionic strength, and Table 2 gives column experiment determinations of both model parameters as a function of $\mathrm{pH}$.

\section{One-Dimensional Transport with Biodegradation}

Degradation of quinoline during transport was investigated as a function of input solution concentration and flow rate. The objectives of these experiments are to determine 1) the effect of contaminant plume properties, such as solute concentration and flux, on microbial activity, 2) the appropriate conceptual model for microbial degradation in a flow system, and 3) the proper 
TABLE 1. Equilibrium Partition Coefticient $\left(K_{p}\right)$ for Quinoline Sorption During Column Transport in the Absence of Microbes

$$
\begin{aligned}
& \frac{\mathrm{pH}}{5.5} \frac{\begin{array}{c}
\mathrm{K}_{\mathrm{p}}\left(\mathrm{cm}^{3} / \mathrm{g}\right) \\
\text { lonic Strength }
\end{array}}{\frac{10^{-2.6}}{9.6,8.0}} \frac{10^{-2.2}}{\frac{10^{-1.6}}{3.6,7.0}} \\
& 5.5 \quad 15.7,22.3 \\
& 5.6 \quad 10.1,8.2 \\
& 5.85 \quad 19.5,22.1 \\
& 6.85 \\
& 7.91 \\
& 42.6,41.3 \\
& \text { 2.7, } 1.8
\end{aligned}
$$

\begin{tabular}{|c|c|c|}
\hline $\mathrm{pH}$ & ${ }_{(\mathrm{cm} / \mathrm{g})}^{\mathrm{K}_{\mathrm{B}}}$ & $\begin{array}{c}K_{b} \\
(1 / s e c)\end{array}$ \\
\hline 5.5 & 10.9 & 0.0044 \\
\hline 5.6 & 56.7 & 0.000075 \\
\hline 5.85 & 11.6 & 0.00049 \\
\hline 6.85 & 25.4 & 0.00042 \\
\hline
\end{tabular}

TABLE 2. Equilibrium Partition Coefficients $\left(K_{0}\right)$ and Reverse Rate Coefficients $\left(K_{b}\right)$ for Quinoline Obteined by First-Order Kinetic Sorption/Transport Model Fit

mathematical model to quantitatively predict this transport-affected degradation. Column experiments were performed in autoclaved glass columns with a $2.5-\mathrm{cm}$ inside diameter packed with glass beads to a length of $1 \mathrm{~cm}$. The glass beads did not sorb quinoline. The column was inoculated with induced microbes (to a population density of $10^{9} \mathrm{cfu}^{-1}$ ) and acclimated to quinoline transformation according to the procedures outlined above. Concentrations of quinoline in the influent solution and flow rate of the influent solution were varied, and equilibrium response in effluent solution composition was measured by an in-line UV detector. Experimental results are reported below; conceptual model identification and associated mathematical modeling are planned near-term efforts.

Figure 4 shows the quinoline consumption rate in the column as a function of residence time and input concentration. The consumption rate for a fixed input solution concentration is affected by the flow rate, demonstrating that the degradation reaction cannot be described by a simple firstorder model. In addition, the $5-\mu \mathrm{g}-\mathrm{ml}^{-1}$ curve

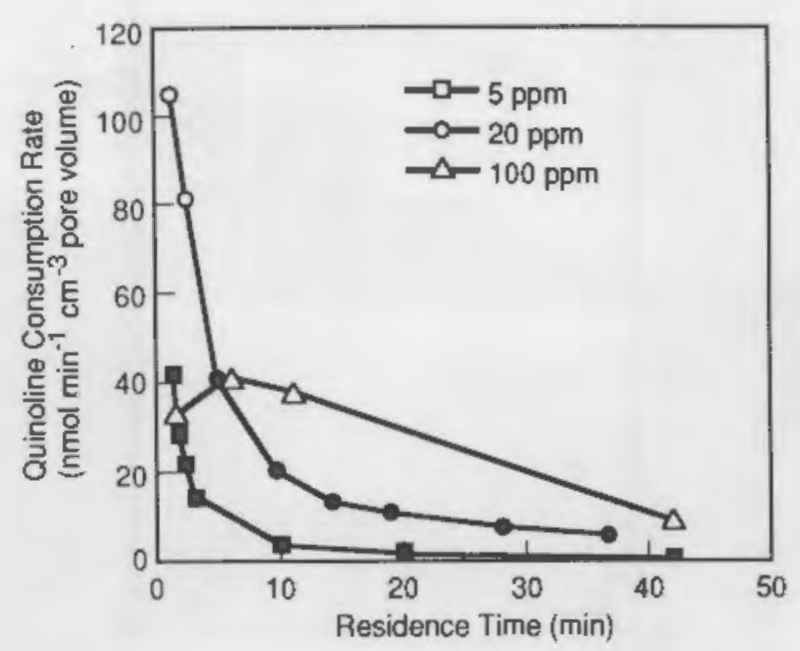

FIGURE 4. Quinoline Consumption Rate in Flow Column as a Function of Residence Time and input Solution Concentration (black symbols represent $100 \%$ consumption of inflowing quinoline)

represents $100 \%$ consumption at all residence times, while the $20-\mu \mathrm{g}-\mathrm{ml}^{-1}$ curve represents $100 \%$ consumption only for residence times of $5 \mathrm{~min}$ or greater. At input concentrations and residence times resulting in less than $100 \%$ consumption, the consumption reflects the inherent capacity of the acclimated column to consume the increased flux of quinoline. The lower consumption rate of the $100-\mu \mathrm{g}-\mathrm{ml}^{-1}$ solution at the shortest residence time is likely caused by a combination of saturation of the enzyme system and toxicity induced by the high concentration of quinoline. Figure 5 shows results of these same experiments plotted as histograms that report concentrations of quinoline, its first transformation product (2-hydroxyquinoline), and further metabolites. This figure shows that similar quinoline fluxes into the column, with different combinations of input concentration and residence time, result in a different extent of degradation and a different effluent solution composition. By using data showing few or no further metabolites or showing no quinoline in the effluent, the initial reaction of quinoline to 2-hydroxyquinoline was shown to be four to six times faster than the subsequent reaction of 2-hydroxyquinoline to further metabolites (see Figure 6).

Figure 7 shows the results of a pulse injection of a quinoline-laden solution into the acclimated 


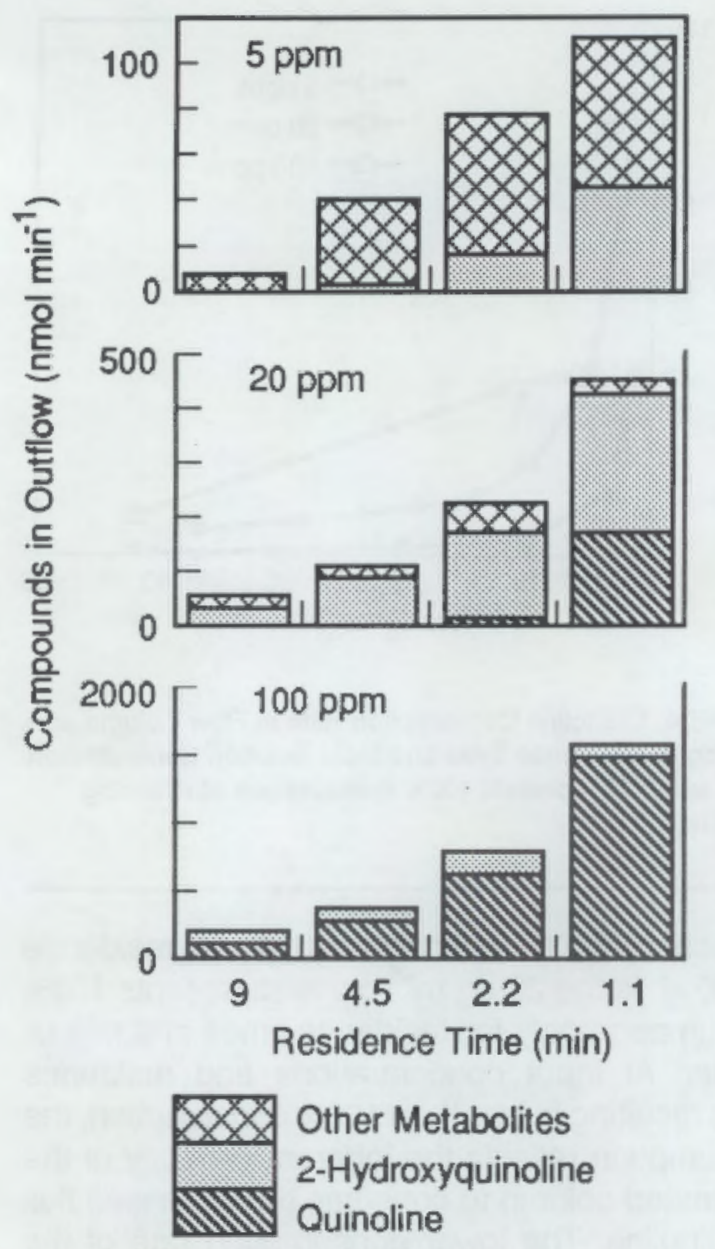

FIGURE 5. Composition of Column Effluent Solution as a Function of Residence Time and Input Solution Quinoline Concentration

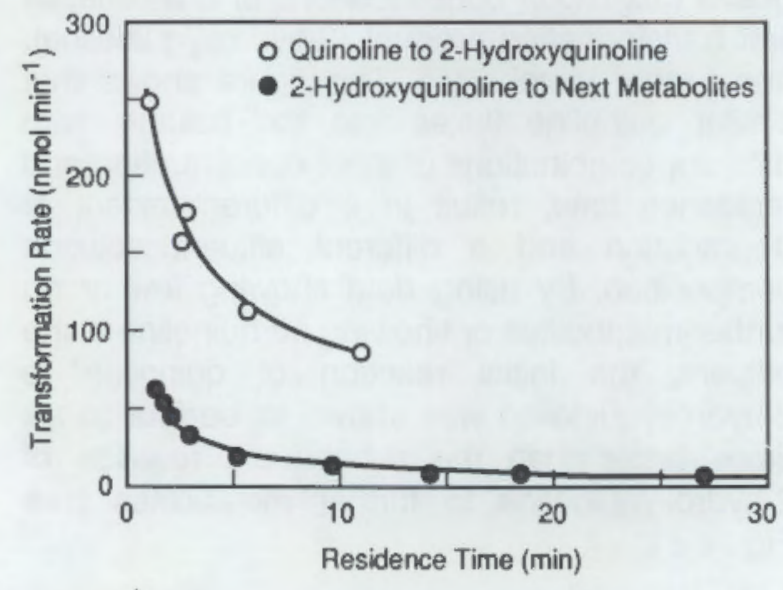

FIGURE 6. Comparison of the Rates of the First and Subeequent Transformation Reactions of Quinoline as a Function of Reaidence Tlme

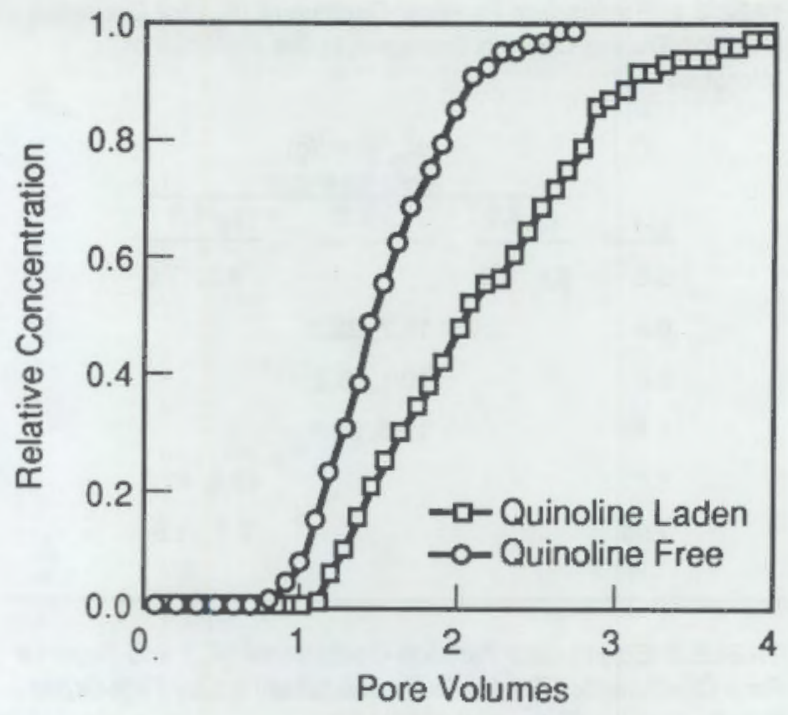

FIGURE 7. Breakthrough Curves of a Pulse Injection of Quinoline into a One-Dimensional Column

1-cm-long glass bead column. Because the breakthrough curve of the quinoline-laden solution is shifted to the right of where a curve for a nonsorbing tracer should occur implies that there may be sorption to biomass occurring in the column.

\section{One-Dimenslonal Transport with Sorption and Blodegradation}

One-dimensional transport experiments were performed in columns packed with model porous media (i.e., clay-coated alumina particles) and inoculated with quinoline-degrading bacteria. The objectives of these experiments are to identify and quantify important synergistic interactions between sorption and degradation during transport, as well as the conditions under which they are expected to occur. The procedures for clay coating and column inoculation are as described in the above methodology section. The $1-\mathrm{cm}$-long column used for these experiments was the same as that used for the transport with biodegradation experiments. Based on the results of the column biodegradation experiments, a solute residence time of 2 min was chosen so that the effluent solution would contain measurable amounts of both quinoline and 2-hydroxyquinoline (approximately 50\% each). This residence time was sufficiently fast that sorption of quinoline to the solid mineral surface did not occur according to equilibrium partitioning during solute breakthrough. 
The results of this experiment are reported in Figure 8, which shows the breakthrough of quinoline and 2-hydroxyquinoline in the column effluent. For mass balance purposes, Figure 8 also shows the sum of these two curves and a hypothetical piston flow breakthrough curve of quinoline if it were unaffected by the transport column. Comparison of the areas under the summed curve and the hypothetical curve indicate that only $6 \%$ of the quinoline input is unaccounted for by the two measured breakthrough curves. (This $6 \%$ was either transformed to further metabolites or remained sorbed in the column.) The small lag in the quinoline breakthrough from 1 pore volume indicates that the column was in a net adsorption phase of sorption nonequilibrium. The calculated quinoline consumption rate for this column experiment is approximately equal to that for the degradation-only column experiment with similar input concentration and residence time, indicating that sorption did not affect degradation rate in this case. This is to be expected because in this netadsorption phase situation, a large fraction of quinoline remains unsorbed and in solution, and therefore available for biodegradation just as in the column with no sorbent. Additional experiments are planned where the sorption nonequilibrium will be in a net-desorption phase. In this latter case,

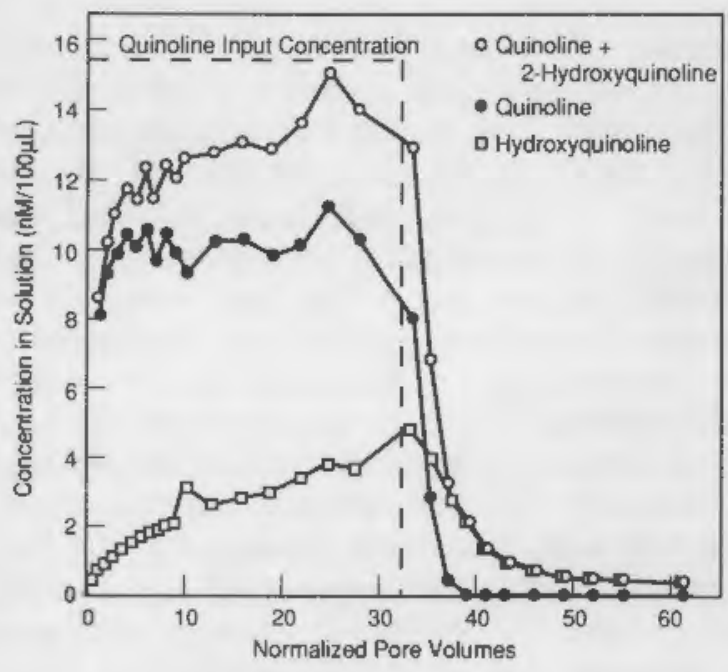

FIGURE 8. Breakthrough Curves for Quinoline and 2-Hydroxyquinoline in Columne with Sorption and Biodegradation the biodegradation rate may ultimately be controlled by the rate of desorption of quinoline from the solid surface.

\section{Multidimensional Tracer Transport In Layered Porous Media}

Before intermediate-scale experiments can be performed with chemically and microbiologically reactive contaminants, the flow and transport physics of the spatially heterogeneous (layered) porous media systems must be understood. To date, inorganic tracer $\left(\mathrm{CaCl}_{2}\right)$ transport experiments have been conducted in a layered multidimensional flow cell. The objectives of these experiments are to determine 1) the mechanism of interlayer transfer of solutes (molecular diffusion or transverse dispersion), and 2) the effect of largescale physical kinetics (i.e., slow diffusion of solutes into and out of lower permeability layers) in spatially averaged "effective" descriptions of the intermediate-scale transport.

Figure 9 is a schematic representation of the flow cell and associated operating equipment. The cell measures $1 \mathrm{~m}$ in length, $20 \mathrm{~cm}$ in height, and $10 \mathrm{~cm}$ in cross-sectional width. Two model porous media (alumina particles with different size distributions) were packed into the flow cell such that a horizontal, higher-permeability layer of $2-\mathrm{cm}$ thickness existed in the center of the cell. Tracer solution was pumped uniformly into the saturated cell over the entire vertical cross-sectional area of one end. Solution samples of small volume were extracted from numerous horizontal and vertical locations within the cell and analyzed for tracer with an in-line electrical conductivity meter. Mixed solution at the outflow end was also similarly analyzed.

Figure $10 \mathrm{a}$ and $\mathrm{b}$ presents tracer breakthrough curves at different vertical locations (i.e., different distances from the central, higher permeability layer) for two horizontal locations. At $20 \mathrm{~cm}$ from the input location (Figure 10a), breakthrough at both the 10-cm height (within the higher permeability layer) and the $6-\mathrm{cm}$ height (within the lower permeability layer) appears to be proceeding according to advective-dispersive transport that is unaffected by the presence of the other layer. 


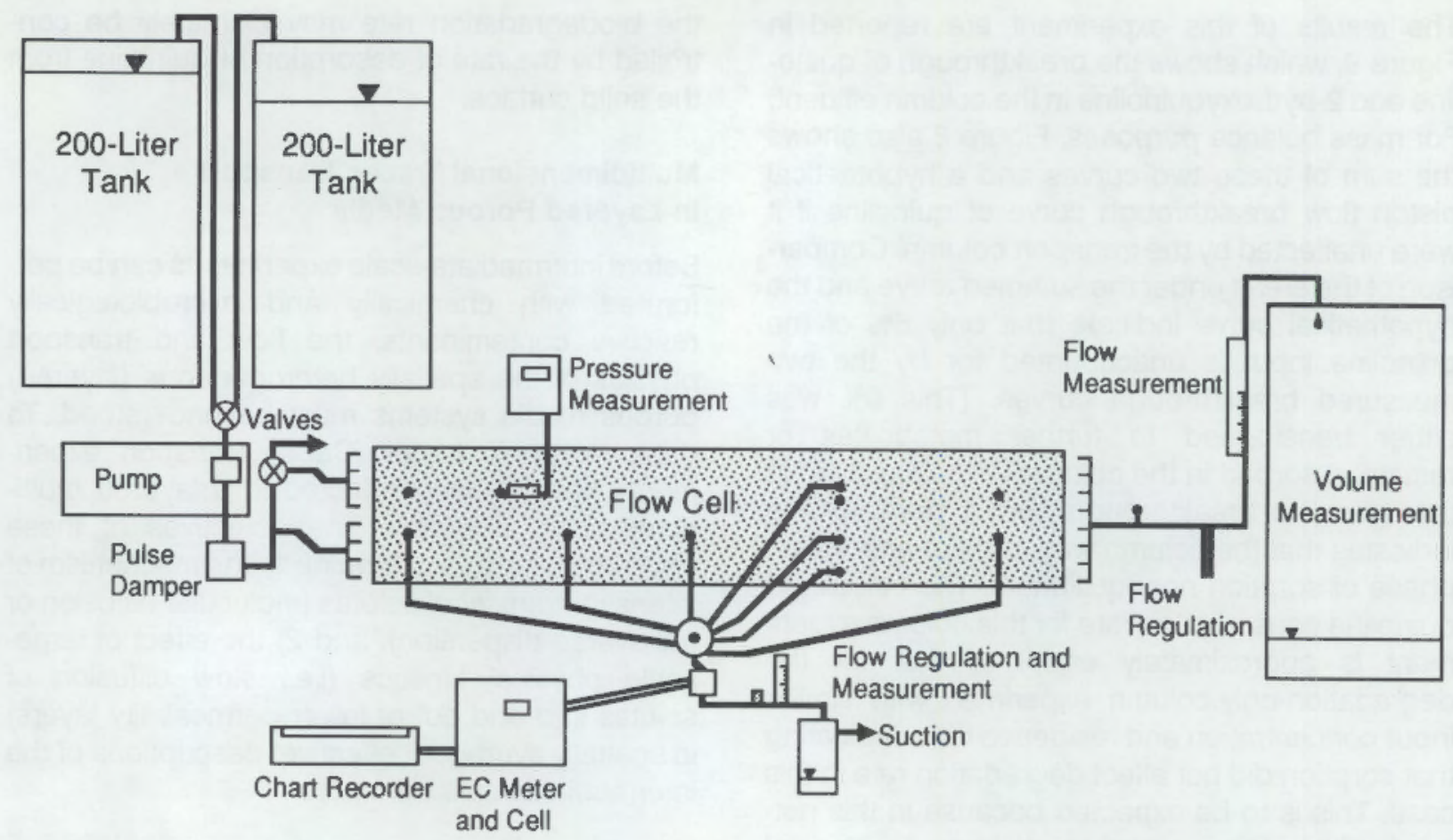

FIGURE 9. Multidimensional Flow Cell and Associated Experimental Apparatus

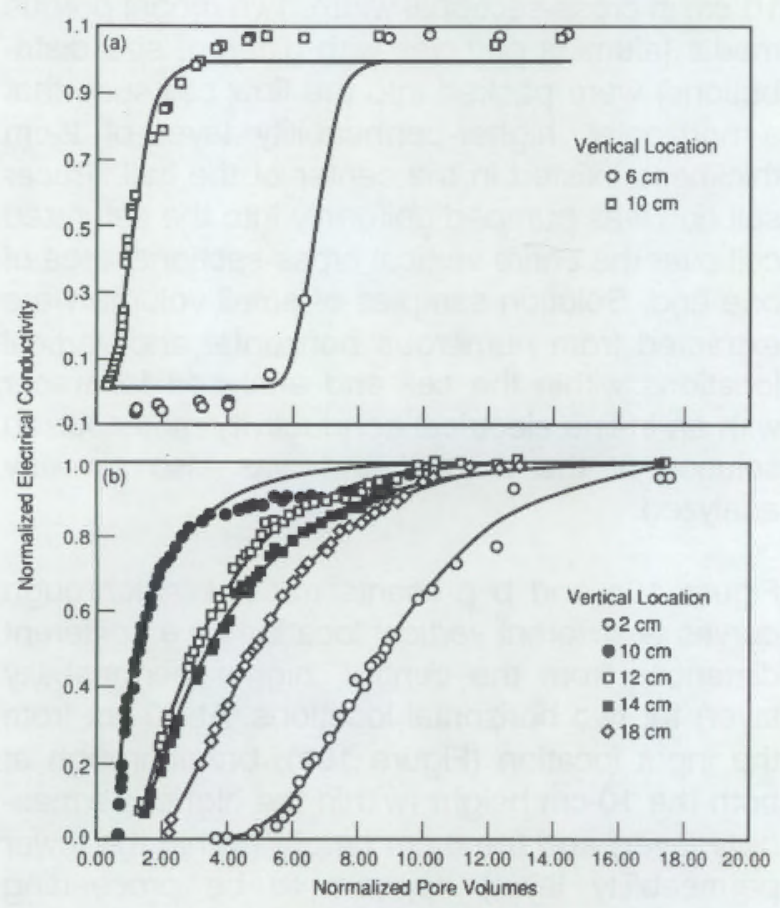

FIGUAE 10. Tracer Breakthrough (measured by electrical conductivity of effluent solution) at Various Horizontal and Vertical Locations in the Layered Multidimensional Flow Cell. Data and model curve fits are shown for breakthrough at a) $20-\mathrm{cm}$ and b) $70-\mathrm{cm}$ horizontal distance from the inlet.
Dispersion, indicated by the slope of the breakthrough, is relatively low in both cases. At $70 \mathrm{~cm}$ from the input location (Figure 10b), breakthrough at the 10-cm height (within the higher permeability layer) still exhibits a sharp front. However, in contrast, breakthrough at heights removed from the central layer now shows a more gradually sloping front. This occurs because, at this later time in the plume migration, the interlayer transfer of tracer progresses sufficiently to effect the response at the sampling ports in the lower permeability regions. Figure $10 \mathrm{a}$ and $\mathrm{b}$ also shows effective one-dimensional transport model fits to the breakthrough curves. Effective dispersion coefficients fitted by these simple models are such that the "apparent" dispersion increases with time (or distance). This scale effect in apparent dispersion has been commonly observed in the field (which is spatially heterogeneous) and similarly documented in previous controlled laboratory experiments. Further spatially averaged modeling of these data was done by assuming that the interlayer transfer (an inherent multidimensional transport process) could be approximated by an effective one-dimensional, two-region transport model with large-scale, physical-kinetic control. 
Values of the effective, two-region mass transfer coefficient obtained by fitting the spatially averaged model to data coincided closely with values predicted from a more accurate (yet still simplified) two-dimensional model of the interlayer transfer process. Future mathematical analysis of these will use fully multidimensional transport models that incorporate mechanistic process descriptions and explicitly account for the layering geometry.

\section{University Research Collaboration}

Cooperative research, funded by $\mathrm{PNL}$, is being conducted with A. J. Valocchi and B. E. Rittmann of the University of Illinois. These university researchers are working jointly with PNL staff to develop a multidimensional modeling capability for analyzing intermediate-scale experiments investigating chemically and microbiologically reactive organic solute transport in heterogeneous porous media systems. Initial modeling work consists of modeling the two-dimensional tracer transport experiments described above. Future model development will include incorporating the ability to describe kinetically controlled organic solute sorption by ion exchange, microbial degradation by biofilms or microcolonies, and synergistic sorption/degradation interactions. These model augmentations will be guided by the results of reactive transport experiments conducted at PNL.

\section{Subsurface Flow Physics of Immiscible Organic Liquids}

\section{S. Simmons, J. F. McBride, J. W. Cary, and R. J. Lenhard}

High concentrations of chlorinated hydrocarbons with low solubility have been found dissolved in groundwaters beneath DOE sites. The sources of contamination are probably such organic liquids held in the vadose zone within waste burial sites. Basic scientific information about how immiscible organic liquids behave in the subsurface environment is needed to help control and remediate contamination problems. Models that can predict the movement of organic chemicals in the subsurface are needed to implement effective cleanup strategies. Therefore, this project is performing intermediate-scale laboratory experiments to understand the physical mechanisms that govern multiphase flow of immiscible organic liquids in subsurface porous media. The intermediate-scale experiments on organic liquid flow emphasize natural three-dimensional behavior. Improved multiphase flow and transport models are expected to result from this research.

In this project, we are studying how well multiphase flow theory, as based on a continuum conceptualization of flow in conjunction with Darcy's law, accurately predicts organic liquid migration in the subsurface. Migration of an organic immiscible liquid (oil) in the vadose zone involves complicated coupled simultaneous flows of air, water, and nonaqueous oil phases governed by capillary forces in porous media. The capillary forces cause both retention and movernent of all fluids in a porous medium. To model multiphase immiscible flows, it is necessary to discover the constitutive relations that comprise the basic parameters controlling flow. The constitutive relations consist of retention relations expressing the functional connection between fluid saturations and capillary pressures and the permeability equations for each fluid involved. This research emphasizes deriving these constitutive relations by using mainly basic physical parameters such as interfacial tension and viscosity of the particular fluids.

A central scientific hypothesis being tested is called fluid-media scaling. The mathematical statement for this hypothesis describes how to construct three-phase flow constitutive relations from just the retention and permeability equations for air and water in a specific porous medium. Homogeneous sands and glass beads are used as simple test media, for instance. To test constitutive relations, the associated equations must be incorporated into a multiphase flow computer code and simulation results compared with observed experimental behavior. A problem for this research is how to deal with the influences of natural subsurface heterogeneity. Thus, other experiments are aimed at studying multiphase flow behavior in heterogeneous media. An associated work objective is to help develop computer models that better account for subsurface heterogeneity.

\section{Intermediate-Scale Experiments}

Many three-dimensional box experiments that provide visual documentation of the flow behavior of organic liquids infiltrating unsaturated porous media were performed this year. These experiments provided data on water and organic liquid 
saturation distributions that are used to test the predictive accuracy of multiphase flow theory.

In the experiments, an example organic immiscible liquid (oil) infiltrates from a nearby point source (1.5-cm-diameter ring) into a box filled with moist (water unsaturated) sand or glass beads. A diagram of the general experimental setup was given in last year's annual report (Simmons et al. 1989). The side of the boxes are about $24 \mathrm{~cm}$. To minimize boundary effects, experiments are performed so that the infiltrated quantity of oil $(500 \mathrm{ml})$ does not reach the side walls. The oils selected for study, based on contrast in their viscosity and interfacial tension, are Soltrol-220 ${ }^{\circledR}$, mineral oil and a transmission fluid. Oil viscosities relative to water are $4.7,77$, and 71 , respectively. Interfacial tensions with air are 26, 31, and 31 dynes $/ \mathrm{cm}$, respectively. Density for these oils ranges from 0.8 to $0.85 \mathrm{gm} / \mathrm{ml}$ relative to unity for water. The spreading coefficient, which is the difference between the air-water and the sum of the air-oil and oil-water interfacial tensions, measures the tendency of an oil to spontaneously spread as a film over a water surface. Selected oils span the range of spreading coefficient.

Transmission fluid, with a positive spreading coefficient (24), tends to spread strongly over a water surface, whereas mineral oil with a negative coefficient $(-16)$ tends to form oil droplets and not spread on water. Soltrol-220 has a coefficient nearly equal to zero after contaminating the liquid (water) interface. Organic components of Soltrol that eventually reduce the oil-water interfacial tension after prolonged contact cause it to exhibit spreading as well. McBride et al. (1989) explain how a positive spreading coefficient is associated with a spreading pressure that causes an oil to spontaneously spread over an exposed air-water interface within a porous medium.

Although transmission fluid and mineral oil have nearly the same viscosity, they behave quite differently during infiltration into moist sand or glass beads. The visualization experiments showed that transmission fluid infiltrated uniformly

(4) Soltrol-220 is a registered trademark of Phillips Petroleum Company, Bartlesville, Oklahoma.
(Figure 1), whereas mineral oil displayed unusual channeling behavior (Figure 2). We hypothesize that the channeling behavior is caused by mineral oil's negative spreading coefficient. For oils with a

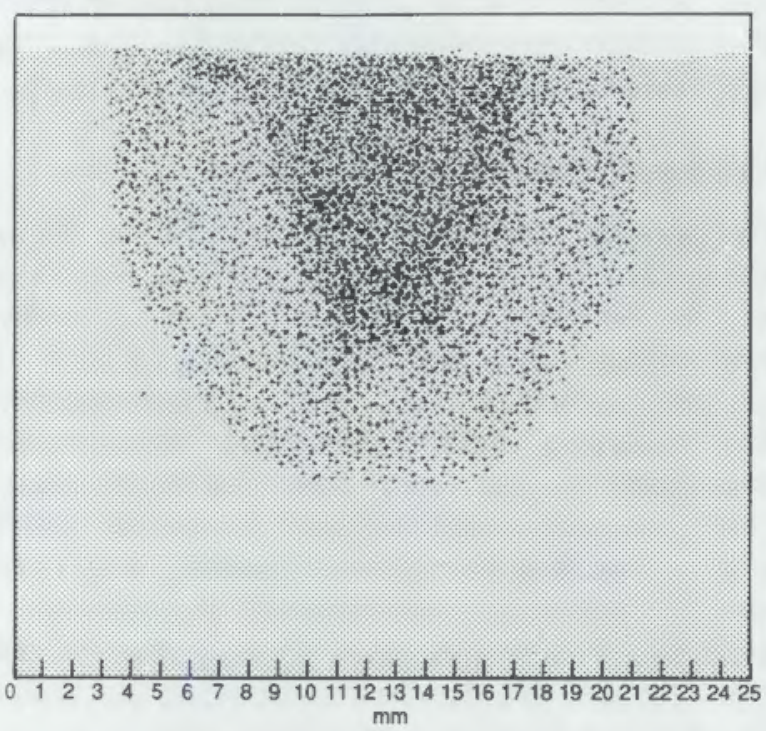

FIGURE 1. Transmission Fluid Plume Observed in Glass Beads at the Central Plane

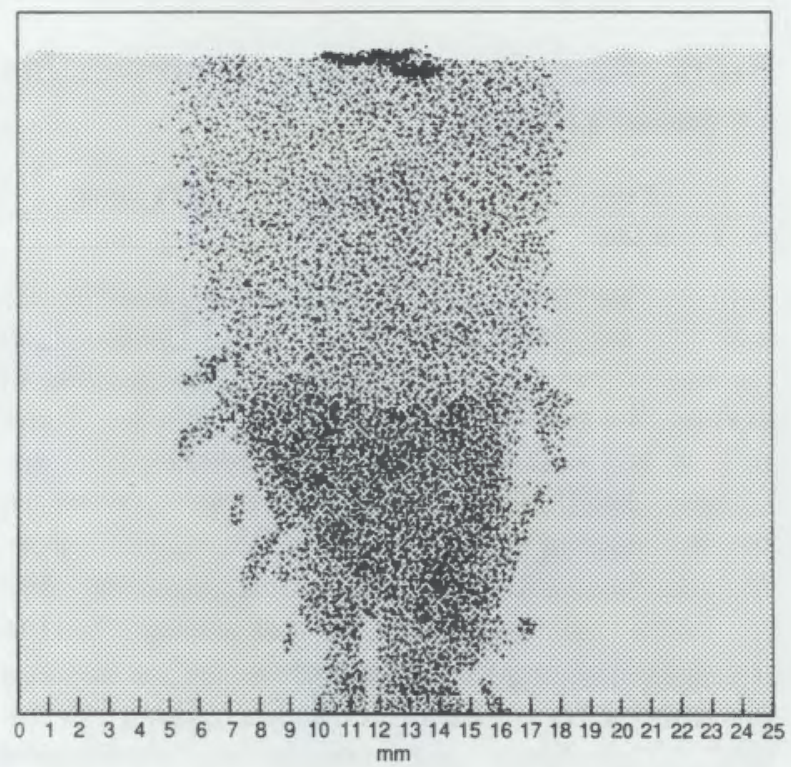

FIGURE 2. Mineral Oil Plume Observed in Glass Beads at the Central Plane 
positive or zero spreading coefficient, the oil spreads through the pore space evenly. As oil infiltrates a region, water is expelled, and this process further enhances conduction of oil into the increasing available pore space volume. Measurements of water and oil contents obtained from core samples confirmed the predicted regular flow behavior of Soltrol, transmission fluid, and water in porous media. However, modeling could not predict the channeling behavior of mineral oil. The unique data obtained this year consist of photographs of oil distributions exposed on the surface of vertical cross sections and core measurements of liquid contents taken on two perpendicular vertical central planes. The data are adequate to reconstruct the three-dimensional shape patterns. An assay method using porous polyethylene strips to absorb oil directly from slurried core samples was used to measure oil contents. This assay method, which could easily be applied in the field, is described in Cary et al. (1990).

Measured distributions of Soltrol and transmission fluid in water-wet sand are shown in Figures $3 a$ and $4 \mathrm{a}$. Corresponding water content distributions are shown in Figures $3 \mathrm{~b}$ and $4 \mathrm{~b}$. In these examples, the least water is displaced or expelled by the Soltrol, which has relatively low viscosity and flows rapidly compared to the other two oils. However, transmission fluid displaced a considerable amount of water from the profile, as shown in Figure $4 \mathrm{~b}$. The average initial water content of 0.07 was reduced to nearly zero in the region of the oil plume. The Soltrol plume also exhibited sinking into the profile before the core samples could be collected immediately affer complete infiltration. Transmission fluid, being much more viscous, remained near the profile surface. Mineral oil, although the visual pattern of infiltration was entirely different because of channeling, also displaced water substantially, but less than transmission fluid. Thus, oils with positive or negative spreading coefficient cause displacement of water but possibly for different physical reasons. Soltrol, being least viscous, apparently moves rapidly into the porous medium before water has time to be displaced. Transmission fluid and mineral oil with high viscosity move slowly and allow sufficient time for water to be expelled by capillary pressure differences connected with the interfacial tension change within the plume region.
Electro-optical organic liquid sensor probes were used to track the front advance of Soltrol in the sand. Cary et al. (1989a) describe design and operation of these probes. The oil arrival time was measured for various depths (Figure 5 ) by using a line of probes spaced at 3-cm-depth increments. The front advance was also simulated as shown in Figure 5. The discrepancy is partly caused by delayed response time of the probes.
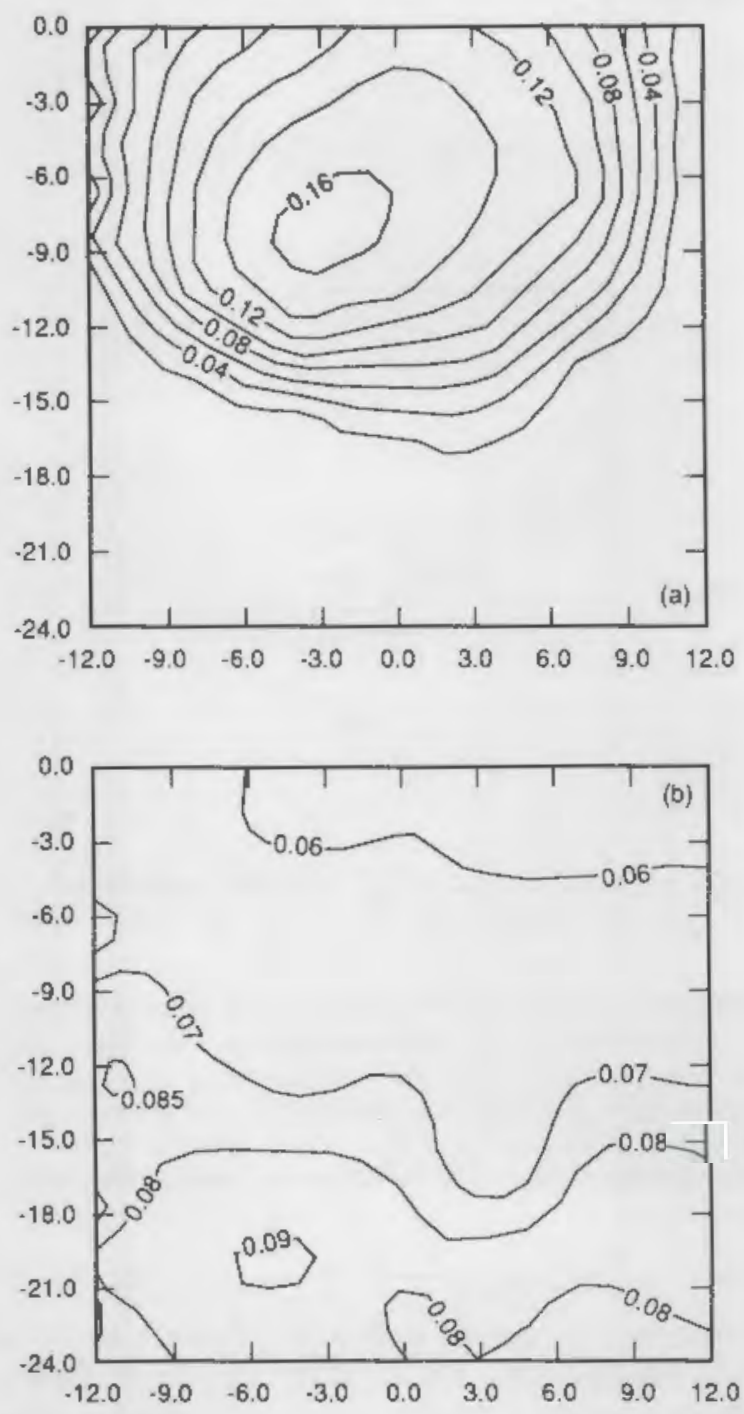

FIGURE 3. Soltrol-220 Infiltration in Water-Wet Sand a) Volume Soltrol-200 Content and b) Volume Water Content. Highest Soltrol-220 content is approximately at $8-\mathrm{cm}$ depth, indicating redistribution has occurred by the time of sampling. Water contents are fairly uniform in the horizontal direction. 

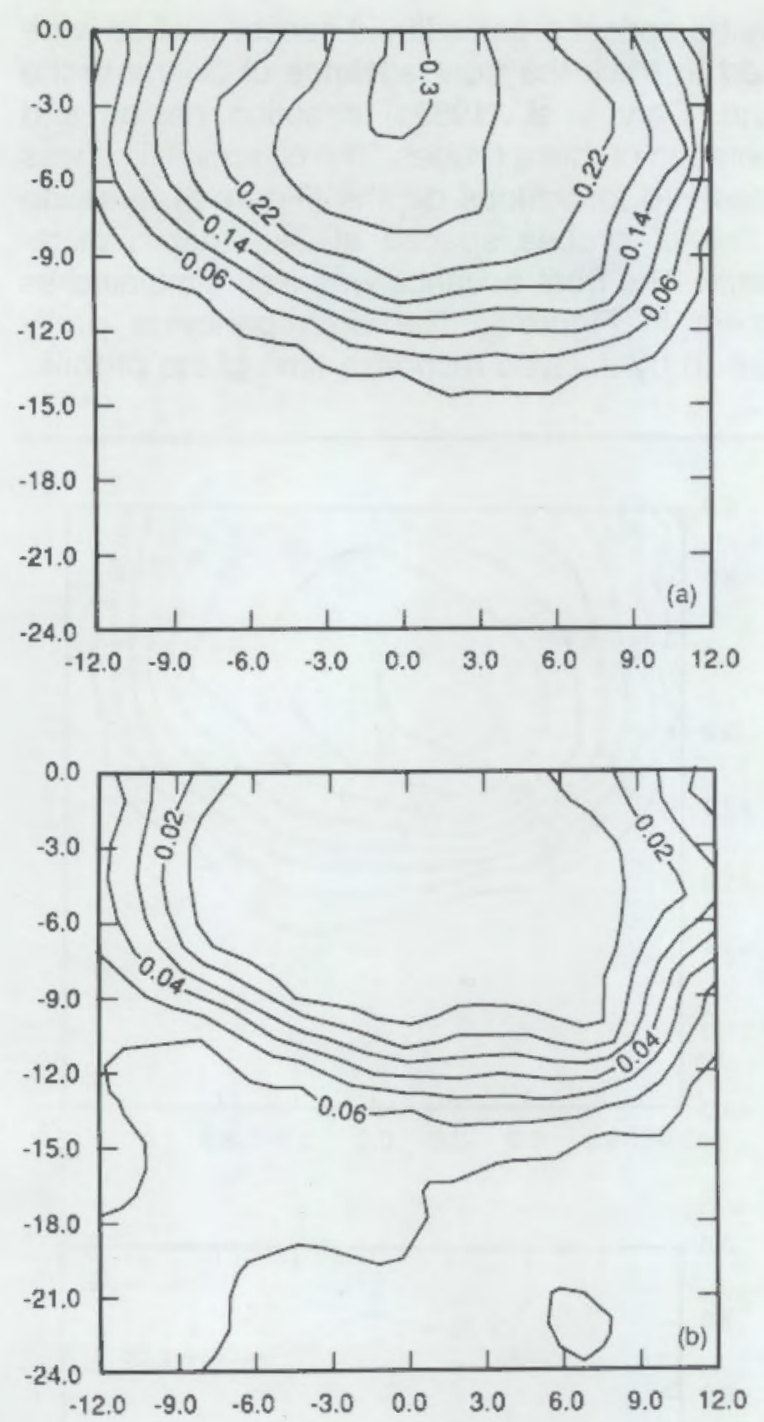

FIGURE 4. Transmission Fluid Infiltration in Water-Wet Sand a) Volume Transmission Fluid Content and b) Volume Water Content. Greatest transmission fluid content is near the point source, indicating very little redistribution before destructive sampling. Water content contour plot reveals that water has been greatly displaced by the advancing transmission fluid front.

However, the curves in Figure 5 have a classical time dependence for advance of a front. Similar efforts to track a mineral oil front failed because of erratic channeling.

\section{Simulations}

Through collaboration with Virginia Polytechnic Institute (VPI) modelers, a three-phase flow code in radial coordinates was made available to PNL

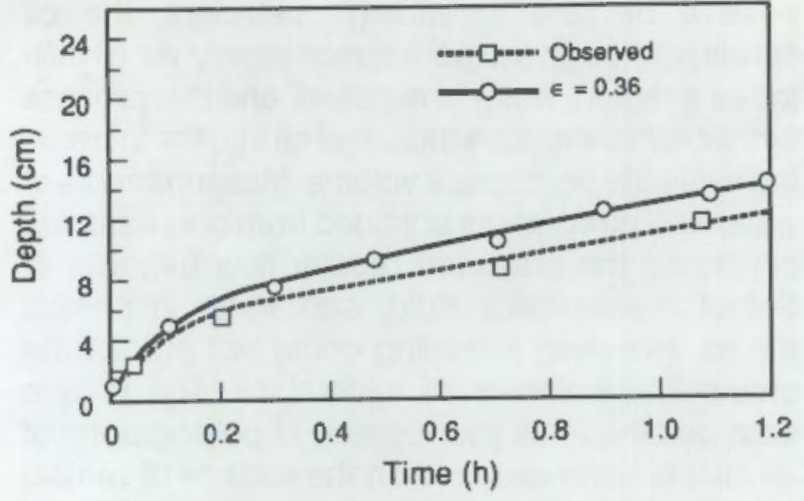

FIGURE 5. Soltrol-220 Infiltration in Water-Wet Sand. Advance of the Soltrol-220 front along the vertical axis as indicated by the electro-optic sensors compared to that predicted by numerical simulation. Discrepancy is in part caused by the fact that the sensor indicates arrival some time after the actual arrival of the organic liquid front. Because of channeling, similar electro-optic sensor data for mineral oil infiltration cannot be interpreted.

to perform simulations of the box infiltration experiments. Part of the code's development was accomplished through OHER funding provided by PNL. Formation of the code is described by Kaluarachchi and Parker (1989). Constitutive relations used in the code called MOFHYS are based on fluid-media scaling as required to test the theory. A simulation of Soltrol distribution following infiltration is shown in Figure 6. Downward movement of the plume's peak is indicated during the $20 \mathrm{~min}$ required to obtain oil content measurements after infiltration ceased. A similar delay time was included in the simulation. Although the actual and simulated infiltration times differ substantially, the predicted development of the Soltrol distribution is like that measured in Figure $3 a$. We believe that the independently determined parameters used in the simulation do not accurately reflect those effectively controlling flow in the experiment. In particular, the saturated conductivity of water in the sand-packed box may be much larger than the $60 \mathrm{~cm} / \mathrm{h}$ value used in the simulations. Also, the measured Soltrol plume is more irregular than the perfectly symmetrical one predicted in an ideally uniform sand pack. Still the ability of the code to predict the distribution of an oil with nearly zero spreading coefficient appears reasonable. However, because of mass balance errors for the oils with spreading coefficient substantially different from zero, the accuracy of simulations is still 


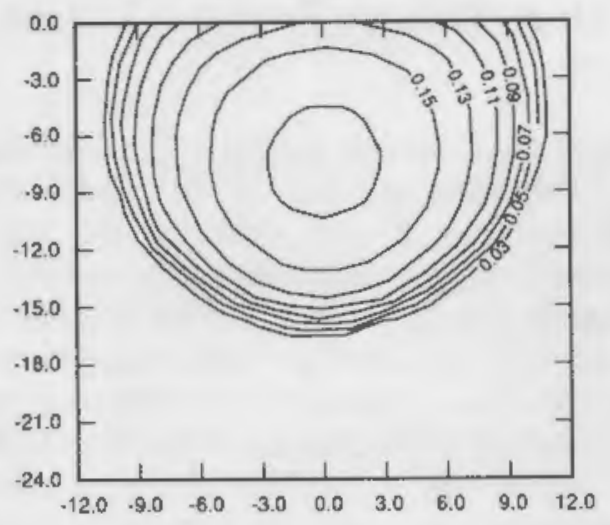

FIGURE 6. Soltrol-220 infiltration in Water-Wet Sand. Numerical simulation was performed by using independently measured fluid and porous media properties. Predicted and observed infiltration time do not agree. Estimate of Soltrol220 content distributions at an equivalent sampling time after infiltration is, however, similar to that observed.

uncertain. The data indicate further numerical refinements of the code are needed to reproduce the experimental results. Future work will also focus on whether the constitutive relations and parameters are correct.

\section{Column Experiments}

Work continued on improving a simplified onedimensional three-phase flow model that is used to evaluate column experiments (Cary et al. $1989 \mathrm{~b})$. The model is used to test how constitutive relations should be mathematically formulated. The capillary conductivity model included in the flow model was extended to account for the case when water infiltrates through an oil-wetted porous medium. Previous column experiments showed that water infiltrated through an oil-wetted medium more rapidly than predicted because of the assumption in the simulation that water always fills the smaller, less permeable pores first. The capillary conductivity model was modified to allow partial reversal of the wetting order assumption (i.e., oil may stay in some of the smaller pores without being displaced by water). This causes water to flow more rapidly in larger unfilled pores. Spreading pressure associated with positive or zero spreading coefficient oils was also included as a possible mechanism for increasing the oil infiltration rate into a moist porous medium. Some column experiments gave unexplained more rapid imbibition of oil. The tendency of certain oils to spread on water because of spreading pressure is being studied as a possible explanation.

Because water infiltrated an air-dry sand more slowly than predicted, a conductivity weighting procedure was implemented in the flow model to simulate a "Haines" jump-like phenomenon. When wetting front advance is modeled using a difference code, it is necessary to define how conductivity should be weighted between the nodes where liquid contents are calculated. Generally, conductivity for the flow between nodes is defined in terms of some average value or perhaps an upstream value. This model modification is inspired instead by the physics involved in the "Haines" jump phenomenon for which a liquid advances sporadically into a dry medium only as the liquid content at the wetting front reaches a critical limit. The weighting causes a front to advance slower and be sharper in a sand. This modification is expected to be especially important when modeling flow through layered porous media.

The effectiveness of these model modifications in better describing sequential oil and water infiltration/redistribution in the column experiments is still uncertain.

Cooperative research with VPI and State University partly supported by PNL led to a publication describing how hysteresis can be modeled (Lenhard et al. 1989). A unique hysteresis model for three-phase flows was incorporated in the MOFHYS code provided by VPI. Processes of entrapment of air and nonaqueous phase liquid (NAPL) by water and of air by NAPL are included in the model. When fluid entrapment effects are included, simulation results show that a significant portion of total NAPL may become entrapped below a raised water table. Entrapped, immobile ganglia of NAPL become sources from which contaminant components (e.g., benzene, toluene) dissolve into the aqueous phase to be transported away by groundwater flow. Thus, fluid entrapment effects are important to account for in a contaminant transport model. The implications of hysteresis for multiphase flow in the subsurface will be part of future research.

Through the Northwest Organization for Colleges and Universities for Science (NORCUS) program 
for DOE-university outreach, this project has also supported a graduate student at Princeton University who is examining the process of dissolution of trichloroethylene (TCE). In that work, the rate of dissolution in groundwater of residual, entrapped TCE is being quantified and modeled. The constitutive equation for the concentration dependent dissolution process may eventually be incorporated in multiphase transport models needed by DOE.

\section{References}

Cary, J. W., J. F. McBride, and C. S. Simmons. 1989a. "Electro-Optic Detection of Liquid in Translucent Porous Material." Soil Sci. Soc. Am. J. 53:1591-1595.

Cary, J. W., C. S. Simmons, and J. F. McBride. 1989b. "Predicting Oil Infiltration and Redistribution in Unsaturated Soils." Soil Sci. Soc. Am. J. 53:335-342.

Cary, J. W., J. F. McBride, and C. S. Simmons. 1990. "Assay of Organic Contents in Predominantly Water-Wet Unconsolidated Porous Media." Journal of Contaminant Hydrology (in press).

Kaluarachchi, J. J., and J. C. Parker. 1989. 'An Efficient Finite Element Method for Modeling Multiphase Flow." Water Resour. Res. 25:43-54.

Lenhard, R. J., J. C. Parker, and J. J. Kaluarachchi. 1989. "Model for Hysteretic Constitutive Relations Governing Multiphase Flow 3. Refinements and Numerical Simulations." Water Resour. Res. 25:1727-1736.

McBride, J. F., J. W. Cary, and C. S. Simmons. 1989. "Direct Measurement of the Spreading Pressure of Organic Liquids on Water." Journal of Colloid and Interface Science 132:363-372.

Simmons, C. S., J. W. Cary, and J. F. McBride. 1989. "Subsurface Organic Fluid Flow." In Pacific Northwest Laboratory Annual Report for 1988 to the DOE Office of Energy Research: Part 2, Environmental Sciences. PNL-6800 Pt. 2, pp. 29-34, Pacific Northwest Laboratory, Richland, Washington.

\section{Subsurface Science Program Liaison}

\section{J. Wright}

The goal of the Liaison project is to provide scientific and logistical support to the Subsurface Science Program. It also provides the formal mechanism through which information relevant to the research program and DOE sites is collected, integrated, and evaluated for technology transfer and/or joint research potential and program relevance, and then disseminated to the appropriate parties. Additionally, it provides a unique opportunity to identify and facilitate a multidisciplinary approach for resolving hazardous waste-related basic research problems.

The Liaison activity provides a technical interface between the research activities of the Subsurface Science Program and the application of the research results to $D O E$ waste remediation efforts. This includes 1) assisting subprogram managers and scientists in focusing the goals of each subprogram to maintain a coherent direction among the subprograms; 2) organizing research workshops and information transfer meetings; 3) writing, editing, and publishing scientific documents, proceedings, and newsletters: 4) facilitating interactions with applied research groups, DOE sites, universities and industry; and 5) providing educational information on the issues of environmental restoration and the current progress of basic research and remediation efforts. Figure 1 illustrates the multidisciplinary relationship of the Liaison as a connective link between the four major areas of Subsurface Science Program basic research, involving eight subprograms, and the contaminated DOE sites.

The immediate project activities include the following meetings, workshops, and publications. A series of subprogram meetings will develop the goals for FY 1990-1995 and produce a draft document. These meetings are scheduled as follows: 1) Deep Microbiology Transition Program, September 24-27, 1989; 2) Multiphase Fluid Flow, November 9-10, 1989; 3) Multicomponent Predictive Models/Expert Systems, November 13-14, 


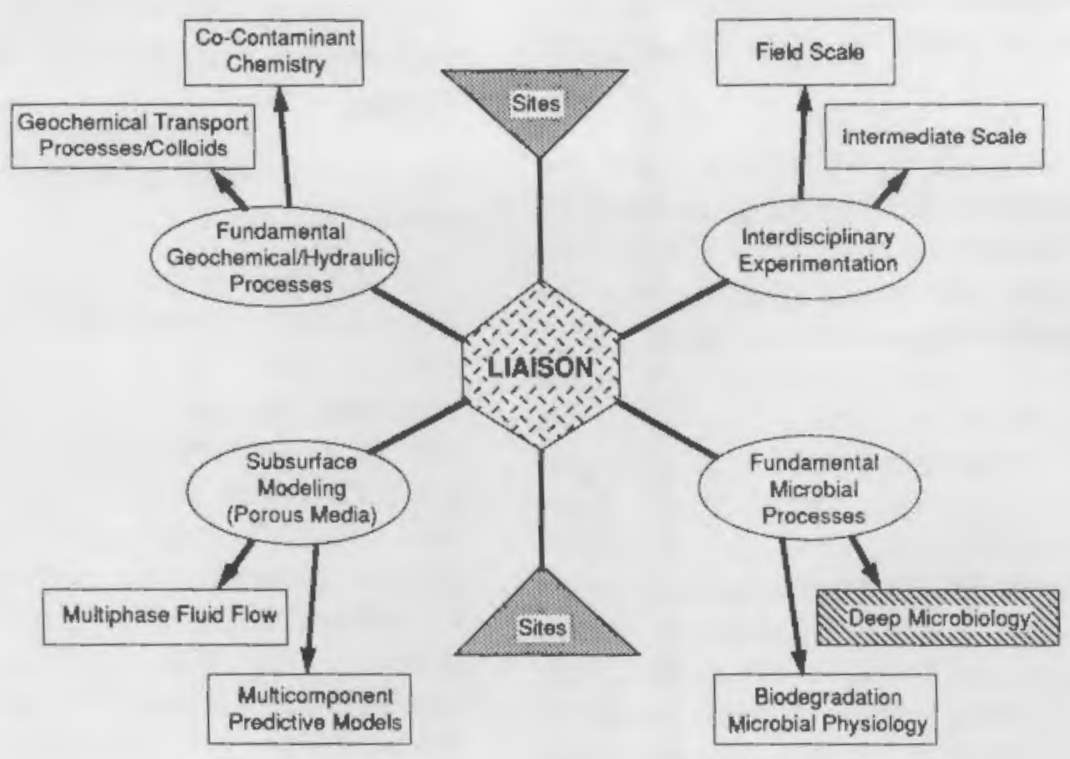

FIGURE 1. Interaction of Liaison Between Basic Research and DOE Sites

1989; 4) Colloids, November 29-December 1 , 1989; 5) Biodegradation, December 5-6, 1989; 6) Co-Contaminants, December 7-8, 1989; 7) intermediate Scale, December 11-12, 1989. A subprogram coordinators meeting scheduled for January 28-31, 1990, will provide guidance to the program manager on progress within each subprogram, and the goals and direction of the basic research activities of each project. This can be used at the program level to develop strategies for future programmatic goals and funding needs. At the Subsurface Science Program Biannual Meeting, March 5-8, 1990, technical reports will be given by the principal investigators from each project. This meeting will provide an additional opportunity for interaction among the research investigators and indicate areas where collaborative projects will be advantageous to the basic research needs of the program. Because the annual meeting is open, representatives from other federal agencies, industry, and universities will be able to learn about the results of basic research in a timely manner, and provide input from their experiences at contaminated sites that is useful in formulating experimental objectives.

Technical meetings provide a mechanism for the Liaison to interact with scientists involved in basic areas relevant to the goals and needs of the
Subsurface Science Program and to target possible collaborative endeavors for the program manager. Meetings scheduled for this year include: American Chemical Society Pacific Chemistry Meetings, December 17-22, 1989; Deep Microbiology International Meeting, January 14-18, 1990; and V. M. Goldschmidt Conference on Geochemistry, May 2-4, 1990.

Workshops will be held in several areas to obtain information from government, industry, and private consultants on the status of current remediation practices and endeavors that will be invaluable in understanding natural systems and the successes and failures of present remediation practices. The following case-history workshops are scheduled for FY 1990: Geostatistics, February 1990; Intermediate Scale Workshop, April 24-26, 1990; Bioremediation, May 23-25, 1990; Chemical Remediation, August 1990. The Liaison project will also assist as needed in developing a seminar series at PNL in four areas: Microbiology/Remediation, Deep Microbiology/Transition Program and Sampling, Multiphase Fluid Flow/Thermal Effects, and Multiphase Fluid Flow/Modeling. These seminar series will bring in three to four speakers in each area for general interest and information. The resources of the Liaison are available for implementation of workshops and seminar series at all 
locations of Subsurface Science Program research projects subject to guidance from the program manager.

Publications scheduled for FY 1990 include the following. A Subsurface Science Program Abstract Volume will be published in November 1989, which contains the scope and overall objectives of the Subsurface Science Program and subprograms. A complete review of in situ remediation technologies in FY 1990 will be published. This review will be used to develop workshops and to provide guidance on research strategies and issues of importance that have already been recognized in field situations. An extended proceedings volume of results reported at the Annual Meeting in March will be released to the public in May 1990. This proceedings will make results of basic research and access to scientists involved in different areas of research available to interested persons. Publication of Subsurface Microbiology News and Information will begin with the Winter Quality Edition in December 1989.

Other activities include arranging for DOE site visits to discuss specific characteristics of contaminants, soils, and sediments, as well as water flow and aquifer chemistry for each site, and to obtain soil and rock samples for use in basic research projects.

This project will assist in achieving the Subsurface Science Program goal of early and continued transfer of needed data and technology with the DOE sites, and will ensure that proven technologies and verified data and models emerge at the conclusion of the program for use by DOE and others in their hazardous waste management efforts. The project will provide a communication network between basic research projects to applied research, DOE sites, other federal agencies, universities, and industry. The Liaison activities will facilitate and expedite effective transfer of ideas, information, skills, and technology for the development of remediation activities at waste sites.

\section{Estimating Steady-State Diffusive and Advective Fluxes from Different Soil Types}

\author{
P. C. Owczarski, D. J. Holford, H. D. Freeman, \\ and G. W. Gee
}

The objective of this computer modeling study, which is part of the Radon Transport Modeling in Soils Project, is to calculate the effects of changing soil parameters (porosity, permeability, and water content) and soil pressure gradients on the surface flux of radon from five homogeneous soils (clay, silt, loam, sand, and gravel). The flux data on these effects could be used as a baseline for comparison with fluxes generated from heterogeneous soils. Also, these data are suitable for estimating soil fluxes from various soil types over the whole range of soil water content.

Radon flux was calculated using Rn3D, a threedimensional finite element code developed by Holford et al. (1988, 1989) at the New Mexico Institute of Mining and Technology (under contract DE-FG04-86ER60432) and at PNL. The code simulates the transport of radon gas within and from unsaturated soils. Rn3D accounts for radon diffusion in the air-filled and water-filled pore space, radon advection in air-filled pore space, radon solubility in water, and Knudsen diffusion in capillaries. The emanation coefficient (e) has the following dependence on saturation (s): for $s$ between 0 and 0.2 , e exhibits a linear dependence, $e=0.1+1.5 \mathrm{~s}$; while above $s=0.2$, $e$ is constant at $e=0.4$. This simple representation approximates the observed behavior of the emanation coefficient in many soils.

The study system is a hypothetical, onedimensional soil column $10 \mathrm{~m}$ deep filled with homogeneous $20^{\circ} \mathrm{C}$ soil of one of the five types. The baseline atmospheric pressure was $1.013 \mathrm{x}$ $10^{5} \mathrm{~Pa}$, and ${ }^{226} \mathrm{Ra}$ activity was $110 \mathrm{~Bq} / \mathrm{kg}$. The soil surface $(z=0)$ was assumed to always have a zero radon concentration $(C=0)$; the soil pressure $(p)$ was uniform over the 10-m depth in the 
absence of applied pressure gradients and transients, and the concentration gradient at the 10-m depth was zero. In this simple system, the surface fluxes of ${ }^{222} \mathrm{Rn}$ were calculated for the following two options: 1) steady-state diffusion only $(\mathrm{dp} / \mathrm{dz}=0)$ and 2) steady-state diffusion plus advection ( $d p / d z=a$ constant not equal to 0 ).

\section{Steady-State Diffusion}

Molecular diffusion of radon is always occurring in both the aqueous and gas phases in the soil. If diffusion is the only active process in the soil, then a baseline concentration profile is established in the soil along with a baseline radon flux at the soil surface. Any transient or steady pressure gradients in the soil cause perturbations in the concentration profile and the corresponding surface flux. The steady-state diffusive fluxes for each soil over the entire range of saturations are plotted in Figure 1. This figure shows that water content can mask the differences in soil type and is, therefore, a very important parameter in understanding radon transport in soils.

\section{Steady-State Diffusion with Advection}

A constant pressure gradient was applied on the soil column in the $z$ direction, so it enhanced the surface flux. A steady pressure gradient, caused by the stack effect, is typical around buildings during the heating season. Pressure differentials from the stack effect can easily range from 0 to $10 \mathrm{~Pa}$. As a starting point, a pressure of $5 \mathrm{~Pa}$ was distributed over the $10-\mathrm{m}$ column giving a pressure gradient of $-0.5 \mathrm{~Pa} / \mathrm{m}$. This gradient was applied to each soil type over a range of saturations from $0 \%$ to $98 \%$. The percent enhancement of surface flux above diffusion caused by advection is plotted in Figure 2.

\section{Estimating Soil Radon Fluxes}

To use Figures 1 and 2 quantitatively to estimate diffusive and advective radon surface fluxes, one must have some knowledge of the soil in question. The minimum requirements include knowledge of the soil classification (i.e., clay, silt, loam, sand, or gravel), ${ }^{226} \mathrm{Ra}$ activity, and water content. With these, Figure 1 values can be used directly to estimate a diffusive flux. This estimated flux would equal the value in Figure 1 times the soil ${ }^{226} \mathrm{Ra}$ activity in $\mathrm{Bq} / \mathrm{kg} / 110$.

To estimate the advective enhancement of surface diffusive flux, one must have an estimate of the pressure gradient on the soil column. Figure 2 advective enhancements are for a gradient of $-0.5 \mathrm{~Pa} / \mathrm{m}$ (surface pressure lower than

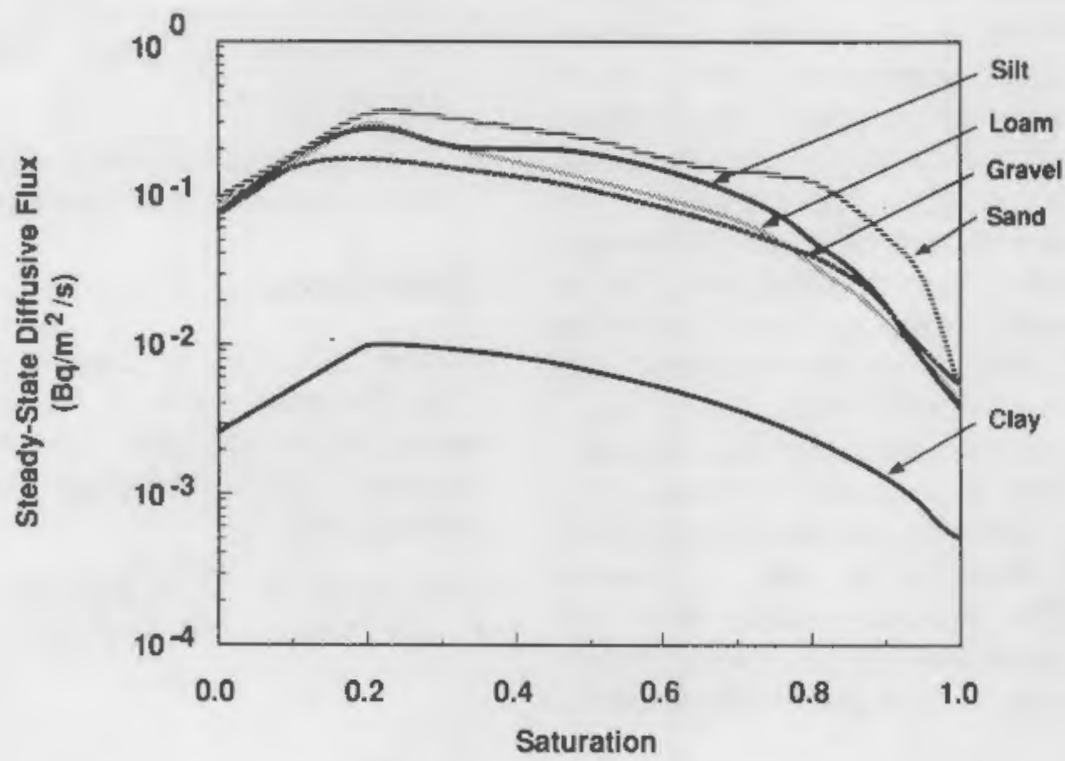

FIGURE 1. Steady-State Diffusive Radon Flux Versus Saturation for Five Generic Soils 


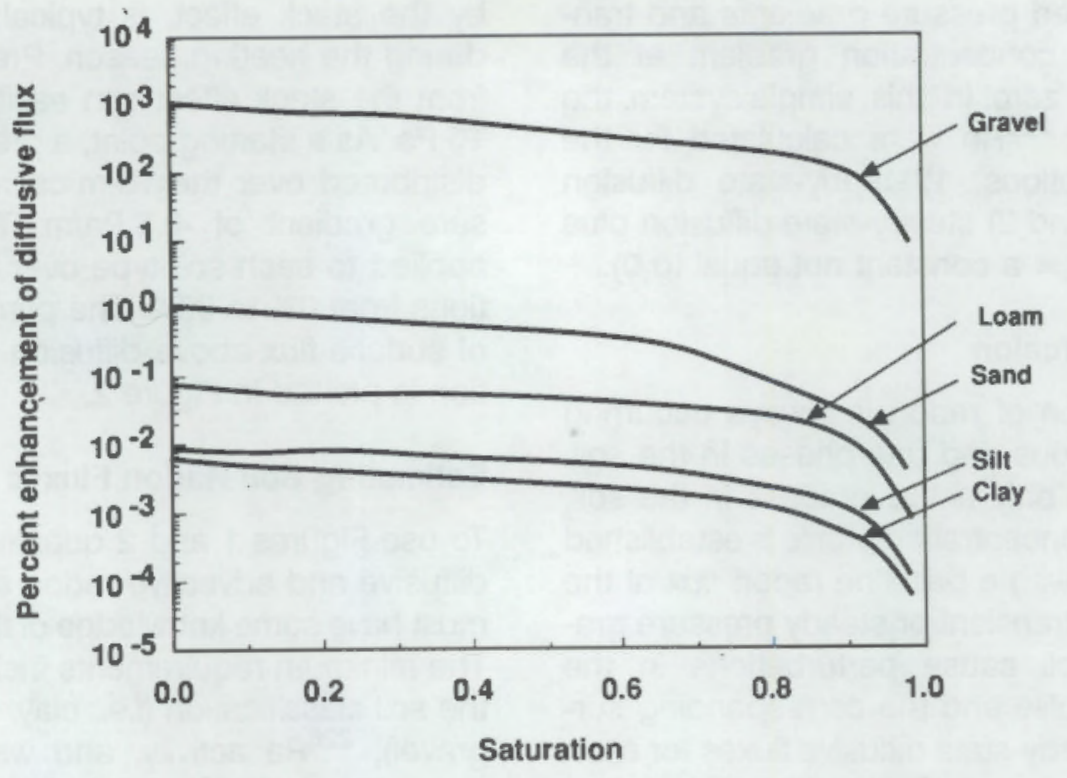

FIGURE 2. Percent Enhancement of Diffusive Flux Caused by a Steady Pressure Gradient Versus Saturation for $\mathrm{dP} / \mathrm{dz}=-0.5 \mathrm{P} / \mathrm{m}$

10-m depth). Any flux enhancement from Figure 2 is directly proportional to the gradient. Therefore, total estimated fluxes are proportional to Figure 1 value $\times\left({ }^{226} \mathrm{Ra}\right.$ activity/110) $\times \quad[1 .+$ $(\%$ enhancement/100) $\times$ (gradient/0.5)] for any constant degree of saturation.

This technique is valid only for obtaining order of magnitude estimates of the influence of soil moisture and pressure gradients on radon flux. A high degree of uncertainty exists in this method due to the uncertainty in identifying the user's soil with one of the generic soils. This identification is difficult since real soils are mixtures of the soil types and the range of particle sizes, and particle and bulk dry densities of the user's soil might be unlike the generic soils. Other uncertainties could be the presence of heterogeneities in the soil (e.g., layers, spacially variable water content, aggregation of soil particles, large cracks or micropores, rocks, roots, etc.), a different emanation coefficient versus saturation relationship, and an uneven pressure gradient in the soil column. Also, the relationship for advective enhancement of flux departs from linearity at large pressure gradients.

\section{Conclusions}

Results from this sensitivity analysis of five generic homogeneous soil types at different moisture saturations indicate the following:

- Water saturation levels can influence radon fluxes as significantly as differences in soil type.

- Steady pressure gradients on soil columns can significantly increase fluxes from highly permeable soils.

- Surface fluxes from soils can be estimated from soil property and emanation data.

\section{References}

Holford, D. J., G. W. Gee, P. C. Owczarski, and H. D. Freeman. 1988. "A Finite Element Model of Radon Advection and Diffusion in Unsaturated Cracked Soils." Abstract, Transactions, EOS 69(44):1216.

Holford, D. J., S. D. Schery, J. L. Wilson, and F. M. Phillips. 1989. Radon Transport in Dry, 
Cracked Soil: Two-Dimensional, Finite Element Model. PNL-7116, Pacific Northwest Laboratory, Richland, Washington.

\section{Future Subsurface Science Research}

Under the auspices of the newly formed Environmental Sciences Research Center, PNL will continue to realign research to focus on basic scientific issues underlying environmental restoration problems at DOE sites. These sites are rapidly being identified through comprehensive sitewide characterization and monitoring activities, and at least 4000 are now known. Research will, therefore, place greater priority on developing information of generic value in predicting and remediating the behavior of organic-radionuclide mixtures and halogenated solvents of immediate concern to most DOE sites. Continued emphasis will be placed on experiments in the Subsurface Environmental Research Facility (SERF), which allows examination of coupled processes under controlled conditions, as a bridge between detailed mechanistic experiments in the laboratory and heterogeneous environments in the field. In addition, several field sites will be identified on DOE lands in collaboration with the national DOE Subsurface Science Program where unique contamination events with radioisotopes may be used to study the manifestation of fundamental chemical, microbiological, and hydrologic processes in natural, heterogeneous porous media. Collectively, the laboratory, intermediatescale, and field research will greatly improve scientific understanding and models of contaminant dynamics in subsurface systems to 1) better predict contaminant concentrations for minimization of environmental risk and 2) establish more effective subsoil and aquifer remediation techniques. 


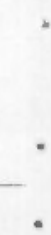




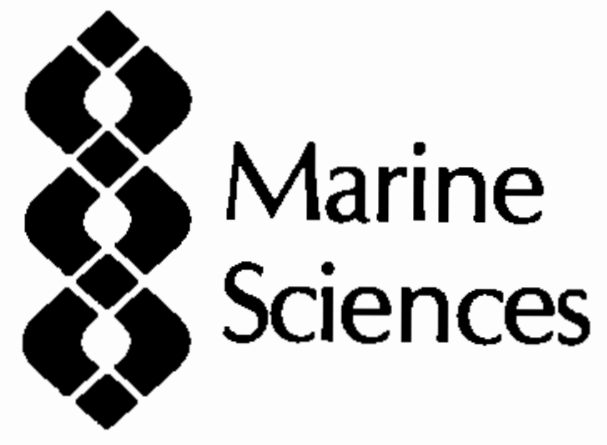




\section{Marine Sciences}

The goal of this research, which is coming to a close this year, is to use invertebrate models to elucidate the mechanisms of cancer induction and progression in humans, which may result from environmental exposures to energy-related chemicals or other cancer inducing factors. Physical and chemical stresses can act synergistically with naturally present pathogenic microorganisms or with latent cancer in the organisms to result in significant diseases in both humans and marine invertebrates. Previous research was used to select the one most applicable model among marine invertebrates to study these fundamental biological processes. This model is hemic neoplasia on the bay mussel, Mytilus edulis, a proliferative or cancer-like process, which shows increasing similarities to human and other mammalian leukemias.

\section{Cause and Progression of Leukemia in a Marine Invertebrate}

\section{R. A. Elston, L. Berntsen-Stephens, D. Bonar, K. Brooks, A. Lee, and J. Moore}

The prevalence of hemic neoplasia was determined in 54 populations of mussels in Washington State. Thirty of these populations were positive for the disease with many exhibiting high prevalence and average intensity of the disease. Some industrialized sites such as Port Angeles harbor were among the highest in disease intensity. Although such observations do not permit any definitive conclusions regarding the promotion of the neoplastic disease by environmental factors, they suggest that further investigations regarding chemical induction and neoplasia are needed.

In addition to previous studies demonstrating a host cellular basis for remission in Mytilus edulis, studies have been conducted on five additional populations of Mytilus to determine their susceptibility to hemic neoplasia. These include eastern North American Mytilus edulis and three west coast populations of bay mussels (i.e., Mytilus galloprovincialis, Mytilus edulis, and Mytilus galloprovincialis hybrids) as well as the distinct species, Mytilus californianus. The results indicated a decreasing proportion of susceptible individuals of Mytilus in populations geographically distant and genetically distinct from the susceptible Puget Sound and Willapa Bay, Washington, mussels used in our studies. These results suggest that populations of Mytilus edulis, which are more or less continuous in coastal areas, gradually shift in their genetic predisposition to the disease. Some mussels in all populations retain full susceptibility to the disease while the other mussels have acquired the ability to prevent or reverse the progression of the neoplastic process, possibly, in part at least, as a result of the cellular recognition and containment response of certain individual mussels to hemic neoplasia.

In two experimental studies using flow cytometry to determine the DNA content of individual hemocytes, it was found that progressive neoplastic disease is characterized by the formation of pentaploid cells in circulation, corresponding to the morphologically transformed cells. Subsequently, these pentaploid cells form an autonomously cycling population of replicating cells in circulation with a corresponding $\mathrm{G}_{2}$ population of cells that are decaploid.

A surprising discovery was made that an independent and mutually exclusive pathway of neoplastic transformation takes place in which tetraploid cells (morphologically neoplastic) predominate in the circulating cell population and that a corresponding $\mathrm{G}_{2}$ population of octoploid cells appears in circulation. The rate of mitosis in this alternate tetraploid form of the disease is higher, as evidenced by a higher mitotic index (5.5 per 1000 cells as compared with 1.1 per 1000 cells in the pentaploid form) and an elevated $S$ (synthesis) phase of the cell cycle $(28.7 \%$ of cells in S phase as compared with $15.3 \%$ in the pentaploid form). This important discovery may explain the relatively low apparent prevalence of the tetraploid-octoploid disease in natural populations in comparison with the more frequently observed pentaploid-decaploid disease. The relatively rapid mitotic rate of the tetraploid-octoploid disease appears to result in a more rapidly progressive and fatal condition, which results in a 
shorter residence time for these individuals in the population. The basis for the two forms of hemic neoplasia remains unknown but represents a fertile area for further mechanistic research on the etiology and transformation process.

Preliminary karyological studies have been conducted on mussels with the disease in order to elucidate the chromosomal basis for the altered ploidy levels in hemic neoplasia. Typical karyotype preparation methods used for mammalian cells were not successtul, but a procedure used for studying cultured cells was modified that proved satisfactory for producing spreads of metaphase chromosomes in either normal fertilized mussel ova or neoplastic hemocytes.

Diploid metaphase chromosome figures with 14 pairs of chromosomes were observed in these initial preparations: 4 metacentric, 7 submetacentric, and 3 telocentric, minute pairs of chromosomes. Tetraploid cells of the tetraploidoctoploid disease form seem to have a true and complete duplicate of $2 n$ chromosomes. Pentaploid cells, however, have 70 chromosomes plus numerous fragments.

Preliminary screens for oncogenes have been performed because an important aspect of the karyological studies will be in situ hybridization of DNA sequences (including known oncogenes) to chromosome preparations. Southern blots of genomic DNA cut with EcoR 1 and probed with v-myc, v-fos, v-Ha-ras, and v-Ki-ras (Oncor, Inc., Gaithersburg. Maryland) produced bands for $v$-mye and v-Ha-ras only.

A panel of monoclonal antibodies against both normal and neoplastic Mytilus hemocytes has been developed with our collaborating laboratory in France (IFREMER - La Tremblade). Two antibody-producing clones (14F1 and 16G10) reacting specifically with epitopes occurring on neoplastic cells have been selected and further characterized. These epitopes have been partially characterized using Western blotting, peroxidase staining, and immunogold labeling of sections of tumor cells. Peptides have been identified of 80 and $110 \mathrm{kd}$, which occur on neoplastic cells from the pentaploid form of the disease, by separating proteins from water soluble neoplastic cell homogenates by SDS-PAGE and reactivity on Western blots using anti-mouse immunoglobulin peroxidase-labeled antibodies in conjunction with our monoclonal antibodies. The immunogold labeling indicates that these epitopes occur on the surface of the transformed cells. These studies were conducted on fully transformed neoplastic cells.

In exhaustive histological studies, it has been observed that prior to the point at which hemic neoplasia becomes a systemic disease, neoplastic hemocytes can often be found localized in the region of the accessory gills, between the mantle and the base of the most distal folds of the primary gill. In this region, cells with neoplastic morphology can be observed in the endothelium of the vascular spaces. This finding suggests that this endothelium may be at least one site of initiation of the hemic neoplasia in the mussel and, as well, that this endothelium may be the normal site of hematopoiesis in the mussel (which has never been determined).

Development of an in vitro infectivity system would greatly facilitate studies of viral activation, cell cycling, chromosomal lesions, and expression of neoplastic antigens and viral genes as well as provide a controlled environment to examine the mechanism of remission as effected by normal hemocytes. In attempts to develop such an in vitro system, a tissue culture medium was formulated based on the amino acid content of mussels tissue and supplemented with nucleic acid precursors, organic acids, sugars, vitamins, trace elements and Mytilus hemolymph. Neoplastic cells can be aseptically obtained and maintained for about 6 weeks using this medium. During the first 3 weeks of maintenance, the cells can increase as much as fivefold, but following this the cultures cease replication and appear to slowly degenerate. This method does, however, enable us to maintain and use particular replicating populations of hemocytes for experimental studies for up to 3 weeks.

\section{Future Research}

DOE support of this program will be discontinued in FY 1990. 


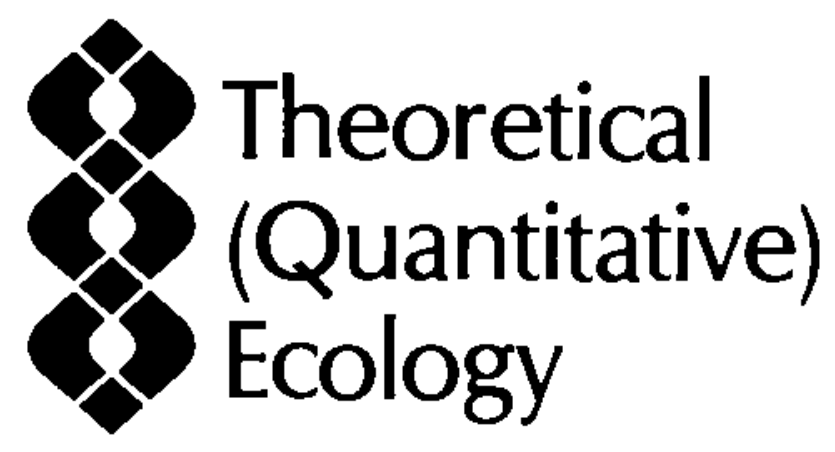




\section{Theoretical (Quantitative) Ecology}

Recent national concerns include hazards from chemical waste sites, subsurface transport of pollutants, and possible global changes. Approaches to study these issues and other field problems in ecology are limited by the lack of theory and suitable designs for sampling contaminants and populations in time and space. This program provides a firm scientific basis for the myriad of field studies required to understand these issues. The program places strong emphasis on developing field designs based on clear objectives, incorporating sampling theory rather than classical experimental designs, and using modem technology to aid in solving global problems (e.g., satellite imagery). Applicable designs for classes of sampling developed in other disciplines are generally unknown to ecologists and environmental scientists. Hence, a portion of the research is devoted to expanding and adapting methods from geostatistics (e.g., remote sensing and industrial research). In addition, the project combines elements of experimental design, survey and analytic sampling, and modeling with geostatistical and biometrical methods to develop or adapt cost-effective innovative field statistical methods for the study of environmental phenomena, population dynamics, and hazardous waste problems.

New findings from research conducted in the theoretical ecology program during FY 1989 include:

- demonstrating that satellite data from both LANDSAT and SPOT can be used to duplicate groundbased methods for determining the optimum size and dispersion of transects over landscapes (i.e., $600 \mathrm{~m}$ long dispersed at least $100 \mathrm{~m}$ apart)

- developing simulation studies which show that double sampling can combat one of the major shortcomings in contemporary fieldwork--inadequate sampling

- discovering that radio-telemetry is an excellent way to account for edge effects in population studies.

\section{Dynamics of Wild Populations}

\section{L. Eberhardt}

One of the major problems in attempting to develop principles for theoretical ecology is the lack of suitable field data for testing models; therefore, any attempts to apply the model results to various present-day concepts of global threats may be overshadowed by our inability to show that the models have any basis in real data. $A$ main goal of the research is to focus on actual data involving real populations. Another goal of the research is to develop and evaluate techniques to provide numerical assessments of trends and other evidence of change in such populations. During FY 1989, these goals led to investigating the following four research areas.

1. Research on life tables led to development of an "augmented" life table that includes a measure of the dynamics of the population. Research indicated the following:
- The classical life table is useful only for studies of a stationary population or a single cohort.

- Changing populations can be assessed through an 'augmented" life table incorporating reproductive data and the elements of the Lotka-Leslie equations for population dynamics.

- Approximate solutions serve when individual age-specific rates are not available for all age classes.

- Confusion about definition of parameters can be reduced by comparing growth rates from population projections with solutions of Lotka's equations.

2. A second area of research showed that simple approximation to the Lotka equations permits using various combinations of population dynamic parameters to determine adult female survival rates needed to sustain a constant 
population of grizzly and polar bears. The approximation should be useful in evaluating more complex models. Data on polar bears were used to illustrate a method for estimating the ratio of juvenile survival rates to that for adults. Such a ratio may be useful in establishing appropriate combinations of subadult and total adult survivorship for sustained population levels.

3. The third area of research included a modeling study of a seal population. The age of about 16,000 female fur seals from the Pribilof Islands in pelagic collections was determined from 1958 through 1974. A simple simulation model of the female population was used to vary population parameters until a minimum chi-square value was achieved for the fit of simulated annual age structures to those observed in the pelagic collection. Population trajectories resulting from either a diminishing reproductive rate or diminishing adult female survival rate approximated estimated pup population sizes, which were not used in developing the model except a subset of five observations used to constrain model trajectories to the observed pup populations. The main finding of the study was that adult female survival rates varied sharply during 1964 through 1974, after the major period of harvests of female fur seals. Further study of the age structure data may be useful in evaluating the poorly understood long-term reduction in Pribilof fur seals.

4. The fourth area of research assessed the use of radio-telemetry for mark-recapture studies when edge effects are important (i.e., individual animals move in and out of the study plot on which the actual mark-recapture work is done). Research results indicated the following:

- Radio-telemetry provides a technique for estimating abundance under such circumstances, giving an average value for population density on the area over time, rather than an absolute estimate of abundance.

- Monte Carlo simulations indicate that either a bias-corrected version of the "mean Petersen" or a Petersen estimate based on the means of the observations may be suitable for estimating abundance from radiotelemetry data.

- The proposed bias correction may make it possible to obtain useful abundance estimates for very small populations, given sufficiently high probabilities of marking and recapture.

\section{Designs for Environmental Field Studies}

\section{J. M. Thomas and L. L. Eberhardt}

Research conducted during FY 1989 has shown that techniques for efficient field observation developed in a number of disciplines are unknown $o r$ at best, very much peripheral to the interests and experience of most ecologists who are involved in the passive observation of some process not under their control. For the most part, these techniques amount to observation by sampling in space or time. Biases may be guarded against in the designs, or at least better identified. The main drawback to field observation is the weakening of the strong inferences made possible by controlied experimentation. Often good experimentation can at least identify the most likely ways that inferences based on observation can go wrong. One major objective of this research is to provide new quantitative techniques within a workable classification of designs for environmental field studies.

Because inferences based on unreplicated experiments or passive observation of some population or uncontrolled process are so uncertain, it is doubtful that any particular inferential scheme can be adhered to. Several formal inferential processes have been proposed, as well as the wider use of the hypothetico-deductive method, in which a hypothesis is formulated and then tested by specific experiments testing deductions from the hypothesis.

Unfortunately, natural systems are subject to chance fluctuations, and environmental research techniques rarely measure anything exactly and consistently. In these circumstances, it appears desirable to adhere to a flexible viewpoint in which a long series of successive studies each yield a 
statistical decision, but a conclusion ultimately depends on a reassessment of the whole series of individual results, some of which may then be rejected. Such an outcome is generally unattainable under the rules of strict logic, even if false rejections of statistical tests in individual hypothesis testing can actually be maintained near the assumed rate.

Experiments occur when the investigator controls the circumstances of the study. The major error made in many contemporary analyses is that of confusing control of events or treatments with control of the observational process. Thus, replication denotes the ability to repeat a treatment, not just to take repeated observations. It is important to treat the observational process as a sampling scheme. Thus, in our classification scheme, the initial dichotomy is one of differentiating between conducting a controlled experiment and observing some uncontrolled process by sampling.

When events are controlled by the observer, replicated and unreplicated experiments cover nearly all the textbook approaches. Experiments designed to efficiently estimate parameters in specific nonlinear models, such as those used for reaction kinetics in chemistry to guide pilot plant operations on an experimental basis, are also under the control of the observer. Even though it might seem that studies designed to investigate events such as the impacts of operating a new power generating station or changes in atmospheric pollution caused by opening a new freeway are controlled by the investigator, these studies are generally not under the control of the investigator. In addition, such studies are often retrospective as opposed to being designed before the event takes place. Our research indicates that intervention analysis, which involves the use of time series methods to study the effects of distinct perturbations, is generally superior when enough population cycles are available. Unfortunately, few yearly cycles of population abundance are available in circumstances of interest to most ecologists.

We have found that four categories of sampling can be based on observing a process when no distinct perturbation is evident and that they can be characterized by the way samples are allocated over prospective sampling units in the population. The best known is survey, or descriptive sampling, which is usually concerned with estimation of means of totals. We have used a survey sampling technique known as "double sampling" as a way to calibrate relative measures of abundance (indices) against direct estimates of absolute numbers in a population. These methods offer opportunities to use the more cost-effective population indices as a means to estimate wild population numbers. Other workers have divided survey sampling into descriptive and analytical sampling where descriptive surveys are designed to obtain information about large groups and analytic surveys seek to discover differences among population subgroups and to ascertain the reason for the differences. $A$ sampling study can be classified as observational when contrasting portions of the population are deliberately selected for study. Sampling for pattern has emerged from geostatistical research where the need is to assess the extent and value of a body of ore or the volume and extent of an oil field. In many applications, sampling locations may not be controlled by the observer, and the methodology may be most useful as a way to reduce biases resulting from haphazard sampling. These techniques are useful for making maps of contaminant plumes and have the advantage of an accompanying error of the estimated contours. A portion of our continuing research has been directed toward assessing the validity of these techniques in ecology and for mapping hazardous waste sites.

During FY 1989, additional research was conducted (in concert with an exploratory research project) on ecological scaling issues as a part of studies on sampling for pattern. We substantiated last year's findings that plant transects must be at least $600 \mathrm{~m}$ long and at least $100 \mathrm{~m}$ apart. In addition, we reproduced these results (Figure 1) using LANDSAT scenes which included the area near a road on the ALE Reserve. Similar results were obtained based on SPOT data.

\section{Future Research}

The two currently funded theoretical ecology projects will be combined into a single program in FY 1990. The resulting single program will focus on theoretical and quantitative ecology. Research areas selected for emphasis include: 


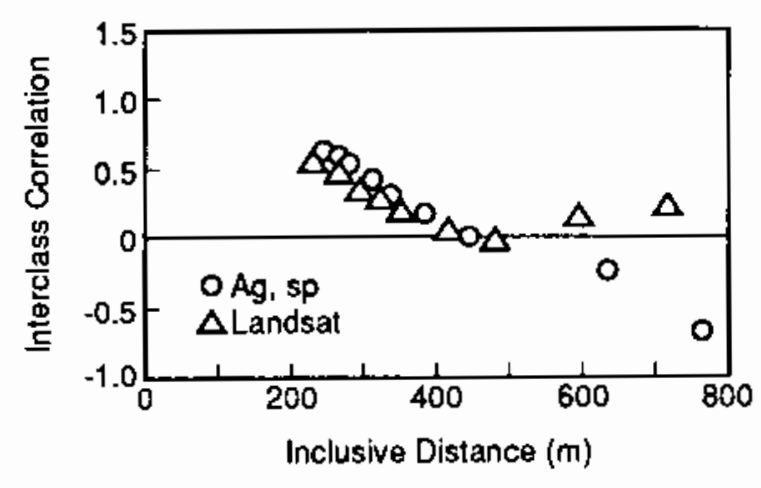

FIGURE 1. Intracless Correiation as a Function of Distance Based on a 126-m Transect for Agropyron spicatum and o $120-m$ Trensect Constructed from LANDSAT Pixels $\left(30 \mathrm{~m}^{2}\right)$. The wheatgress results were calculated from cover measure. mente taken over a $2000-\mathrm{mm}$ trensect. The zero correlation point is the distence at which the segments are independent of one another, or where factors that affect cover are no longer similar.

- Sampling for modeling - We expect to deal with growth curves, since it is expensive to obtain adequate observations on growth processes, particularly population growth. Hence, we plan initial studies on the techniques of sampling for modeling on the logistic growth model.

- Observational studies - We will continue our approach using data on actual populations to estimate parameters for simple models. Contrasting populations will be used to explore the prospects for using the approach in observational studies. Initial investigations will be started using data on a predator-prey system.

- Sampling for pattern - Research will be initiated to determine how well the basic assumptions of kriging methodology are met in ervironmental and ecological studies in which appropriate measurements are presently available. In addition, we plan to extend our efforts in determining the spatial scale for plant species other than Agropyron spicatum as well as the same species at other locations.

- Analytic sampling - We expect that research on analytical sampling will focus on developing the concept of sampling as the principal approach for field ecology, with experiments largely designed to fit within an overall matrix of field observation based on sampling designs. The theoretical approach to this concept will most likely be based on the superpopulation idea, and at least initially wili follow existing statistical theory based on that approach. 


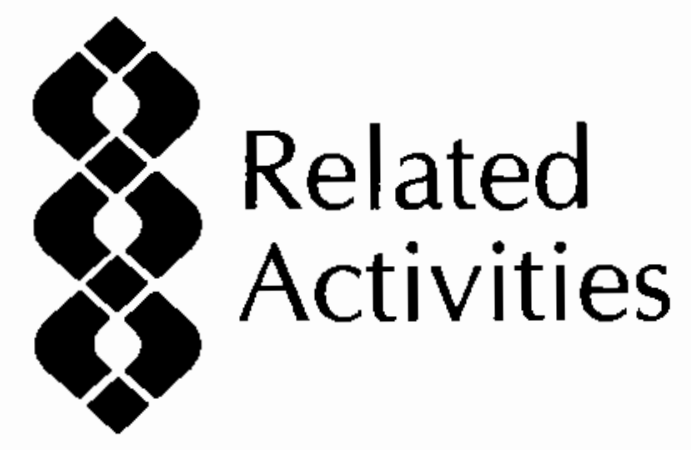




\section{Exploratory Research}

Exploratory research projects are used to conduct preliminary investigations of new and promising scientific concepts that have a high potential of making substantial contributions to environmental research. In FY 1989, exploratory research projects investigated the biogenic cycling of volatile nitrogen-containing species, new concepts for measuring and extrapolating ecological measures to the regional scale, development of a knowledge-based system for predicting ecological change, remote detection of vegetationstressed communities, and new research concepts in marine systems.

\section{Biogenic Cycling of Volatile Nitrogen-Containing Species}

\section{B. D. McVeety and S. O. Farwell}

The short-term goal of this exploratory research project was to develop the technical capability necessary for determining the spatial and temporal fluxes of volatile nitrogen species that are produced in soil/plant systems associated with semi-arid environments. The long-term goal has been to develop the technical expertise at PNL for quantifying a suite of carbon-, sulfur-, and nitrogen-containing biogenic gases and their emission rates from globally important ecosystems. Using these capabilities, the careful study of terrestrial biogenic emission rates is possible, leading to a better understanding of global elemental budgets and the role biogenic emissions play in maintaining them.

The known volatile compounds of major significance to the biogeochemical nitrogen cycle are $\mathrm{NH}_{3}, \mathrm{NO}_{1} \mathrm{NO}_{2}, \mathrm{~N}_{2} \mathrm{O}, \mathrm{N}_{2}$, and possibly organic amines $\left[\mathrm{CH}_{3} \mathrm{NH}_{21}\left(\mathrm{CH}_{3}\right)_{2} \mathrm{NH}_{2}\right]$. Therefore, we focused our efforts on developing and validating a sensitive analytical methodology for field-based emission measurements of these specific gases. We have worked to keep the system design flexible, allowing for the detection and identification of other currently unknown volatile nitrogen compounds that may also play a significant role in nitrogen budgets.

Building on the sulfur gas sampling and analysis expertise developed at the University of Idaho, the first year of work was conducted at the University by a graduate student working with Dr. Farwell. Their effort focused on fashioning a nitrogenspecific gas chromatograph detector from a Monitor Labs 8440 E NO chemiluminescence detector. The defection cell was redesigned to minimize its volume and better accommodate the small flow rates typical of capillary gas chromatography (GC). This modification resulted in an order of magnitude sensitivity improvement. A thermal/catalytic oxidation inlet system employing a platinum tube heated to $1200^{\circ} \mathrm{C}$ was added to the detector inlet. This conversion system transformed the nitrogen-containing species eluting from a high-resolution $\mathrm{GC}$ column to $\mathrm{NO}$ for subsequent detection through the $\mathrm{NO}+\mathrm{O}_{3}=\mathrm{NO}_{2}$ $+\mathrm{O}_{2}$ chemiluminescence reaction. Although the modified detector was sufficient to test the selectivity of the nitrogen-specific detection mechanism, it was more than an order of magnjtude less sensitive then a detector built by Sievers Research (Boulder, Colorado). This detector, the Model 270 NO chemiluminescence detector, was optimized for capillary gas chromatographic analysis and uses photon counting to further reduce its detection limit.

The second-year research was focused on transferring the general gas sampling and measurement capability from the University of Idaho to $\mathrm{PNL}$, and further developing and refining the nitrogen-specific chromatographic detection system at PNL. Through capital equipment support, a Sievers 270 chemiluminescence NO detector was purchased for use on this project during the second year.

The Sievers detector was successfully interfaced to a Hewlett-Packard (HP) 5890 capillary gas chromatograph through a customized minj-tube furnace. A separate power supply and temperature controller were required to operate the furnace. After additional insulation was added to the tube furnace, it was squeezed between the $G C$ and the NO detector. A $20-\mathrm{cm}$ length of 1/8-in.-diameter stainless steel tubing was passed between the GC and the NO detector through the 
fumace. The interface distance was minimized to maintain the resolution of sample components produced through the chromatographic separation process.

A small platinum tube, $0.8 \mathrm{~mm}$ in diameter and $25 \mathrm{~cm}$ in length, was snaked through the $1 / 8$-in. stainless steel tube, reducing the interface dead volume to a level compatible with the wide-bore 0.53-mm-diameter capillary column. Initially, a severe background problem developed because of the short interface, as light generated in the white-hot area of the tube furnace was passed down the tube to the photomultiplier. This problem was solved by bending several 90-degree corners into the interface tube.

A gas sampling cryogenic concentration/injection system was designed and built for the HP $\mathbf{5 8 9 0}$ gas chromatograph using miniature three-way Teflon valves and a six-port Teflon injection valve. The valves were wired to allow control of their action from the computing integrator that also initiates and terminates GC operation and handles data acquisition. Using this arrangement, the injection/detection system has been successfully tested using various dilutions of NO gas standards and emissions for low-loss permeation vials. The detection limit of the system was determined to be about $0.4 \mathrm{pg}$ nitrogen with a signal-to-noise ratio of 5 to 1 . Using cryogenic focusing, sub-parts-pertrillion measurements of nitrogen-containing compounds are now possible.

Of the various gaseous nitrogen compounds tested using the thermal/catalytic conversion process, two compounds were found to be either inert or difficult to oxidize. Fortunately, $\mathrm{N}_{2}$ was inert to oxidation using this process, as the $\mathrm{N}_{2}$ background would have made the detector difficult to use in our atmosphere. Yet it was also discovered that $\mathrm{N}_{2} \mathrm{O}$ was resistent to oxidation. The oxidation/ conversion efficiency of $\mathrm{N}_{2} \mathrm{O}$ to $\mathrm{NO}$ using this system was about $5 \%$ at $1200^{\circ} \mathrm{C}$, giving an indication of the stability of the molecule. Thus, it was necessary to outfit another GC with a cryogenic concentration/injection system and also an electron capture detector for the $\mathrm{N}_{2} \mathrm{O}$ analysis.

(B) Teflon is a registered trademark of E.I. du Pont de Nemours and Company, Wilmington, Delaware.
The analytical capabilities developed within this project are being coupled with the portable, closed-loop controlled-environment whole-plant gas exchange chambers developed at PNL for application to a waste barriers project. Future plans are to participate in experiments being conducted at PNL on plant gas exchange and the microbial community. Initially, within the laboratorycontrolled environment, experiments designed to test the performance of the collection, separation, and detection system will be conducted using the whole-plant gas exchange chambers. These experiments will help identify and resolve any major problems before field tests are initiated next spring.

\section{Optimal Measurement Scales and Experimental Design for Detecting and Predicting Global Ecosystems Change}

\section{J. M. Thomas, V. I. Cullinan, and M. A. Simmons}

The goal of this project is to develop a methodology for quantifying landscape changes that result from global or regional environmental impacts. The results will allow predictions about desertification by providing a way to monitor landscape-level change and thus will be usable in assessing global change issues.

To achieve this goal, project objectives are to 1) develop quantitative methods for scaling measurements of ecologic processes in arid environments to landscape levels; 2) demonstrate that satellite-based (SPOT AND LANDSAT) imagery can replace ground-based estimates of ecological scale; 3) provide estimates of physical sample size, dispersion, and numbers of samples needed for studies of global change or landscape-level monitoring; and 4) provide a theoretical link between landscape-level measurements and anaIytical sampling methods for studying global change and the processes that cause desertification.

The methods are based on a fundamental principle of ecology that states that components of ecosystems are interrelated. Thus, the spatial scale and strength of these interrelationships are basic attributes by which ecological processes can be characterized. The concept of the scale at which ecological processes occur is particularly 
relevant to studies of global ecosystem changes. Plant cover data were obtained for desert grasses and shrubs at two locations, which show that transect size and dispersion needed to detect change over large areas are much larger than currently used (transects of about $600 \mathrm{~m}$ dispersed about $100 \mathrm{~m}$ apart compared to $1-\mathrm{m}$ transects about $1 \mathrm{~m}$ apart currently used). In concert with the OHER project entitled Designs for Environmental Studies, the ground-based findings were substantiated using LANDSAT scenes ( $30-\mathrm{m}$ by $30-\mathrm{m}$ pixels) that included the area both above and below a road on the ALE Reserve. In addition, SPOT scenes were obtained that provided resolution at the 20-m scale. Again, as was the case with LANDSAT, the ground-based variance and correlation models were duplicated using the SPOT scenes. Most of the assumptions made in deriving the models have been checked using computer simulations that sampled the ground-based transect data.

Based on these results, it was concluded that 1) the scale at which similar processes no longer influence percentage cover is between 300 and $600 \mathrm{~m}$, depending on the location and plant species measured; and 2) the optimal transect segment length is at least $100 \mathrm{~m}$ for all species. LANDSAT and SPOT imagery provided similar estimates of scale.

These results are significant because the scale at which ecological processes occur is relevant to studies of global ecosystem changes. Remotely sensed images of ecosystems on large scales are currently obtained from satellites to study the nature of processes that affect change. Just as the nature of the process may be masked by measuring the system on too small a scale, however, so too may the nature of the process be masked by measuring the system on too large a scale. The results also relate to biosphere/geosphere modeling via the proportionality between plant cover and ET. Since ET strongly influences water balance in arid regions, it must be considered in hydrologic and atmospheric models used to project future changes in water balance.

Our results imply that long-term ecological monitoring or monitoring to detect global change should consider the size and spacing of sampling units over landscapes. Moreover, if ground truth for satellite-based measures can be obtained, then LANDSAT methodology may offer an inexpensive satellite-based means to assess global change.

During FY 1990, it is planned to conduct research directed toward developing fundamental statistical models that allow multiple scales and to initiate studies of the effects of multiple plant species on the current models of spatial correlation and variance. These results will be crucial to applying the models to more complicated semi-arid settings and grasslands. Two tasks are planned. In the first, measurements of plant cover at the interface of arid grasslands and the ponderosa pine region of the Blue Mountains will be made to demonstrate the theory. This task will involve muttiple scales and will cover a geographic area of interest in the arid West. In the second task, the methodology will be extended for use in monitoring arid land ecosystems to detect change. This task can be accomplished by estimating the Poisson parameters from the model we have developed and using computer simulation of plant removals (e.g. via rodents or insects) to determine efficiency in detecting change in plant cover.

\section{A Knowledge-Based System for Evaluating Human Disturbance and Global Climate Change in Arid Regions}

\section{G. Foley, K. A. Hoover, and J. M. Thomas \\ (PNL) and J. Coughlan (University of Montana)}

Available models do not integrate knowledge of small-scale hydrologic processes to the large spatial scale of a typical drainage basin over the time scales necessary for quantitative prediction of response to human disturbance or climate changes. These models do not deal with the details of basin geometry, do not address runoff/ evapotranspiration/recharge processes representative of semi-arid/arid environments in a physically based predictive fashion, and lack validation (i.e., predictive) testing at relevant spatial and time scales. Such models are inappropriate for studies of the hydrological and ecological effects of watershed modification and changing climate, water availability, and desertification in the arid west.

This exploratory work is designed to develop the conceptual model and implementation plan for a 
computational framework (executive shell) and prototype process submodels to spatially integrate experimental-scale (point) fluvial and ecosystem process models at the intermediate scale of slopes and small drainage basins in shrub-steppe ecosystems. As part of this effort, process submodels and data representative of semiarid/arid ecosystems must be developed or adapted. The resultant shrub-steppe ecosystem and hydrologic model, which would not be completed to a working prototype within the scope of this project, would provide for the first time the fult capabilities of emerging GIS and digital terrain analysis technology, arid-land process models, and advanced computer workstations for predicting effects of surface/vegetation disturbance and climate changes on intermediate-scale drainage basins.

Previous models of shrub-steppe ecosystems were derived from the IGBP grassland modeling effort, in which the goal was to develop a general model of grassland ecosystems. The product of that effort was a grassland ecosystem model, ELM, which was fully implemented to model Colorado's grasslands. Spin-offs based on ELM sub-models were more readily used. The modeling approach taken by the IGBP models with regard to photosynthesis and transpiration, however, was empirical and therefore not very useful over much less studied areas because it required estimates of many parameters. Moreover, it could not use satellite input. Thus, although information gained from ELM is valuable, the model is not suited for global or regional studies.

Part of the overall goal of this exploratory research is to develop a regional ecosystem modeling framework (REMF) capable of simulating effects of dynamic vegetation, climatic, and hydrologic conditions in a shrub-steppe ecosystem. To accomplish this goal, GIS, remote sensing, and expert system technologies must be integrated with process models of climate and plant growth to generate evapotranspiration and gas exchange estimates for large regions. The REMF will be applicable to different climatic and atmospheric conditions inasmuch as it is possible to model such complex interactions. The REMF can provide the critical link between generalized, large-scale models of the biosphere and smaller-scale process models by confiming or parameterizing larger-scale biosphere models.

The REMF defines an automated system required to manipulate and apply the volumes of data necessary for smaller-scale models. Figure 1 illustrates the major components of an example REMF and illustrates the flow of control between them. This REMF can use either LANDSAT TM $(30 \mathrm{~m})$ or NOAA-9-AVHRR $(1-\mathrm{km})$ imagery data to parameterize vegetative cover across an arid landscape for use in an ecosystem model. In preliminary studies, LANDSAT TM 30-m pixels will be used. A GIS will coordinate the integration of land surface parameters to the ecosystem model. The GIS selects data for each pixel and invokes a climate and ecosystem model to produce individual estimates of evapotranspiration and photosynthesis-respiration balances. Regional estimates are summations of estimates for the individual land units.

Expert systems technology has been suggested to model conceptual knowledge relating process models to geographic influences on ecosystemlevel model parameters and to identify and correct any inconsistencies between data layers. An expert system will also be a part of the shrubsteppe ecosystem model to better represent plant phenology and plant responses to changing environmental conditions. A weak link in current ecological growth models is that they try to represent complex plant behavior with equations. Thus, an expert system would better approximate the logic of plant responses. This hypothesis has been previously suggested, but never implemented or tested. Because of the links to process modeling and expert system technologies, REMF is unique, unlike a general-purpose hydrologic modeling system such as SHE (Abbott et al. 1986). A great deal of time and effort will be required to implement the complete REMF shown in Figure 1. In the early stages of this exploratory project, the core of an REMF shrub-steppe ecosystem model and accompanying climatic simulator (enclosed by dotted lines in Figure 1) will be built. 


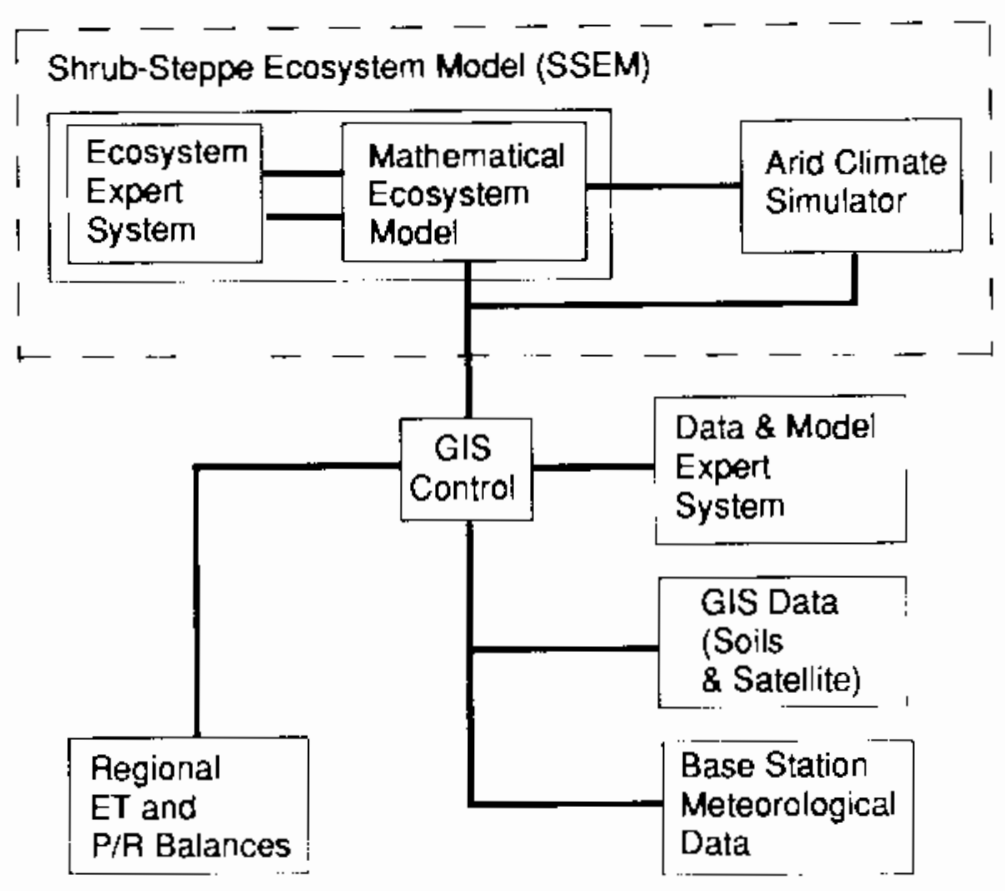

FIGURE 1. Diagram of the Major Computing Systems Composing a Regional Ecosystem Modeling Framework (REMF) to Generate Evapotranspiration (ET) and Photosynthesie-Respiration (P/R) Balances for a Shrub-Steppe Ecosystem. The control is centered in the Geographic Information System (GIS). Expert system rules mediate between the GIS database and the climate and ecosystem models, checking deta integrity and adjusting the models to each land unit's attributes. The ecosystem model uses expert system technologies to best approximate plant responses.

\section{Reference}

Abbott, M. B., J. C. Bathurst, J. A. Cunge, P. E. O'Connell, and J. Rasmussen. 1986. "An Introduction to the European Hydrological System - Systeme Hydrologique Europeen, "SHE," 1: History and Philosophy of a Physcially-Based, Distributed Modeling System, "Journal of Hydrology 87:45-59.

\section{Remote Sensing of Plant Stress: Correlations with Plant Bjochemical Processes}

\section{R. J. Fellows, B. A. Le Baron, and D. E. Gibbons}

The objective of this project is to determine if significant correlations can be observed between environmentally induced plant metabolic damage and canopy reflectance properties in the near- and far-infrared range as determined by scanning spectrophotometry. Analyses of the reflectance data will be compared with specific changes in selected marker metabolic pathways known to be stress sensitive. Correlative changes could then be explored in other species for potential extrapolation to field and possibly satellite remote sensing applications. These activities differ from those currently undertaken at PNL in that the proposed studies will attempt to provide a biochemical/ molecular basis for spectral changes of vegetation.

Environmental stress (exposure to extraordinarily unfavorable conditions), including that induced by atmospheric pollutants or groundwater contaminants, provokes an alarm response (defensive and/or adaptive) in all higher plants provided the organism is not in a dormant state. This initial response will be an increase in metabolism on the cellular level and is divided into two primary phases. The first phase consists of enzymatic attempts at oxidation, reduction, or hydrolysis of the compound to alter its toxicity. The second 
phase comprises a conjugation/stabilization series of processes to either reduce the toxicity of or sequester the species.

Chemical stabilization often begins with reduction of the highly reactive oxidized species. A high level (millimolar concentration) of reductant within the cell available for conjugation is considered very important in this step. Such a reductant may comprise reduced glutathione (GSH) and the enzyme responsible for its production, glutathione reductase (NADPH) glutathione oxidoreductase. The activity of this enzyme has been shown to increase significantly in plants under periods of temperature and water stress and exposure to atmospheric pollutants such as $\mathrm{SO}_{2}$ '

Determination of stress on the cellular and wholeplant levels, however, requires varying degrees of physical destructive sampling and can be further complicated in a field situation by the natural population variations of age and physical stature. These limitations may be mitigated through the use of remote sensing techniques in which differences in spectral reflectance in the visible $(0.4$ to $0.7 \mu \mathrm{m})$, near-infrared $(0.7$ to $1.55 \mu \mathrm{m})$, and midinfrared $(1.55$ to $2.35 \mu \mathrm{m})$ regions have been shown to correlate with several forms of plant stress, including water, nitrogen, disease, heavy metals, and $\mathrm{SO}_{2}$, in various terrestrial ecosystems.

Although changes in spectral properties of vegetation may correlate with stress, the direct promotion is not ensured unless ground-truthing is also conducted. The reflectance of spectral radiation may be affected by the angle of interception, position within the canopy, canopy species composition, and canopy background conditions. Selection of individual "marker" wavelengths, characteristic to stress responses in predominant vegetation types, may eliminate some of this problem. Previous work has reported such correlations with changes in specific wavelengths in connection with chlorosis or plant lignin levels, both symptomatic of advanced or necrotic levels of stress. To date, however, no studies have considered the early stages of stress when remedial action may still be possible. The characterization of precise spectral changes that may occur during this early stress period (determined by the increased activity of known stress marker enzymes) may provide "marker" wavelengths, which could then be monitored remotely as indicators of vegetation stress status.

In FY 1990, soybeans (Glycine max) will be grown hydroponically under standard growth chamber conditions. The plant roots will be exposed to herbicides such as Glyphosate, which does not directly affect either photosynthetic pigment production or lignification. This exposure will be conducted at differing concentrations and exposure times and will be followed by reflectance measurements under a standardized light source, geometry, and neutral background using PNL's state-of-the-art Deadalus-Portable Field Spectroradiometer. At the same time, single leaves will be removed from random positions within the canopy and assayed for GSH reductase activity. These results will be statistically compared with spectral changes to determine if specific wavelengths within the spectra could prove useful as markers of stress. Algorithms will be developed to eliminate as much of the extraneous spectral noise as possible. If significant correlations are evident using these improved signals, then experiments will be conducted in FY 1991 employing additional exposures so that a signal scale of plant stress severity level might be constructed for soybeans and other species under both greenhouse and field conditions.

It is expected that the project will be of immediate supportive value to ongoing remote sensing programs within PNL for the continued evolution of such narrow-band, hyperspectral spectroscopic studies as the evapotranspiration work at the ALE Reserve. The potential for direct correlation between spectral and biochemical changes in a plant species may provide an accurate means of calibrating the remote sensing data obtained to date. A successful completion of the proposed experiments would result in a publication.

\section{Fluxes of Biogenic Gases from the Ocean Surface}

\section{E. A. Crecelius}

The objective of this project is the operation of oceanic surface water mesocosms for the purpose of investigating factors affecting the fluxes of 
geoclimatologically significant trace gases from the sea surface. In particular, the system will investigate dimethyl sulfide (DMS) production by estuarine phytoplankton.

A novel analytical method has been developed that allows the direct speciation of elemental and organomercurial compounds in air samples. This method has also been applied to rain samples by derivitization of the aqueous species to their volatile ethyl-analogs before cryogenic gas chromatography and cold vapor fluorescence detection. A permanent sampling tower has been setup on Cheekah Peak, on the northwest coast, and daily samples are now being collected by a subcontractor and delivered to PNL on a weekly basis for analysis. A publication has resulted from the work, detailing the analytical methods and the firstever observations of organomercury species in rain. During FY 1989, the program was redirected to the study of volatile sulfur compounds; this direction better matches the future research areas of DOE than do the previous mercury speciation studies.

In FY 1990, the seawater mesocosm system will be tested. This system will be a valuable tool in future research concerning fluxes of important biogenic and anthropogenic trace gases at the sea surface. This facility will allow the effects of turbulence, wave breaking, and surface microlayer to be investigated in a controlled manner. Because the system under design will be sealed from the environment, it will allow experiments to be conducted with radiolabeled tracers, as well as natural gases. In addition, a methodology of organosulfur compounds will be added to our trace element speciation capabilities. In FY 1990, experiments will be initiated to enhance our understanding of the biogeochemical contacts on the fluxes of gases important to the climate change modeling, such as DMS, $\mathrm{CO}_{2}$, and $\mathrm{N}_{2} \mathrm{O}$.

\section{Development of a Passive Diffusion Sensor for the Measurement of Ambient Mercury Vapor Concentrations}

N. S. Bloom

The objective of this project is to construct a discrete collector for atmospheric mercury levels
(1-5 pg/L) based on passive diffusion into a short quartz column packed with gold-coated quartz sand. Several physical designs will be evaluated for collection efficiency and ease of construction. The selected design will then be carefully examined under a variety of conditions to 1) calibrate the collection rate; 2) examine the effects of temperature, mercury concentration, and air turbulence on collection rate; and 3) determine the between-column reproducibility. Finally, the calibrated columns will be tested under field conditions, and the data will be compared with data collected using the traditional pumped-air sample methodology.

After consideration of the limited budget for this project, it was decided that the only sample device configuration that could be produced and tested was one made of quartz tubing, packed with goldcoated quartz sand held in place between quartz wool plugs. Sample columns of this type are currently in use at other laboratories for mercury sampling by pumping large volumes of air through the column before analysis. The minute amounts of mercury (approximately $1-10 \mathrm{pg}$ ) were easily detected as they were trapped on the test column by diffusion over a period of days.

Columns tested were all $10 \mathrm{~cm}$ long, with a packed zone containing $1 \mathrm{~cm}$ of gold-coated sand at the center. The ends were sealed until use with plugs, which maintained blanks in the range of 1-2 pg Hg per sample. Sample columns with internal diameters ranging from 0.4 to $0.8 \mathrm{~cm}$ were examined for collection efficiency and compared to columns containing no quartz wool plugs (and a small piece of gold foil). These experiments gave the expected results, showing the collection efficiency of the columns to increase proportionally to the square of the column diameter. Typically, the quartz wool plugs reduced columns. The quartz wool plugs serve as a diffusive barrier minimizing the short-term changes in concentration and turbulence on the average collection rate. Other types of samples, based upon diffusion of mercury through permeable membranes, were considered but were rejected as too costly to fabricate.

Twenty columns with internal diameters of $0.7 \mathrm{~cm}$ were constructed as identically as possible under laboratory conditions. These columns were tested for reproducibility by setting them in the ambient 
room air (approximately $2-5 \mathrm{pg} / \mathrm{L} \mathrm{Hg}$ ) for 1 week and analyzing the mercury collected. In general, the columns produced uniform results, with a standard deviation of about 3 to $4 \mathrm{pg} \mathrm{Hg}$ per sample, or about three times the variability contributed by the blanks. The 12 most reproducible columns were sub-selected for all further work. It is anticipated that even smaller standard deviations could be obtained if the columns were manufactured by an automated mechanical procedure.

The test columns were next carefully calibrated at room temperature by comparison of mercury collection rates to the mean mercury concentration in the room air. The room air concentration was monitored by taking daily 24-hour integrated samples by pumping air through gold columns under vacuum. Air flow was quantified using an integrating mass flowmeter. The room temperature was $21^{\circ} \mathrm{C}\left( \pm 1^{\circ} \mathrm{C}\right)$ during this period, and the weekly averages of seven daily mercury measurements were typically $3.5 \mathrm{pg} / \mathrm{L}( \pm 0.5 \mathrm{pg} / \mathrm{L})$. The calibration procedure was repeated three times for 1 week each, using all 12 columns. This experiment revealed that the collecting efficiency of the test columns was $9.2 \mathrm{~L}$ air/week $( \pm 0.3 \mathrm{~L} / \mathrm{wk})$. Reproducibility of the columns under these conditions varied from $5 \%$ to $15 \%$ among the 12 columns for the three tests.

The columns were then tested for temperature effects by placing them in ovens or refrigerators at constant temperature, and measuring the actual mercury concentrations as well as the values collected by the columns. The results were less clear because of problems in assessing the correct blanks at higher temperatures and a rather high level of mercury in the oven $(20-40 \mathrm{pg} / \mathrm{L}$, varying directly with temperature). The elevated mercury in the oven made continuous monitoring of the actual concentration impossible. Thus, discrete 1-hour samples were taken several times each day and averaged. As the 1-hour samples were much more uncertain than the 24-hour integrals, the data collected included more extraneous noise. Overall, however, when considering data collected from $-2^{\circ} \mathrm{C}$ to $55^{\circ} \mathrm{C}$, the temperature effect appears very small (when a linear regression was performed, an increase in uptake rate of about $0.2 \%$ for every $10^{\circ} \mathrm{C}$ was observed, although the $r^{2}$ for the test was only $(0.65)$. These results suggest that, within the normal environment range, temperature variations within a sampling period can be ignored and an average value used.

It was impossible, within the funds remaining in the project, to conduct an ambitious field testing project at the Oak Ridge National Laboratory (where a major mercury problem exists and daily samples are taken at many locations), as was originally hoped. Instead, the collectors were tested over a 1-month period at a residential location in Sequim, Washington. The values collected at this site (1.5 to $4.2 \mathrm{pg} / \mathrm{L} \mathrm{Hg})$ are nearly as low as clean background oceanic air $(1.8 \mathrm{pg} / \mathrm{L})$. The results of the four consecutive sampling periods show good agreement between the data from the passive collectors and the actual 1-week averages, as measured using the mass flowmeter/ pumping system. On average, the passive collectors reported about 10\% lower levels, with the trend toward better agreement at higher mercury levels. Although it was impossible to continue the work necessary to prove the assertion, the discrepancy was probably due to incorrect assessment of the blank values--a difficult and critical process when the total signal is on the order of only three to five times the blank value. 


\section{Educational Institution Interactions}

As part of its mission, PNL contributes to the expansion of science and technology education by building partnerships and developing collaborative programs with high schools, colleges, and universities in the region. Through these programs, students and teachers are provided access to some of the Laboratory's unique facilities, such as the advanced Biogeochemical Laboratories, the Environmental Research Park, Marine Sciences Laboratory, Aerosol Research Center, Watershed Research Facility, Subsurface Environmental Research Facility, and the Hanford Research and Model Validation Facility.

The Northwest Organization for Colleges and Universities for Science (NORCUS) and the Associated Western Universities (AWU) serve as the mechanisms for students and faculty appointments to these programs. The programs are coordinated by the PNL offices of University Programs and Pre-University Education.

\section{Pre-University Interactions}

PNL scientists participate in pre-university education activities such as 1) classroom instruction and demonstrations; 2) student apprenticeships, workshops, and field days in the laboratory; 3) teacher workshops and cooperative studies; and 4) technical support and assistance to local and regional schools.

During FY 1989, PNL hosted one of seven DOE High School Student Honors Research Institutes. This institute offered students from across the United States and several foreign countries the unique opportunity to study arid, alpine, river, stream and ocean ecosystems. PNL researchers guided students in field observations, laboratory experimentation, analytical experimentation, computer modeling and the use of advanced satellite technologies. Spanning the state of Washington, students learned how researchers solve environmental problems within the context of PNL's advanced capabilities in environmental sciences. Students worked closely with PNL scientists to observe, analyze, and measure environmental change--both natural and human induced-learning about interactions among the hydrologic, atmospheric, and biotic components of the environment, on both local and global scales, to better understand the potential impacts of these changes on local and global systems. Students worked at PNL in Richland, Hanford's ALE Reserve, and PNL's Marine Sciences Laboratory in Sequim.
Researchers also worked in the laboratory with teachers participating in the national DOEsponsored Teacher Research Associates (TRAC) program. This program gives teachers an opportunity to participate in "hands-on" science for 8 weeks during the summer. Eight of 20 national/ regional appointees were assigned to environmental sciences research work participating in research in marine sciences, terrestrial sciences, geosciences, and atmospheric sciences. Teachers assisted in such activities as 1) the development of marine water column and sediment bioassays, 2) geochemical studies of low-level nuclear/ hazardous waste disposal, 3) vegetation and bird nesting classification studies in sagebrush-grass communities, 4) microbiological studies, 5) modeling of crustal plate motions and geology of the Pacific Northwest, 6) precipitation studies, 7) wind energy studies, and 8) gathering of radiotelemetry, weather, and climatic data for use in ALE Reserve studies. Each teacher participating in the program developed instructional strategies for use in the classroom based on their laboratory experience.

Researchers participated in a 1-week marine research experience for Washington State high school students at the Marine Sciences Laboratory. Studies included estuarine, intertidal, near shore, field and forest studies of animals and plants as well as water quality issues, marine toxicant studies, and marine organism pathology. 
Researchers made presentations at local, regional, and community schools through the expanded Sharing Science with Schools Program. These presentations covered subjects such as wildife biology, ecology, and marine biology.

\section{University Interactions}

Through NORCUS, PNL provides university undergraduates, graduates, postdoctoral scientists, and faculty an opportunity to work together in research activities and participate in seminars, scientific meetings, and symposia.

During FY 1989, several university faculty, graduate, and undergraduate students participated in Environmental Sciences programs; some of their research projects are summarized below. The Environmental Sciences Program also hosted numerous visiting scientists during the year for workshops, seminars, and DOE program reviews.

In addition, PNL staff also are members of the graduate and teaching faculty at a number of universities, including the University of Washington, Washington State University, and the University of idaho. Their faculty appointments build on both PNL and university programs by sharing ideas and technology through research and teaching interactions.

\section{Hanford Environmental Research Park}

The focus of Environmental Research Park activities has been changed from its previous aim of providing logistic support for graduate students to that of providing a synthesis of existing ecological data sets among the six Research Park locations in Washington, Idaho, New Mexico, Illinois, Tennessee, and South Carolina.

Workshops summarizing ecological data sets, plant succession, analysis of line transect data, and computer facilities were conducted at New Mexico State University, Oak Ridge National Laboratory, and PNL during the past year.

\section{Subsurface Science}

Subsurface science research has been conducted in close coordination with university scientists. Through subcontracts and NORCUS appointments, PNL is collaborating with scientists from
Oregon State University, University of Wisconsin, Purdue University, University of Florida, Florida State University, University of Illinois, Virginia Polytechnic Institute, and Princeton University. For example, Dr. J. Westall of Oregon State University is providing expertise and research perspective on the interfacial science and mechanistic modeling of organic and inorganic solute adsorption, currently unavailable at PNL.

Collaboration with academic subsurface investigators has continued as part of the DOE Deep Microbiology program. This collaboration by Florida State University and University of Illinois investigators has continued this year. Dr. D. Balkwill of Florida State University will continue to cooperate through his work on elucidating the variation and diversity of heterotrophic bacteria in aquifers. Drs. A. Valocchi and B. Rittman of University of illinois are collaborating on the development of a model for multidimensional solute transport with microbiological and chemical reactions.

This year, collaborations were initiated with Dr. D. Johnstone at Washington State University. Dr. Johnstone spent several months this past summer at PNL studying starvation effects on subsurface bacteria. Collaborations are continuing on starvation-degradation interactions.

Faculty and graduate students from Virginia Polytechnic Institute and Princeton are performing some of the modeling necessary to test hypotheses on multiphase flow. Drs. J. Parker and R. Lenhard of Virginia Polytechnic Institute are modeling idealized two-dimensional flow cell experiments and making codes available to PNL to better evaluate flow experiments. At Princeton, Dr. G. F. Pinder is directing graduate research on the interphase transfer between isolated organic liquid globules and water in porous media.

\section{Marine Sciences}

Battelle's Marine Sciences Laboratory is collaborating with the University of Washington to determine the fate and potential effects of spilled fuel oil on the inter- and subtidal ecology of the Olympic National Park and other areas of the Washington coast. 
Mr. Roger J. Peters received his master of science degree in June 1989 from the School of Fisheries, University of Washington. His thesis work was conducted at the Marine Sciences Laboratory in Sequim, Washington, and was supported in part by NORCUS. His thesis was entitled, "A Comparison of Two Methods for Determining Avoidance of Water Soluble Petroleum Hydrocarbons by Salmonids."

\section{Theoretical Ecology}

Cooperative research is currently being conducted with $\mathrm{Dr}$. John Skalski of the University of
Washington Center for Quantitative Sciences and Dr. Don Siniff of the University of Minnesota's population dynamics group. The theoretical projects also supported a postdoctoral scientist (Dr. Valerie Cullinan) who has been conducting research on quantitative-methods in landscape ecology and a doctoral student (Mr. Steve Smith) who worked on new methods for the analysis of survival data under intervention scenarios. These appointees as well as other university scientists strengthen our research capabilities in theoretical and quantitative ecology. 


.




\section{Technology Transfer}

Technology originating from research by DOE or other government agencies and industry may have great value in solving many of the pressing problems of the nation. This cross-fertilization of technology and ideas can have a synergistic effect, adding to the usefulness of the research. Contract arrangements between DOE and Battelle Memorial Institute allow for inventive ways of accelerating the development of technology and to facilitate transfer to and implementation in sectors that may make the best use of the information. Examples of technology transfer activities to other Federal agencies and industry are summarized below.

\section{Detecting and Managing Change in Terrestrial Ecosystems}

PNL is actively engaged in extending laboratoryand program-based concepts to the marketplace. This process has been made substantially easier through the National Competitiveness Technology Transfer Act of 1989. The "Biobarrier Concept," originally developed in 1978, through DOE/OHER and DOE/UMTRAP Programs, to limit the growth of plant roots into waste containment areas has been adapted to a variety of commercial needs. Through the joint venture process, PNL has developed a series of commercial root control products incorporating a class of herbicides known as dinitroanilines and sustained-release polymer delivery systems. Products can be engineered to provide protection for anywhere from 5 to 100 years depending on application needs. Product lines are currently available from Reemay Incorporated of Old Hickory, Tennessee, which markets a geotextile fabric incorporating biobarrier systems for root control. These products control root growth into buried waste zones, and are used in the vertical configuration to protect sidewalks and curbs from upheaval by tree roots. Agrifim International of San Francisco, California, markets a line of buried drip irrigation devices in which the critical orifice is protected from clogging by roots, and markets a product to limit adventitious shoot and root growth in agronomic plant species. Mantaline Corporation of Mantua, Ohio, markets sewer line sealing gaskets which if breached will prevent root intrusion. In addition, a number of other product applications are in the licensing stage.

Currently, a variety of new product applications are being developed and deployed through the joint venture process. These include sustainedrelease systems for mammalian growth hormones, microbial nutrients, plant growth regulators, and insecticides. Notably among these are applications pertinent to DOE needs. The first application is a chemical/biological control method to depress the fire ant population in the southern tier states. The fire ant is attracted to electrical fields and can cause significant damage to electrical systems, and thus poses a threat to construction of the DOE Supercollider proposed for construction in Texas. The second application is a biodegradable, sustained-release, mixed density system to deliver microbial nutrients within aquifers, and thus promote the effective use of microbial remediation methods for groundwater cleanup.

In 1983 the PNL Aerosol Wind Tunnel Research Facility was developed to address the impacts of air-suspended materials to both the environment and industry. This facility, located on the Hanford Site, includes a climate-controlled wind tunnel that has provided valuable information to studies for the Department of Defense, DOE, U.S. Nuclear Regulatory Commission (NAC), and the U.S. Environmental Protection Agency (EPA). Specific environmental conditions are achieved within the facility's wind tunnel. Controlled conditions include wind speed from 0 to $31 \mathrm{~m} / \mathrm{s}$ (0 to $70 \mathrm{mph}$ ), temperature from -2 to $46^{\circ} \mathrm{C}\left(28\right.$ to $\left.115^{\circ} \mathrm{F}\right)$, and humidity from $5 \%$ to more than $95 \%$. In addition, lamps are used to recreate both visible and ultraviolet wavelengths present in nature and to permit studies of photochemical reactions such as those associated with pollutant transformations in pesticides and smog. Once an appropriate environment is created within the wind tunnel, aerosols are generated and vapors created by a variety of methods including mechanical powder dispersion, 
liquid atomization, and combustion. In addition, specific aerosol tracers are used in studies of deposition and resuspension. Aerosols are characterized using physical, chemical, and optical methods.

The wind tunnel provides the capability to investigate real-world events in a simulated environment and allows tests to be performed at specific characterized conditions in a cost-effective manner. Ongoing research that could result in improved technology includes study of the use of natural materials for long-term stabilization of protective barriers for waste sites in arid lands; characterization of the aerosol retention effectiveness of engineered safety features present in nuclear power plants; pesticide spray efficacy; and studies of the generation, transport, physical properties, chemical fate, and environmental effects of aerosols. Other future plans include investigations of acid fog, pesticide sprays, particle resuspension from waste sites, dynamics of freeze-thaw and frozen lens formation in soils; development of aerosol tracers for subsurface drilling activities; stabilization of mill tailing sites; and impacts of aerosols on the environment.

\section{Subsurface Transport}

Research on the OHER SUbsurface Transport program led to the invention of a device, submitted for patent, for measuring the concentration and relative distribution of water and organic liquids in porous media. The potential for technology transfer applications is great. For example, the device can be used to detect leaks from underground tanks of gasoline, diesel and jet engine fuels, and industrial solvents.

The low-cost device is constructed from a lightemitting diode and a light-detecting cell on either side of a small (4-mm-thick by $1-\mathrm{cm}$-square) plate. The plate, if made of porous fritted glass, preferentially absorbs water; if made of porous fritted polyethylene, it absorbs organic liquids. The amount of liquid the porous plate absorbs is related to the amount of the liquid in the surrounding soil. In turn, the amount and capacity of the absorbed liquid changes the amount of light reaching the light-detecting cell. Because the cell responds to the varying light with a change in electrical resistance, the reading on an ohm meter reflects the amount of liquid in the soils or sediments. For organic liquids in the subsurface, the reading indicates the level of contamination.

The device is a major advance in the technology available for measuring liquids in partially saturated soil and other similar media. It allows in situ measurements; it is not compromised by the electrical conductivity of soluble ions; it requires little maintenance; and it is much cheaper than previous methods.

Two studies funded by EPA are using capabilities developed in the DOE subsurface transport program. in a recently completed study for the EPA Office of Research and Development, estimates of octanol/water partition coefficients and water solubilities were reported for selected high molecular weight chlorinated dioxins and dibenzofurans. Accurate measurements of the physicochemical properties of hazardous compounds are important in exposure assessment. An ongoing study funded by the same EPA office is evaluating the status of knowledge of the influence of volatilization and particle resuspension processes on the atmospheric concentration of contaminants at hazardous waste sites. The results are being used to identify research needed to evaluate the relative influence of vapor versus particle transport of lowvapor-pressure, highly sorbed organic compounds downwind from hazardous waste sites. Thus, the results from both these studies are helping EPA guide regulatory policy aimed at making sound decisions for existing hazardous waste problems, and help anticipate problems created by future waste disposal practices.

Before genetically engineered microorganisms (GEMs) can be released into the field, standard biotechnology risk assessment protocols must be developed to adequately test GEM fate and ecological impact in the laboratory. These laboratory systems must mimic the field to be of use for risk assessment. One study funded by EPA is determining how well intact soil-core microcosms mimic the field in determining the fate of added microorganisms and their impacts on ecosystem structure and function. Preliminary results suggest that intact soil-core microcosms can adequately predict microbial fate and ecological effects on other microorganisms and plant growth and function. A field-microcosm comparison is currently under way. These results are promising in developing 
the intact soil-core microcosm as a standard biotechnology risk assessment protocol that is both cost effective and adequately mimics the field.

\section{Marine Sciences}

During 1989, numerous requests were received from regional fish and shelfish farms and from federal and state government agencies to provide advice or research on health management or disease problems of fish and shelfish. This activity applies to both farmed and natural populations of fish and shellfish. No other organization provides this assistance. Over eighty instances of such assistance were provided. in conducting these activities, specific research methodologies or specific disease discoveries were used that resulted directly from the OHER-sponsored research conducted on this program since 1985. 


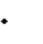


Publications
and
Presentations 


\section{Publications}

\section{Detecting and Managing Change in Terrestrial Ecosystems}

Beedlow, P. A., P. Van Voris, and L. E. Rogers. 1988. 'Theoretical Perspective on Ecosystem Disturbance and Recovery." In Shrub-Steppe: Balance and Change in a Semi-Arid Terrestrial Ecosystem, eds. W. H. Rickard, L. E. Rogers, B. E. Vaughan, and S. F. Liebetrau. Elsevier Science Publishing Company, Inc., New York.

Bolton, H., Jr., J. L. Smith, and R. E. Wildung. 1988. Nitrogen Mineralization Potential of Arid Shrub-Steppe Soils." In Agronomy Abstracts, 80th Annual Meeting of the American Society of Agronomy. American Society of Agronomy, Madison, Wisconsin.

Cushing, C. E., and B. E. Vaughan. 1988. 'Springs and Streams." In Shrub-Steppe: Balance and Change in a Semi-Arid Terrestrial Ecosystem, eds. W. H. Rickard, L. E. Rogers, B. E. Vaughan, and S. F. Liebetrau, pp. 85-107. Elsevier Science Publishing Company, Inc., New York.

Eberhardt, L. E., R. G. Anthony, and W. H. Rickard. 1989. "Movement and Habitat Use by Great Basin Canada Goose Broods." J. Wildl. Manage. 53:740-748.

Eberhardt, L. E., R. G. Anthony, and W. H. Rickard. 1989, "Survival of Juvenile Canada Geese During the Rearing Period." $\checkmark$. Witoll. Manage, 53:372-377.

Eberhardt, L. E., G. G. Books, R. G. Anthony, and W. H. Rickard. 1989. "Activity Budgets of Canada Geese During Brood Rearing." Auk 106:218-224.

Evans, R. D., R. A. Black, and S. O. Link. (in press). "Rehydration induced Change in PressureVolume Relationships of Artemisia tridentata (Nutt.) var tridentata." Plant, Cell, and Environment.

Gee, G. W., P. A. Beedlow, and R. L. Skaggs. 1988. Water Balance." in Shrub-Steppe: Balance and Change in a Semi-Arid Terrestrial Ecosystem, eds. W. H. Rickard, L. E. Rogers, B. E. Vaughan, and S. F, Liebetrau. Elsevier Science Publishing Company, inc., New York.
Hall, J. A. 1988. "Early Chick Mobility and Brood Movernents in the Forster's Tern (Sterna foresteri)." J. of Field Ornithol. 59:247-251.

Link, S. O., G. W. Gee, and J. L. Downs. (in press). The Effect of Water Stress on Bromus tectorum and Pos secunda." J. Range Manage.

Link, S. O., G. W. Gee, M. E. Thiede, and P. A. Beedlow. (in press). "Response of a Shrub-Steppe Ecosystem to Fire: Soil Water and Vegetational Change." Arid Soil Research and Rehabilitation.

Link, S. O., and T. H. Nash III. 1988. 'A Comparison of Lichens from Contrasting Environments Based on Models of $\mathrm{CO}_{2}$ Exchange. Lichen Physiology and Biochemistry 3:37-51.

Link, S. O., M. E. Thiede, R. D. Evans, J. L. Downs, and G. W. Gee. 1989. "Responses of Artemisia tridentata and Grayia spinosa to Increasing Seasonal Drought." Northwest Sci. 63:63.

McCorquodale, S. M., L. L. Eberhardt, and L. E. Eberhardt. 1988. "Dynamics of a Colonizing Elk Population." J. WildI. Manage. 52:309-313.

McCorquodale, S. M., K. J. Raedeke, and R. D. Taber. 1989. "Home Ranges of Elk in an Arid Environment." Northwest Sci. 63;29-34.

Poston, T. M., D. C. Klopfer, and M. A. Simmons. (in press). "Short-Term Bioaccumulation Studies of Neptunium in Freshwater Biotas.' Health Phys.

Rickard, W. H. 1988. "Climate of the Hanford Site." In Shrub-Steppe: Balance and Change in a SemiArid Terrestrial Ecosystem, eds. W. H. Rickard, L. E. Rogers, B. E. Vaughan, and S. F. Liebetrau, pp. 13-21. Elsevier Science Publishing Company, Inc., New York.

Rickard, W. H., L. E. Rogers, B. E. Vaughan, and S. F. Liebetrau, eds. 1988. Shrub-Steppe: Balance and Change in a Semi-Arid Terrestrial Ecosystem. Elsevier Science Publishing Company, Inc., New York. 
Rickard, W. H., and B. E. Vaughan. 1988. "Plant Communities: Characteristics and Responses." in Shrub-Steppe: Balance and Change in a Semi-Arid Terrestrial Ecosystem, eds. W. H. Rickard, L. E. Rogers, B. E. Vaughan, and S. F. Liebetrau, pp. 109-179. Elsevier Science Publishing Company, Inc., New York.

Rogers, L. E., R. E. Fitzner, L. L. Cadwell, and B. E. Vaughan. 1988. Terrestrial Animal Habitats and Population Responses." In Shrub-Steppe: Balance and Change in a Semi-Arid Terrestrial Ecosystem, eds. W. H. Rickard, L. E. Rogers, B. E. Vaughan, and S. F. Liebetrau, pp. 181-256. Elsevier Science Publishing Company, Inc., New York.

Rogers, L. E., and W. H. Rickard. 1988. "Introduction: Shrub-Steppe Lands.' In Shrub-Steppe: Balance and Change in a Semi-Arid Terrestrial Ecosystem, eds. W. H. Rickard, L. E. Rogers, B. E. Vaughan, and S. F. Liebetrau, pp. 1-12. Elsevier Science Publishing Company, Inc., New York.

Wildung, R. E., and T. R. Garland. 1988 "Soils: Carbon and Mineral Cycling Processes.' in ShrubSteppe: Balance and Change in a Semi-Arid Terrestrial Ecosystem, eds. W. H. Rickard, L. E. Rogers, B. E. Vaughan, and S. F. Liebetrau, pp. 23-59. Elsevier Science Publishing Company, Inc., New York.

\section{Subsurface Science}

Ainsworth, C. C., J. M. Zachara, and S. C. Smith. 1989. "Carbazole Sorption by Surface and Subsurface Materials: Influence of Sorbent and Solvent Properties." Soil Sci. Soc. Ann. J. 53:1391-1401.

Balkwill, D. L., J. K. Fredrickson, and J. M. Thomas. 1989. Vertical and Horizontal Variations in the Physiological Diversity of the Aerobic Chemoheterotrophic Bacterial Microflora in Deep Southeast Coastal Plain Subsurface Sediments." Appl. Environ. Microbiol. 55:1058-1065.

Bolton, H., Jr., S. W. Li, D. J. Workman, and D. C. Givin. 1989. "Chelate Biodegradation in Subsurface Sediments." In Agronomy Abstracts, 81st Annual Meeting American Society of Agronomy, p. 211. American Society of Agronomy, Madison, Wisconsin.
Brockman, F. J., B. A. Denovan, R. J. Hicks, and J. K. Fredrickson. 1989. "Isolation and Characterization of Quinoline-Degrading Bacteria from Subsurface Sediments." Appl. Environ. Microbiol. 55:1029-1032.

Brockman, F. J., B. A. Denovan, B. D. McVeety, L. R. Bohn, R. J. Hicks, and J. K. Fredrickson. 1989. "Quinoline Degradation by a Bacterium Isolated from Deep Subsurface Sediments.' In Bioremediation - The Use of Genetically Engineered or Adapted Microorganisms in the Treatment of Hazardous Wastes. Hazardous Materials Control Research Institute, Silver Spring, Maryland.

Cary, J. W., and J. F. McBride. 1989. 'Trichloroethylene Residuals in the Capillary Fringe as Affected by Air-Entry Pressures.' J. Environ. Qual. 18:72-77.

Cary, J. W. J. F. McBride, and C. S. Simmons. (in press). "Assay of Organic Liquid Contents in Predominantly Water-Wet Unconsolidated Porous Media." J. Contaminant Hydrology.

Cary, J. W., J. F. McBride, and C. S. Simmons. 1989. "Electro-Optic Detection of Liquid in Translucent Porous Material." Soil Sci. Soc. Am. J. 53:1591-1595.

Cary, J. W., C. S. Simmons, and J. F. McBride. 1989. "Observations of Water and Oil Infiltration into Soil; Some Simulation Challenges." Water Resour. Res. 25:73-80.

Cary, J. W. C. S. Simmons, and J. F. McBride. 1989. 'On Predicting Oil Infiltration and Redistribution in Unsaturated Soils." Am. Soll Sci. Soc. J. 53:335-342.

Cary, J. W. C. S. Simmons, and J. F. McBride. (in press). "Permeability of Air and Immiscible Organic Liquids in Porous Media." Water Aesources Bulletin.

Conca, J. L., and J. Wright. (in press). "Diffusion Coefficients in Gravel Under Unsaturated Conditions." Water Aesour. Res. 
Conca, J. L., and J. Wright. (in press). 'Effect of Meteoric Infiltration on the Aqueous Chemistry of Paintbrush Tutf During Exposure at the Surface." Radioactive Waste Management and the Nuclear Fuel Cycle.

Cotter, J. M., D. J. Holford, and D. M. Thomas. 1989. "Modeling Radon Transport in Soil Gas." EOS 70(43).

Fredrickson, J. K., T. R. Garland, R. J. Hicks, S. W. Li, K. M. McFadden, and J. M. Thomas. 1989. "Chemolithotrophic and Heterotrophic Bacteria in Deep Subsurface Sediments and Their Relationship to Pore Water Chemistry. "Geomicrobjology J. 7:53.66.

Fredrickson, J. K., R. J. Hicks, S. W. Li, and F. J. Brockman. 1988. "Plasmid Incidence in Bacteria from Deep Subsurface Sediment." Appl. Environ. Microbiol. 54:2916-2923.

Girvin, D. C., A. J. Scott, and H. Bolton, Jr. 1989. influence of EDTA and Fe(III) on Cobalt Sorption by y-A1203." In Agronomy Abstracts, 81st Annual Meeting American Society of Agronomy, p. 65. American Society of Agronomy, Madison, Wisconsin.

Hicks, R. J., and J. K. Fredrickson. 1989. "Aerobic Metabolic Potential of Microbial Populations Indigenous to Deep Subsurface Environments." Geomicrobiology J. 7:67-77.

Holford, D. J., G. W. Gee, P. C. Owczarski, and H. D. Freeman. 1988. "A Finite Element Model of Radon Advection and Diffusion in Unsaturated, Cracked Soils.' Abstract, Transactions, EOS 69(44): 1216 .

Holford, D. J., S. D. Schery, J. L. Wilson, and F. M. Phillips. 1989. Radon Transport in Dry, Cracked Soil: Two-Dimensional, Finite Element Model. PNL-7116, Pacific Northwest Laboratory, Richland, Washington.

Kaluarachchi, J. J., and J. C. Parker. 1989. "An Efficient Finite Element Method for Modeling Multiphase Flow." Water Resour. Res. 25:43-54.

Lenhard, R. J., J. C. Parker, and J. J. Kaluarachchi. 1989. "Model for Hysteretic Constitutive Relations Governing Multiphase Flow 3. Refinements and Numerical Simulations." Water Resour. Res. 25:1727-1736.
Long, P. E. 1989. "Interaction of Basalt Flows with Water During Emplacement and Solidification." In Continental Magmatism Abstracts, Bulletin 131, New Mexico Bureau of Mines and Mineral Resources. General Assembly, Santa Fe, New Mexico, June 25 - July 1, 1989.

Long, P. E., J. M. DeGraft, and A. Aydin. 1989. - Use of Joint-Growth Directions and Rock Textures to Infer Thermal Regimes During Solidification of Basattic Lava Flows." J. Volcanology and Geothermal Research 38:309-324.

Long, P. E., R. T. Holcomb, R. P. Denlinger, and J. E. Cox. 1989. "Vesicularity of Basalt Near the Surface of a Lava Flow That Ponded in Kilauea Caldera, July 19-22, 1974.' EOS 70(43):1422.

McBride, J. F. 1990. Review of "Dense Chlorinated Solvents in Porous and Fracture Media: Model Experiments." J. Environ. Qual. 19:1.

McBride, J. F., F. J. Brockman, and J. E. Szecsody. 1989. "Kinetics of Quinoline Degradation, Sorption, and Desorption in a Clay-Coated Model Soil Containing a Quinoline-Degrading Bacterium.' Abstract In Chemical Mediation of Pollutant Transport in Aqueous Systems. American Chemical Society, Honolulu, Hawaii.

McBride, J. F., J. W. Cary, and C. S. Simmons. 1989. "Direct Measurement of the Spreading Pressure of Organic Liquids on Water.' $J$. Colloid and Interface Sci. 132(2):363-372.

McCarthy, J. M., and J. M. Zachara. 1989. 'Subsurface Transport of Contaminants: The Role of Colloidal Particles." Environ. Sci. \& Technol. 23:496-502.

Murphy, E. M., S. N. Davis, A. Long, D. Donahue, and A. J. T. Jull. 1989. "Characterization and Isotopic Composition of Organic and Inorganic Carbon in the Milk River Aquifer." Water Resour. Res. 25(8):1893-1905.

Murphy, E. M., S. N. Davis, A. Long, D. Donahue, and A. J. T. Jull. $1989 .{ }^{114} \mathrm{C}$ in Fractions of Dissolved Organic Carbon in Ground Water.' Nature 337(6203):153-155.

Murphy, E. M. J. M. Zachara, and S. C. Smith. (submitted). Influence of Mineral-Bound Humic Substances on the Sorption of Hydrophobic Organic Compounds.' Environ. Sci. \& Technol. 
Owczarski, P. C., D. J. Holford, H. D. Freeman, and G. W. Gee. (submitted). 'Effects of Changing Water Content and Atmóspheric Pressure on Radon Flux from Surfaces of Five Soil Types." Geophysical Research Letters, special radon issue.

Owczarski, P. C., D. J. Holford, H. D. Freeman, and G. W. Gee. 1989. "Effects of Soil Porosity, Permeability, and Water Content on Radon Flux from Soil Surfaces." Abstract, Transactions, EOS 70(15):500.

Russell, B. F., P. E. Long, D. Balkwill, T. J. Phelps, R. Colwell, G. Stomberg, A. L. Jacobsen, J. H. Kitchen, and $\mathrm{H}$. Bledsoe. 1989. 'Obtaining Microbially Representative Geologic Samples from Boreholes: DOE Proposed Requirements." EOS 70(43):1079.

Simmons, C. S., J. W. Cary, and J. F. McBride. 1989. "Subsurface Organic Fluid Flow." In Pacific Nonthwest Laboratory Annual Repont for 1988 to the DOE Office of Energy Research: Part 2, Environmental Sciences. PNL-6800, Pt. 2, pp. 29-34, Pacific Northwest Laboratory, Richland, Washington.

Szecsody, J. E., and G. P. Streile. 1989. 'Tracer Advection and Diffusion In Layered Systems.' Abstract in EOS: Transactions of the American Geophysical Union 70(43):1092.

Wright, J. (in press). "Conodont Apatite: Structure and Geochemistry." In Metazoan Biomineralization: Patterns, Processes and Evolutionary Trends, ed. J. Carter. 28th International Geological Congress, Paleontological Society and American Geophysical Union, Washington, D.C.

Wright, J. (in press). "Conodont Geochemistry, a Key to the Paleozoic." In 1st International Senckenberg Conference and 5th European Conodont Symposium (ECOS V Contributions III, ed. W. Ziegler. Courier Forschungsinstitut Senckenberg, Frankfurt, Germany.

Wright, J., J. L. Conca, J. Repetski, and J. Clark. (in press). "Microgeochemistry of Some Lower Ordovician Cordylodams from Jilin, China.' In Ist international Senchkenberg Conference and 5 th European Conodont Symposium (ECOS V) Contributions $I I$, ed. W. Ziegler, Courier Forschungsinstitut Senkenberg, Frankfurt, Germany.
Zachara, J. M., J. A. Kittrick, L. S. Dake, and J. B. Harsh. 1989. 'Solubility and Surface Spectroscopy of Zinc Precipitates on Calcite.' Geochimica et Cosmochimica Acta 53:9-19.

Zachara, J. M., C. C. Ainsworth, and R. L. Schmidt. (in press). The Effect of Ring Number on the Sorption of N-Heterocycle Compounds by Reference Clays and Natural Clay Isolates from Subsurface Materials," Contam. Hydrol.

Zachara, J. M., C. C. Ainsworth, C. C. Cowan, and A. L. Schmidt. (in press). The Sorption of Aminonaphthalene and Quinoline on Amorphous Silica.' Environ. Sci. \& Technol.

Zachara, J. M., J. K. Fredrickson, F. J. Brockman, J. F. McBride, D. K. Balkwill, and C. T. Resch. (submitted). "Microorganisms in Deep Cretaceous Age Sediments of the South Carolina Coastal Plain: Sampling Complications and Vertical Population Variations.' Water Resour. Res.

\section{Marine Sciences}

Dungan, C. F., R. A. Elston, and M. H. Schiewe. 1989. "Evidence for Colonization and Destruction of Hinge Ligaments in Cultured Juvenile Pacific Oysters (Crassotrea gigas) by Cytophaga-Like Bacteria," Appl. Environ. Microbiol. 55(5):11281135.

Farley, C. A., P. H. Wolf, and R. A. Elston. 1988. 'A Long-Term Study of 'Microcell' Disease in Oysters with a Description of a New Genus, Mikrocytos (G. N.), and Two New Species, Mikrocytos mackini (sp. N.) and Mikrocytos roughleyi (sp. N.)." Fishery Bulletin 86(3):581.

Tibbs, J. F., R. A. Elston, R. W. Dickey, and A. M. Guarino. 1989, "Studies on the Accumulation of Antibiotics in Shellfish.' Northwest Environ. J. 5(1).

Bower, S. M., D. T. Whitaker, and R. A. Elston. 1989. 'Detection of the Abalone Parasite Labyrintholoides haliotides by a Direct Fluorescent Antibody Technique.' $J$. Invertebr. Pathol. 53:281-283. 


\section{Theoretical Ecology}

Athey, L. A., J. M. Thomas, W. E. Miller, and J. Q. Word. 1989. "Evaluation of Bioassays for Designing Sediment Cleanup Strategies at a Wood Treatment Site.' Environ. Toxicol. and Chem. 8:223-230.

Carlile, D. A., J. A. Skalski, J. E. Batker, and J. M. Thomas. 1989. "Determination of Ecological Scale." Landscape Ecology 2:203-213.

Eberhardt, L. L. (in press). 'A Fur Seal Population Model Based on Age Structure Data.' Canadian J. Fisheries and Aquatic Sci.
Eberhardt, L. L. (in press). "Fadio-Telemetry for Mark-Recapture Studies with Edge Effects." J. Appl. Ecol.

Thomas, J. M., L. A. Athey, and J. A. Skalski. (in press). "Statistical Approaches to Screening Hazardous Waste Sites for Toxicity." In Symposium on Waste Testing and Quality Assurance: Second Volume, ASTM STP 1062, ed. D. Friedman. American Society for Testing and Materials, Philadelphia, Pennsylvania. 


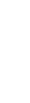




\section{Presentations}

\section{Detecting and Managing Change in Terrestrial Ecosystems}

Bolton, H., Jr., J. L. Smith, and R. E. Wildung. 1988. "Nitrogen Mineralization Potential of Arid Shrub-Steppe Soils." Presented at the American Society of Agronomy Annual Meetings, November 27 - December 2, Anaheim, California.

Campbell, M. D., G. W. Gee, M. L. Rockhold, and M. J. Fayer. 1989. "Continuous Measurements of Water Balance at Arid Sites Using Weighing Lysimeters." Presented at the American Society of Agronomy Annual Meetings, October 14, 1989, Las Vegas, Nevada.

Evans, R. D., R. A. Black, and S. O. Link. 1989. "Osmotic Relations of Artemisia tridentata in Pesponse to Drought." Presented at the 40th Annual American Institute of Biological Sciences Meeting, August 6-10, 1989, Toronto, Ontario, Canada.

Jeffries, D. J., S. O. Link, and J. M. Klopatek. 1989. " $\mathrm{CO}_{2}$ Fluxes of Cryptogamic Crusts in Response to Resaturation." Presented at the Ecological Society of America Meeting, August 6-10, 1989, Toronto, Ontario.

Kirkham, R. A., L. J. Fritschen, and M. O. Smith. 1989. "A Comparison of Evapotranspiration Measurement Methods at the Semiarid Hanford Site." Presented at the American Society of Agronomy Meeting, October 15-20, 1989, Las Vegas, Nevada.

Link, S. O., J. M. Klopatek, D. L. Jeftries, and R. J. Beymer. 1989. "Potential Ecosystem Contributions of Carbon and Nitrogen by Cryptogamic Crusts in Semiarid Landscapes.' Presented at the G. L. Stebbins Symposium: New Developments in Plant Evolution, August 6-10, 1989, Toronto, Ontario.

Link, S. O., M. E. Thiede, R. D. Evans, J. L. Downs, and G. W. Gee, 1989. "Aesponses of Anemisia tridentata and Grayia spinosa to Increasing Seasonal Drought." Presented at the Northwest Science Meetings, March 21-24, 1989, Richland, Washington.

\section{Subsurface Science}

Ainsworth, C. C., and J. M. Zachara. 1989. "Dibenzothiophene Carbon-Peferenced Partitioning with Soil Depth: Implications of Transport Predictions." Presented at the Pesticides in Groundwater Symposium of the American Society of Agronomy Annual Meetings, October 15-20, 1989, Las Vegas, Nevada.

Ainsworth, C. C., B. D. McVeety, and S. C. Smith. 1988. Transformation of an Aromatic Amine at the Surface of Smectite Clays." Presented at the ASA-CSSA-SSSA 1988 annual meetings, November 27 - December 2, 1988, Anaheim, California.

Ainsworth, C. C., B. D. McVeety, and S. C. Smith. 1989. "Surface Catalyzed Transformation of Aminonaphthalene by Reference and Soil Clays." Presented in the symposium of the Chemical Mediation of Pollutant Transport in Aqueous Systems at the PACIFICHEM '89 Meeting, December 17-22, 1989, Honolulu, Hawaii.

Bolton, H., Jr., and D. C. Girvin. 1989. "Microbiology Controlling Chelated Radionuclide Transport." Presented at the Subsurface Science Program Review, June 7, 1989, Gaithersburg, Maryland.

Bolton, H., Jr., S. W. Li, D. J. Workman, and D. C. Girvin. 1989. "Chelate Biodegradation in Subsurface Sediments." Presented at the American Society of Agronomy Annual Meetings, October 19, 1989, Las Vegas, Nevada.

Brockman, F. J., B. A. Denovan, B. D. McVeety, L. R. Bohn, A. J. Hicks, and J. K. Fredrickson. 1988. 'Quinoline Degradation by a Bacterium isolated from Deep Subsurface Sediments." Presented at the Conference on Hazardous Waste Treatment by Genetically Engineered or Adapted Organisms, November 30 - December 2, 1988, Washington, D.C. 
Brockman, F. J., J. F. McBride, and J. E. Szecsody. 1989. "Kinetics of Quinoline Degradation, Sorption, and Desorption in a Clay-Coated Model Soil Containing a Quinoline-Degrading Bacterium.' Symposium on Chemical Mediation of Pollutant Transport in Aqueous Systems, International Chemical Congress Annual Meeting.

Cary, J. W. 1988. "Porous Polyethylene for Detection and Assay of Immiscible Organic Liquids in Unconsolidated Porous Media." Presented at American Geophysical Union Fall Meeting, December 5-9, 1988, San Francisco, California.

Cary, J. W., J. F. McBride, and C. S. Simmons. 1988. 'Liquid Contents of Porous Material: The Electro-Optic Approach." Presented at ASA-CSSASSSA 1988 Annual Meetings, November 27 . December 2, 1988, Anaheim, California.

Cary, J. W., J. F. McBride, and C. S. Simmons. 1988. 'Movement of Hazardous Immiscible Organic Liquids in Soil.' Presented at American Society of Agricultural Engineers Winter Meeting, December 13-16, 1988, Chicago, Illinois.

Cary, J. W., J. F. McBride, and C. S. Simmons. 1989. "Hydraulic Conductivity at a Wetting Front Weighted to Simulate the Haines Jump Phenomenon." Presented at Soil Science Society of America Annual Meetings, October 15-20, 1989, Las Vegas, Nevada.

Cary, J. W., C. S. Simmons, and J. F. McBride. 1988. "Permeability of Air and Immiscible Organic Liquids in Porous Media." Presented at the American Society of Agricultural Engineering, December 14, 1988, Chicago, Illinois.

Fredrickson, J. K., D. Balkwill, J. Zachara, J. McBride, S. Li, and D. Workman. 1989. "Microbial Distribution and Diversity Within Single Formations of Southeast Coastal Plain Unconsolidated Subsurface Sediments." Presented at the Annual Meeting of the American Society of Microbiology, May 14-18, 1989, New Orleans, Louisiana.

Gee, G. W., K. K. Nielson, and V. C. Rogers. 1988. "Radon Gas Transport in Wet Soils." Presented at the 1988 Annual Meeting of ASA-CSSA-SSSA, November 27 - December 2, 1988, Anaheim, California.
Girvin, D. C., and H. Bolton, Jr. 1989. "Chemistry Controlling Chelated Radionuclide Transport." Presemted at the Subsurface Science Program Review, June 7, 1989, Gaithersburg, Maryland.

Girvin, D. C., A. J. Scott, and H. Bolton, Jr. 1989. "Influence of EDTA and Fe(III) on Cobalt Sorption by $\gamma$-A1203." Presented at the American Socjety of Agronomy Annual Meetings, October 19, 1989, Las Vegas, Nevada.

Hicks, R. J., C. A. Ainsworth, L. R. Bohn, F. J. Brockman, B. D. McVeety, and S. C. Smith. 1989. "Effects of Clay Suspensions on the Biodegradation of Quinoline." Presented at the Annual Meeting of the American Society of Microbiology, May 14-18, 1989, New Orleans, Louisiana.

Holford, D. J., P. C. Owczarski, and H. D. Freeman. 1988. "Modeling Radon Transport in Soils." Presented at the 1988 Symposium on Radon and Radon Reduction Technology, October 18-21, 1988, Denver, Colorado.

Lenhard, R. J., and J. C. Parker. 1989. Validating a Hysteresis Air-Flow Model That Accounts for Effects of Air Entrapment." Presented at Soil Science Society of America Annual Meetings, October 15-20, 1989, Las Vegas, Nevada.

McBride, J. F., F. J. Brockman, and J. E. Szecsody. 1989. "Kinetics of Quinoline Degradation, Sorption, and Desorption in a ClayCoated Model Soil Containing a QuinolineDegrading Bacterium." Presented at the symposium on Chernical Mediation of Pollutant Transport in Aqueous Systems, American Chemical Society, December 17-22, 1989, Honolulu, Hawaii.

McBride, J. F., J. W. Cary, and C. S. Simmons. 1988. The Spreading of Organic Liquids on Water: An Important Physical Process in Three-Phase Immiscible Fluid Flow:" Presented at American Geophysical Union Fall Meeting, December 5-9, 1988, San Francisco, California. 
McBride, J. F., J. W. Cary, and C. S. Simmons. 1988. "Uncoupling the Residual Water Content Parameter Between Retention and Conductivity Functions.' Presented at ASA-CSSA-SSSA 1988 Annual meetings, November 27 - December 2, 1988, Anaheim, California.

McBride, J. F., J. W. Cary, and C. S. Simmons. 1989. "interfacial Spreading and ThreeDimensional Hydrocarbon Infittration in a WaterWet Sand." Invited presentation at NATO Advanced Study institute on Transport in Porous Media, July 9-18, 1989, Pullman, Washington.

McBride, J. F., C. S. Simmons, and J. W. Cary. 1989. Three-DimensionalOrganic Liquid Infittration in a Water-Wet Sand." Presented at Soil Science Society of America Annual Meetings, October 1520, 1989, Las Vegas, Nevada.

Murphy, E. M., J. M. Zachara, and S. C. Smith. 1988. The Effect of Mineral-Bound Humic Substances on the Adsorption of Hydrophobic Organic Compounds." Presented at the American Geophysical Union Fall Meeting, December 5-9, 1988, San Francisco, California.

Owczarski, P. C., D. J. Hofford, H. D. Freeman, and G. W. Gee. 1989. 'Effect of Soil Porosity, Permeability, and Water Content on Radon Flux from Soil Surfaces." Presented at the American Geophysical Union Annual Spring Meeting, May 7-12, 1989, Baltimore, Maryland.

Szecsody, J. E., and G. P. Streile. 1989. Tracer Advection and Diffusion in Layered Systems." Presented at the American Geophysical Union Fall Meeting, December 4-8, 1989, San Francisco, California.

Zachara, J. M. 1989. "Sorption of lonizable $\mathrm{N}$-Aromatic Compounds on Specimen Smectite in Water and Methano//Water Mixtures.' Presented at the Division of Environmental Chemistry Special Symposium on Environmental Behavior of Complex Mixtures, September 10-15, 1989, American Chemical Society, Miami Beach, Florida.

Zachara, J. M., and P.S.C. Rao. 1989. "Influence of Sorption on Degradation Processes in Groundwater." Presented in the Chemical Mediation of Pollutant Transport in Aqueous Systems Symposium at the PACIFICHEM '89 Meeting, December 17-22, 1989, Honolulu, Hawaii.
Zachara, J. M., C. C. Ainsworth, and C. E. Cowan. 1988. "Adsorption and Surface Speciation of Organic Bases on Silica." Presented at the American Geophysical Union Fall Meeting, December 5 8, 1988, San Francisco, California.

Zachara, J. M., C. C. Ainsworth, and S. C. Smith. 1988. The Effect of Cosolvent on the Adsorption of Quinoline by Subsoil: A Thermodynamic Perspective." Presented at the ASA-CSSA-SSSA 1988 Annual Meeting, November 27 - December 2, 1988, Anaheim, California.

Zachara, J. M., E. M. Murphy, and S. C. Smith. 1989. "Influence of Mineral Bound Humic Substances on the Sorption of Hydrophobic Organic Compounds by Subsurface Sorbents." Presented at the International Symposium for Governing the Movement and Fate of Contaminants in the Subsurface Environment, July 23-26, 1989, Stanford University, Stanford, California.

\section{Theoretical Ecology}

Cullinan, V. I., and J. M. Thomas. 1989. 'Scales for Studying Ecological Processes." Presented at the Fourth Annual Landscape Ecology Symposium, March 16, 1989, Fort Collins, Colorado.

Eberhardt, L. L. 1989. 'Estimating the Populations of Ungulates." Presented at the Centennial Lecture Series on Predation of Wolves and Ungulates, May 18, 1989, University of Montana, Missoula, Montana.

Simmons, M. A., J. M. Thomas, and C. M. Panwala. 1989. "A Method for Studying the Relationship Between Plant Distribution and Ecological Processes.' Presented at the Northwest Scientific Association, March 21-24, 1989, Richland, Washington.

Simmons, M. A., J. M. Thomas, and C. M. Panwala. 1989. "Plant Distribution and Ecological Processes." Presented at the Symposia on Biological Resources of the Columbia Basin Southeastern Washington, March 23, 1989, Richland, Washington. 
Thomas, J. M. 1989. "A Comparison of Laboratory Derived Toxicity Estimates Based on Waste-Site Soils with Plant Cover and Composition." Presented at the 10th Annual Meeting of the Society of Environmental Toxicology and Chemistry, Octaber 31, 1989, Toronto, Canada.
Thomas, J. M., and M. A. Simmons. 1988. "Use of Ecological Scaling as a Means to Directly Measure Landscape Level Rick to Plants." Presented at the 9th Annual Meeting of the Society for Toxicology and Chemistry, November 13-17, 1988, Arlington, Virginia. 


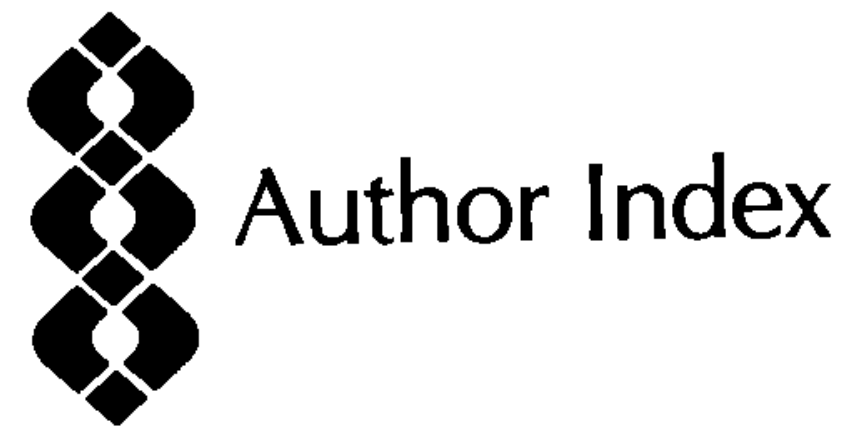




\section{Author Index}

Ainsworth, C. C.; 26

Berntsen-Stephens, L.; 59

Bonar, D.; 59

Bloom, N. S.; 71

Bolton, H., Jr.; 8,35

Brockman, F. J.; 13, 39

Brooks, K; 59

Campbell, M. D.; 7

Cary, J. W.; 47, 49, 51, 52

Crecelius, E. A.; 70

Coughlan, J. (University of Montana); 67

Cullinan, V. 1.; 66, 75

Elston, R. A.; 59

Eberhardt, L. L.; 61, 62

Farwell, S. 0.; 65

Fellows, R. J.; 69
Foley, M. G.; 67

Franz, J. A.; 20

Fredrickson, J. K.; $13,20,21$, 24, 25

Freeman, H. D.; 54, 56

Gee, G. W.; 7, 8, 54, 56

Gibbons, D. E.; 1, 7, 69

Girvin, D. C.; 35

Holford, D. J.; 54, 56

Hoover, K A.; 67

Kirkham, R. R.; 1

Le Baron, B. A.; 1, 69

Lee, A.; 59

Lenhard, R. J. (Virginia

Polytechnic Institute); 47,

52, 74

Linehan, J. C.; 20
Link, S. O.; 1, 8, 9, 10

McBride, J. F.; 39, 47, 48, 52

McVeety, B. D.; 65

Moore, J.; 59

Murphy, E. M.; 20, 26

Owczarski, P. C.; 54, 56

Rao, P.S.C. (University of

Florida); 26

Simmons, C. S.; 47, 48, 52

Simmons, M. A.; 66

Streile, G. P.; 39

Szecsody, J. E.; 39

Thomas, J. M.; 25, 62, 66, 67

Westall, J. C. (Oregon State

University); 26, 74

Wright, J. V.; 55

Zachara, J. M.; 26 

Distribution 


\section{OFFSITE}

W. R. Albers

EH-12, GTN

Department of Energy

Washington, DC 20545

D. Anderson

ENVIROTEST

1108 NE 200th Street

Seattle, WA 98155-1136

V. E. Archer

Rocky Mountain Center

for Occupational \&

Environmental Health

Building 512

University of Utah

50 North Medical Drive

Salt Lake City, UT 84112

Assistant Secretary

Environment, Safety

\& Health

EH-1, FORS

Department of Energy

Washington, DC 20585

S. I. Auerback

Oak Ridge National

Laboratory

Building 1505, MS-6036

P.O. Box 2008

Oak Ridge, TN 37831-6036

J. A. Auxier

IT Corporation

312 Directors Drive

Knoxville, TN 37701

F. Badgley

13749 NE 41 st Street

Seattle, WA 98125
D. L. Balkwill

Department of Biological Sciences 309 Nuclear Research Bldg.

Florida State University

Tallahassee, FL 32306

R. M. Baltzo

Radiological Safety Division

University of Washington

Seattle, WA 98105

R. W. Barber

EH-131, GTN

Department of Energy

Washington, DC 20545

A. D. Barker

Battelle Columbus Laboratories

505 King Avenue

Columbus, $\mathrm{OH} 43201$

J. R. Barker

Office of Environmental

Audit and Compliance

Department of Energy

Washington, DC 20545

W. W. Barker, Chairman

Department of Biology

Central Washington University

Ellensburg, WA 98926

N. F. Barr

ER-72, GTN

Department of Energy

Washington, DC 20545

J. E. Baublitz

Office of Nuclear Energy

NE-20, GTN

Department of Energy

Germantown, MD 20545
J. R. Beall

ER-72, GTN

Department of Energy

Washington, DC 20545

P. A. Beedlow

Environmental Protection

Agency

200 SW 35th Street

Corvallis, OR 97333

M. H. Bhattacharyya

BIM Division, Bldg. 202

Argonne National Laboratory

9700 South Cass Avenue

Argonne, IL 60439

R. A. Black

Department of Botany

Washington State University

Pullman, WA 99164

L. Bliss

Department of Botany

University of Washington

Seattle, WA 98105

H. S. Bolton

National Oceanic \&

Atmospheric Administration

HG Hoover Building,

Room 5222

Department of Commerce

LAX 1

Washington, DC 20230

C. M. Borgstrom

Acting Director, NEPA

EH-25, Room 3E080

Department of Energy

1000 independence

Avenue, SW

Washington, DC 20585 
L. C. Brazley, Jr.

NE-22, GTN

Department of Energy

Washington, DC 20545

\section{A. Brodsky \\ 16412 Kipling Road \\ Derwood, MD 20855 \\ W. Broecher \\ Lamont Geological \\ Observatory \\ Columbia University \\ Palisades, NY 10964 \\ D. R. Buhler, Chairman \\ Toxicology Program \\ Oregon State University \\ Corvallis, OR 97331}

G. Burley

Office of Radiation Programs, ANR-458

Environmental Protection

Agency

Washington, DC 20460

W. W. Burr, Chairman

Medical \& Health Sciences

Division

Oak Ridge Associated

Universities

P.O. Box 117

Oak Ridge, TN 37830

L. K. Bustad

College of Veterinary Medicine

Washington State University

Pullman, WA 99164-7010

S. Calcese

Water Resources Center

University of Wisconsin

1975 Willow Drive

Madison, WI 53706

J. T. Callahan

Associate Program Director

Ecosystems Studies Program

National Science Foundation

Washington, DC 20545
R. J. Cattin, President

Robert J. Catlin Corporation

701 Welch Road, Suite 1119

Palo Alto, CA 94304

H. H. Cheng, Head

Department of Soil Science

University of Minnesota

1991 Upper Buford Circle

St. Paul, MN 55108

G. Chesters, Director

Water Resources Center

University of Wisconsin

1975 Willow Drive

Madison, WI 53706

Chief

Game Management Division

Department of Game

600 North Capitol Way

Olympia, WA 98501

J. S. Coleman

ER-15, GTN

Department of Energy

Washington, DC 20545

W. Conley

ER-75, GTN

Department of Energy

Washington, DC 20545

J. Corey

Environmental Sciences

Savannah River Laboratory

Drawer $\mathrm{E}$

Aiken, SC 29801

Council on Environmental

Ouality

722 Jackson Place, NW

Washington, DC 20503

T. V. Crawtord

Atomic Energy Division

Savannah River Laboratory

E. I. duPont de Nemours \& Company

Aiken, SC 29808
J. Cushman

Water Resources Research

Center

Purdue University

Lilly Hall

West Lafayette, IN 47907

J. T. Davis

San Francisco Operations Office

Department of Energy

1333 Broadway

Oakland, CA 94612

F. G. Dawson

Battelle Memorial Institute

505 King Avenue

Columbus, $\mathrm{OH} 43201$

R. S. Denning

Battelle Columbus

Laboratories

5050 King Avenue

Columbus, $\mathrm{OH} 43201$

Department of Energy

Environment \& Health

Division

P.O. Box 5400

Albuquerque, NM 87115

G. DePlanque, Director

Department of Energy-EMEL

375 Hudson Street

New York, NY 10014

Director

New England Marine

Laboratories

Washington Street

P.O. Box 1637

Duxbury, MA 02332

Director

Washington State

Department of Ecology

Olympia, WA 98501 


\author{
K. R. Dixon \\ Washington Department \\ of Wildlife \\ 600 North Capital Way \\ Olympia, WA 98504

\section{T. J. Dobry, Jr. \\ DP-221, GTN \\ Department of Energy \\ Washington, DC 20545 \\ DOE/Office of Scientific \& \\ Technical Information (12) \\ H. Drucker \\ Argonne National Laboratory \\ 9700 South Cass Avenue \\ Argonne, IL 60439}

A. P. Duhamel
ER.74, GTN
Department of Energy
Washington, DC 20545
D. N. Edgington
University of Wisconsin
Center for Great Lakes
Studies
P.O. Box 413
Milwaukee, WI 53201
C. W. Edington, Director
National Research Council
2101 Constitution Avenue, NW
Washington, DC 20418

W. H. Ellett

BRER--National Research

Council, MH-370

2101 Constitution Avenue, NW

Washington, DC 20418

\section{E. Elliott \\ U.S. Cotton Research Station \\ USDA-ARS \\ 17053 Shafter Avenue \\ Shafter, CA 93263}

\author{
R. D. Evans \\ Department of Botany \\ Washington State University \\ Pullman, WA 99164
}

\section{S. J. Farmer}

17217 77th Avenue W.

Edmonds, WA 98020

B. H. Fimiani

Battelle, Pacific Northwest

Laboratories

Washington Operations

370 L' Enfant Promenade, Suite 900

901 D Street, SW

Washington, DC 20024

W. O. Forster
ER/OHER/ERD
Department of Energy
Washington, DC 20545

Arnold Gahler

Environmental Protection Agency

Region $X$ Laboratory

P.O. Box 549

Manchester, WA 98353

C. George

Office of Defense Programs

DP-12, GTN

Department of Energy

Germantown, MD 20545

T. F. Gesell

Idaho Operations Office

Department of Energy

785 DOE Place

Idaho Falls, ID $83402-4149$

W. C. Ghiorse

Microbiology Department

415 Stocking Hall

Cornell University

Ithaca, NY 14853

R. D. Gilmore, President

Environmental Health

Sciences, Inc.

Nine Lake Bellevue Building

Suite 104

Bellevue, WA 98005

E. D. Goldberg

Scripps Institute of

Oceanography

La Jolla, CA 92039
M. Goldman

Department of Radiological

Sciences (VM)

University of California

Davis, CA 95616

G. Goldstein

ER-74, GTN

Department of Energy

Washington, DC 20545

F. B. Golley

Institute of Ecology

University of Georgia

Athens, GA 30601

K. Grossman

P.O. Box 1680

Sag Harbor, NY 11963

J. D. Hair

National Wildlife Federation

1400 16th Street, NW

Washington, DC 20036

D. H. Hamilton, Jr.

ER-72, GTN

Department of Energy

Washington, DC 20545

W. R. Hansen

MS-F643

Los Alamos National

Laboratory

P.O. Box 1663

Los Alamos, NM 87545

F. Harrison

Biomedical \& Environmental

Research Program

Lawrence Livermore National Laboratory, C-523

University of California

P.O. Box 808

Livermore, CA 94550

D. W. Hayne

Department of Statistics

North Carolina State

University

Box 8203

Raleigh, NC 27695-8203 
A. P. Hull

Safety and Environmental
Protection Division
Brookhaven National
Laboratory
Building 535-A

Upton, Long Island, NY 11973

R. O. Hunter, Jr.
ER-1, FORS
Department of Energy
1000 Independence
Avenue, SW
Washington, DC 20585
F. Hutchinson
Department of Molecular
Biophysics \& Biochemistry
Yale University
260 Whitney Avenue
P.O. Box 6666
New Haven, CT 06511

H. Ishikawa, General Manager

Nuclear Safety Research

Association

P.O. Box 1307

Falls Church, VA 22041

K. L. Jackson, Chairman

Radiological Sciences

Group SB-75

University of Washington

Seattle, WA 98195

A. Janetos

Environmental Protection Agency

401 M Street, SW

Washington, DC 20460

A. W. Johnson

Vice President for

Academic Affairs

San Diego State University

San Diego, CA 92182
L. J. Johnson

Idaho National Engineering

Laboratory

IRC MS 2203

P.O. Box 1625

Idaho Falls, ID 83415

R. Johnson

Office of Radiation

Programs (ANR-460c)

Erivironmental Protection

Agency

$401 \mathrm{M}$ Street, SW

Washington, DC 20460

G. Y. Jordy, Director

ER-30, GTN

Department of Energy

Washington, DC 20545

R. F. Kendall

Bartlesville Energy Research

Center

Department of Energy

P.O. Box 1398

Bartlesville, OK 74005

H. Kibby

Enviromental Protection

Agency

200 SW 35th Street

Corvallis, OR 97333

M. Kosorok

Department of Statistics

Brigham Young University

Provo, UT 84602

R. T. Kratzke

NP-40

Department of Energy

Germantown, MD 20585

D. Krenz

DOE-Albuquerque Operations Office

P.O. Box 5400

Albuquerque, NM 87115
R. T. Lackey

Environmental Protection

Agency

200 SW 35th Street

Corvallis, OR 97333

W. Lauder

Office of Health and

Environmental Research

Office of Energy Research

Department of Energy

Germantown, MD 20545

Librarian

Brookhaven National

Laboratory

Research Library, Reference

Upton

Long Island, NY 11973

Librarian

Colorado State University

Documents Department--The Libraries

Ft. Collins, CO 80523

Librarian

Department of Fisheries/Oceanography

151 Oceanography

Teaching Building

University of Washington

Seattle, WA 98195

Librarian

Electric Power Research

Institute

3412 Hillview Avenue

P.O. Box 10412

Palo Alto, CA 94303

Librarian

Environmental Research

Laboratory

Environmental Protection

Agency, ORD

200 SW 35th Street

Corvallis, OR 97333 
Librarian

Environmental Research

Laboratory

Environmental Protection Agency

Sabine Island

Gulf Breeze, FL 32561

Librarian

Environmental Research Laboratory

Environmental Protection Agency, ORD

Narrangansett, fil 02882

Librarian

Environmental Research Laboratory-Duluth

N. A. Jaworski, Director 6201 Congdon Blvd.

Duluth, MN 55804

Librarian

Frances Penrose Owen

Science \& Engineering Library

Washington State University

Pullman, WA 99164-3200

Librarian

Health Sciences Library, SB-55

University of Washington

Seattle, WA 98195

Librarian

Lawrence Livermore National Laboratory

University of California

Technical Information

Department, L-3

P.O. Box 808

Livermore, CA 94550

Librarian

Los Alamos National

Laboratory

Report Library, MS P364

P.O. Box 1663

Los Alamos, NM 87545
Librarian

Northwest and Alaska

Fisheries Center

National Marine Fisheries

Service, NOAA

2725 Montlake Blvd., East

Seattle, WA 98112

Librarian

Roben S. Kerr Environmental

Research Laboratory

Environmental Protection

Agency, ORD

Ada, OK 74320

Librarian

Southeast Fisheries Center

National Marine Fisheries

Services, NOAA

75 Virginian Beach Drive

Miami, FL 33149

Librarian (Serials Section)

University of Washington

Seattle, WA 98195

Librarian

Washington State University

Pullman, WA 99164-6510

Library

Holcomb Research Institute

Butler University

Indianapolis, IN 46208

Library

Serials Department

(\#80-170187)

University of Chicago

1 t00 East 57th Street

Chicago, IL 60637

O. R. Lunt

Laboratory of Biomedical

\& Environmental Sciences

University of California

900 Veteran Avenue

Los Angeles, CA 90024-1786
J. N. Maddox

ER-73, GTN

Department of Energy

Washington, DC 20545

J. R. Maher

ER-65, GTN

Department of Energy

Washington, DC 20545

C. R. Mandelbaum

ER-32, GTN

Department of Energy

Washington, DC 20545

J. Mangeno

Department of the Navy

Nuclear Propulsion

Directorate

0808 National Center ND2,

Frd Floor Mail Room

Washington, DC 20362-5101

B. Manowitz

Energy and Environment

Division

Brookhaven National

Laboratory

Upton,

Long Island, NY 11973

R. S. Marianelli

Office of Basic Energy

Science

Department of Energy

Washington, DC 20545

O. D. Markham

Radiological and

Environmental Sciences

Laboratory

Department of Energy

785 DOE Place

Idaho Falls, ID 83402

S. Marks

c/o U.S. Marine Corps

Air Station

ABCC/RERF

FPO

Seattle, WA 98764-5000 


K. Marsh
Lawrence Livermore
National Laboratory
P.O. Box 808
Livermore, CA 94550
W. H. Matchett
Graduate School
New Mexico State University
Box 3G
Las Cruces, NM 88003-0001
H. M. McCammon
ER-75, GTN
Department of Energy
Washington, DC 20545
R. O. McClellan, President
Chemical Industry Institute
of Toxicology
P.O. Box 12137
Research Triangle
Park, NC 27709
C. B. Meinhold
Radiological Sciences
Division
Bldg. 703M
Brookhaven National
Laboratory
Upton, Long Island, NY 11973

M. L. Mendelsohn
Biomedical and
Environmental Research
Program
Lawrence Livermore National
Laboratory, L-452
University of California
P.O. Box 5507
Livermore, CA 94550

F. M. Molz

Department of Civil Engineering

Auburn University 238 Harbert Engineering Center

Auburn, AL 36849
D. B. Moore

Westinghouse Savannah

River Company

773-A, A-229

Aiken, SC 29808

J. J. Morgan

California Institute of

Technology

Mail Code 138-78

Pasadena, CA 91125

W. F. Mueller

New Mexico State University

Box 4500

Las Cruces, NM $88003-4500$

I. Murarka

Electric Power Research

Institute

3412 Hillview Avenue

P.O. Box 10412

Palo Alto, CA 94304

T. Murphy, Director

Environmental Research Laboratory

Environmental Protection Agency

200 SW 35th Street

Corvallis, OR 97333

J. R. Naidu

Safety and Environmental

Protection Division

Brookhaven National Laboratory

Building 535-A

Upton, Long Island, NY 11973

N. S. Nelson

Office of Radiation Programs

(ANR-461)

Environmental Protection Agency

401 M Street, SW

Washington, DC 20460

J. M. Nenhold

Department of Wildlife Resources

Utah State University

Logan, UT 84322-5200
W. R. Ney, Executive Director

National Council on

Radiation Protection

and Measurements

7910 Woodmont Avenue

Suite 1016

Washington, DC 20014

C. R. Nichols

Idaho Operations Office

Department of Energy

785 DOE Place

Idaho Falls, ID 83404

Nuclear Regulatory

Commission

Advisory Committee on

Reactor Safeguards

Washington, DC 20555

E. O'Donnell

Mail Stop NLS-260

Nuclear Regulatory

Commission

Washington, DC 20555

R. E. Pacha

Department of Biological

Sciences

Central Washington University

Ellensburg, WA 98926

O. Pavlovski

Institute of Biophysics

Ministry of Public Health

Givopisnaya 46

Moscow D-182

USSR

G. Petersen

Department of Agriculture

Pennsylvania State University

University Park, PA 16802

G. Pinder

Princeton University

School of Engineering/

Applied Science

Princeton, NJ 08544 


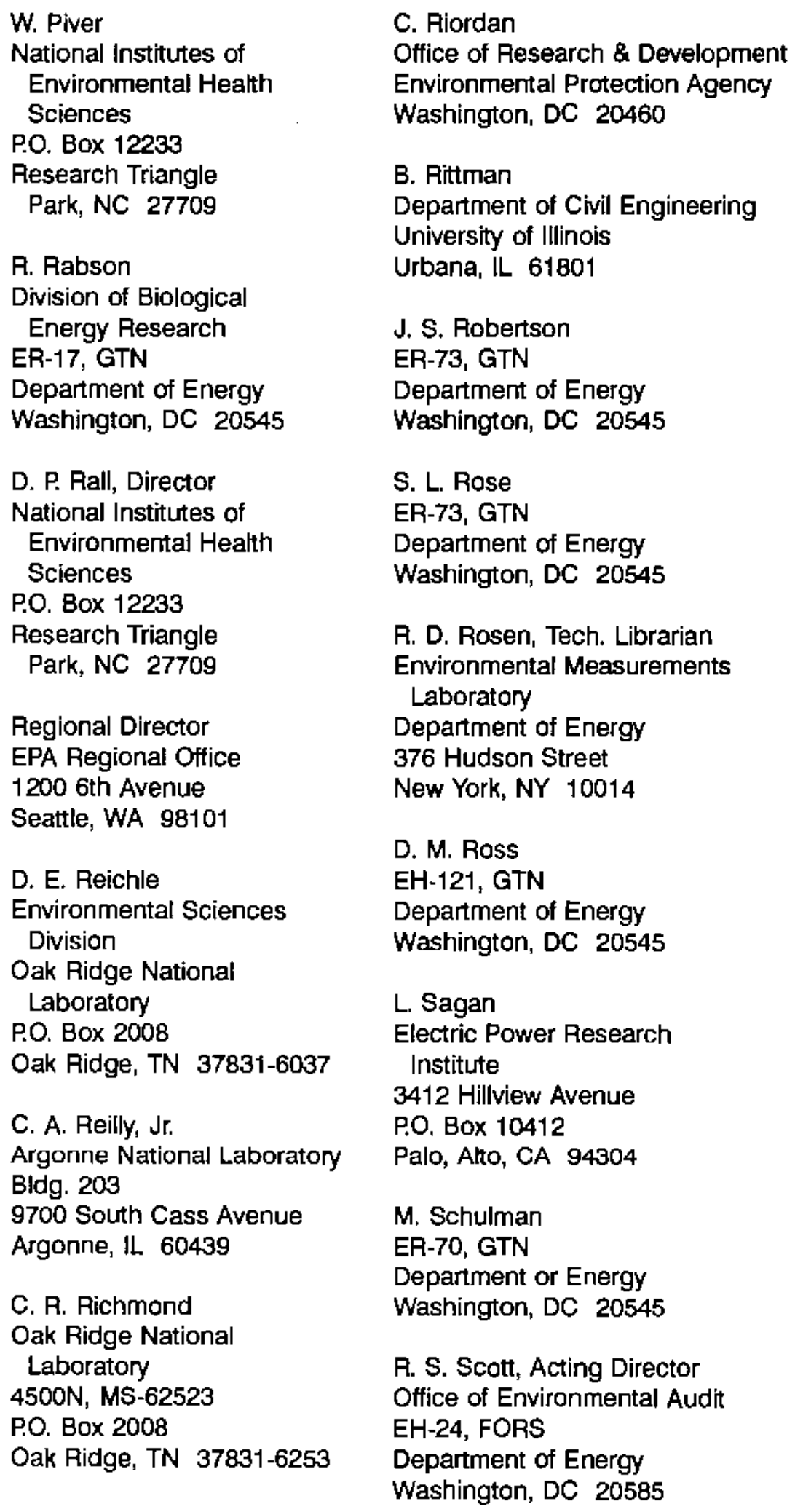

\author{
G. H. Setlock \\ Rockwell International \\ North American Space \\ Operations \\ Rocky Flats Plant, MS-250 \\ P.O. Box 464 \\ Golden, CO 80402 \\ R. 8. Setlow \\ Brookhaven National \\ Laboratory \\ Upton, \\ Long Island, NY 11973
}

R. Shikiar

Battelle - Seattle $4000 \mathrm{NE}$ 41st Street Seattle, WA 98105

D. B. Shipler Battelle Memorial Institute 505 King Avenue

Columbus, $\mathrm{OH} 43201$

R. H. Silverman Lawrence Berkeley Laboratory

Bldg. 50A/5104

Berkeley, CA 94720

J. Simmons

Bioaffects Analysis Branch

Environmental Protection Agency

401 M Street, SW

Washington, DC 20460

W. K. Sinclair, President

National Council on

Radiation Protection

7910 Woodmont Avenue

Suite 1016

Bethesda, MD 20814

J. Skalski

Center for Quantitative

Science

HA-20

3737 15th Avenue, N

Seattle, WA 98195 
D. A. Smith

ER-72, GTN

Department of Energy

Washington, DC 20545

G. S. Smith

New Mexico State University

Box 3-I

Las Cruces, NM 88003-0001

L. M. Smith

Marine Science Center

Environmental Protection

Agency

Newport, OR 97365

M. Smith, Director

Savannah River Ecology

Laboratory

University of Georgia

Savannah River Plant

P.O. Box A

Aiken, SC 29801

G. A. Smithwick

EH-20, FORS (7A-097)

Department of Energy

Washington, DC 20585

\section{LE. Sommers}

Department of Agronomy

Colorado State University

Ft. Collins, CO 80523

J. N. Stannard

University of California

17441 Plaza Animado \#132

San Diego, CA 92128

R. W. Starostecki Department of Energy

1000 Independence

Avenue, SW

Washington, DC 20585
R. J. Stern

EH-10, FORS

Department of Energy

Washington, DC 20585

D. K. Stevens

ER-11, GTN

Department of Energy

Washington, DC 20545

L. F. Stickel

Patuxent Wildlife Research

Center

Laurel, MD 20810

E. T. Still

Kerr-McGee Corporation

P.O. Box 25861

Oklahoma City, OK 73125

P. M. Stone

ER-6, FORS

Department of Energy

Washington, DC 20585

J. M. Suflita

Department of Botany \& Microbiology

University of Oklahoma

Norman, OK 73019

A. Swartzman

Center for Quantitative

Studies

University of Washington

3737 15th Avenue

Seattle, WA 98115

J. Swinebroad

EH-12, GTN

Department of Energy

Washington, DC 20545
Technical Information

Service

Savannah River Laboratory

Room 773A

E.l. duPont de Nemours \&

Company

Aiken, SC 29801

R. G. Thomas

ER-72, GTN

Department of Energy

Washington, DC 20545

L. O. Trfin

Swan Valley Route

Seeley Lake, MT 59868

University of Washington

Department of Biostatistics

SC-32

Seattle, WA 98195

A. J. Valocchi

Civil Engineering Department

University of Illinois

205 North Mathews

Urbana, IL 61801

P.K.M. Van der Heijde

International Groundwater

Modeling Center

4600 Sunset Avenue

Indianapolis, IN 46208

C. R. Vest

Battelle, Pacific Northwest

Laboratories

Washington Operations

370 L'Enfant Promenade,

Suite 900

301 D Street, SW

Washington, DC 20024 
G. L. Voelz

Los Alamos National

Laboratory

MS-K404

P.O. Box 1663

Los Alamos, NM 87545

B. W. Wachholz

Radiation Effects Branch

National Cancer Institute

EPN, Room 530

8000 Rockville Pike

Bethesda, MD 20892

A. A. Walters

Assistant to the Associate

Director

Los Alamos National

Laboratory

MS-A114

P.O. Box 1663

Los Alamos, NM 87545

W. W. Weyzen

Electric Power Research Institute

3412 HIllview Avenue

P.O. Box 10412

Palo Alto, CA 94303

R. W. Whicker

Department of Radiology \&

Radiation Biology

Colorado State University

Ft. Collins, CO 80521

R. P. Whitfield

DOE - Savannah River

Operations Office

P.O. Box A

Aiken, SC 29801

F. J. Wobber

Department of Energy

14 Goshen Court

Gaithersburg, MD 20879-4403
R. W. Wood

PTRD, OHER

ER-74, GTN

Department of Energy

Washington, DC 20545

R. G. Woodmansee

Department of Range Science

Colorado State University

Fort Collins, CO 80523

S. R. Wright

Savannah River Operations Office

P.O. Box A

Aiken, SC 29801

Zhu Zhixian

Laboratory for Energy-Related

Health Research

University of California

Davis, CA 95616

\section{FOREIGN}

E. L. Alpen

University of California

Study Center

21 Stratton Ground

London SW1 P2HY

ENGLAND

M. Anderson

Library

Department of National

Health \& Welfare

Ottawa, Ontario

CANADA

D. C. Aumann

Institut für Physikalische Chemie

Universităt Bonn

Abt. Nuklearchemi

Wegelerstrabe 12

5300 Bonn 1

FEDEPAL REPUBLIC OF GERMANY
M. A. Balakrishnan, Head

Library \& Information Services

Bhabha Atomic Research

Centre

Bombay-400 085

INDIA

A. M. Beau, Librarian

Département de Protection

Sanitaire

Commissariat à l'Énergie

Atomique

BP No. 6

F-92265 Fontenay-aux-Roses

FRANCE

G. Bengtsson,

Director-General

Statens Stralskyddsinstitut

Box 60204

S-104 01 Stockholm

SWEDEN

D. J. Beninson

Gerencia de Protección

Radiológica y Seguridad

Comisión Nacional de

Energia Atómíca

Avendida del Libertador 8250

$2^{\circ}$ Piso Of. 2330

1429 Buenos Aires

ARGENTINA

A. Bianco

ENEA, Dipart. Protezione

Via le Regina Margherita 125

I-00198 Roma

ITALY

Cao Shu-Yuan, Deputy Head

Laboratory of Radiation

Medicine

North China Institute of

Radiation Protection

P.O. Box 120

Tai-yuan, Shan-Xi

THE PEOPLE'S REPUBLIC

OF CHINA 


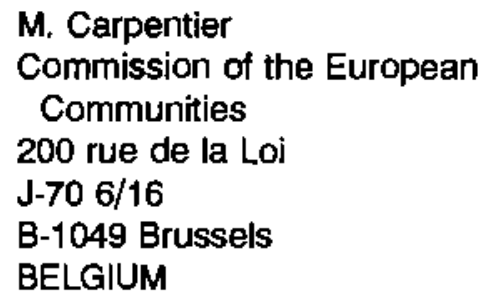

\section{A. Carregado Gerencía de Protección Radiológica y Seguridad Comisión Nacional de Energía Atómica Casilla de Carreo 40 1802 Aeropuerto Int.

G. M Desmet

Commission of the

European Communities

DG XII

200 rue de la Loi

B-1049 Brussels

BELGIUM

Director

Commissariat à l'Énergie Atomique

Centre d'Etudes Nucléaires

Fontenay-aux-Roses (Seine)

FRANCE

Director

Commonwealth Scientific and Industrial Research

Organization

Aspendal, Victoria

AUSTRALIA

Director

Laboratorio di Radiobiologia

Animale

Centro di Studi Nucleari

Della Casaccia

Comitate Nazionale per

I'Energia Nucleare

Casella Postale 2400

I-00100 Roma

ITALY

D. Djuric

Institute of Occupational and

Radiological Health

11000 Beograd

Deligradoka 29

YUGOSLAVIA

Estacao Agronómica Nacional

Biblioteca

2780 Oeiras

PORTUGAL
L. Feinendegen, Director Institut für Medezin

Kernsforschungsanlage Jülich

Postfach 1913

D-5170 Jülich

FEDERAL REPUBLC OF

GERMANY

R. M. Fry, Head

Office of the Supervising

Scientist for the Alligator

Rivers Region

P.O. Box 387

Bondi Junction NSW 2022

AUSTRALIA

A. Geertsema Saso Technology (Pty), Ltd.

P.O. Box 1

Sasolburg 9570

REPUBLIC OF SOUTH

AFRICA

G. B. Gerber

Radiobiology Department

Commission of the European Communities

200 rue de la Loi

B-1049 Brussels

BELGIUM

A. R. Gopal-Ayengar 73-Mysore Colony Mahul Road, Chembur Bombay-400 074

INDIA

A. Grauby

Service d'Etudes at de Recherches sur l'Environment Commissariat à l'Énergie Atomique

Caderache, No. 1

BAT 15313115

St. Paul Les Durance

FRANCE 


\author{
J. L. Head \\ Department of Nuclear \\ Science \& \\ Technology \\ Royal Naval College, \\ Greenwich \\ London SE10 9NN \\ ENGLAND
}

\section{D. Hill \\ Assessments Department \\ National Radiological \\ Protection Board \\ Chilton, Didcot \\ Oxon OX11 ORO \\ ENGLAND}

International Atomic

Energy Agency

Documents Library

Attn: Mrs. Javor

Kaerntnerring 11

A-1010 Vienna 1

AUSTRIA

K. E. Lennart Johansson

Radiofysiska Inst.

Regionsjukhuset

S-901-82 Umeå

SWEDEN

H. J. Klimisch

BASF Aktiengesellschaft Abteilung Toxikologie, Z470

D-6700 Ludwigshafen

FEDERAL REPUBLIC OF GERMANY

G. H. Kraft

c/o GSI Postbox 110541

Planck Str.

D-6100 Darmstadt

FEDERAL REPUBLIC OF

GERMANY

T. Kurnatori

National Institute of Radiological Sciences

9-1, Anagawa-4-chome

Chiba-shi 260

JAPAN
Li De-Ping

Professor and Director of

North China Institute of

Radiation Protection, NMI

Tai-yuan, Shan-Xi

THE PEOPLE'S REPUBLIC

OF CHINA

Librarian

Australian Nuclear Science \&

Technology Organization

Private Mail Bag 1

Menai NSW 2234

AUSTRALA

Librarian

Centre d'Etudes

Nucléaires de Saclay

P.O. Box 2, Saclay

Fig-sur-Yvette (S\&O)

FRANCE

Librarian

CSIRO

314 Albert Street

P.O. Box 89

East Melbourne, Victoria

AUSTRALIA

Librarian

CSIRO

Division of Atmospheric Research

Station Street

Aspendal, Victoria $\mathbf{3 1 9 5}$

AUSTRALIA

Librarian

CSIRO

Division of Wildlife and Ecology

P.O. Box 84

Lyneham, ACT 2602

AUSTRALIA

Librarian

Department of Fisheries

and Ocearis

Freshwater institute

501 University Crescent

Winnipeg, Manitoba R3T 2N6

CANADA
Librarian

Department of Fisheries

and Oceans

Pacific Biological Station

P.O. Drawer 100

Nanaimo, British Columbia

V9R 5K6

CANADA

Librarian

HCS/EHE

World Health Organization

$\mathrm{CH}-1211$ Geneva 27

SWITZERLAND

Librarian

Kernforschungzentrum

Karlsruhe

Institut für Strahlenbiologie

Postfach 3640

D-75 Karlsruhe 1

FEDERAL REPUBLIC OF

GERMANY

Libranian

Max-Planck-Institut

für Biophysics

Forstkasstrabe

D-6000 Frankfurt/Main

FEDERAL REPUBLIC OF

GERMANY

Librarian

Ministry of Agriculture, Fisheries \& Food

Fisheries Laboratory

Lowestoft, Suffolk NR33 OHT

ENGLAND

Librarian

National Institute of

Radiological Sciences

9-1, Anagawa-4-chome

Chiba-shi 260

JAPAN

Librarian

OECD - NEA

38, Blvd. Suchet

75016, Paris

FRANCE 
Librarian

Supervising Scientist for the Alligator Rivers Region

Level 23, Bondi Junction Plaza

P.O. Box 387

Bondi Junction NSW 2022

AUSTRALIA

Library

Atomic Energy Commission of Canada, Ltd.

Whiteshell Nuclear Research Establishment

Pinawa, Manitoba ROE tLO

CANADA

Library (Serials Section)

British Geological Survey

Nicker Hill, Keyworth

Nottingham NG12 5GG

ENGLAND

Library

Department of Fisheries and Oceans

West Vancouver Laboratory

4160 Marine Drive

West Vancouver, BC V7N 1N6

CANADA

Library

Department of Meteorology

University of Stockholm

Arrhenius Laboratory

S-106 91 Stockholm

SWEDEN

Library

Ris $\varnothing$ National Laboratory

DK-4000 Roskilde

DENMARK

B. Lindell

National Institute of

Radiation Protection

Fack S-104 01

Stockholm 60

SWEDEN
A. M. Marko

9 Huron Street

Deep River, Ontario

KOJ 1 PO

CANADA

H. Matsudaira, Director-General

National Institute of Radiological Sciences

9-1, Anagawa-4-chome

Chiba-shi 260

JAPAN

H. J. Metivier

Institut de Protection et de Sûreté Nucléaire

Centre d'Études de Service de Fomtenay-aux-Roses

BP No. 6

F-92265 Fontenay-aux-Roses

FRANCE

S. F. Mobbs

National Radiological

Protection Board

Chilton, Didcot

OxOn OX11 ORQ

ENGLAND

C. Myttenaere

Laboratoire de Physiologie

Végétale (NVE)

Place Crois du Sud, 4

B-1348 Louvain-La-Neuve

BELGIUM

J. C. Nénot, Deputy Director Département de Protection

Centre d' Etudes Nucleaires

BP No. 6

F-92260 Fontenay-aux-Roses FRANCE

J. P. Oliver

ENEA (OECD) Health and

Safety Office

38, Blvd. Suchet

Paris

FRANCE
R. Osbome

Atomic Energy Commission of Canada, Ltd.

Biology and Health Physics

Division

Chalk River Nuclear

Laboratories

P.O. Box 62

Chalk River, Ontario KOJ1JO

CANADA

V. Prodi

Department of Physics

University of Bologna

Via Irnerio 46

|-40126 Bologna

ITALY

Reports Librarian

Harwell Laboratory, BIdg. 465

UKAEA

Harwell, Didcot

OxOn OX11 ORB

ENGLAND

P.J.A. Rombout

Inhalation Toxicology

Department

National Institute of Public

Health and Environmental

Protection

P.O. Box 1

NL-3720 BA Bilthoven

THE NETHERLANDS

M. Rzekiecki

Commissariat à l'Énergie

Atomique

Centre d'Etudes

Nucleaires de Cadarache

BP No. 13-St. Paul

Les Durance

FRANCE

H. Smith

International Commission on

Radiological Protection

P.O. Box 35

Didcot

OxOn OX11 ORJ

ENGLAND 


\section{J. W. Stather National Radiological Protection Board Building $\mathbf{3 8 3}$ \\ Chilton, Didcot Oxon OX11 ORQ ENGLAND}

Sun Shi-Quan, Head

Radiation-Medicine Department

North China Institute of Radiation Protection, NMI P.O. Box 120

Taj-yuan, Shan-Xi

THE PEOPLE'S REPUBLIC OF CHINA

G. Tarroni

ENEA-PAS-FIBI-AEROSOL

Laboratorio Fisica Sanitaria

Via Ercolani 8

1-40138 Bologna

ITALY

J. W. Theissen
Radiation Effects Research
Foundation
5-2 Hijiyama Park
Minami-Ku
Hiroshima 732
JAPAN
D. Van As
Atomic Energy Corporation
P.O. Box 582
Pretoria 0001
REPUBLIC OF SOUTH
AFRICA

Vienna International Centre Library

Gifts and Exchange

P.O. Box 100

A-1400 Vienna

AUSTRIA
Wang Hengde

North China Institute of

Radiation Protection

P.O. Box 120

Tai-yuan, Shan-Xi

THE PEOPLE'S REPUBLIC

OF CHINA

Wang Renzhi

Institute of Radiation Medicine

11\# Tai Ping Road

Beijing

THE PEOPLE'S REPUBLIC

OF CHINA

Wang Ruifa,

Associate Director

Laboratory of Industrial Hygiene

Ministry of Public Health

2 Xinkang Street

P.O. Box 8018

Deshengmenwai, Beijing 100088

THE PEOPLE'S REPUBLIC

OF CHINA

Wang Yibing

North China Institute of

Radiation Protection

P.O. Box 120

Tai-yuan, Shan-Xi

THE PEOPLE'S REPUBLIC

OF CHINA

Wei Lü-Xin

Laboratory of Industrial Hygiene

Ministry of Public Health

2 Xinkang Street

Deshengmenwai, Beijing 100088

THE PEOPLE'S REPUBLIC

OF CHINA

B. C. Winkler, Director

Licensing

Raad Op Atomic

Atoomkrag Energy Board

Privaatsk $\times 256$

Pretoria 0001

REPUBLIC OF SOUTH AFRICA
Wu De-Chang

Institute of Radiation Medicine

27\# Tai Ping Road

Beijing

THE PEOPLE'S REPUBLIC

OF CHINA

\section{ONSITE}

\section{DOE Richland Operatlons Otfice}

M. W. Tiernan/

R. D. Freeberg A5-55

P. W. Kruger A5-90

\section{Hanford Envlronmental Health}

M. J. Swint H1-02

Westlnghouse Hanford Co.

(2)

R. M. Mitchen H4-55

D. E. Simpson B3-51

Pacific Northwest Laboratory (142)

R. C. Adams K6-52

C. C. Ainsworth K3-61

R. W. Baalman K1-50

J. F. Bagley K1-45

W. J. Bair (15) L6-52

R. M. Bean P8-08

H. Bolton K4.06

F. J. Brockman K4-06

L. L. Cadwell P7-50

D. A. Cataldo K4-12

D. B. Cearlock K1-42

T. D. Chikalla P7-75

T. T. Claudson K1-66

E. A. Crecelius SEQUI

D. W. Dragnich K1-46

L L. Eberhardt P7-50

R. M. Ecker SEQUI

C. E. Elderkin K6-03

R. A. Elston SEQUI

J. W. Falco K6-78 
R. J. Fellows K4-12

R. M. Fleischman K1-43

J. K. Fredrickson K4-06

J. S. Fruchter K6-81

T. R. Garland K3-61

G. W. Gee K6-77

D. E. Gibbons K6-84

E. S. Gilbert P7-82

D. C. Girvin K3-61

W. A. Glass K4-13

M. J. Graham K6-80

R. H. Gray K1-30

M. S. Hanson K1-51

P. C. Hays K6-86

M. G. Hefty K6-86

L. A. Holmes K1-06

J. R. Houston A3-60

E. A. Jenne K3-61

J. R. Johnson K3-53

B. J. Kelman K4-10

M. L. Knotek Ki-48

W. W. Laity K2-15

M. W. Ligotke P7-50

S. O. Link P7-50

P. E. Long K6-84

J. A. Mahaffey P7-82
J. F. McBride K6-77

B. D. McVeety K4-12

M. E. Mericka P7-50

J. R. Morrey P7-14

R. W. Nelson K6-77

G. P. O'Connor P7-50

P. C. Owczarski K6-03

T. L. Page K1-73

J. F. Park P7-50

R. W. Perkins P7-35

W. H. Rickard P7-50

R. G. Riley (5) K6-81

J.T.A. Roberts $\mathrm{K} 1-40$

L. E. Rogers (5) P7-50

J. L. Ryan P7-63

P. F. Salter P8-01

G. F. Schiefelbein K2-03

R. P. Schneider P7-50

B. D. Shipp K1-73

C. S. Simmons K6-77

M. A. Simmons P7-50

C. L. Simpson K1-79

R. L. Skaggs K6-77

R. M. Smith K6-96

G. M. Stokes K1-08

J. A. Stottlemyre K6-78
J. A. Strand SEQUI

G. P. Streile K6-77

J. E. Szecsody K6-77

W. L Templeton K1-30

T. S. Tentorde (2) K1-50

M. E. Thiede P7-50

J. M. Thomas P7-50

R. C. Thompson P8-08

L. H. Toburen P8-47

P. Van Voris K4-12

B. E. Vaughan K1-70

W. C. Weimer P7-22

R. E. Wildung (20) P7-50

L. D. Williams K1-41

J. V. Wright K6-84

G. E. Wukelic K6-84

J. S. Young K6-81

J. M. Zachara K3-61

J. D. Zimbrick P7-50

Health Physics Department Library

Life Sciences Library (2)

Publishing Coordination

Technical Report Files (5) 